\title{
Review of Generation and Flow of Recycled Uranium at Hanford
}

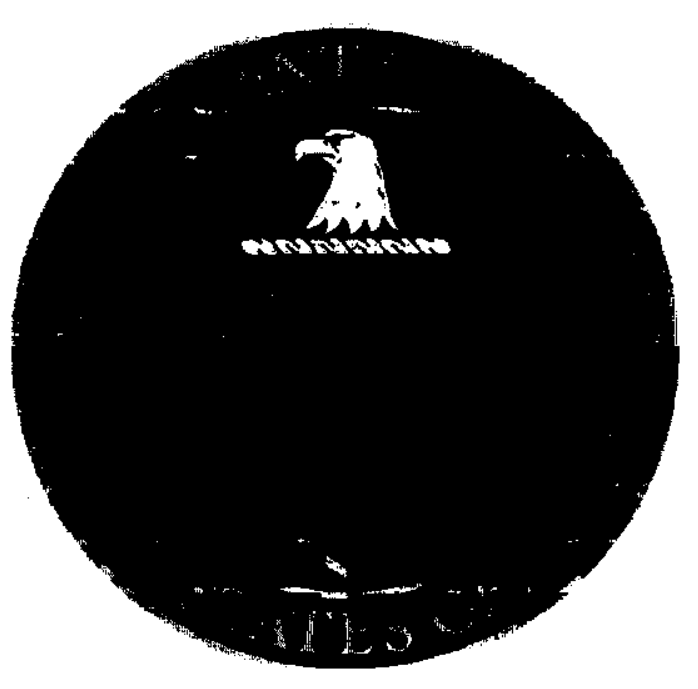

\section{Richland Operations Office}

June 30, 2000 


\section{Acknowledgements:}

Although there were one or more initial authors for various portions of Hanford's "Review of Generation and Flow of Recycled Uranium at Hanford" report, the actual process was highly iterative in that most of the team members listed below (and others on the DOE-HQ Working Group and senior RL management) reviewed, edited, commented and otherwise made significant contributions to several if not all sections of the final report. In addition, in the course of researching and preparing this report, many individuals and groups not specifically listed below provided invaluable services to this project in advising team members of the existence of and assisting in locating, acquiring, and interpretation of various documentation covering Hanford's $50+$ years of operation. Principal contributors to this study included:

\section{Department of Energy}

James E. Mecca - RL Project Manager, Uranium Mass Balance Project Angel Joy - RL Deputy Project Manager, Uranium Mass Balance Project Gail M. Splett - RL Database Research and Support/Office of Chief Counsel Lupe Ellingson - RL Safeguards and Security

Ricky L. Stutheit - RL Safeguards and Security

\section{Contractor Support}

Fluor Hanford

Ronald R. Borisch - Project Manager

David A. Dodd

Alan A. Grasher

Richard C. Hoyt

Gary B. Hulse

\section{Mactec}

Cart E. Alderson

Rebecca L. Knox

William J. Wiley III

Science Applications International Corp

Roy E. Barker

David C. Lini

Louis H. Rodgers

Joseph A. Teal

\section{Department of Energy} James E. Mecca - RL. Project Manager, Uranium Mass Balance Project

Informatics

Arthur J. Gutzman Jr.

Sarah L. Davis

Lance A. Ingraham

Deborah L. Martin

International Technology

Greg M. Clark

Robert D. Filbert

Cogema

Monte D. Crippen

\section{Fluor Hanford}

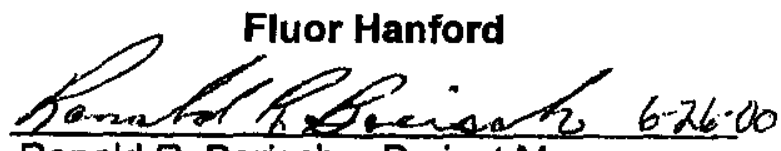

Ronald R. Borisch - Project Manager 


\section{Review of Generation and Flow of Recycled Uranium at Hanford}

\section{Table Of Contents}

\section{Executive Summary}

\section{Page}

- Hanford Recycled Uranium Project ...................................................... 1

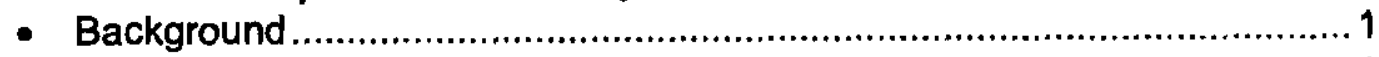

- Hanford's Role in Recycled Uranium ................................................... 1

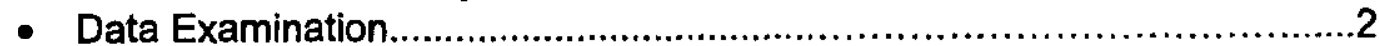

- Significant Information.......................................................................... 2

\section{Section}

1.0 Hanford Uranium Mass Balance Project

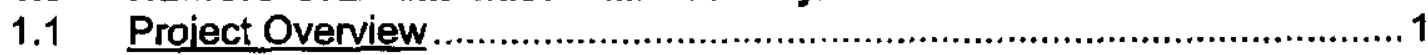

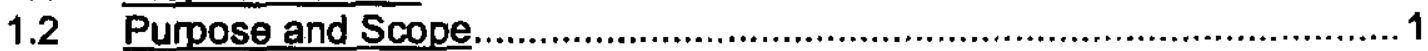

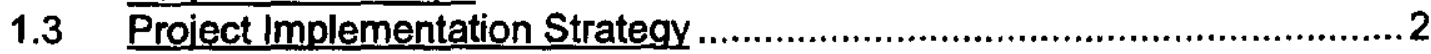

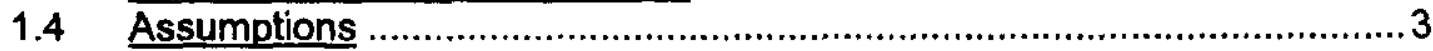

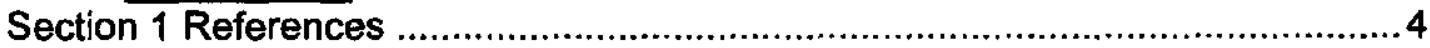

2.0 Hanford Site Historical Overview

2.1 Site Description ….........................................................................

2.2 Key Uranium Processing Facilities ......................................................

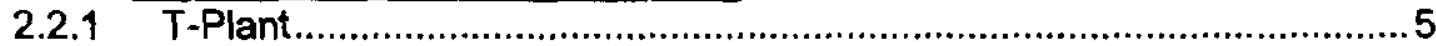

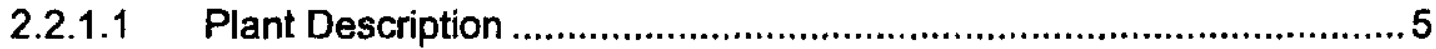

2.2.1.2 T-Plant Material Flowsheet.......................................................

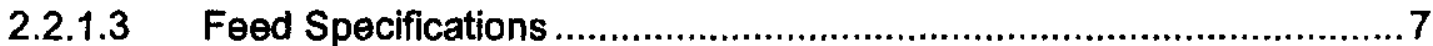

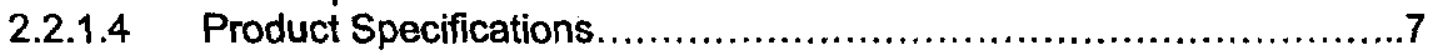

2.2.1.5 Operating History............................................................... 7

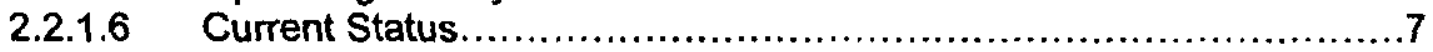

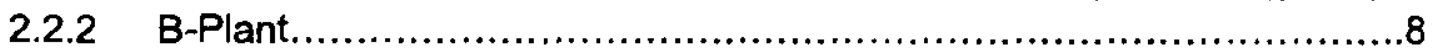

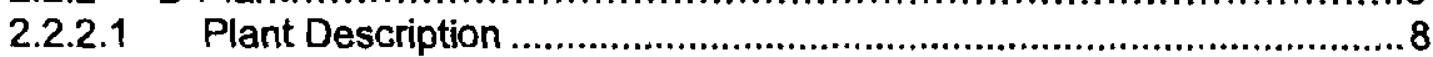

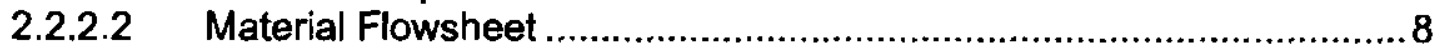

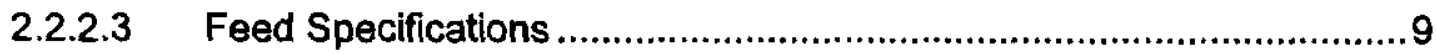

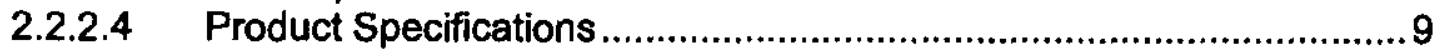

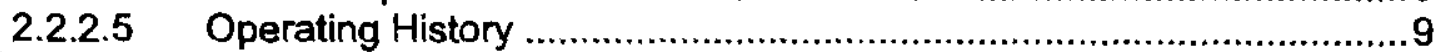

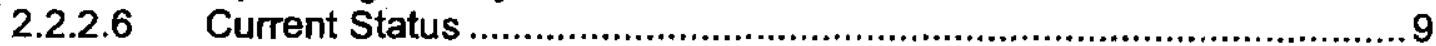

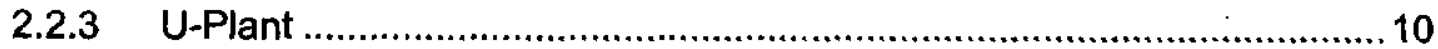

2.2.3.1 Plant Description........................................................10

2.2.3.2 Material Flowsheet....................................................... 10

2.2.3.3 Feed Specifications.......................................................11

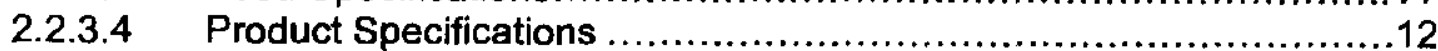

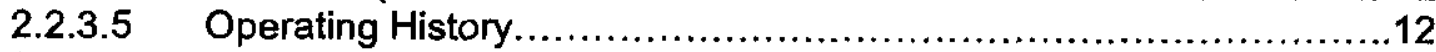

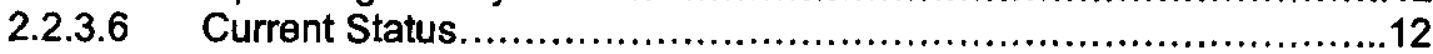




\section{Table of Contents}

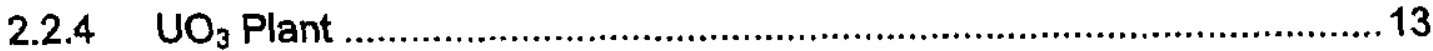

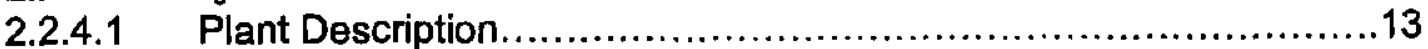

2.2.4.2 Material Flowsheet.....................................................14

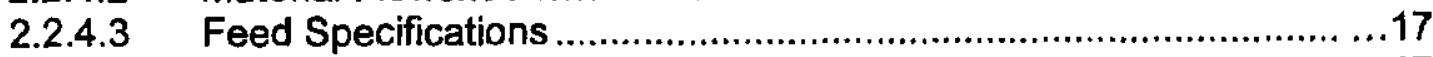

2.2.4.4 Product Specifications ................................................................. 17

2.2.4.5 Operating History ........................................................................ 19

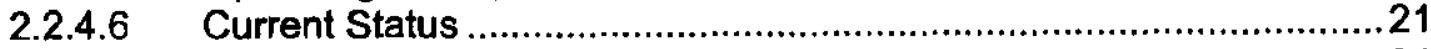

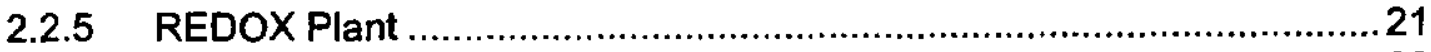

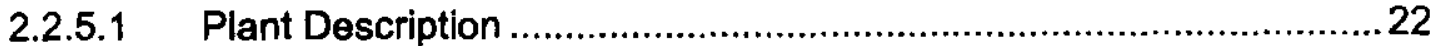

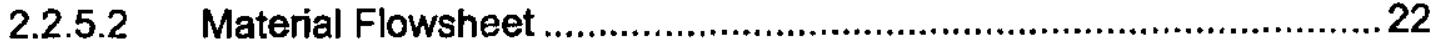

2.2.5.3 Feed Specifications ..................................................................23

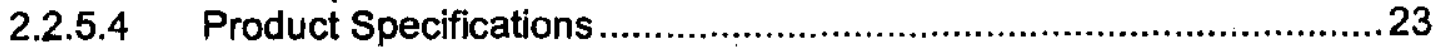

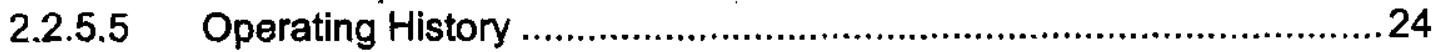

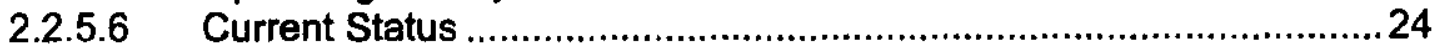

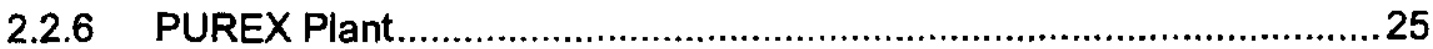

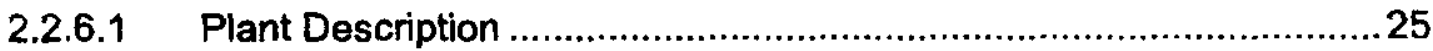

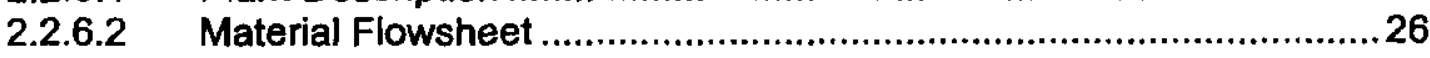

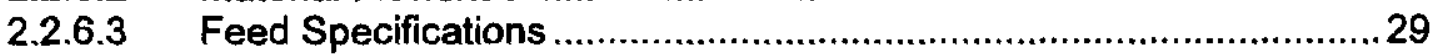

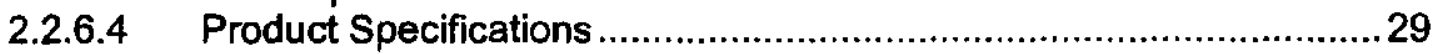

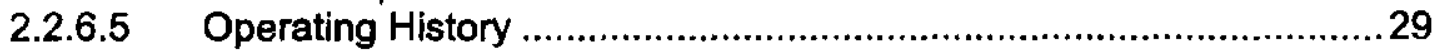

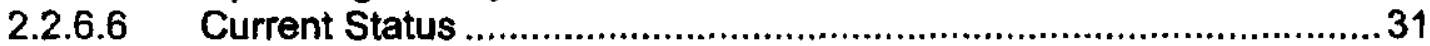

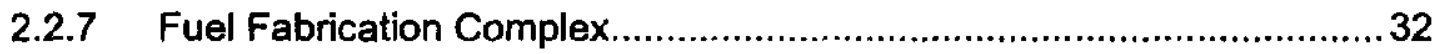

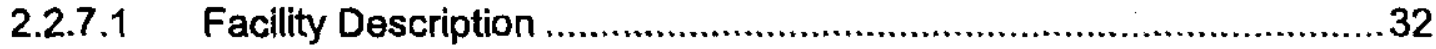

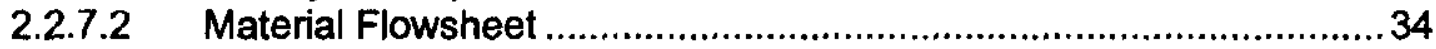

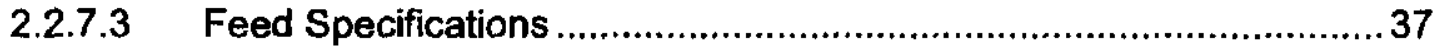

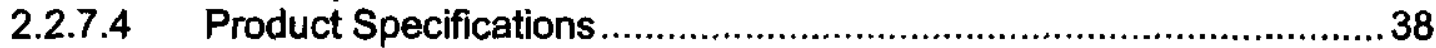

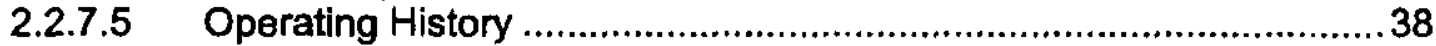

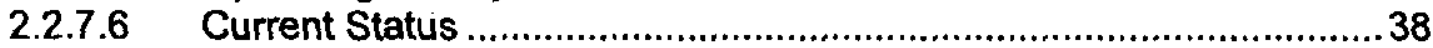

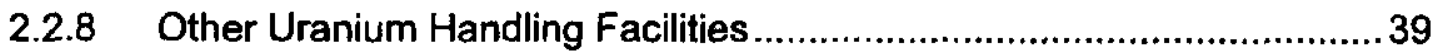

2.2.8.1 308 Building Mixed Oxide Fuel Fabrication...................................39

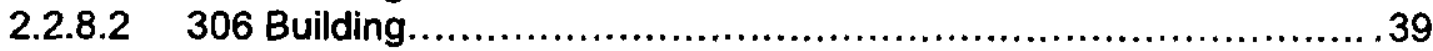

2.2.8.3 234-5Z Plutonium Finishing Plant (PFP) ............................. 39

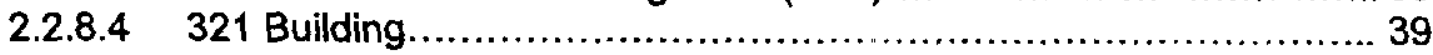

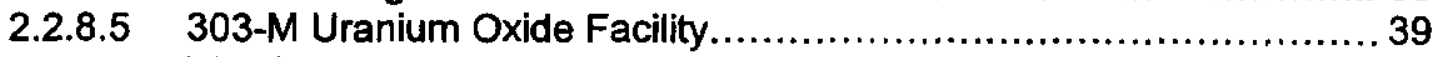

2.3 Activity Summary......................................................... 40

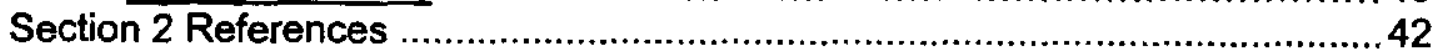

3.0 Recycled Uranium (see appendices for expanded detail) .......................

3.1 Uranium Recycle Description ...............................................................

3.1.1 Hanford Key Interfaces for Recycled Uranium....................................1

3.1.2 Beginning of Hanford In-Scope Recycled Uranium Transactions........... 8

3.1.2.1 Key Hanford Historical Dates for Recycled Uranium ......................... 8

3.1.2.2 Production Channel Material Transactions....................................8

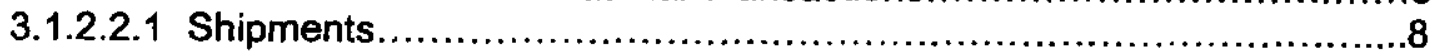

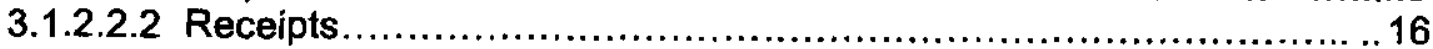




\section{Table of Contents}

3.1.3 Out of Scope Uranium Transactions....................................16

3.1.3.1 Hanford Production Channel............................................. 16

3.1.3.2 Out-of-Scope Research and Development Programs.................. 17

3.1.3.3 Recycled Uranium Timeframe Summary............................. 18

3.1.4 Data Presentation - Isolation of Specific Timeframes..................... 18

3.1.5 Hanford Historical Timeline References................................. 19

3.1.6 Key Dates/Assumptions for Uranium Transactions...................... 21

3.1.6.1 Beginning Shipment of Recycled Depleted Uranium Trioxide $\left(\mathrm{UO}_{3}\right)$.. 21

3.1.6.2 Initial Shipments of Recycled Low-Enriched Uranium

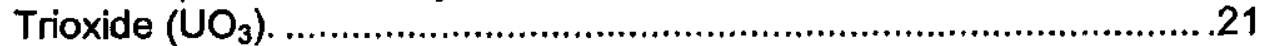

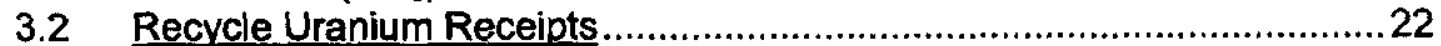

3.2.1 Uranium Forms Received from Offsite................................... 22

3.2.2 Initial Recycled Uranium Receipts into Hanford...........................22

3.2.3 Receipts Prior to July 1952 (Out of Scope) .............................23

3.2.4 Beginning Receipts of Recycled Uranium at Hanford.......................23

3.2.5 Quantities of Recycled Uranium Received from

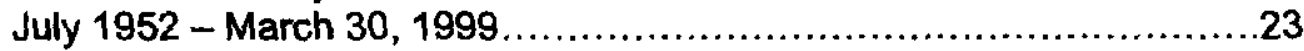

3.2.6 Hanford Receipts of Recycled Uranium from Paducah.....................24

3.2.7 Hanford Receipts of Recycled Uranium from Femald

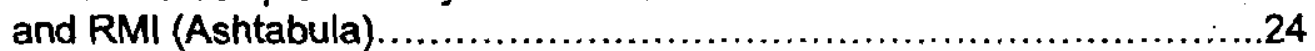

3.2.8 Hanford receipts of Recycled Uranium from Oak Ridge....................24

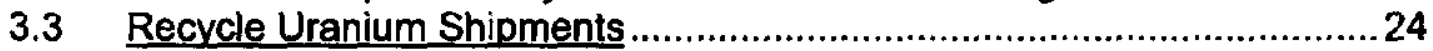

3.3.1 Recycled Uranium Streams Shipped Offsite..............................24

3.3.2 Uranium Shipments from 300 Area Fuel Fabrication Facilities..............28

3.3.3 Hanford Shipments of Recovered Uranium and Trioxide Product...........32

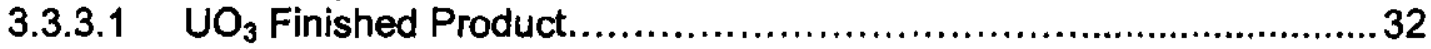

3.3.3.2 Introduction of Fission Products.......................................32

3.3.4 Out-of-Scope Research and Development Spent Fuel.....................33

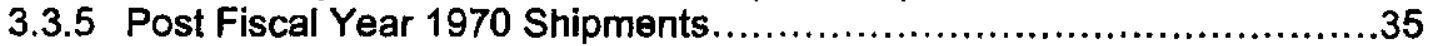

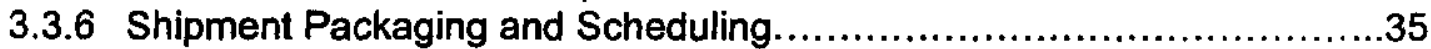

3.3.7 Transaction Material Control and Accountability (MC\&A) ...................... 35

3.3.8 Sample Exchange Program and Sample Shipments........................35

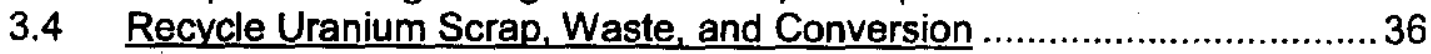

3.4 .1 Introduction .................................................................. 36

3.4.2 Reactor Fuel Element Fabrication......................................... 36

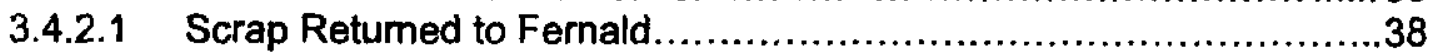

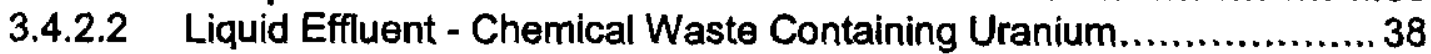

3.4.2.3 Airborne Effluents....................................................... 40

3.4.2.4 Solid Waste............................................................... 40

3.4.2.5 300 Area Process Trenches............................................40

3.4.3 Hanford Separation Plants................................................ 40

3.4.4 Recovery of Uranium in the U-Plant.......................................41

3.4.5 Uranium Trioxide $\left(\mathrm{UO}_{3}\right)$ Plant............................................41

3.4.6 Summary of Uranium Discharged to Wastes at Hanford.....................42

3.4.7 Uranium Losses Through Transmutation and Fission...................... 43

3.5 Overall Recycled Uranium Site Material Balance...............................43 


\section{Table of Contents}

Section 3 References.

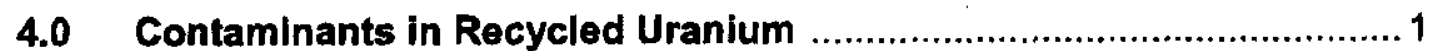

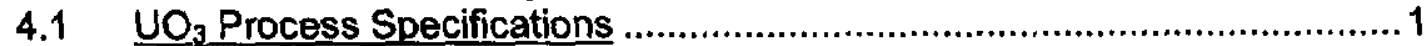

4.1.1 Feed Specifications...........................................................

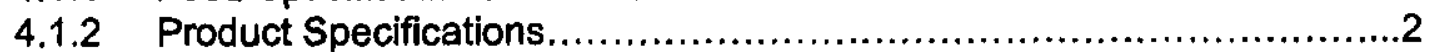

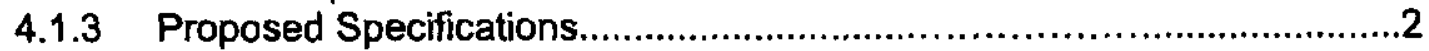

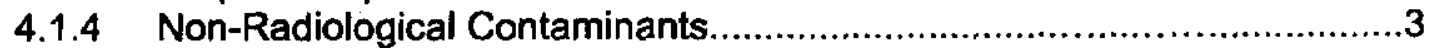

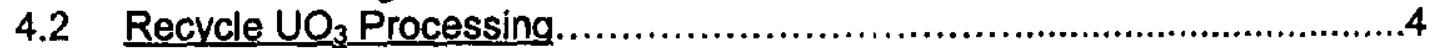

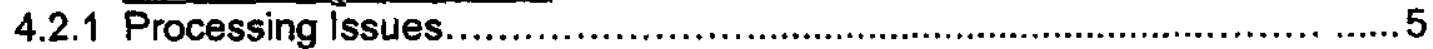

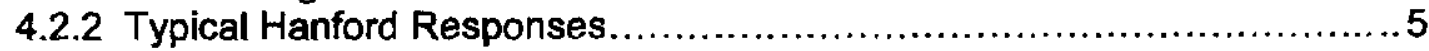

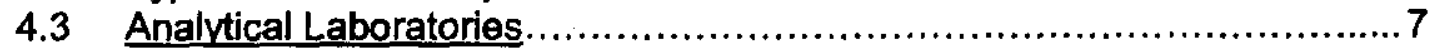

4.3.1 $\mathrm{UO}_{3}$ Product Sampling and Subsampling .................................

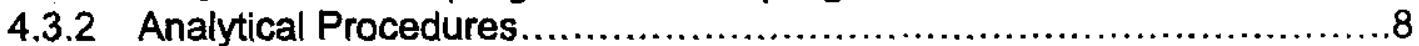

4.3.3 Analytical Methods and Errors...........................................10

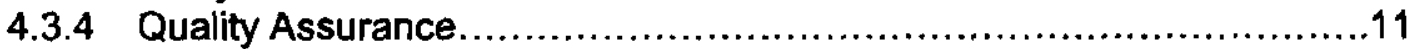

4.3.4.1 Quality Assurance Program ............................................11

4.3.4.2 In-House Standards Program......................................12

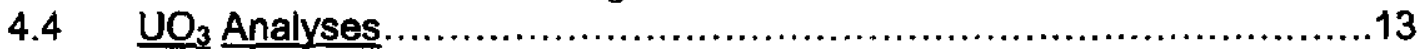

4.4.1 Impurity Concentrations in UNH.......................................13

4.4.2 Analyses Performed and Results........................................13

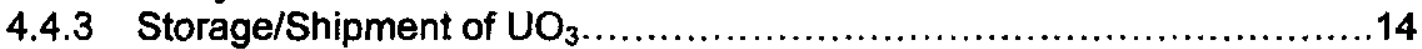

4.4.4 Storage of $\mathrm{UO}_{3}$ at Hanford..............................................15

4.4.5 $\mathrm{UO}_{3}$ Processed In/After 1984 Restart of PUREX/UO ${ }_{3}$ Plants...............18

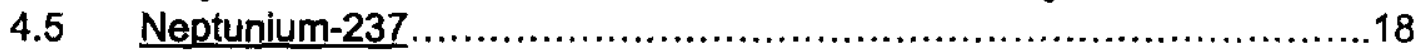

4.5.1 Neptunium Concentration in Recycled Uranium...............................18

4.5.2 Neptunium-237 $\left({ }^{237} \mathrm{~Np}\right)$ Formation............................................18

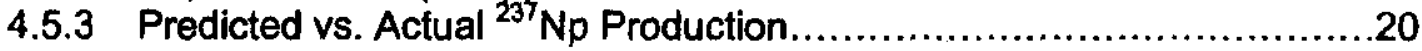

4.5.4 Enhancing Production of Neptunium......................................20

4.6 Technetium-99 Analytical Results...................................................22

4.6.1 Technetium-99 Concentration in Recycled Uranium..........................22

4.6.2 Hanford Technetium Measurements....................................................22

4.6.3 Paducah Measurements of Technetium-99 in Recycled Uranium from Hanford...........................................23

4.6.4 Fernald Measurements of Technetium-99 in Recycled Uranium from Hanford ............................................23

4.7 Uranium Isotopic Composition...........................................................23

4.7.1 Natural Uranium................................................................23

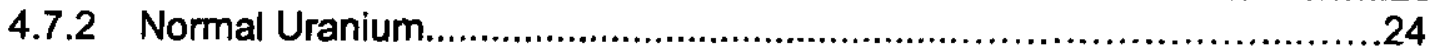

4.7.3 Low Enriched Uranium (LEU) ......................................................24

4.7.4 Typical Recovered LEU Uranium Oxide ........................................24

4.8 Contaminants in Uranium Metal...........................................2.

4.8.1 Non-radiological Composition...............................................2.27

4.8.2 Metallographic Testing.............................................................. 28

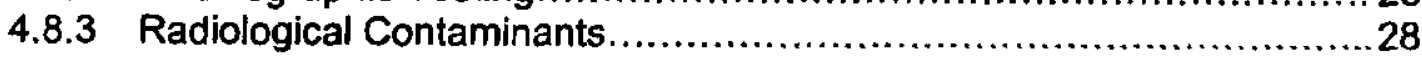

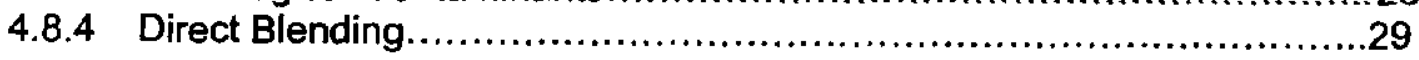




\section{Table of Contents}

5.0 Current Inventory of Recycled Uranium ........................................ 1

5.1 Current Hanford Management Contractor (PHMC) Inventory of Recycled Uranium ................................................................1

5.2 Pacific Northwest National Laboratories(PNNL) Current Inventory of Recycled Uranium 2

6.0 Discussion and Conclusions ................................................... 1

6.1 Recycled Uranium Shipped and Received ......................................... 1

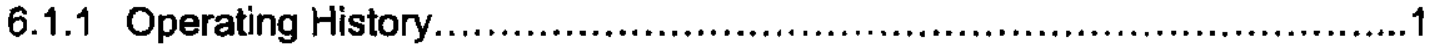

6.1 .2 Recycled Uranium Specifications............................................

6.1.3 Recycled Uranium Shipments and Receipts.............................1

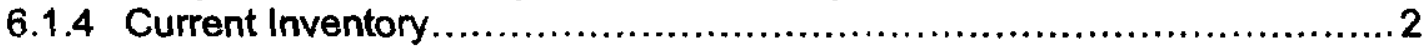

6.1.5 Shipper/Receiver Differences..............................................2

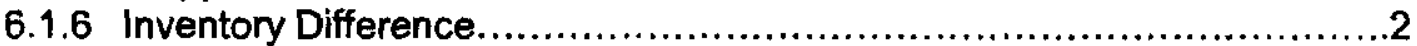

6.2 Typical Impurities and Isotopic Composition ...........................................

6.2 .1 Plutonium...........................................................................

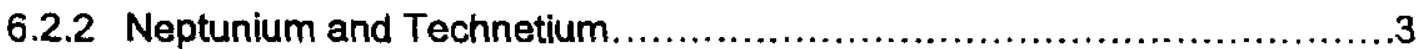

6.3 Activity Assessment and Occupational Potential Exposure....................4

6.4 Data Validation.............................................................. 10

6.4.1 Recycled Uranium Shipped from Hanford ........................................... 10

6.4.2 Impurities Shipped with $\mathrm{UO}_{3}$ from Hanford ....................................... 10

6.4.3 Discussion of Pu Differences Between K-25 and Hanford ...................... 11

Section 6 References.......................................................... 16 


\section{Table of Contents}

Tables

\section{Section 3}

Table 3-1

Table 3-2

Table 3-3

Table 3-4

Table 3-5

Table 3-6

Table 3-7

Table 3-8

Table 3-9

Table 3-10

Section 4

Table 4-1

Table 4-2

Table 4-3

Table 4-4

Table 4-5

Table 4-6

Table 4-7

Table 4-8

Table 4-9

Table 4-10

Table 4-11

Table 4-12

Section 6

Table 6-1
Total Recycled Uranium Received from Offsite Sources

24

Hanford Receipts from Paducah

25

Hanford Receipts from Fernald

Hanford Receipts from Oak Ridge (K-25 \& Y-12)

26

27

Summary of Recycled Uranium Shipments from Hanford 28

Hanford Uranium Shipments to Paducah 29

Hanford Summary Shipments to Fernald in MTU 30

Hanford Summary Shipment to Oak Ridge (K-25 \& Y-12) 31

Uranium Waste at Hanford

Hanford Mass Balance-Total In-Scope \& Out-of-Scope

42

45

$\mathrm{UO}_{3}$ Process Specifications 3

Summary of $\mathrm{UO}_{3}$ Shipments in 1952 and LEU 1967-1972 14

Summary of Drummed $\mathrm{UO}_{3}$ Product

Analyses of $\mathrm{UO}_{3}$ Produced In/After 1984 at Hanford

16

Special Process Batch

19

20

Calculated Production of Neptunium in Hanford Reactors 20

Neptunium Analyses on UNH $\quad 22$

Typical Uranium Isotopic Ratio of LEU Produced In/After 25 1970

Deeply Depleted $\mathrm{UO}_{3}$ Isotopic Data

25

${ }^{235} \mathrm{U}$ Isotopic Data of Pre-1972 Product or Depleted $\mathrm{UO}_{3} \quad 26$

Chemical Specifications for Uranium Metal Billets 27

Transuranic Content in Ingot Composites 30

Assessment of Activities at Hanford Where Workers Were

5

Most Likely to Contact Recycled Uranium 


\section{Table of Contents}

\section{Figures}

\section{Section 1}

Figure 1-1

\section{Section 2}

Figure 2-1

Figure 2-2

Figure 2-3

Figure 2-4

Figure 2-5

Figure 2-6

Figure 2-7

Figure 2-8

Figure 2-9

Figure 2-10

Figure 2-11

Figure 2-12

Figure 2-13

Figure 2-14

Figure 2-15

Figure 2-16

Section 3

Figure 3-1

Figure 3-2

Figure 3-3A

Figure 3-3B

Figure 3-3C

Figure 3-3D

Figure 3-4A

Figure 3-4B

Figure 3-5

Figure 3-5

(Cont)

Figure 3-6

Figure 3-7
Hanford Recycled Uranium Project Functional Breakdown

The Hanford Site, Richland, Washington

Hanford Major Process Flows and Facility Interfaces

2

T-Plant Process Flow Diagram

Simplified U-Plant Tributyl Phosphate (TBP) Process Flow

Diagram

11

$\mathrm{UO}_{3}$ Plant Process Diagram Involving Batch Pot Calciners 14

$\mathrm{UO}_{3}$ Plant Process Diagram Involving Continuous Calciners

$\mathrm{UO}_{3}$ Product Loadout System

Copy of Early $\mathrm{UO}_{3}$ Product Specification

16

19

REDOX Process Flow Diagram (Simplified)

23

PUREX Process Flow Diagram (Excluding the Plutonium

Production and Rework Facilities)

27

Example of PUREX Production Specification

30

Early Photograph of Fuel Fabrication Facilities in the 300 Area

33

Fuel Fabrication Process for Single-Pass Reactors

35

N Reactor Fuel Fabrication Process

36

303-M Uranium Oxide Facility

40

41

Processed Recycled Uranium

Major "Tier 1" Sites for Hanford Recycled Uranium Transactions

2 Major DOE Field Facilities

Material Flow-Manhattan Engineer District: 1942-1946

Material Flow-Atomic Energy Commission: 1946-mid 1950s

Material Flow-Atomic Energy Commission: mid 1950s-mid 1960s

Material Flow-Atomic Energy Commission/Energy Research

and Development Agency/Department of Energy:

mid 1960s-late 1980s

First Hanford Shipment of $\mathrm{UO}_{3}$ Containing Transuranics \&

Analytical Data

Second Hanford Shipment Containing Transuranics

and Analytical data

Example of Historical Transfer Forms-Cover Page

Example of Historical Transfer Form for

Shipment from Hanford to Paducah (circa 1971)

Product Acceptance Form Hanford Depleted $\mathrm{UO}_{3}$ to Paducah (circa 1971)

3

4

5

6

7

9

11

13

14

15

1949 Schematic Diagram Showing Uranium Flow in 300 Area 


\section{Table of Contents}

Figure 3-8 Typical Metal Billet Receipt Inbound from RMI/Fernald in the $1980 \mathrm{~s}$

Figure 3-9 $\quad \mathrm{UO}_{3}$ T-Hoppers at Hanford Rail Spur, 200 West Area

Figure 3-10 Uranium Flow and Inventory in Fuels Manufacturing Process (CY 1978)

Figure 3-11 Waste Acid and Uranium-Bearing Acid Recovery System

Section 4

Figure 4-1

Example Page of Specifications for $\mathrm{UO}_{3}$ Plant

Section 5

Figure 5-1

Hanford Total PHMC Uranium Inventory

\section{Section 6}

Figure 6-1

Figure 6-2

Figure 6-3

Figure 6-4

Estimate of Personnel Having Work Potentially Involving Exposure to Recycled Uranium at Specific Facilities Plutonium Contained in Recycled Uranium Shipped from Hanford Neptunium Contained in Recycled Uranium Shipped from Hanford Neptunium Contained in Recycled Uranium Shipped from Hanford 


\section{Table of Contents}

DOE/RL-2000-43

\section{Appendices}

$\begin{array}{ll}\text { Appendix A } & \begin{array}{l}\text { Acronyms and Glossary of Terms } \\ \text { Acronyms } \\ \text { Glossary of Terms }\end{array} \\ & 2\end{array}$

Appendix B Section 3 - Supplemental Information

Table 3.2.1 Out-of-Scope Hanford Receipts (as reference)

Table 3.2.2 1950-FY 65 Hanford (GE Company) Uranium Receipts from Offsite

Table 3.2.3 Hanford FY 1966-70 Uranium Receipts

Table 3.2.4 Hanford Chemical Processing Contractor (HVA) Uranium

Receipts FY 1971-March 31, 1999

Table 3.2.5 Hanford Chemical Processing Contractor (HRA) Uranium Receipts FY 1971-March 31, $1999 \quad 30$

Table 3.2.6 Hanford Chemical Processing Contractor (HUD \& HTA) Uranium Receipts FY 1971-March 31, 1999

Table 3.2. 7 Hanford Reactor/Fuel Fab Contractor (HXA) Uranium Receipts FY 1971-March 31, 1999

Table 3.2.8 Pacific Northwest National Laboratory (PNNL) Uranium Receipts FY 1965-March 31, 1999

Table 3.3.1 December 1947 Through June 51 Hanford (GE Company)
Uranium Shipments Offsite

Table 3.3.1 December 1947 Through June 51 Hanford (GE Company)
Uranium Shipments Offsite

Table 3.3.2 FY 1952-65 Hanford (GE Company) Uranium Shipments to Offsite Locations

Table 3.3.3 FY 1966-70 Hanford Uranium Offsite Shipments

Table 3.3.4 Hanford Chemical Processing Contractor (HVA) Uranium Shipments FY 1971-March 31, 1999

Table 3.3.5 Hanford Chemical Processing Contractor (HRA) Uranium Shipments FY 1971-March 31, 1999

Table 3.3.6 Hanford Chem. Processing Contrs (HUD \& HTA) Uranium Shipments FY 1971-March 31, 1999

Table 3.3.7 Hanford Reactor Contractor (HXA) Uranium Shipments FY 1971-March 31, 1999

Table 3.3.8 Pacific Northwest National Laboratory (PNNL) Offsite Uranium Shipments

\section{Appendix C Section 4 - Supplemental Information}

Table 4-1 Detailed Analyses of 1952 Produced $\mathrm{UO}_{3}$

Table 4-2 Detailed Analysis of LEU UO

Table 4-3

Detailed Analysis of Drummed $\mathrm{UO}_{3}$ Product 


\section{Table of Contents}

DOE/RL-2000-43

\section{Appendix D Section 5 - Supplemental Information}

Table 5.1.1 Current Inventory of Hanford In-Scope Uranium

Table 5.1.2 Pacific Northwest National Laboratory (PNNL) Recycled

Uranium Inventory as of March 31, 1999

Appendix E Description of Research Strategles Used in Study

E.0 Uranium Mass Balance Project Document Retrieval and Review Process

Figure E-1 Complexity and Range of Information to be Researched at 2 Hanford

Figure E-2 Uranium Mass Balance Project Document 3 Identification/Review Process

E.1 Databases Used

E.2 Database Keyword Searches 5

Table E-1 Keywords Used in Searching Databases . 7

E.3 Technical Review of Keyword Search Results 7

E.4 Obtaining Documents and Boxes of Records 8

E.5 Additional Document Searches 9

E.6 Technical Review of Documents 9

E.7 Project Records 9

E.8 References 10

Appendix F Supplemental Information on Hanford Fuel Fabrication

F.1 Single Pass Reactor Fuel Fabrication 3

F.1.1 Fuel Canning 3

F.1.2 Single Pass Fuel Fabrication Changes 4

F.2 N-Reactor Fuel Fabrication Processing 5

F.2.1 N-Reactor Fuel Fabrication 5

F.2.2 Co-Extrusion Process 6

F.3 Material Sources 7

F.4 References 8

Appendix $G$ Supplemental Information on the $\mathrm{UO}_{3}$ Plant

G.1 Operating History Uranium Trioxide $\left(\mathrm{UO}_{3}\right)$ Plant 3

G.2 Process Operations 6

G.3 Waste Generation 7

G.4 Radiation Exposure 8

G.5 Contaminate Partitioning 8

G.6 $\mathrm{UO}_{3}$ Related Incidents 9

G.7 References 10 


\section{Table of Contents}

Appendix H Timeframe of Events at Hanford

\section{Appendlx I Estimates of Annual Recycled Uranium Constituents Shipped Offsite}

Table 1-1 Historical Hanford Recycled Uranium Receipts (MTU)

Table I-2 Historical Hanford Recycled Uranium Shipments (MTU)

4

Table 1-3 Estimated Minimum Pu in Historical Hanford Recycled Uranium Shipments (Gm)

Table 1-4 Estimated Mean Pu in Historical Hanford Recycled Uranium Shipments (Gm)

Table 1-5 Estimated Maximum Pu in Historical Hanford Recycled Uranium Shipments (Gm)

Table I-6 Estimated Minimum Np in Historical Hanford Recycled Uranium Shipments $(\mathrm{Kg})$

Table 1-7 Estimated Mean Np in Historical Hanford Recycled Uranium Shipments $(\mathrm{Kg})$

Table I-8 Estimated Maximum $\mathrm{Np}$ in Historical Hanford Recycled Uranium Shipments (Kg)

Table I-9 Estimated Minimum Tc in Historical Hanford Recycled Uranium Shipments $(\mathrm{Kg})$

Table 1-10 Estimated Mean Tc in Historical Hanford Recycled Uranium Shipments $(\mathrm{Kg})$

Table I-11 Estimated Maximum Tc in Historical Hanford Recycled Uranium Shipments $(\mathrm{Kg})$

Table 1-12 Estimated Constituents Based On Low Value Of Constituent Boundary Range

Table I-13 Estimated Constituents Based On Mean Value Of Constituent Boundary Range

Table 1-14 Estimated Constituents Based On High Value Of Constituent Boundary Range 


\section{EXECUTIVE SUMMARY}

DOE/RL-2000-43

\section{Hanford Recycled Uranium Project}

On August 8, 1999, Energy Secretary Richardson announced a set of activities to address the extent of potential exposure to recycled uranium and its constituents, and the quantities of uranium involved at Department of Energy (DOE) operated sites. The DOE-HQ Recycled Uranium Project was to gather the pertinent information and provide a report of its findings to the Secretary by June 2000 . On September 15, 1999, selected field offices were directed to support this Recycled Uranium Project.

The Richland Operations Office (RL) assembled a multi-contractor team of senior staff in response to the Headquarters directive to gather and consolidate the requested supporting information and to provide this information in a formal report in support of the June 2000 date. Based on the direction contained in the Secretary's letter, Hanford facilities and activities involving the production, treatment, and handling of recycled uranium and the trace impurities of plutonium (Pu), neptunium $\left({ }^{237} \mathrm{~Np}\right)$, and technetium $\left({ }^{99} \mathrm{Tc}\right)$ isotopes were investigated.

\section{Background}

"Hanford Engineering Works" was established in secrecy during World War II to produce plutonium for an atomic bomb in support of the ongoing defense effort. Hanford produced the Pu used for the first atomic explosion test in New Mexico in July 1945. Since the first Pu production, Hanford continued to grow and support defense and other missions as directed. During its operating period, 1943 through 1993, Hanford built and operated 9 production reactors, five separations plants, several reactor fuel manufacturing facilities, a uranium trioxide $\left(\mathrm{UO}_{3}\right)$ production facility and several Pu processing facilities. Additional facilities were built to support the production of plutonium, recovery of uranium, waste treatment, and provide site infrastructure. Plutonium was Hanford's primary product and recovered uranium was a secondary product. Peak nuclear materials production was reached in the 1960 s, when all nine production reactors were in operation. Altogether, Hanford supplied Pu for the United States nuclear weapons program for more than four decades. Weapons material production was halted in the late 1980 s.

The Hanford Site presently consists of $\sim 1,450$ square kilometers ( -560 -square-miles), located just north of the city of Richland, in the south central part of Washington State. The Hanford Site is managed by the DOE Richland Operations and River Protection Offices.

\section{Hanford's Role in Recycled Uranium}

During Hanford's early years of operation, irradiated fuel was processed in T-Plant and B-Plant to recover Pu. Uranium from the irradiated fuel remained in the high level waste, which was sent to large underground storage tanks. In early 1952, operation of the Reduction-Oxidation Plant (REDOX) was initiated to process irradiated fuel, 


\section{Error}

An error occurred while processing this page. See the system log for more details. 


\section{EXECUTIVE SUMMARY}

uranium went to the Paducah Gaseous Diffusion Plant (GDP) in KY, 4,404 MT of recycled uranium went to the K-25 GDP and the Y-12 Plant at Oak Ridge, TN, and 25,251 MT of recycled uranium was shipped to Fernald, $\mathrm{OH}$. An additional $\sim 5,646$ MT of recycled uranium was sent to over 100 other destinations for research and miscellaneous non-defense and defense needs.

- Approximately $\sim 4,006 \mathrm{MT}$ of uranium remains at Hanford, excluding uranium in tanks and solid waste and uranium which was discharged to the cribs. This uranium is in various forms: metal received for making fuel, unused fuel, irradiated fuel (not in the scope of this study), uranium as oxide in mixed-oxide fuel (at the Fast Flux Test Facility and in vaults at the Plutonium Finishing Plant) and recovered uranium as $\mathrm{UO}_{3}$ for recycle.

- In the $\sim 50$ years (1943 through the mid-1990s) Hanford was in operation, $\sim 2,174$ MTU waste was generated. (Approximately 958 MTU now reside in the waste tanks, $\sim 1,054$ MTU is in solid waste, and $\sim 162$ MTU of liquids present on the Hanford site were discharged to cribs.)

- With the exception of a few years in the 1940s, the metal turnings and scrap produced during fuel rod manufacture were shipped offsite for recovery. Most of this scrap metal was converted to uranium oxide before shipment. It has been estimated that, overall, -10 percent $(-11,927 \mathrm{MTU})$ of the uranium received might have gone to scrap during fuel fabrication and was shipped offsite for recovery. Shipping records for the $\sim 112,287$ MTU shipped do not show the distinction between the shipment of scrap and the shipment of recovered uranium as $\mathrm{UO}_{3}$ but most of this $\sim 11,927$ MTU would have been recycled uranium. No Hanford process has been identified which would have changed the as-received ratio of Pu to uranium, or concentrated the constituents in the scrap prior to shipment.

- An estimated $\sim 140 \mathrm{MTU}$ was consumed during reactor operations and the generation of plutonium.

- A material difference of $\sim 0.56 \mathrm{wt} \%$ (664.1 MTU) is indicated in the data reviewed between uranium received and uranium which was used up in the reactors, shipped, and uranium currently on site. The uranium currently on site includes the stored inventory of unirradiated uranium, uranium in irradiated fuel, uranium in tank waste and solid waste, and uranium in wastes in the cribs. This difference can be primarily attributed to limited available data from the early years of Hanford's operations, uncertainties in the quantities of uranium in tank waste and other waste forms, and uncertainties in the estimated amount of uranium that was consumed during reactor operation and the generation of $\mathrm{Pu}$.

- Hanford first began receiving recycled uranium metal billets for reactor fuel rod manufacture starting about July 1952 . The recycled uranium used to produce these billets had been processed through the GDPs and was reported to contain 


\section{EXECUTIVE SUMMARY}

approximately 10 parts Pu per trillion parts uranium. After about 1963, as a result of a manufacturing change at Fernald, the metal biliet Pu concentration rose to a level "not to exceed 10 parts plutonium per billion parts of uranium." Hanford did not routinely perform a Pu analysis of the incoming billets.

Information provided by Fernald indicates that the metal produced from recycled uranium contained ${ }^{99} \mathrm{Tc}$ ranging from $<0.01$ to $6.1 \mathrm{ppm}$ and ${ }^{237} \mathrm{~Np}$ with an upper limit of $-500 \mathrm{ppb}$.

The prospect of an ingestion or inhalation dose in dealing with this metal is remote.

- In 1951, a tentative Pu specification for $\mathrm{UO}_{3}$ was established at 100 parts per billion ( $\mathrm{ppb}$ ), based upon the expected composition of a blended UNH product mix from U-Plant and REDOX Plants. Preliminary specifications were identified by Oak Ridge in 1952 which required the $\mathrm{Pu}$ specification for $\mathrm{UO}_{3}$ to be lowered to $10 \mathrm{ppb}$. This limit was subsequently firmed up in 1953 and remained in place from that time until $\mathrm{UO}_{3}$ production was terminated in 1993.

- Shipments of recycled $\mathrm{UO}_{3}$ powder from Hanford to the GDPs contained only trace amounts of Pu, usually less than $10 \mathrm{ppb}$. The preponderance of Hanford recycle $\mathrm{UO}_{3}$ powder shipments had Pu concentrations of 5 or less ppb in the recycled uranium. Six shipments of $\mathrm{UO}_{3}$ have been identified which contained Pu concentrations of 12,13,16, 19, 22, \& $30 \mathrm{ppb}$. These shipments involved $\sim 193$ MTU containing an average plutonium impurity level of $\sim 18 \mathrm{ppb}$ $(\sim 3.4 \mathrm{~g} \mathrm{Pu})$. Documentation reviewed indicates that the receiver sites were typically notified of these conditions and accepted these limited quantities of recycled uranium prior to their shipment from Hanford.

- Analytical results on every lot of $\mathrm{UO}_{3}$ powder shipped to the GDPs have not been located. Thus a quantitative assessment of the total Pu shipped with the recycled uranium was not possible. Based upon the findings that the predominant Pu concentration was in the range of 1 to $5 \mathrm{ppb}$, it is estimated that approximately 110 to $\mathbf{5 5 0}$ grams of Pu (with a mean of $\mathbf{3 3 0}$ grams) was included with the $\sim \mathbf{1 0 9 , 7 9 2}$ MTU shipped from Hanford.

- Hanford did not routinely analyze the $\mathrm{UO}_{3}$ product produced before 1980 for ${ }^{237} \mathrm{~Np}$ or ${ }^{99} \mathrm{TC}$, as it was not a specification requirement. Hanford did analyze the recycled $\mathrm{UO}_{3}$ powder for total beta and gamma emissions and conformed to the required specification levels of less than a $100 \%$ increase in beta activity and less than a $300 \%$ increase in gamma activity above that of aged natural uranium. In some later campaigns where analyses were performed, the measured ${ }^{237} \mathrm{~Np}$ concentrations typically ranged from 20 to $500 \mathrm{ppb}$, and ${ }^{99} \mathrm{TC}$ concentrations ranged from 3-12 ppm. A rough estimate, based on limited analytical data, indicates that the $\sim 109,792 \mathrm{MT}$ of recycled uranium shipped offsite might have contained 2 to $55 \mathrm{Kg} \mathrm{Np}$ and 330 to $1,320 \mathrm{Kg} \mathrm{Tc}$. 


\section{Error}

An error occurred while processing this page. See the system log for more details. 


\section{EXECUTIVE SUMMARY}

The operation, maintenance, and waste handling operations associated with all of these facilities contributed to some personnel exposure and environmental releases. However, distinguishing exposures to trace quantities of transuranics and fission products in recycled uranium from those associated with normal Hanford operations (which involved the handling and processing of significant quantities of irradiated fuel, high-level waste, and PU) is considered extremely. difficult. Any such dose assessment is further complicated by the past practice of transferring personnel between facilities to meet work needs, necessitating the development of a historical worker profile in order to establish which portions of the dose can be attributed to the various facilities and process operations.

Plutonium was Hanford's principal product and all production processes were designed and operated to maximize plutonium recovery. The primary Hanford facilities which had the highest potential for uranium uptake by personnel were the $\mathrm{UO}_{3}$ Plant, which handled large quantities of dry $\mathrm{UO}_{3}$ powder, and the fuel fabrication facilities in the 300 Area of Hanford which handled uranium metal and uranium fabrication scrap.

An Occupational Potential Exposure (OPE) estimate suggests that $\sim 1,128$ staff at the Hanford site worked in areas directly involving the handling and processing of recycled uranium. Of these personnel, it is estimated that $\sim 456$ could have had moderate OPE (some potential or incidental exposure to recycled uranium but at levels not expected to have any measurable health effect). This is only a rough estimate. For a more thorough analysis of worker contact with recycled uranium, including an examination of Hanford's uranium bioassay records, a more detailed review would be required. 


\section{Section 1 \\ DOE/RL-2000-43 \\ Hanford Uranium Mass Balance Project}

\section{Section 1.0 Hanford Uranium Mass Balance Project}

\subsection{Project Overview}

On August 8, 1999, the Secretary of Energy announced a comprehensive set of actions to address issues at the Department of Energy's (DOE) Paducah Gaseous Diffusion Plant in Paducah, Kentucky, that may have the potential to affect the health of the workers. One of the issues with DOE complex-wide significance involved the need to determine whether radioactive fission products and plutonium in uranium feed and waste streams existed in concentrations that present potential health or environmental concerns. The fission products and transuranic contaminants are contained in uranium that has been irradiated in a nuclear reactor and then processed in a separations plant to recover the uranium for reuse.

A working group was established to address this issue from a DOE complex-wide perspective. The Hanford Uranium Mass Balance Project was established to provide Hanford-specific data to the working group for inclusion in a complex-wide report. The Project Team was established, staffed with present and former Hanford workers, many with direct experience related to the facilities, processes and materials involved in the recycling of uranium or with the identification and retrieval of historical data at Hanford.

Between October 1999 and April 2000, a systematic search of available historical data was conducted and technical members of the Project Team evaluated relevant information. This report represents the results and conclusions of their evaluation.

\subsection{Purpose and Scope}

The purpose of this Project was to develop and provide data to the DOE Working Group that is responsive to a letter from the Deputy Secretary of Energy [Glauthier 1999] to all DOE elements dated September 15, 1999, and two follow-up memorandums from EH-1 [Michaels 1999]. Specifically, the data was to be sufficient to permit the working group to:

- Identify the mass flow of DOE recycled uranium from earty production to March 1999 , including ultimate use and disposition, and create an inter-site flow sheet for public availability.

- Identify the characteristics and contaminates in the major uranium streams, specifically, the technetium, neptunium, plutonium or other isotopic content of concern to worker or public health and safety.

- Conduct site mass balance activities sufficiently thorough to identify any significant implications for personnel exposure or environmental contamination. 


\section{Section 1 Hanford Uranium Mass Balance Project

- Conduct an occupational radiation exposure profile project at the Paducah, Portsmouth, and former Oak Ridge K-25 facilities.

The Hanford Uranium Mass Balance Project included an evaluation of shipments, receipts, and current inventories of recycled uranium to quantitatively estimate the flow and characteristics of recycled uranium to and from Hanford. It also included an evaluation of all Hanford facilities involved in processing recycled uranium, particularly with respect to the potential for concentrating plutonium or radioactive contaminants in the recycled uranium.

The uranium materials within the scope of this project are:

- All uranium (depleted, natural, or enriched, and in all physical and chemical forms) that has ever been irradiated in a reactor and separated from all or some of the fission products and transuranic products.

The uranium materials considered out-of-the-scope of this project are:

- Irradiated fuel and targets which have not been processed to separate all or some of the fission products and transuranic products from the uranium.

- Uranium in waste or under environmental management.

- Uranium in sources, samples, or under NRC agreement or State controls.

This information is intended to enable DOE to assess the historical potential for worker exposure from recycled uranium and its trace transuranic and fission product impurities.

\subsection{Project Implementation Strategy}

DOE Richland Operations Office (RL) management determined that the Project Team would be staffed with present and former Hanford chemists, engineers and other workers with knowledge of the Hanford facilities, processes and materials related to the recovery and reuse of recycled uranium. The Team also included personnel with experience in DOE nuclear material control and accountability, and document classification and declassification requirements and processes.

Hanford currently has approximately 75,000 boxes of historical records in archives, both on site and off. A discussion of the document research process used on this study is provided in Appendix E. The Project organization and functional activities are depicted in Figure $1-1$.

In addition to the database searches, the RL Project Team made extensive use of the first hand knowledge of Team members to identify and search out specific 


\section{Error}

An error occurred while processing this page. See the system log for more details. 


\section{Section 1 \\ Hanford Uranium Mass Balance Project \\ DOE/RL-2000-43}

- Radioactive contaminants in the uranium trioxide shipped from Hanford for which no radiochemical data has been found are assumed to be in the same range as those for which analytical data was located.

\section{References}

Glauthier 1999

Memorandum, T. J. Glauthier, Deputy Secretary of Energy, to All Department Elements, Paducah Gaseous Diffusion Plant - Follow-Up Activities, U. S.

Department of Energy, Washington, DC, September 15, 1999 


\section{SECTION $2 \quad$ DOE/RL-2000-43 HANFORD SITE HISTORICAL OVERVIEW}

\subsection{Hanford Site Historical Overview}

\subsection{Site Description}

The Hanford site was established by the Manhattan Project as the plutonium production site for the U.S. World War II defense effort. The site initially consisted of $\sim 1,735$ square kilometers ( -670 square miles) of primarily remote, semiarid land. Over time, this has been reduced to $\sim 1,450$ square kilometers ( -560 square miles) as parcels of land no longer needed by the site were made available for other uses. The site has access to significant water and power supplies and nearby barge shipping, road, air, and rail facilities. Construction was initiated in March 1943 to build facilities to produce plutonium for the first atomic bombs. The principal early facilities included B-, D-, and F-Reactors, the 313 Fuel Fabrication Facility, the T-Plant and B-Plant fuel processing facilities for plutonium separation, and the 231 Isolation Process facility for final plutonium purification and concentration. Waste storage tanks, laboratory facilities, warehousing, roads, power plants, housing, and a myriad of other support facilities were simultaneously built during the construction period. Initial plutonium production commenced in September 1944 when the first reactor was brought on line. The first batch of refined plutonium was available for the war effort in February 1945.

Buildup of the Hanford site continued for many years in support of nuclear weapons program needs. Additional facilities were eventually needed to satisfy planned plutonium production requirements and to improve process efficiencies. An additional six reactors and four processing facilities were constructed and operated, including: the Reduction Oxidation (REDOX) Plant, U-Plant, $\mathrm{UO}_{3}$ Plant, and the Plutonium-Uranium Extraction (PUREX) Plant. During the plutonium production years at Hanford, uranium was received at the site, fabricated into nuclear fuel, irradiated for plutonium production, and processed to recover the plutonium. Until about 1952, the waste from plutonium separation, which included fission products and unused uranium, was stored in large, underground waste tanks. After 1952, uranium was mined from these tanks and recovered for reuse. All subsequent fuel processing operations included uranium recovery and recycle. Most of this uranium was shipped offsite for recycle and contained residual trace quantities of transuranics and fission products. By 1994, all plutonium production and uranium recovery activities were shutdown and a cleanup mission for the Hanford site was initiated. A brief historical timeline of Hanford's history is provided in Appendix $\mathrm{H}$. 


\section{Error}

An error occurred while processing this page. See the system log for more details. 


\section{SECTION 2 \\ HANFORD SITE HISTORICAL OVERVIEW \\ DOE/RL-2000-43}

support functions were located nearby in facilities in the 700,1100, and 3000 Areas. Completed fuel was shipped to the reactors at the 100 Areas (B, C, D, DR, F, H, KE, $\mathrm{KW}$, and $\mathrm{N}$ ) located along the south shore of the Columbia River in the northern portion of the Site for use in the reactors. After irradiation, the fuel was stored in pools at the reactors for a cooling period and then transported in special rail cars to the separation processing facilities located in both the $200 \mathrm{~W}$ and $200 \mathrm{E}$ Areas. Discarded high level waste from the separation plants were transferred to storage in underground storage tanks located in both the $200 \mathrm{~W}$ and $200 \mathrm{E}$ Areas. All recovered solutions of uranium were transported to the $\mathrm{UO}_{3}$ Plant located in the $200 \mathrm{~W}$ Area for conversion to oxide.

\subsection{Key Uranium Processing Facilities}

As part of the Manhattan Project and its successors, the U. S. Atomic Energy Commission (AEC), Energy Research and Development Administration (ERDA), and the U. S. Department of Energy (DOE), a number of specialized facilities were constructed at the Hanford site and operated between 1943 and 1986 to produce fuel for the nine plutonium production reactors and to recover plutonium and uranium from the irradiated fuel. A historical overview of all the major plants, process flows, and facility interfaces at Hanford is shown in Figure 2-2. All of the uranium received at Hanford for non-research reactor operation was fabricated into fuel in the 300 Area throughout Hanford's production mission. This fuel was used in nine production reactors which operated over various time periods. Essentially all of the irradiated fuel went to one of four separation processing facilities; T-Plant, B-Plant, REDOX, and PUREX. In addition, the U-Plant was operated for a short time period to recover uranium from high level waste from the early T-and B-Plants, which did not have the capability to recover uranium during irradiated fuel processing. All of the high level waste from the processing of irradiated fuel was transferred to underground storage tanks. Recovered plutonium was refined and converted to a suitable chemical form in either the 231-Z Isolation Building or the Plutonium Finishing Plant. Recovered uranium (as recycle uranium) was converted to a stable oxide for shipment in the $\mathrm{UO}_{3}$ Plant. The remainder of this section provides a brief description of the facilities, processes, and operating history for the major Hanford uranium processing plants. 


\section{Error}

An error occurred while processing this page. See the system log for more details. 


\section{Error}

An error occurred while processing this page. See the system log for more details. 


\section{SECTION 2 HANFORD SITE HISTORICAL OVERVIEW \\ DOE/RL-2000-43}

process was developed by Glenn T. Seaborg in the early 1940s and applied at Hanford to achieve separation of the plutonium produced from irradiated uranium. Uranium was not recovered, and both the fission products and uranium were sent to large underground waste storage tanks.
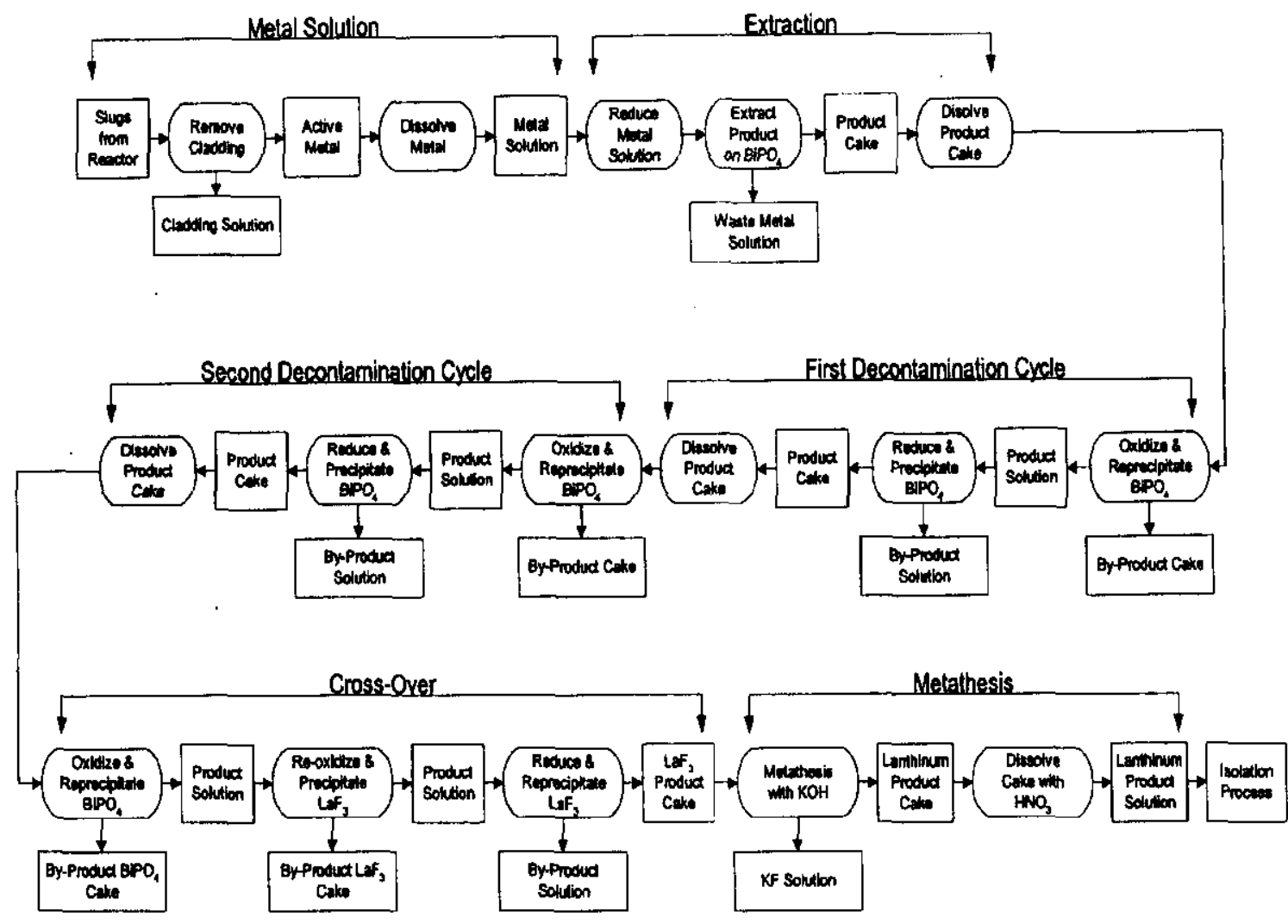

Flgure 2-3 T.Plant Process Flow Dlagram

The process consisted of removing the aluminum cladding from the irradiated fuel rods (also known as "slugs") in dissolver tanks using hot sodium hydroxide. The cladding waste was drained from the dissolver tanks and transferred to the underground waste tanks. The declad slugs were washed with water to remove any residual hydroxide. Nitric acid was then added to dissolve the bare uranium slugs and form a uranium nitrate solution. The uranium nitrate solution was chemically adjusted with sulfuric acid and sodium nitrite to assure extractability of the plutonium from the uranium solution. Bismuth nitrate and phosphoric acid were added to co-precipitate plutonium and bismuth as insoluble phosphates. The solution was centrifuged from the bismuth phosphate co-precipitate. Waste solutions containing uranium and fission products were treated and sent to the underground waste tanks. The solid cake was water washed and dissolved in concentrated nitric acid. The nitrate solution was chemically adjusted to permit precipitation of metal contaminants upon addition of bismuth nitrate while maintaining the plutonium in solution. The solution was again chemically treated and 


\section{SECTION 2 \\ HANFORD SITE HISTORICAL OVERVIEW}

bismuth nitrate and phosphoric acid added to co-precipitate the plutonium, further reducing the metal contaminants. This precipitation, re-solution and re-precipitation process was repeated two more times to further reduce the metal contaminants and reduce volume. Final purification of the plutonium was accomplished by repeated coprecipitation using lanthanum nitrate and hydrofluoric acid to form the lanthanum fluoride which served as the carrier. Upon completion of the purification steps, the plutonium was dissolved in nitric acid and transferred to the Isolation Process Facility (231-Z building) for final treatment and concentration.

\subsubsection{Feed Specifications}

Feed for the extraction process was irradiated natural uranium and the expected plutonium content was low. During the 10 years of T-Plant operation, the irradiated fuel feedstock varied in plutonium and fission products content as the reactor operations were improved and power levels increased.

\subsubsection{Product Specifications}

Plutonium nitrate solution was the principal product of T-Plant and the nitrate solution was further purified at the 231-Z Facility. The uranium and fission products were discharged to the underground waste tanks. Waste transferred to the underground tanks was chemically adjusted to minimize corrosion of the tanks using specifications based on maintaining alkalinity and nitrate/nitrite concentrations. Since uranium did not play an important role in corrosion control, no purity requirements were established for the waste uranium [HW-10475-ABC 1944].

\subsubsection{Operating History}

Processing of irradiated uranium fuel commenced on December 26, 1944, in the TPlant. A number of operational improvements and installation of a third fuel dissolver in 1954 increased plutonium production rates. T.Plant was shut down in March 1956 following startup of the PUREX plant in January 1956.

\subsubsection{Current Status}

T-Plant is used on an irregular basis as an equipment decontamination and repair facility supporting Tank Farms operations. Although recently the 224-T Building was used for TRU waste storage, the TRU has now been removed and 224-T is now being deactivated. 


\section{Error}

An error occurred while processing this page. See the system log for more details. 


\section{SECTION 2 \\ HANFORD SITE HISTORICAL OVERVIEW \\ DOE/RL-2000-43}

\subsubsection{Feed Specifications}

The feed specifications for B-Plant were the same as those for T-Plant, described earlier.

\subsubsection{Product Specifications}

Like T-Plant, B-Plant's principal product was plutonium nitrate solution. The uranium and fission product wastes delivered to the underground tanks were chemically adjusted to assure adequate control of expected tank corrosion using specifications based on maintaining alkalinity and nitrate/nitrite concentrations [HW-10475-ABC 1944].

\subsubsection{Operating History}

B-Plant began processing irradiated uranium fuel in April 1945 using the bismuth phosphate process. Plutonium recovery continued until 1952 when the plant capacity became unnecessary once the combined output of T-Plant and REDOX was sufficient to satisfy production needs. In 1968, the plant was converted to a waste fractionation plant. Cesium and strontium were removed from the high level tank wastes and encapsulated [Gerber 1996].

\subsubsection{Current Status}

The cesium and strontium capsules are currently being stored in water filled basins in an addition on the west end of the plant. Present plans call for vitrification of these capsules as high level waste. The remainder of the plant has been shutdown. 


\section{Error}

An error occurred while processing this page. See the system log for more details. 


\section{SECTION 2 \\ HANFORD SITE HISTORICAL OVERVIEW \\ DOE/RL-2000-43}

tributyl phosphate (TBP). The TBP was found to complex very well with both uranium and plutonium to allow their separation from fission products and from each other after proper chemical adjustments. The process consisted basically of contacting the clarified and concentrated acidic uranium solution that had been sluiced from the waste storage tanks with TBP carried in a hydrocarbon solvent to complex the uranium with the TBP. This process was done as a one-pass counter-current solvent extraction process using packed columns. The uranium complexed with the TBP and thus transferred to an organic phase, while the fission products remained in the aqueous phase. The acidic aqueous waste from the column was neutralized and returned to the underground waste tanks for storage. The uranium was then stripped from the TBPuranium complex in the organic phase in another packed column with acid of a specific molarity. The resultant uranium solution was then concentrated in an evaporator to a consistent concentration for feed to the $\mathrm{UO}_{3}$ Plant. The concentrated uranium nitrate solution (uranyl nitrate hexahydrate (UNH)) was analyzed to assure that it met feed specifications for the $\mathrm{UO}_{3}$ Plant and then transferred to that facility for conversion to shippable powder. Product solutions not meeting the stringent specification of the $\mathrm{UO}_{3}$ Plant were recycled back through the extraction process. In order to accommodate the required throughput rate, there were two extraction trains in U-Plant.

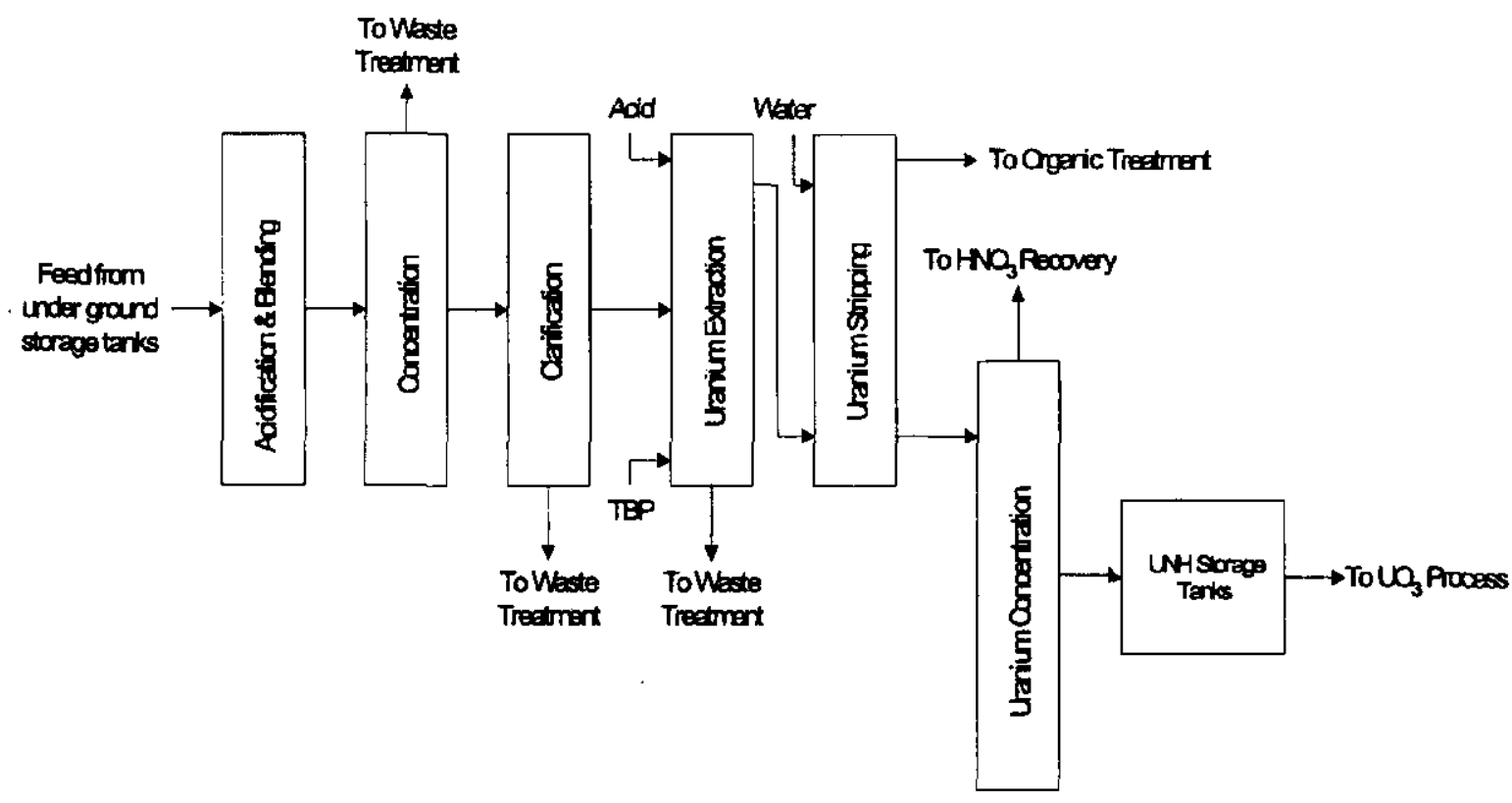

Figure 2-4 Simplifled U-Plant Tributyl Phosphate (TBP) Process Flow Diagram

\subsubsection{Feed Specifications}

Feed for U-Plant came from the underground storage tanks which contained high level waste from the $B$ and $T$ separation plants. The uranium-bearing tank wastes consisted 


\section{SECTION 2 \\ HANFORD SITE HISTORICAL OVERVIEW}

of sludge and supernatant liquor (sludge washings and solutions). The sludge contained approximately 75 percent of the uranium. The plutonium content of the uranium waste was about two to four grams per metric ton (MT) of uranium (2-4 ppm $\mathrm{Pu}$ ). Approximately $20 \mathrm{MT}$ of slurried tank waste was required to produce one ton of recovered uranium for conversion to $\mathrm{UO}_{3}$. A description of the chemical constituents of the "mined" uranium feed can be found in the Uranium Recovery Technical Manual [HW-19140 1951].

\subsubsection{Product Specifications}

The U-Plant product specifications were dictated by the specifications for the $\mathrm{UO}_{3}$ powder produced in the $\mathrm{UO}_{3}$ Plant. The initial specification in the 1951 technical manual [HW-19140 1951] indicated the UNH product from U-Plant should contain less than $80 \mathrm{ppb} \mathrm{Pu}$. The $\mathrm{UO}_{3}$ Plant did not further refine the UNH product from the U-Plant process. Blending of the U-Plant product with product from REDOX was expected to help assure the concentration of transuranics and fission product impurities were at acceptable levels. U-Plant did have the capability to concentrate the UNH prior to calcination, however this did not alter the ratio of any impurities to uranium.

\subsubsection{Operating History}

Uranium was scarce in the late 1940s. Escalating demand for weapons materials led to the decision to reclaim uranium from the underground storage tanks. This was first discussed in 1947 when a decision was made to develop a process for extracting uranium from the Hanford waste tanks to supplement the scarce uranium supplies [Peterson 1947]. Over the next few years, a uranium recovery process based upon TPB was developed at Hanford and served as the design basis for both the U-Plant conversion and the PUREX separations operations. U-Plant began recovering uranium from tank wastes in 1952 and completed its mission in 1958. UNH product from U-Plant was routinely blended with UNH product from REDOX. During U.Plant's operating period, 7,200 MTU was recovered from high-level waste for conversion to $\mathrm{UO}_{3}$ and recycle.

Worker exposure to uranium was normally low, as processing occurred remotely in heavily shielded and ventilated canyon cells. The uranium solutions were of low concentration until the solution was evaporated to create the UNH product. Transfer of concentrated $\mathrm{UNH}$ to the $\mathrm{UO}_{3}$ plant was by pipeline. Liquid wastes containing fission products and plutonium were transferred to underground waste storage tanks. Solid wastes were packaged and sent to the Hanford burial sites for disposal.

\subsubsection{Current Status}

U-Plant is presently undergoing decontamination and decommissioning. It's final state is the subject of an ongoing Canyon Disposition Initiative at Hanford. 


\section{Error}

An error occurred while processing this page. See the system log for more details. 


\section{SECTION 2 HANFORD SITE HISTORICAL OVERVIEW \\ DOE/RL-2000-43}

\subsubsection{Material Flowsheet}

The initial $\mathrm{UO}_{3}$ process operations utilized a batch calcination process involving 18 stirred kettles, as shown in Figure 2-5. The concentrated UNH was initially heated in the stirred kettles until it was dry and then further heated until the UNH decomposed into $\mathrm{UO}_{3}$. The nitric acid resulting from the drying and calcining processes was recovered and concentrated. The concentrated nitric acid was returned to the separation plants for reuse. The $\mathrm{UO}_{3}$ powder was removed from the kettles and pneumatically transferred into storage bins. The air used to transport the $\mathrm{UO}_{3}$ was filtered before discharge to the atmosphere. The condensate stream was sampled to verify compliance with existing regulations and discharged to the cribs. The $\mathrm{UO}_{3}$

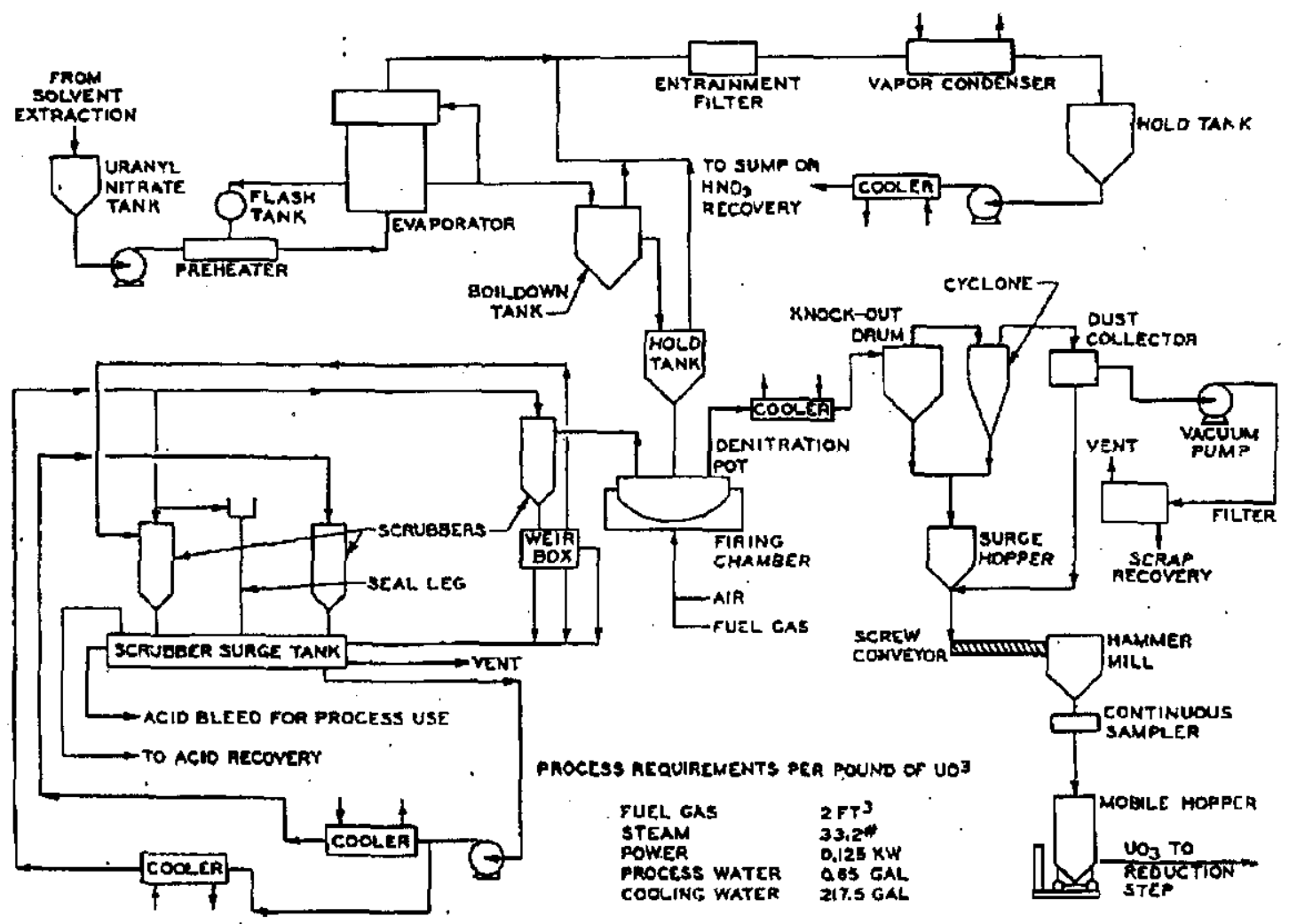

Figure 2-5 $\mathrm{UO}_{3}$ Plant Process Diagram Involving Batch Pot Calciners

product was sampled and tested to assure compliance with product specifications. At times, the powder was ground to a specific particle size to meet chemical reactivity specifications. Sulfuric acid was added to the UNH to control the hydrofluorination reactivity of the $\mathrm{UO}_{3}$ powder at the gaseous diffusion plants. Off-specification $\mathrm{UO}_{3}$ 


\section{SECTION 2 \\ HANFORD SITE HISTORICAL OVERVIEW

powder was either blended with acceptable $\mathrm{UO}_{3}$ product to bring the impurities to within specification requirements, or waivers were obtained before shipment.

In 1956, the 18 kettle calciners were replaced with 6 stirred continuous calciners as shown in Figure 2-6 to improve the product quality and increase the production rate. In addition, an evaporator further concentrated the UNH feed solution from the separation plants to allow more effective calcination. The concentrated UNH was sprayed on a heated $\mathrm{UO}_{3}$ powder bed in the continuous calciners. The $\mathrm{UNH}$ quickly dried, decomposed and was calcined to $\mathrm{UO}_{3}$ powder. The $\mathrm{UO}_{3}$ product overflowed the calciner and was pneumatically transferred to the holding bins pending acceptance testing and subsequent packaging into T-hoppers or drums. Nitric acid driven off in the calcination process was recovered and returned to the separation plants for reuse.

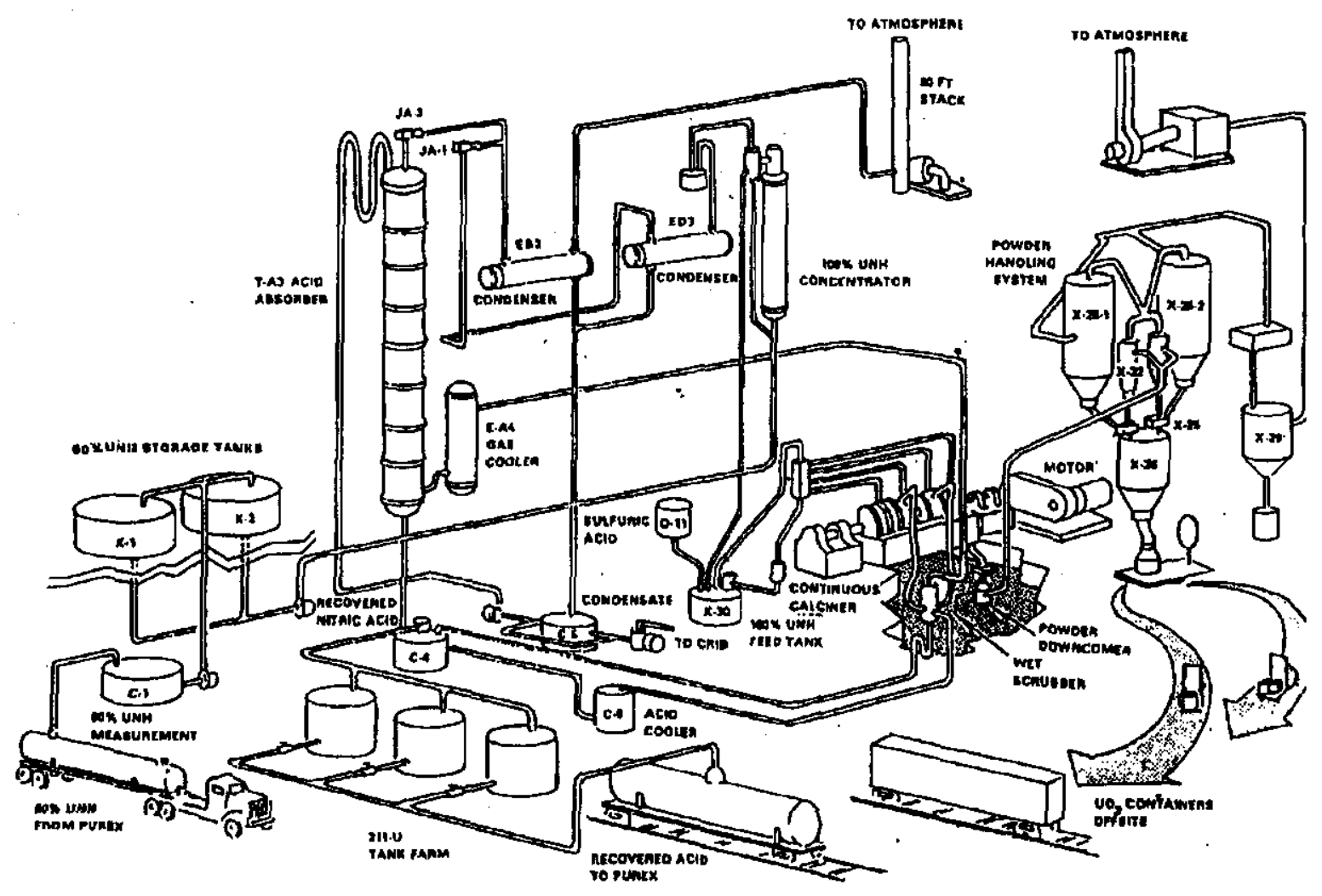

Figure 2-6 $\mathrm{UO}_{3}$ Plant Process Diagram Involving Continuous Calciners

During the time when $\mathrm{UO}_{3}$ Plant operated with continuous calciners, the product loadout system was configured approximately as shown in Figure 2-7. Powder in the pickup bin was fluidized and transported to cyclone separators on the fourth floor of the 224-UA tower. The heavy powder dropped out of the cyclone into the storage hopper. The remaining air and powder fines were filtered on primary bag filters, secondary filter 


\section{SECTION 2 \\ HANFORD SITE HISTORICAL OVERVIEW \\ DOE/RL-2000-43}

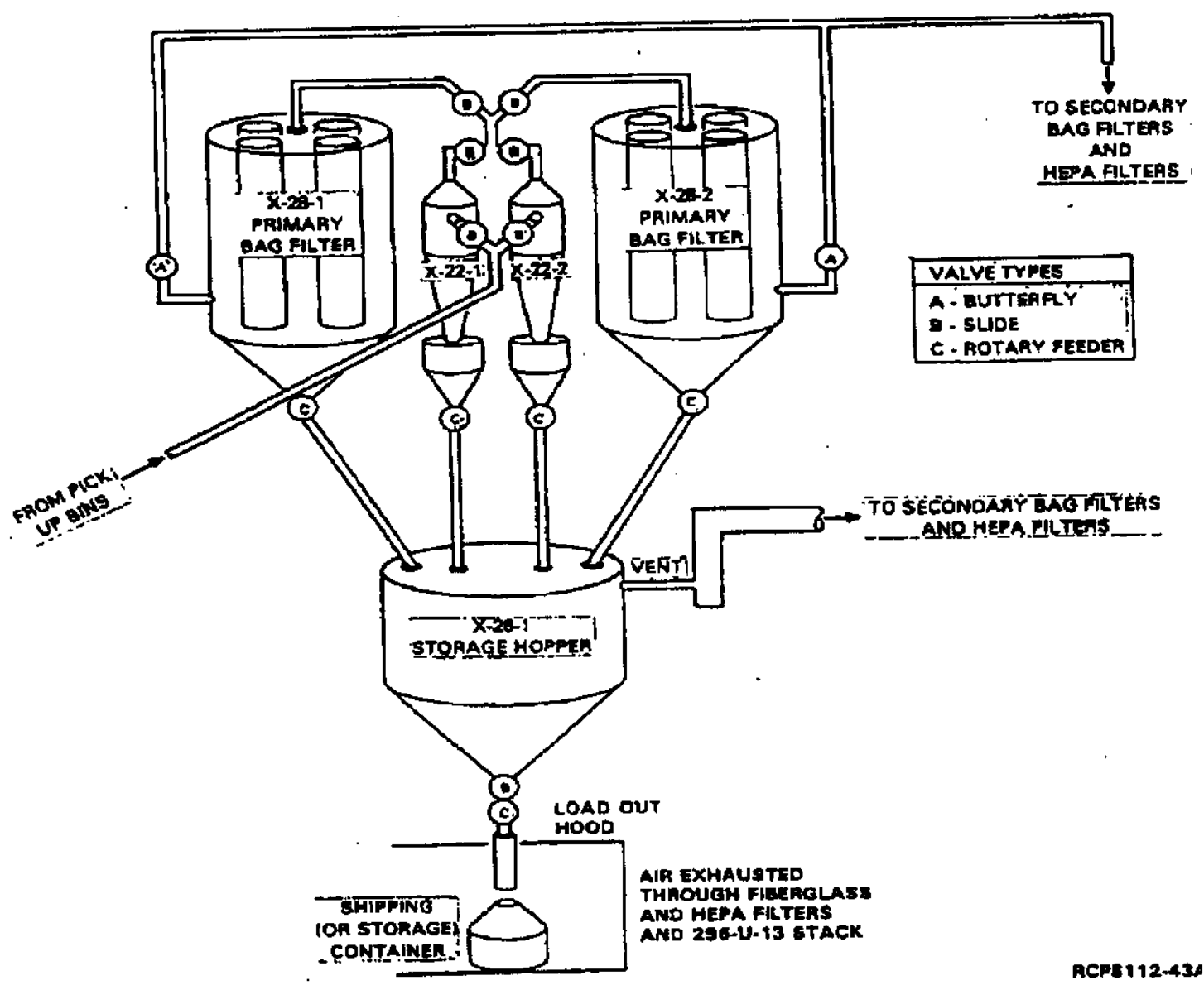

Figure 2-7 $\mathrm{UO}_{3}$ Product Loadout System

bags, and then on high efficiency particulate air (HEPA) filters, which were added during the 1972 to 1984 shutdown time period. The powder was sampled for acceptance testing [Gustavson 1950].

Acceptable powder in the storage hopper was loaded into approved containers in the 224-UA loadout room. A forklift transported these containers to the 2714-U storage area. From this area, the $\mathrm{UO}_{3}$ powder was shipped offsite by railcar or truck.

Of all Hanford uranium recycle activities, operation of the $\mathrm{UO}_{3}$ Plant presented one of the greatest potentials for worker inhalation exposure to uranium and its contaminants because the product was a powder. In this facility, liquid uranium solutions were converted into dry $\mathrm{UO}_{3}$ powder in ventilated batch kettles or continuous calciners. The calciners were ventilated to recover the nitric acid produced during calcination for reuse. The dry powder was handled pneumatically to minimize worker exposure. Packaging of the $\mathrm{UO}_{3}$ into drums and T-Hoppers and maintenance on calciners and off-gas filters 


\section{SECTION 2 \\ HANFORD SITE HISTORICAL OVERVIEW \\ DOE/RL-2000-43}

offered the highest potential for exposure to airborne powder. The transfer operation was performed within a ventilated enclosure to assist in dust control.

More detailed information on the $\mathrm{UO}_{3}$ Plant is provided in Appendix $\mathrm{G}$.

\subsubsection{Feed Specifications}

Feed specifications for the initial operation of the $\mathrm{UO}_{3}$ Plant are provided in the "Uranium Recovery Technical Manual" [HW-19140 1951]. This specification indicates that the product material from REDOX and U-Plant was tightly controlled, as the $\mathrm{UO}_{3}$ process provided no further purification of the uranium. The need for process control was recognized in the late 1940 s and early 1950 s before the plant came on line. The need to maintain the plutonium contamination to very low concentrations was recognized and included in the technical manual. Decisions were made in the late 1940s [Peterson 1947] to enrich the depleted uranium back to normal concentrations. Discussions followed regarding "firm specifications" for the final uranium product to be delivered [Greninger 1950].

The separation plants were originally designed on the basis that the recovered uranium would be sufficiently decontaminated with respect to Pu and gross beta and gamma radiation to permit essentially direct physical handling of the final product in its last form at Hanford. It was also recognized at this early stage that subsequent processing at other plants might result in fractionation or concentration of either fission products or of plutonium and cause a need for more highly specific or greater decontamination than would be required at Hanford. In a 1951 letter [Gamertsfelder 1951], it is stated that "...reclaimed uranium should contain no more than one part plutonium in $7.8 \times 10^{6}$ parts uranium." in order that the hazard due to breathing air contaminated with reclaimed uranium should be no more than $10 \%$ greater than for ordinary uranium.

\subsubsection{Product Specifications:}

A "tentative" $\mathrm{UO}_{3}$ product specification was initially defined in the "REDOX Technical Manual" [HW-18700 1951]. This tentative specification established the following constituent limits:

- Beta Activity from Fission Products

- Gamma Activity from Fission Products

- $\mathrm{UO}_{3}$ Purity

- Plutonium
Not more than $30 \%$ of beta activity of natural uranium

Not more than $300 \%$ of gamma activity of natural uranium

$97 \%$ minimum

100 parts per billion parts of uranium 


\section{SECTION 2 \\ HANFORD SITE HISTORICAL OVERVIEW \\ DOE/RL-2000-43}

Negotiations continued on $\mathrm{UO}_{3}$ specifications in 1952, when preliminary specifications were considered which indicated a desired maximum plutonium concentration of 10 ppbp uranium [Hurd 1952]. In 1953, based on operating experience, representatives from Hanford and Oak Ridge agreed upon the properties of the Hanford $\mathrm{UO}_{3}$ to be included in a firm specification. [Smith 1953]. These properties included fission product activity, plutonium content, purity ( $\mathrm{UO}_{3}$ content), particle size, and volatile impurity content, and specified that "The maximum acceptable plutonium concentration shall be ten parts of plutonium per billion parts of uranium. Plutonium shall be determined on each carload composite." The 1953 revised specification is given in [Smith 1953]. The new constituent levels were established as follows:

\section{Firm Specifications Properties:}

- Gamma Activity - the average gamma activity for any ten consecutive carload shipments shall be $100 \%$ the gamma activity of aged natural uranium. Defined as follows: for the purpose of establishing the average acceptable gamma activity specification, shipments of uranium oxide to K-25 will be considered in designated blocks of ten consecutive carloads. The average acceptable gamma activity due to fission products for a block shall be $100 \%$ the gamma activity of aged natural uranium. For the purpose of establishing the maximum gamma activity specification, one carload of oxide shall be considered a unit. The maximum acceptable gamma activity, due to fission products, for a unit shall be $300 \%$ the gamma activity of aged natural uranium.

- Beta Activity - the maximum acceptable beta activity, due to fission products, shall be $100 \%$ the beta activity of aged natural uranium. Beta activity shall be determined on each carload composite.

- Plutonium Content - the maximum acceptable plutonium concentration shall be ten parts of plutonium per billion parts of uranium. Plutonium shall be determined on each carload composite.

- $\mathrm{UO}_{3}$ Content - the minimum acceptable $\mathrm{UO}_{3}$ content shall be $97 \%$. The $\mathrm{UO}_{3}$ content shall be determined on each lot of 8 drums.

During the operating history of $\mathrm{UO}_{3}$ production, numerous changes were made to the product specification to better control specific isotopes contributing to beta-gamma exposure of workers. Figure 2-6 shows a copy from one of the early Hanford $\mathrm{UO}_{3}$ product specifications, indicating an allowed maximum plutonium concentration of 10 ppbp uranium [Smith 1959]. A more complete discussion on specification development and compliance is provided in Section 4.

Product specifications were also discussed, but not adopted, for ${ }^{233} \mathrm{U},{ }^{232} \mathrm{U},{ }^{237} \mathrm{~Np}$, and ${ }^{99}$ Tc. In 1962 [Judson 1962] it was proposed that the maximum concentration of ${ }^{233} \mathrm{U}$ be set at 90 ppm on a ${ }^{235} \mathrm{U}$ basis, and that ${ }^{232} \mathrm{U}$ be set at $110 \times 10^{-4} \mathrm{ppm}$ on a ${ }^{235} \mathrm{U}$ 


\section{SECTION 2 HANFORD SITE HISTORICAL OVERVIEW

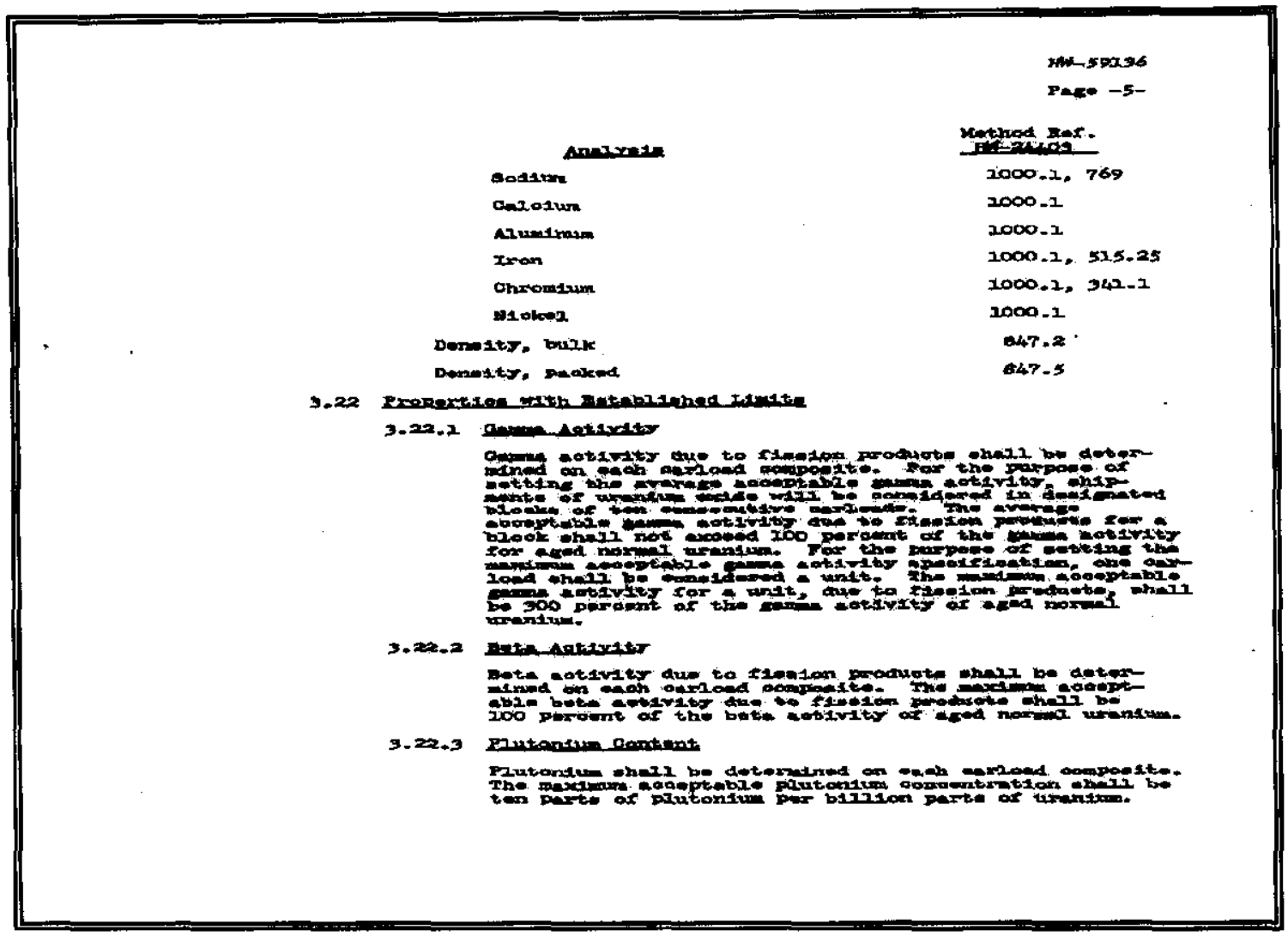

Figure 2-8 Copy Of Early $\mathrm{UO}_{3}$ Product Specification

basis. In 1971, it was recommended a Np specification of $<1 \mathrm{ppm}$ for a lot composite and $<0.3 \mathrm{ppm}$ on 10 lot composites [Elgert 1971]. And in 1982 a ${ }^{99} \mathrm{Tc}$ specification of $0.4 \mathrm{ppm}$ was proposed [Miskho 1982]. At that time it was implied that there was a 400 ppm limit for ${ }^{99} \mathrm{Tc}$, but it has never been part of the Hanford specifications for $\mathrm{UO}_{3}$ product.

\subsubsection{Operating History}

The facility began test runs in January 1952, and was in full operation the following month. Thus, for the first time, a full cycle of uranium into and out of Hanford was completed. The first $\mathrm{UO}_{3}$ calciners simply were large pots that heated the $\mathrm{UNH}$ in batches. During the initial operation of U-Plant, the UNH product resulted in $\mathrm{UO}_{3}$ product which required additional purification to remove non-radioactive impurities. This material was shipped off-site for purification. By the end of 1953, however, process improvements in both the REDOX Plant and U-Plant resulted in UNH so pure that the $\mathrm{UO}_{3}$ Plant product no longer had to be sent offsite for further purification. This $\mathrm{UO}_{3}$ was able to be shipped and used directly at Oak Ridge. 


\section{SECTION 2 HANFORD SITE HISTORICAL OVERVIEW \\ DOE/RL-2000-43}

During $1954, \cup_{3}$ Plant capacity increased to 18 tons per day with the addition of two gas-fired calciners. Overall production in 1954 was limited, however, by the quantity of feed available from the REDOX and U-Plants. A key improvement that year was the use of vacuum cleaning techniques that enabled the plant to recover 90-95 percent of the oxide powder associated with failed filter bags.

During 1955, monthly $\mathrm{UO}_{3}$ production averaged 106 percent that of 1954 , while the unit costs per ton dropped to 92 percent those of the previous year. In 1956, equipment modifications, including new pot agitators, shafts, seals, bearings and supports, as well as new pot cover assemblies, off-gas systems, and gasketing were employed.

In the same time frame, plans went forward to construct the 224-UA Building, a major addition to the $\mathrm{UO}_{3}$ Plant, with six large, new, continuous action calciners. These calciners were developed and designed at Hanford. They had large troughs with paddle agitators that turned and mixed the $\mathrm{UNH} / \mathrm{UO}_{3}$ bed throughout the process. The caking and clogging problems that had plagued the pots were obviated by the below-grade valving of the continuous calciners. The new valves used air to agitate the powder, and provided a seal between the calciner and the powder pickup bin, while passing a continuous stream of $\mathrm{UO}_{3}$.

The new calciners also produced a pebbly product that consisted of spheres with an average diameter of 200 microns (about 1/100th of an inch), as opposed to the granular oxide product of the pots. The first three continuous calciners began operation in the last quarter of 1956 at the same time specially designed T-Hoppers began to replace the 900 pound drums as shipping containers. The T-Hoppers left the site on specially fitted rail flat cars and served as feed hoppers for the Oak Ridge plant customer.

Installation of the last three of the continuous calciners was completed in early 1957. At that time, the 18 pot units were retired from service, and all processing was done through the continuous calciners. Late that year, design was initiated for new facilities which were needed to segregate regular UNH feed from that generated by the processing of enriched metal (E-Metal) in the REDOX Plant. The $\mathrm{UO}_{3}$ powder that resulted from processing the two types of UNH streams had significantly different nuclear reactivity levels. It was necessary to maintain separation of these streams for the customer at Oak Ridge. Routine transfers of enriched $\mathrm{UO}_{3}$ from Hanford to Oak Ridge began in early 1959.

In 1958, U-Plant finished its uranium recovery mission and was shut down. However, the quantity of PUREX Plant UNH product being shipped to the $\mathrm{UO}_{3}$ Plant far surpassed that which had come from U-Plant. Together, the $\mathrm{UO}_{3}$ and PUREX Plants went on to set and surpass production records almost continually, while the REDOX Plant continued to supply a small stream of enriched UNH until its shutdown in 1967.

During 1959, the concentration equipment and the acid recovery system at the $\mathrm{UO}_{3}$ Plant were automated. In 1960, the calciners were also automated so that they could be operated and shut down remotely. In 1963, production of $\mathrm{UO}_{3}$ shipped offsite rose to 


\section{Error}

An error occurred while processing this page. See the system log for more details. 


\section{SECTION 2 HANFORD SITE HISTORICAL OVERVIEW

was the technological answer to the need to increase plutonium production and uranium recovery to satisfy growing national defense needs.

\subsubsection{Plant Description}

Experimentation and design for the REDOX (reduction oxidation) Plant began in 1947 with actual construction beginning in late 1949. The facility commenced operations in 1952. The building is 467 feet long by 161 feet wide by 82 feet high. At one end of the building is a "penthouse", 132 feet high, which housed the extraction columns. It is constructed of thick, steel-reinforced concrete. The processing of irradiated fuel was accomplished in nine below-grade, thickly shielded, concrete cells. Support facilities, including the 222.S laboratory, were constructed in the same time frame. Like the earlier T-and B-Plants, the process first dissolved the irradiated fuel cladding and then dissolved the uranium core. The plutonium was separated from the uranium in a continuous process utilizing methyl isobutyl ketone (hexone). The plant design-basis production rate was about 3 MT uranium per day [Gerber 1996].

\subsubsection{Material Flowsheet}

The REDOX process offered substantial improvement over the T- and B-Plant separation processes by employing continuous solvent extraction. Under specific conditions, plutonium and uranium were found to extract into hexone solvent, allowing separation from the fission products, which remained in aqueous solution. Figure 2-9 shows a simplified flow diagram of the process.

The irradiated reactor fuel was removed from the shipping cask and transferred to a dissolving tank to permit selective removal of the protective aluminum cladding using a caustic solution. The coating waste was neutralized and sent to underground waste tanks for storage. The bare irradiated uranium slugs in the dissolver tank were then reacted with nitric acid to dissolve the uranium and accompanying plutonium and fission products. The resulting uranium nitrate solution was first treated with sodium dichromate and sodium hydroxide to adjust the plutonium valence state and then was contacted with an acidic hexone solvent in a countercurrent extraction column.

The uranium and plutonium formed a complex with the acidified hexone and were separated from the fission products. The aqueous waste was neutralized, treated and transferred to the waste tanks for storage. The plutonium/uranium/hexone complex was treated again to adjust the plutonium and uranium valances to permit separation of the plutonium from the uranium in the next countercurrent extraction column, where the plutonium was stripped from the hexone complex into a nitric acid solution. The uranium/hexone solution was further treated and the uranium removed by a nitric acid wash. Once the separation had been completed, the uranium and plutonium streams were separately treated in two more similar extraction/separation steps through countercurrent extraction columns to further remove impurities and provide product nitrate solutions meeting stringent impurity specifications. Off-specification product 


\section{SECTION 2 \\ HANFORD SITE HISTORICAL OVERVIEW \\ DOE/RL-2000-43}

solutions were sent back into the extraction process for rework. The hexone solvent was washed, neutralized and re-distilled for recycle into the extraction process

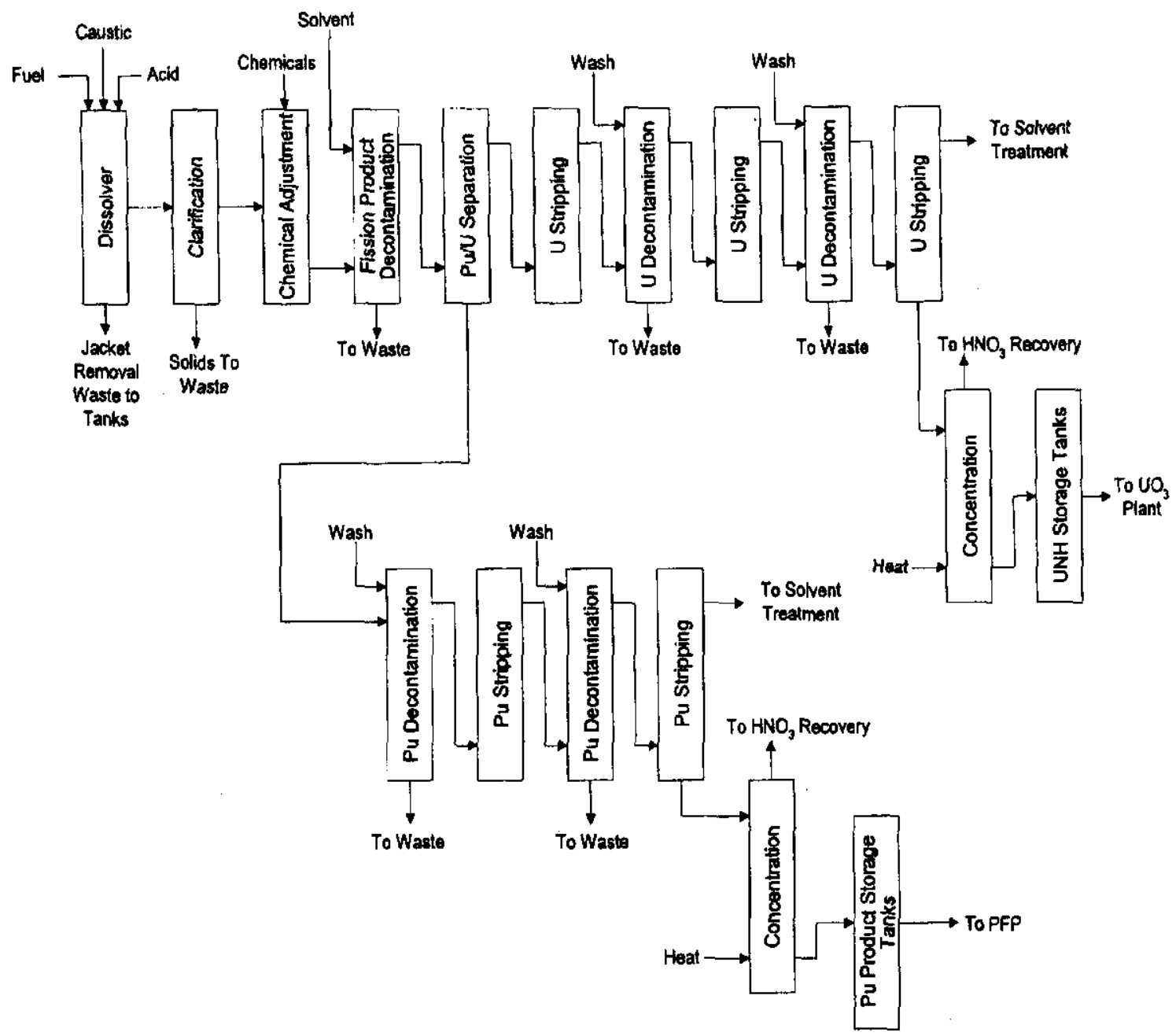

Figure 2-9 REDOX Process Flow Diagram (Simplified)

\subsubsection{Feed Specifications}

The irradiated fuel was aged before processing to eliminate some of the fast decay fission products and to assure that the product beta and gamma radiation limits were met.

\subsubsection{Product Specifications}

The uranium product specifications were driven by the $\mathrm{UO}_{3}$ product specification requirements. The $\mathrm{UO}_{3}$ Plant processing of UNH product from REDOX, did not further 


\section{SECTION 2 \\ DOE/RL-2000-43 \\ HANFORD SITE HISTORICAL OVERVIEW}

refine the uranium, thus the feed UNH from REDOX had to meet the final $\mathrm{UO}_{3}$ product specification limits. The plutonium content of three trial lots of $\mathrm{UO}_{3}$ prepared from material processed through the REDOX Plant in 1952 was less than 5 parts per billion parts (ppbp) uranium [Richards 1952]. It was also reported in June 1952 that the average plutonium concentration in REDOX recovered uranium was less than $1 \mathrm{ppb}$ [HW-24605 1952].

\subsubsection{Operating History}

The REDOX plant commenced "hot" operations in January 1952. By April 1952 the plant achieved its design rate production throughput. At the end of 1952 the plant had exceeded its throughput rate by $50 \%$ for several months. A series of three "Capacity Increase" projects began in 1953 with the result that the production throughput rate being increased by a factor of 2-3 times that achieved in 1953. By the end of 1954 the throughput rate reached 8 tons per day. Additional improvements brought the throughput rate to $11-12$ tons per day by 1958 . Part of the capacity increases included construction of the 233-S Plutonium Concentration Building. Completed in 1957, this building carried out the third and final plutonium concentration cycle. Processing of enriched irradiated fuel assemblies (E-metal) began at REDOX in 1958. E-metal throughput initially was limited to 3 tons per day due to criticality considerations in the plant. After installation of multipurpose annular dissolvers and other process improvements, the plant throughput rate reached 12 tons per day for enriched fuel. The REDOX Plant operated until 1967 when it was shut down [Gerber 1996].

\subsubsection{Current Status}

The REDOX Plant is shut down and awaiting decontamination and decommissioning. The 222-S laboratory is currently in operation supporting waste management and environmental control processes. 


\section{Error}

An error occurred while processing this page. See the system log for more details. 


\section{SECTION 2 \\ HANFORD SITE HISTORICAL OVERVIEW \\ DOE/RL-2000-43}

contaminated cask cars without compromising the ventilation system, and (3) a "soft wall" at the east end of the building that consisted of concrete blocks. These blocks could be removed for the installation of an additional crane, or to enlarge the building at some future date [Gerber 1996].

\subsubsection{Material Flowsheet}

PUREX operated under a number of different flowsheets that were the result of process and equipment improvements and changing reactor fuel compositions. Additionally, some campaigns involved neptunium and the processing of thorium based reactor fuels. A typical process flow diagram for PUREX processing of $\mathrm{N}$-Reactor irradiated fuel is shown in Figure 2-10. Not shown on this diagram is the Plutonium Oxide Production and Rework Facilities that were added in the PUREX N-cell in the early 1980s. This process allowed conversion of recovered plutonium nitrate to plutonium oxide without having to send the solution to the PFP for conversion to the oxide.

The PUREX process was the next generation separations process. It utilized tributyl phosphate (TBP) to complex with plutonium and uranium under specific conditions and to cleanly separate the uranium and plutonium. The irradiated reactor fuel elements were removed from the storage basin and transferred into three dissolvers. The aluminum cladding was dissolved from the uranium fuel rod with sodium hydroxide. The cladding waste solution was treated to meet waste tank corrosion specifications and transferred to the waste tanks.

The PUREX Plant also processed zirconium clad fuel, which required the use of an ammonium fluoride and ammonium nitrate decladding solution at near boiling conditions. The zirconium-containing decladding waste from the dissolvers was centrifuged and treated to meet Tank Farm waste solution corrosion specifications. The centrifuged solids contained recoverable amounts of uranium and were accumulated and subsequently treated for uranium and plutonium recovery. Next, nitric acid was added in two increments to the dissolvers to dissolve the uranium, plutonium, and fission products into a solution that permitted transfer and separation. The dissolvers were maintained at elevated temperature to facilitate fuel dissolution.

Once the uranium and plutonium and fission products were dissolved, the solution was fed continuously into a pulsed extraction column where the uranium, neptunium, and plutonium were stripped away from the nitric acid solution into a normal-paraffinhydrocarbon (NPH) solvent containing TBP. The fission products remained in the aqueous solution and were discarded after treatment to the waste tanks. The decontaminated solution of uranium, neptunium and plutonium in the TBP complex was next pumped through a second pulse column where the plutonium was selectively stripped out of the NPH/TBP complex into an aqueous nitric acid solution.

The NPH/TBP complex containing uranium and neptunium was sent to the next pulse column where the uranium and neptunium were stripped from the TBP complex using a weak aqueous nitric acid solution. The uranium/neptunium solution went to the 


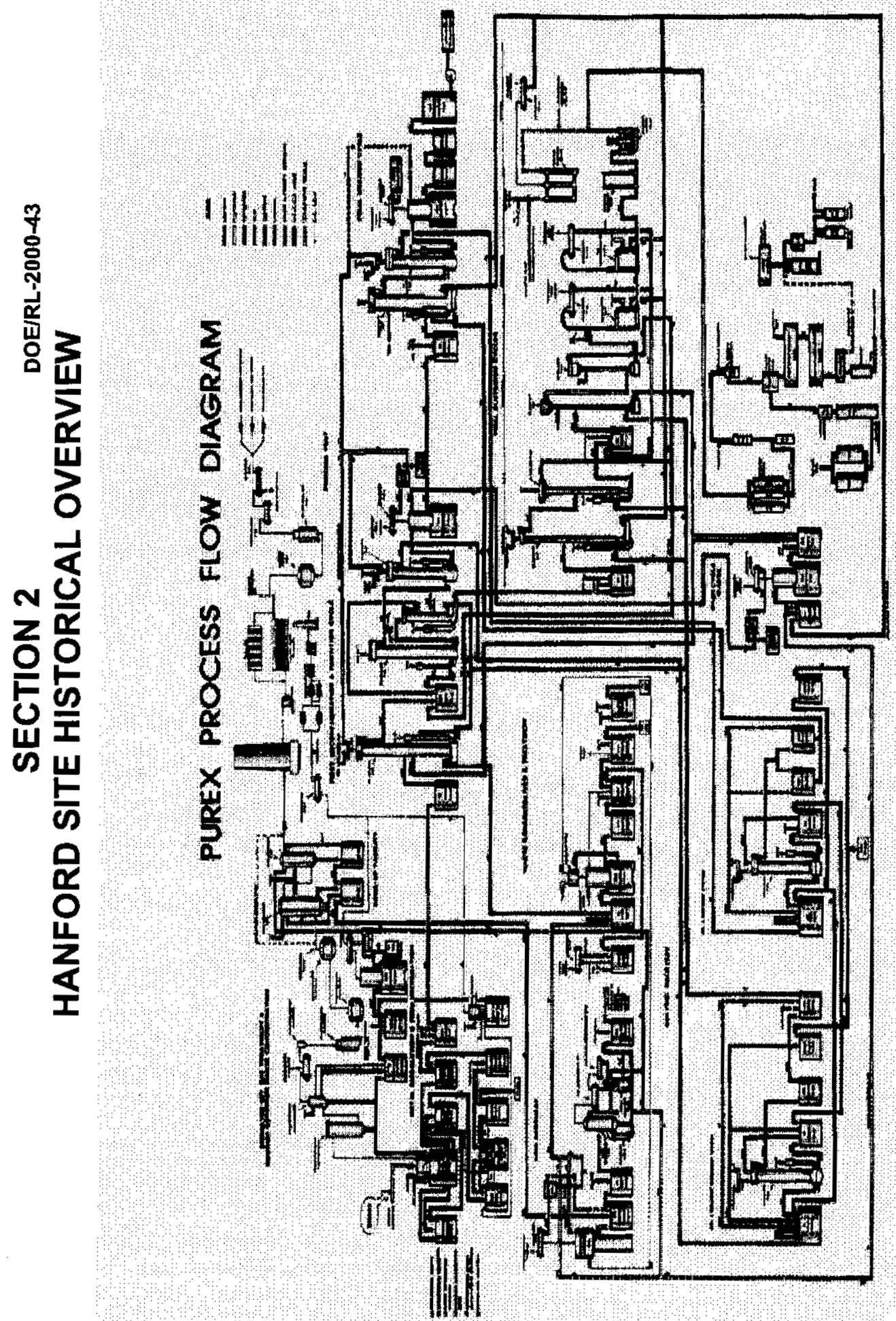

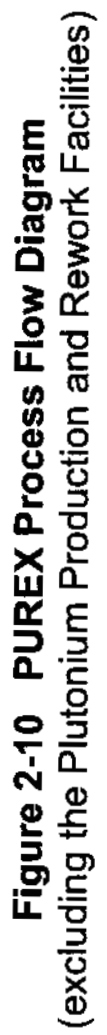




$$
\text { in }
$$




\section{SECTION 2 HANFORD SITE HISTORICAL OVERVIEW \\ DOE/RL-2000-43}

evaporator for concentration before entering the final uranium cycle. The concentrated uranium/neptunium solution was routed to a feed tank for acid adjustment before entering a pulsed stripping column where the uranium/neptunium solution was contacted with NPH/TBP solution. In this column, the uranium was selectively extracted into the NPH/TBP while the neptunium remained with the aqueous flow. The $\mathrm{NPH} / \mathrm{TBP} / \mathrm{uranium}$ complex was then sent to another column for stripping uranium into an aqueous solution which was subsequently concentrated in an evaporator and, after sampling, transferred to the $\mathrm{UO}_{3}$ feed tank.

The plutonium stream from the second pulsed column was sent to the second and third plutonium cycle extraction columns where it was contacted with NPH/TBP solution repeatedly to remove any residual fission products and trace uranium. Following the completion of the two cleaning cycles the plutonium solution was concentrated to meet product specifications.

Product solutions not meeting specification were recycled back through the process for cleanup. If needed, waste solutions from the columns were scavenged for uranium, plutonium and neptunium before treatment to meet waste tank acceptance criteria. The used NPH/TBP solutions were treated to remove impurities, re-acidified and returned to the process. Nitric acid off-gasses were recovered, concentrated into nitric acid, and returned to the process.

\subsubsection{Feed Specifications}

PUREX feed specifications were driven by the type of reactor fuel that was to be recovered for its plutonium content. The process was flexible and permitted feeds of different enrichment. Criticality control of the fuel dissolution process drove the size and configuration of the plant dissolvers. PUREX processed irradiated fuel initially containing up to $2.1 \%{ }^{235} \mathrm{U}$.

\subsubsection{Product Specifications}

The plutonium and uranium product compositions were derived from the feed requirements imposed by the $\mathrm{UO}_{3}$ Plant and the Plutonium Finishing Plant (PFP). A typical specification for the UNH product solution is shown in Figure 2-11. For additional information on specification development, see Section 4.

\subsubsection{Operating History}

The PUREX Plant was originally designed to process up to $200 \mathrm{MT}$ of irradiated uranium per month. It achieved this rate and higher over the years it operated. In 1956 alone, the PUREX plant processed 56 percent of the annual plutonium output of Hanford for that year, which was $59 \%$ above that of 1955. In September 1956, PUREX demonstrated a sustained, instantaneous rate of 16 MTU/day of irradiated uranium and an on-line efficiency of 99 percent. The following year, the total output of plutonium from Hanford increased by 54 percent over that of 1956, with PUREX processing 71 


\section{SECTION 2 HANFORD SITE HISTORICAL OVERVIEW

percent of this new total. The plant demonstrated an instantaneous production rate of 20 MTU/day, with a reduction in the amount of residual fission product activity in the product of 25 fold below design specifications in 1957.

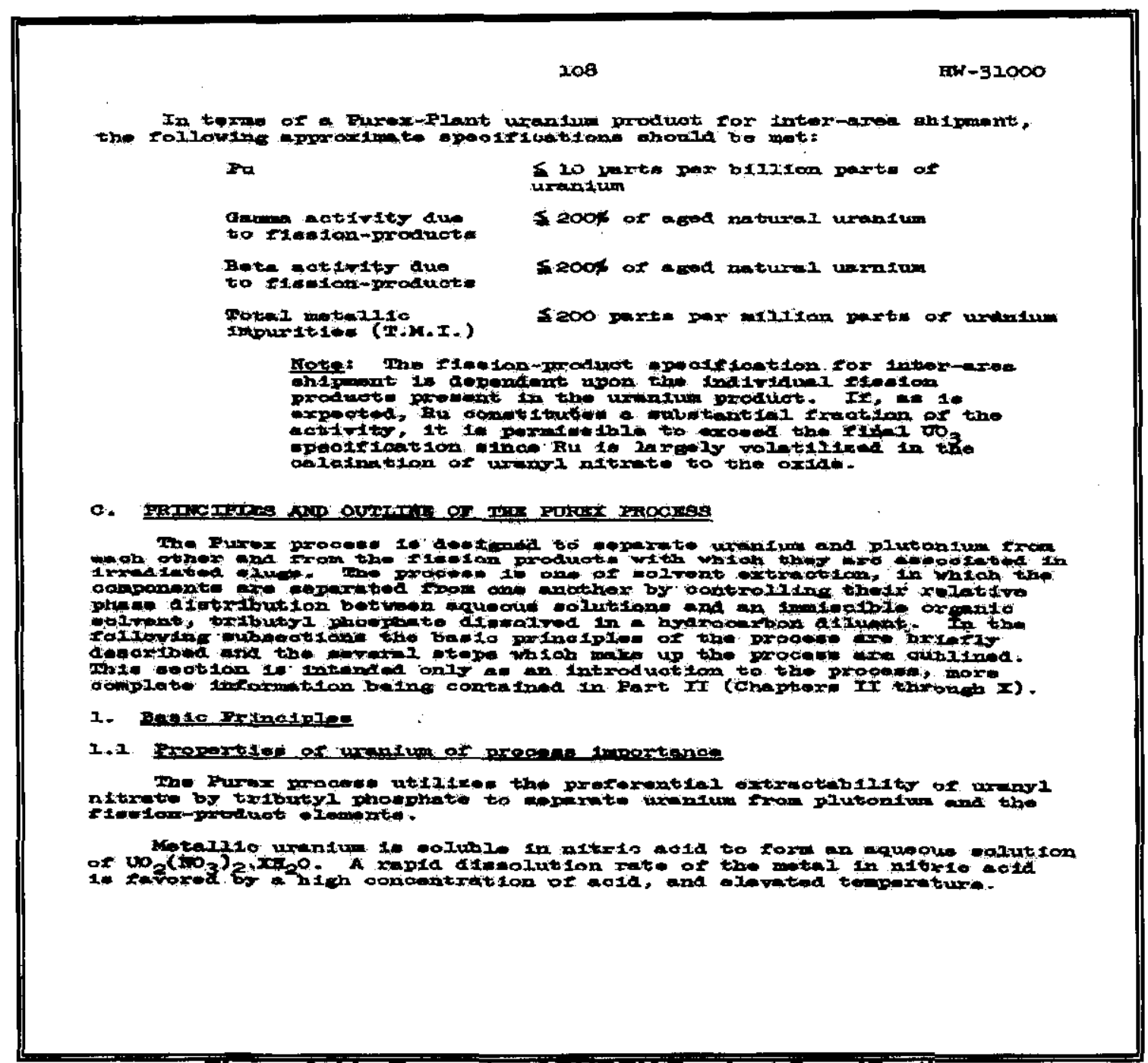

\section{Figure 2-11 Example of PUREX Product Specification}

In 1958, the decision was made to send virtually all of the standard irradiated uranium from the 100 Areas production reactors to PUREX, and to divert processing of enriched uranium containing $0.9475 \mathrm{wt} \%{ }^{235} \mathrm{U}$ ("94 Metal") to the REDOX plant. REDOX equipment was reconfigured and handling techniques were changed to accommodate the higher enrichment levels of the 94 Metal. Additionally in 1958, the PUREX facility began the recovery of neptunium $\left({ }^{237} \mathrm{~Np}\right)$ on an occasional batch basis from its normal product stream. The plant became the AEC's prime supplier of this isotope. For short periods of time, PUREX demonstrated the capacity to operate at 3.6 times its original 


\section{SECTION 2 HANFORD SITE HISTORICAL OVERVIEW

design capacity. In late 1965, other PUREX systems were modified to allow the plant to sustain normal operations at a 4.0 capacity factor, or $33 \mathrm{MTU} /$ day [Gerber 1996].

Beginning in 1963, the PUREX plant was modified to allow for the processing of various fuel types, including fuel from N-Reactor with elements much larger than the four to eight inch long "slugs" from Hanford's single pass reactors. In 1967, the REDOX plant closed, and PUREX became the sole, operating separations facility at Hanford. In 1972, the PUREX plant entered a temporary shutdown period that lasted for 11 years. All of Hanford's single-pass reactors had closed, and most of the available (aged) $\mathrm{N}$ Reactor fuel had been processed. The initial PUREX shutdown was planned for 18 months, to allow the accumulation of N-Reactor fuel. During the shutdown period, other issues arose, including environmental concerns that led to providing upgraded filtration systems, seismic safeguards, backup power sources and many other projects. Increased safety concerns about shipping plutonium in nitrate form from PUREX in the 200-E Area to the Plutonium Finishing Plant in the 200-W Area, led to an additional delay. The shutdown period was extended while facilities were added within the PUREX plant to convert plutonium nitrate to plutonium oxide.

In 1983, the PUREX plant reopened with an operating limit allowing it to process up to 3,000 MTU/year of N-Reactor fuel, or about eight MTU/day. However, the highest sustained (but short-term) production rates in the ensuing years hovered near seven MTU/day, and the highest long-term rates were about three MTU/day. The PUREX facility closed for about six weeks in 1988, for a safety issue, and again for a year beginning in December 1988, after steam pressures briefly fell below levels necessary to support back-up safety equipment. Additional equipment repairs and improvements to waste handling systems also occurred during that closure period. After a stabilization run lasting only a few weeks, the plant again closed in early 1990 in order to prepare additional environmental and safety documentation and facility upgrades. In total, PUREX processed approximately 69 percent of all the irradiated fuel produced at Hanford. In October of that year, the PUREX Plant was placed on standby status by the Secretary of Energy, James Watkins. A final closure order was issued by the DOE in December 1992 [Gerber 1996].

\subsubsection{Current Status}

The PUREX Plant has been deactivated and is awaiting final disposition. 


\section{Error}

An error occurred while processing this page. See the system log for more details. 


\section{Error}

An error occurred while processing this page. See the system log for more details. 


\section{SECTION 2 \\ DOE/RL-2000-43 HANFORD SITE HISTORICAL OVERVIEW}

The foundation and floors were poured concrete. The roof consisted of insulated metal paneling covered with felt and roll tarpaper and a tar and gravel surface. The structure was 300 feet by 140 feet, with a total area of 48,817 square feet. In 1980 , in response to anticipated increases in production, a small addition was placed on the northwest corner of the 333 Building. It consisted of two stories; the ground level for an open bay shop and the second story for offices. The addition was 33 feet by 104 feet, and extended from the HVAC (heating, cooling and ventilating) supply units on the west side of the building to the north exterior wall.

The co-extrusion process was carried out with various equipment pieces, but the most prominent and unique of these was a Loewy Press that actually pressed all of the fuel components ( $U$ core and all of the cladding components) together in one unit. Each $\mathrm{N}$ Reactor fuel element was 26 inches long, weighed approximately 52 pounds and had a tube-in-tube configuration with a coolant channel running down the entire length of the element. Projections also were welded onto each element, as the $\mathrm{N}$-Reactor process tubes were smooth or "ribless." The co-extrusion process provided a better, more uniform bond between core and jacket than had been possible with older methods based on dipping. The new method was beneficial in smoothly cladding the inner and outer tubes.

\subsubsection{Material Flowsheet}

The basic process flow for fuel element preparation for the single pass reactors was to receive and inspect uranium billets from offsite for visual flaws and correct dimensions. Then a sample was irradiated in the 305 Building test reactor. If the reactor tests were acceptable, the lot was accepted and entered the manufacturing process. In the 314 Building, uranium billets were heated in a muffle-type furnace with an interior, inert gas atmosphere. The inert atmosphere, which involved either helium or argon, was used to reduce the oxidation of metal during heating. The uranium was then transferred through a closed passageway to the extrusion press, which also operated in an inert atmosphere. After being extruded, the rods were out-gassed, straightened, and sent to the 313 Building for machining and jacketing. In the 313 Building, uranium fuel rods were machined into fuel cores in lengths of either 4 inches or 8 inches, with 1.3-inch diameters. Known as "slugs," these cores were "canned" or jacketed into finished elements, and then tested and inspected in this building. This jacketed fuel was then sent to the 314 Building for autoclave and radiographic inspection. Figure 2-13 illustrates the fuel fabrication process for the single pass reactors.

Additional fuel fabrication activities were initiated in the early 1960 s for the fabrication of $\mathrm{N}$-Reactor fuel. This process, illustrated in Figure 2-14, is significantly different than single pass reactor fuel process. The fuel was larger in diameter, longer, and consisted of two fuel elements, one within the other. It also had a centered annulus that was created by the co-extrusion tube-in-tube process. The two sizes were made, tested and then assembled to form a finished fuel rod. 


\section{HANFORD SITE HISTORICAL OVERVIEW}

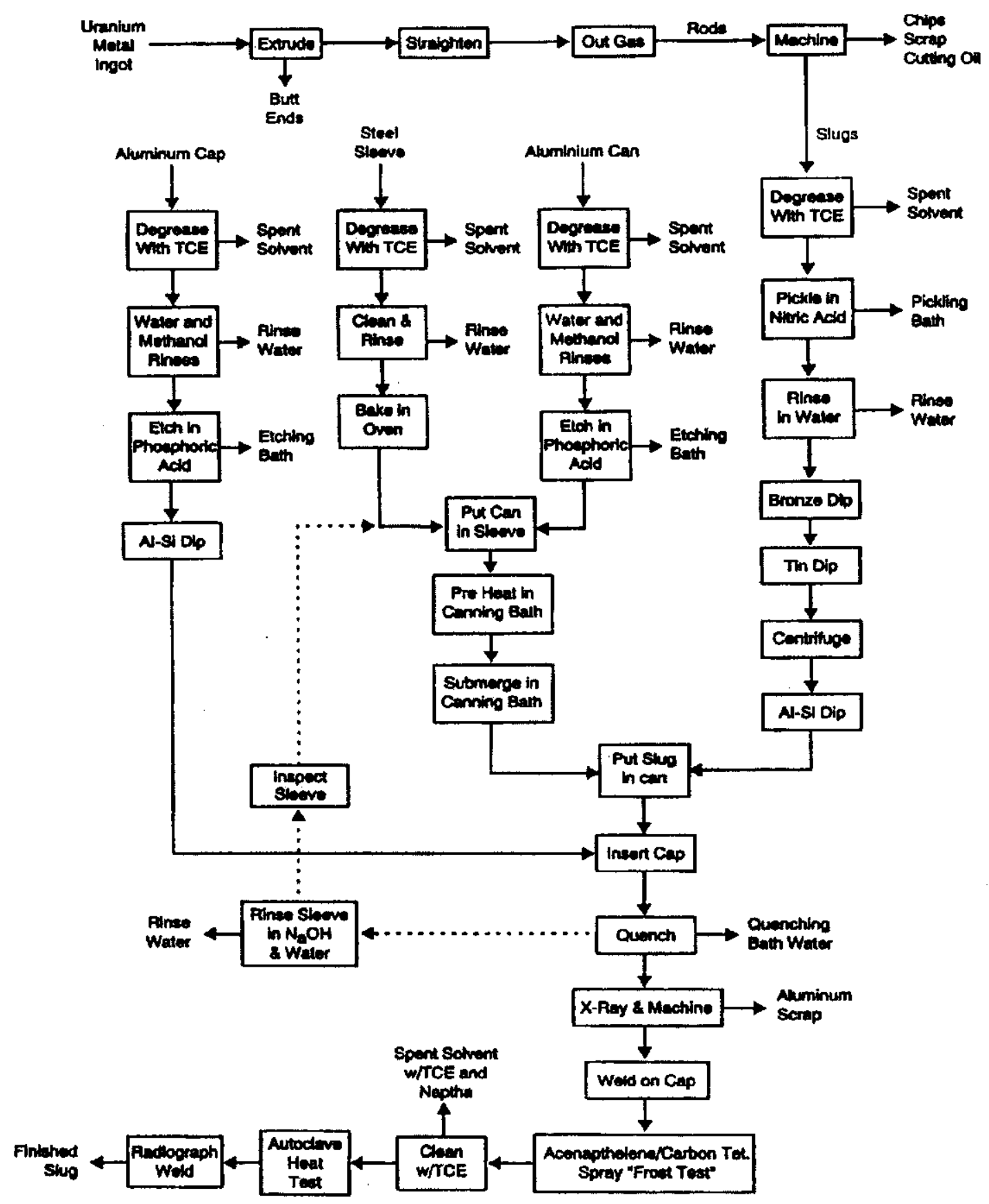

Figure 2-13 Fuel Fabrication Process for Single-Pass Reactors. 


\section{SECTION 2 HANFORD SITE HISTORICAL OVERVIEW}

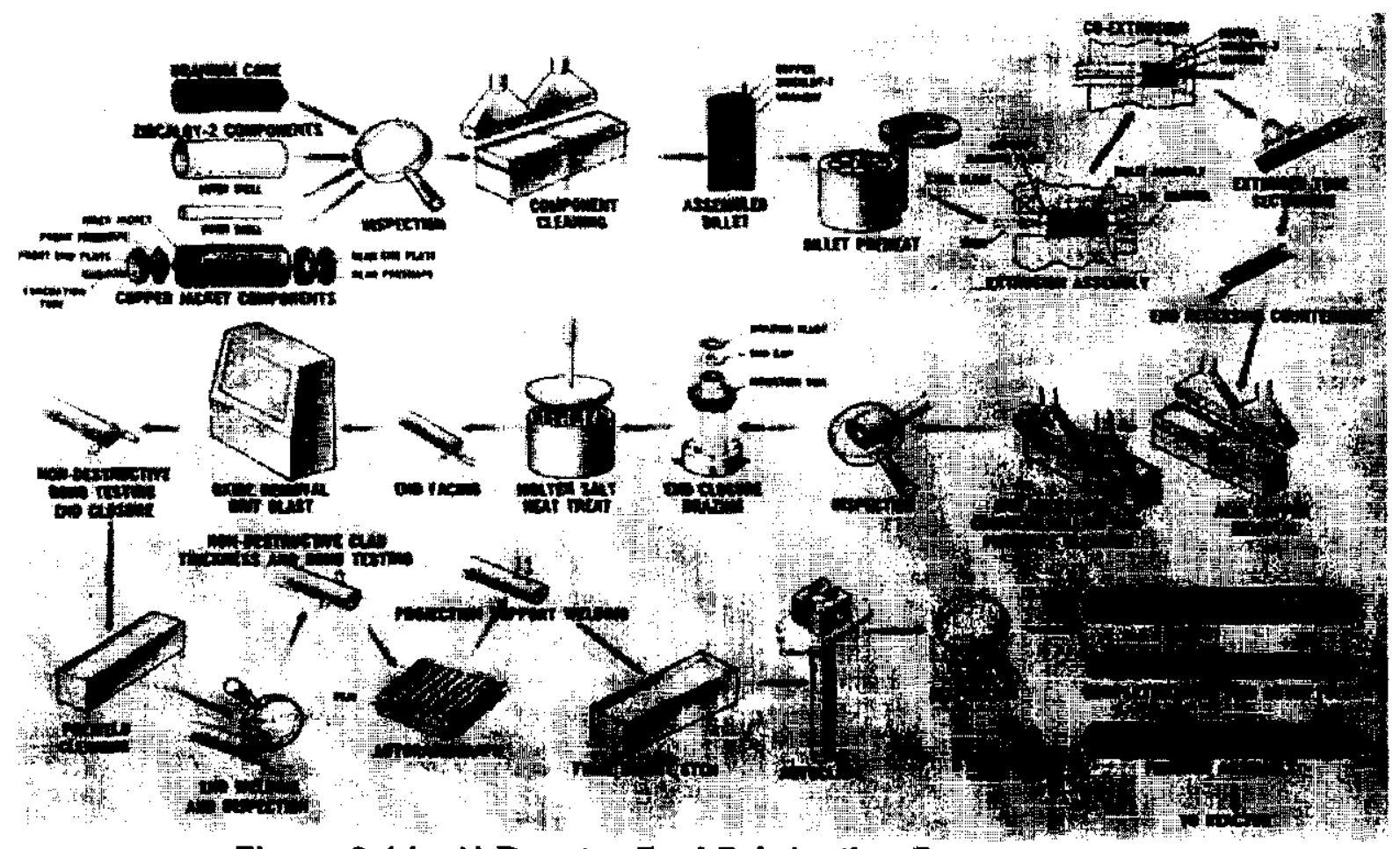

Figure 2-14 N-Reactor Fuel Fabrication Process

More detailed information on past fuel fabrication processes and activities at Hanford can be found in Appendix F.

Over the years, several other ancillary or off-shoot processes have taken place in the 313 and 314 Buildings. Among these have been uranium scrap recovery operations, experimental and/or small-scale fuel making ventures, and waste treatment activities. From its earliest days, concern of the Manhattan Engineer District (MED) about the adequacy of uranium supplies brought strict policies that mandated the reclamation of all possible uranium scraps at federal atomic sites. During the earliest fuel fabrication operations (1943 to mid 1944) at Hanford, difficulties with early fuel canning techniques produced thousands of rejected cores and other scraps, including lathe turnings and metal oxides that formed when canned slugs failed in autoclave tests. In June of 1944, Du Pont reported that "all available space" around the 313 and 314 Buildings was filled with cans of scrap, and the fabrication area fence had to be moved about 30 feet east of the fresh fuel storage building 303-J to allow for more storage space. In addition, beginning with the startup of extrusion press tests in January 1945, extrusion butt ends, oxides, and container residues collected, along with acids from the slug pickling process and from the slug recovery process were generated.

At first, the various types of scrap were shipped to offsite reclamation processing centers. By 1946, the accumulating volume of uranium scraps brought a change in policy at Hanford. This change was the result of scrap storage expense and risks associated with potential fire and security hazards during shipment. Consequently, a 


\section{SECTION 2 \\ DOE/RL-2000-43 \\ HANFORD SITE HISTORICAL OVERVIEW}

"chip recovery" operation began in the 314 Building to process scrap. It operated only a few days a month and involved collecting all chips and turnings from machining operations, sorting them, breaking thern into small pieces, washing, drying, and then pressing them into briquettes. At first, the briquettes themselves were shipped offsite. In May, however, the MED ordered briquetting to be discontinued due to a number of uranium chip fires within the centrifuging step at other sites.

A "melt plant" was established in the 314 Building in late 1947. In that process, uranium scrap could be recovered as metal for fuel fabrication. This was accomplished by combining uranium tetrafluoride $\left(\mathrm{UF}_{4}\right.$ or "green salt") and either calcium chips or magnesium chips, placing this mixture in a dolomite-coated steel vessel, which was then heated until free molten uranium separated from magnesium fluoride or calcium fluoride, and then allowed to cool. The molten uranium settled into large buttons shaped like Derby hats (called "Derbies" by Hanford workers). The Derbies were separated from the slag (calcium fluoride and magnesium fluoride salt) utilizing a jackhammer to break up the slag. These Derbies were then melted in a vacuum furnace, and cast into ingots. These ingots were then rolled into new uranium rods, either offsite or at Hanford, and used to make additional fuel rods.

In the spring of 1946, an additional scrap recovery operation known as the "oxide burner" began on the north side of the 314 Building. All uranium-bearing powder and particulate matter that could be collected from the fuel fabrication facilities, as well as the tailings or settlings from washes and quenches, was burned to convert it to a stable oxide (powder) form. The $\mathrm{UO}_{2}$ was then collected in 5-gallon containers for shipment offsite [Gerber 1992].

Between 1952 and 1954 both the vacuum furnace melting and the oxide burning processes were phased out and replaced with a process which slurried all the scrap into sodium diuranate, stored it in drums, and returned it to the Feed Materials Processing Center (FMPC), Fernald, Ohio, for recovery [Gerber 1996].

The concentration of any transuranics and fission products in the scrap from fuel fabrication activities would have been the same as that of the uranium metal received at Hanford for fuel fabrication. During our review of historical documentation for this study, we have found no information to suggest that the scrap processing activities would have altered the ratio of impurities to uranium.

\subsubsection{Feed Specifications}

Natural uranium was used for billet fabrication until about 1952 when the use of recycled uranium was phased in. The billets were accepted for use based upon material certification and chemical analysis received from the manufacturer. The scrap material was retumed on the basis of the same billet receiving certifications and analysis data since the fuel fabrication process did not make any significant chemical changes. 


\section{SECTION 2 HANFORD SITE HISTORICAL OVERVIEW \\ DOE/RL-2000-43}

\subsubsection{Product Specifications}

Product specifications for the reactor fuel assemblies were based upon conforming to the design requirements of the reactor. Fuel was inspected dimensionally and by radiograph, ultrasonic, and other standard quality measurements. Chemical constituent control was confirmed by supplier certifications. Welds were examined and weld integrity verified.

\subsubsection{Operating History}

The earliest uranium received for the fabrication of reactor fuel arrived at Hanford in October 1943 as extruded rods. The rods were delivered to the Riverland Yards, which were an official part of Hanford and located just east of the Midway power substation and west of the 100-B Reactor Area. Because railroad track had not yet been completed to the 300 Area, the rods were taken by rail to the Construction Camp about 20 miles north of Richland, and then trucked to the 300 Area. Once railroad service to the 300 Area was connected in January 1944, uranium was delivered to the fabrication area by rail.

Newly arrived uranium rods were unpacked and visually inspected (in sample amounts) for cracks and for overall dimensions. A random amount from each lot was taken to the 305 Test Pile Building just west of the 313 Building, and irradiated at a low level to check for warping, cracking, and embrittlement under irradiation. If the sample withstood the process in good form, the entire lot was accepted. Operations began in December 1943. The first uranium fabrication operation at Hanford was machining, in which bare uranium rods were machined to specific core dimensions in the 313 Building. The following month, operators began degreasing the machined cores before inspection, using a commercial product that contained primarily trichloroethylene, Detrex $^{T M}$, a solvent degreaser. Core canning operations actually began in the 313 Building in March 1944.

In the 314 Building, autoclaves for fuel element testing started to operate in July 1944. A scrap recovery process began the following month. Out-gassing and straightening operations started in the 314 Building in September 1944, but Hanford's uranium rods still were being extruded offsite. Beginning in November 1944, uranium was transported to Hanford as billets, which were stored until the extrusion process began to operate in the 314 Building in January 1945. The press testing phase lasted into mid-spring, and then fuel operations commenced. Improved performance ended required shift work in the metal preparation buildings in June 1945, and work proceeded on a straight, 6-day-per-week schedule. From that time until 1948, a complete cycle of metal preparation was conducted at Hanford.

\subsubsection{Current Status}

Fuel and target fabrication in the 300 Area ceased permanently in 1987 with the closure of the N-Reactor. Some of the facilities have been decommissioned. Based on the 


\section{SECTION 2 \\ HANFORD SITE HISTORICAL OVERVIEW \\ DOE/RL-2000-43}

integrated site baseline priorities, cleanup and restoration of the 300 Area presents many challenges. A portion of the 313 building now produces commercial aluminum extrusions. Other buildings are expected to be leased if suitable tenants can be found and after the facilities are decontaminated to guideline levels which allow occupancy by non-rad workers.

\subsubsection{Other Uranium Handling Facilities}

Several other Hanford facilities were involved in handling depleted uranium. These are discussed below. Much of this work supported reactor research activities at both this and other DOE sites.

\subsubsection{308 Building Mixed Oxide Fuel Fabrication}

The fabrication of mixed oxide (plutonium oxide and uranium oxide) fuel in the 308 building utilized both depleted and natural uranium. Operations were conducted in gloveboxes to protect the workers from inhaling the material.

\subsubsection{306 Building}

Depleted uranium oxide fuel pellets were fabricated in rooms 158 and 159 of this facility. These operations were conducted in open-faced hoods.

\subsubsection{234-5Z Plutonium Finishing Plant (PFP)}

In 1972, the flowsheet and piping in the PFP were modified to allow separation and recovery of plutonium from some plutonium-uranium materials. The separated UNH stream was accumulated and trucked to the PUREX plant. At PUREX, the UNH was offloaded and discarded to the underground waste storage tanks since there was no need for the material.

\subsubsection{321 Building}

Development and testing of a continuous calciner for production calciners to replace the batch kettles at the $\mathrm{UO}_{3}$ Plant was performed in the 321 Building. The calciner development proved successful and 6 units were installed in 224UA building. About 200,000 pounds of uranium, as UNH, was trucked from the 200 West area to the 321 Building and processed in caiciner development activities. The $\mathrm{UO}_{3}$ product powder was subsequently returned to the $\mathrm{UO}_{3}$ Plant and blended into the plant's product stream.

\subsubsection{303-M Uranium Oxide Facility}

A small 303-L Building was constructed in 1961 for burning uranium metal scraps to an oxide form that would be suitable for shipment to the FMPC for recovery. Burning was stopped in 1971 due to operating problems. The building was removed in 1976. In 


\section{SECTION 2 \\ HANFORD SITE HISTORICAL OVERVIEW

1983, a new building, 303-M Uranium Oxide Facility, was constructed on the same site. This high bay, $51 \mathrm{ft}$ by $35 \mathrm{ft}$ by $25 \mathrm{ft}$ (high) concrete structure with a one story extension $20 \mathrm{ft}$ by $13.5 \mathrm{ft}$ on the north side was used to convert more than 115 tons of uranium scrap to oxide during it's brief operating period of 1984 to 1987 [Gerber 1992]. A drawing of this facility is shown in Figure 2-15.

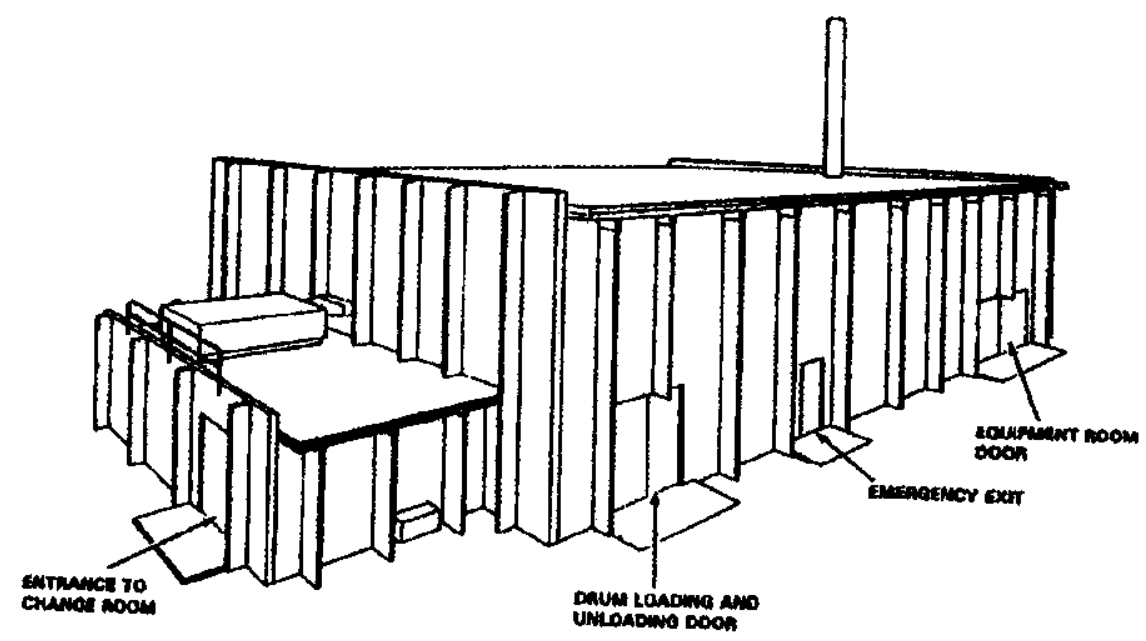

Figure 2-15 303-M Uranium Oxide Facility [Prezbindowski 1983]

\subsection{Activity Summany}

Hanford operation started in 1943 to support the defense effort of World War II. After W.W.II, it continued to support the growing defense effort. In doing so, the initial facilities were expanded and new facilities built to meet the congressional mandates for defense. In 1993, all production efforts supporting defense were terminated and the site was redirected to a clean-up mission. This clean-up mission is under way and some facilities have already been decontaminated and either removed or turned over to private industry for new uses.

The first major facilities at Hanford included B-, D-, and F-Reactors, T-Plant, B-Plant, a Fuel Fabrication complex and a plutonium purification plant. In addition to these major facilities, supporting structures, steam plants, housing, water, and personnel support facilities were simultaneously built. The first reactor was started in September 1944. The first batch of plutonium was shipped from the site in February 1945 to Los Alamos where it was converted into the first atomic device.

After the war, it was recognized that the uranium needed to continue and expand plutonium production was in short supply and new sources of uranium would be 


\section{SECTION 2 HANFORD SITE HISTORICAL OVERVIEW

required. One source was determined to be the irradiated uranium then residing in the high-level waste stored in Hanford's underground waste tanks. In 1947, reuse of this uranium was discussed and actions were taken to develop recovery processes for this waste. By 1952, U-Plant had been converted to process the high-level waste to recover uranium for recycle. The high purity UNH product needed to be converted to a safe, shippable oxide form. Simultaneously with the recovery process development and implementation, a uranium conversion process was developed and the $\mathrm{UO}_{3}$ Plant built to provide a stable, transportable $\mathrm{UO}_{3}$ powder. The uranium trioxide powder was to be shipped to the gaseous diffusion plants for enrichment and conversion to uranium metal billets. In the same time frame, the REDOX process was developed and the REDOX Plant was constructed to support the increase in the nation's plutonium needs. The REDOX facility, commissioned in 1952, recovered both plutonium and uranium as coproducts. REDOX began transferring recovered uranium as $\mathrm{UNH}$ to the $\mathrm{UO}_{3}$ Plant a month or two before UNH was available from U-Plant.

As increased plutonium product was required to meet defense needs, the PUREX process was developed to support the planned production increases and the PUREX separations plant was built, coming online in 1956 . PUREX performance permitted the shut down of the REDOX and T-Plant facilities. The PUREX uranium output was also sent to the $\mathrm{UO}_{3}$ Plant for conversion to oxide. In 1972, PUREX operations were shut down. In 1983, the PUREX plant was reactivated to meet national plutonium requirements created by congressional direction. The $\mathrm{UO}_{3}$ Plant was also brought back on line to process the UNH output of the PUREX plant. In 1993, all plutonium operations were halted and PUREX Plant and the $\mathrm{UO}_{3}$ Plants were shutdown to await decommissioning. Figure 2-16 summarizes the operational periods for the major Hanford Plants.

Figure 2-16 Operating Intervals During Which Major Hanford Facilities Processed Recycled Uranium

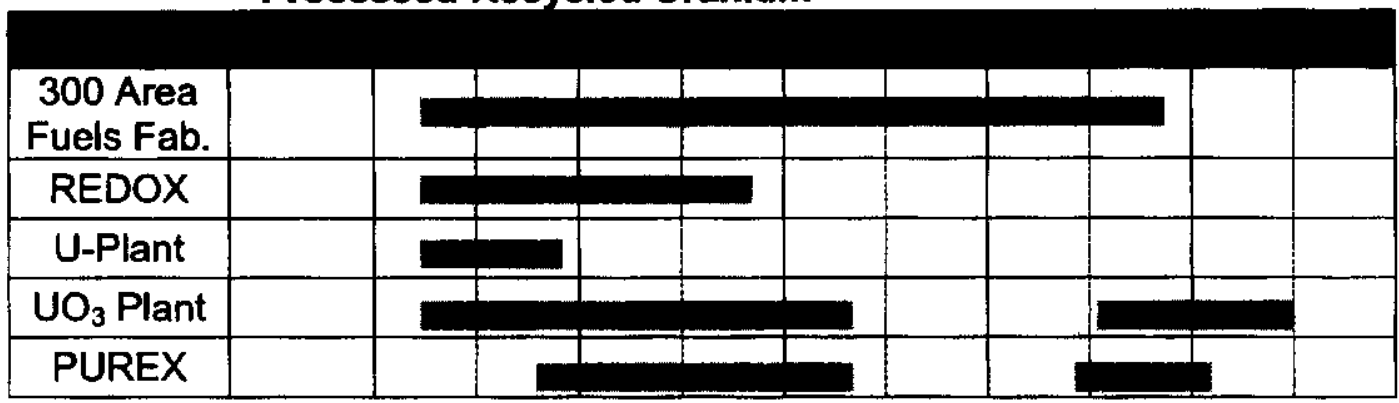

Record searches to support the Uranium Mass Balance Project indicated that Hanford produced a high quality uranium product meeting specifications from the beginning of production. The searches indicated that the recognition of a need for specification occurred several years before the first uranium trioxide production batch was produced. This specification need was driven by both reactor and worker health considerations. Detailed information on recycled uranium specifications and measured impurities is presented in Section 4. 


\section{SECTION 2 DOE/RL-2000-43 HANFORD SITE HISTORICAL OVERVIEW}

\section{References}

Elgert 1971

Letter AEC-2202 from O. J. Elgert to R. P. Corlew, Product Specifications, Hanford Uranium Trioxide, ARH-2051, August 19, 1971

Gamertsfelder 1951

Letter HW-20628 (HAN-36668), C. C. Gamertsfelder to R. H. Beaton, Recent Changes Affecting the Specifications Concerning Activity Levels in Reclaimed Uranium, March 27, 1951

Gerber 1992

WHC-MR-0388, M. S. Gerber, Past Practices Technical Characterization Study, 300 Area, December 1992

Gerber 1996

WHC-MR-0521, Rev 0, M. S. Gerber, The Plutonium Production Story at the Hanford Site, Process and Facilities History, June 1996

Greninger 1950

Letter HW-18871(HAN-33844) from A. B. Greninger, General Electric Company to D. F. Shaw, Atomic Energy Commission, Request For Recovered Uranium Specifications, September 18, 1950

Gustavson 1950

$\mathrm{HW}-19400, \mathrm{D}$. R, Gustavson, An Introduction to the $\mathrm{TBP}$ and $\mathrm{UO}_{3}$ Plants, December 20, 1950

Hurd 1952

Letter KLI-1681 from F. W. Hurd to R. B. Richards, Preliminary Specifications on PUREX Produced Uranium Trioxide, September 18, 1952

HW-10475-ABC 1944

HW-10475-ABC, Hanford Technical Manual, Sections A, B, \& C, Du Pont, May 1, 1944

$H W-187001951$

HW-18700, REDOX Technical Manual, July 10, 1951

HW-19140 1951

HW-19140, Uranium Recovery Technical Manual, November 10, 1951

HW-24605 1952

Monthly Report HW-24605 (HAN-45180), Hanford Works Monthly Report for May 1952, June 20, 1952 


\section{SECTION 2 HANFORD SITE HISTORICAL OVERVIEW

Judson 1962

Letter (DDTS-Generated-1329) from Judson to J. T. Christy, Proposed Specification for Production Reactor Returns $\mathrm{UO}_{3}$ for Gaseous Diffusion Plant Feed, June 5, 1962

Miskho 1982

Letter from G. J. Miskho to General Manager RHO, Uranium Product Specifications, August 11, 1982

Peterson 1947

Memorandum RHTG-46879, from A. V. Peterson, Chief, Production Branch to W. J. Williams, Manager, Field Operations, Meeting with Dr. C. W. Greenwalt on the Use of the K-25 Plant in Connection with Hanford Operations, April 21,1947

Prezbindowski 1983

UNI-M-157, D. L. Prezbindowski, Safety Analysis Report, Fuels Manufacturing Uranium Oxide Facility, May 27, 1983

Richards 1952

Letter HW-23754 (Hanford 43666), R. B. Richards to F. Hurd, $\mathrm{UO}_{3}$ Trial

Production Lots 007, 008, and 009, March 11, 1952

Smith 1953

HW-27990 by R. E. Smith, Summary of Oak Ridge Discussions Relative to Hanford Uranium Trioxide Specifications, May 7, 1953

Smith 1959

HW-59136, R. E. Smith, Product Specifications Uranium Trioxide (Depleted E Metal) for Off-Site Shipment, February 16, 1959 


\section{Section 3 \\ DOE/RL-2000-43 \\ Recycled Uranium}

\subsection{Recycled Uranium}

\subsection{Uranium Recycle Description}

This chapter is designed to quantitatively define the recycled uranium flows to and from Hanford. The transactions into and out of Hanford will focus on the 300 Area Fuel Fabrication complex of facilities and the $\mathrm{UO}_{3}$ Plant (224-U Building).

\subsubsection{Hanford Key Interfaces for Recycled Uranium}

For the Uranium Recycle Project, the Hanford Site is designated as a "Source Site". A source site is viewed as one at which uranium fuel is irradiated, chemically separated, and shipped to offsite locations. These offsite locations are referred to as "Tier 1" sites. Tier 1 sites are those which received recycled uranium directly from the Hanford Site. From the Hanford perspective, uranium transactions offsite are divided into "Major Tier 1 " sites and "Minor Tier 1" sites. The distinction is made primarily as it relates to the quantities of recycled uranium shipped and/or received. The Major Tier 1 and Minor Tier 1 sites (from Hanford's perspective) are identified below:

Major Tier 1 Sites:

- Paducah Gaseous Diffusion Plant (GDP), Kentucky

- Fernald, Ohio (FMPC), previously National Lead of Ohio (NLO)

- K-25 Gaseous Diffusion Pant \& Y-12 Plant, Oak Ridge, Tennessee

Minor Tier 1 Sites:

- All others (see Appendix B tables for these sites)

Major Tier 1 site locations are shown in Figure 3-1. Figure 3-2 shows the locations of many of both the Major and some of the Minor Tier 1 site locations. Figures 3-3A through Figure 3-3D show the flow of material through the complex for various time periods [DOE/EM-0319 1997]. There have been no reviewed records which indicate transfers of recycled uranium directly to the Portsmouth GDP. 


\section{Error}

An error occurred while processing this page. See the system log for more details. 


\section{Section 3 \\ DOE/RL-2000-43 \\ Recycled Uranium}

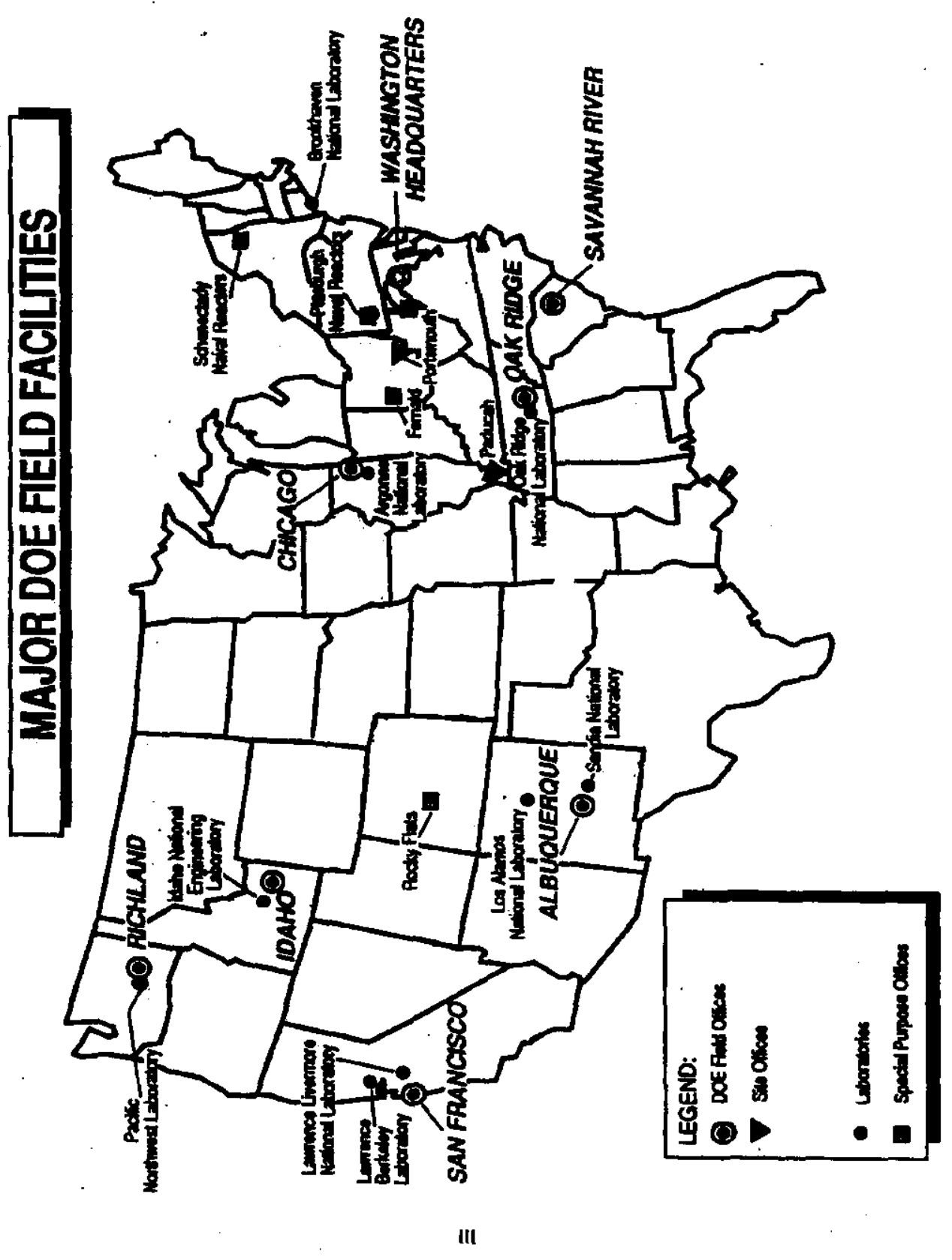

Figure 3-2 Major DOE Field Facilitles 


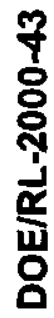
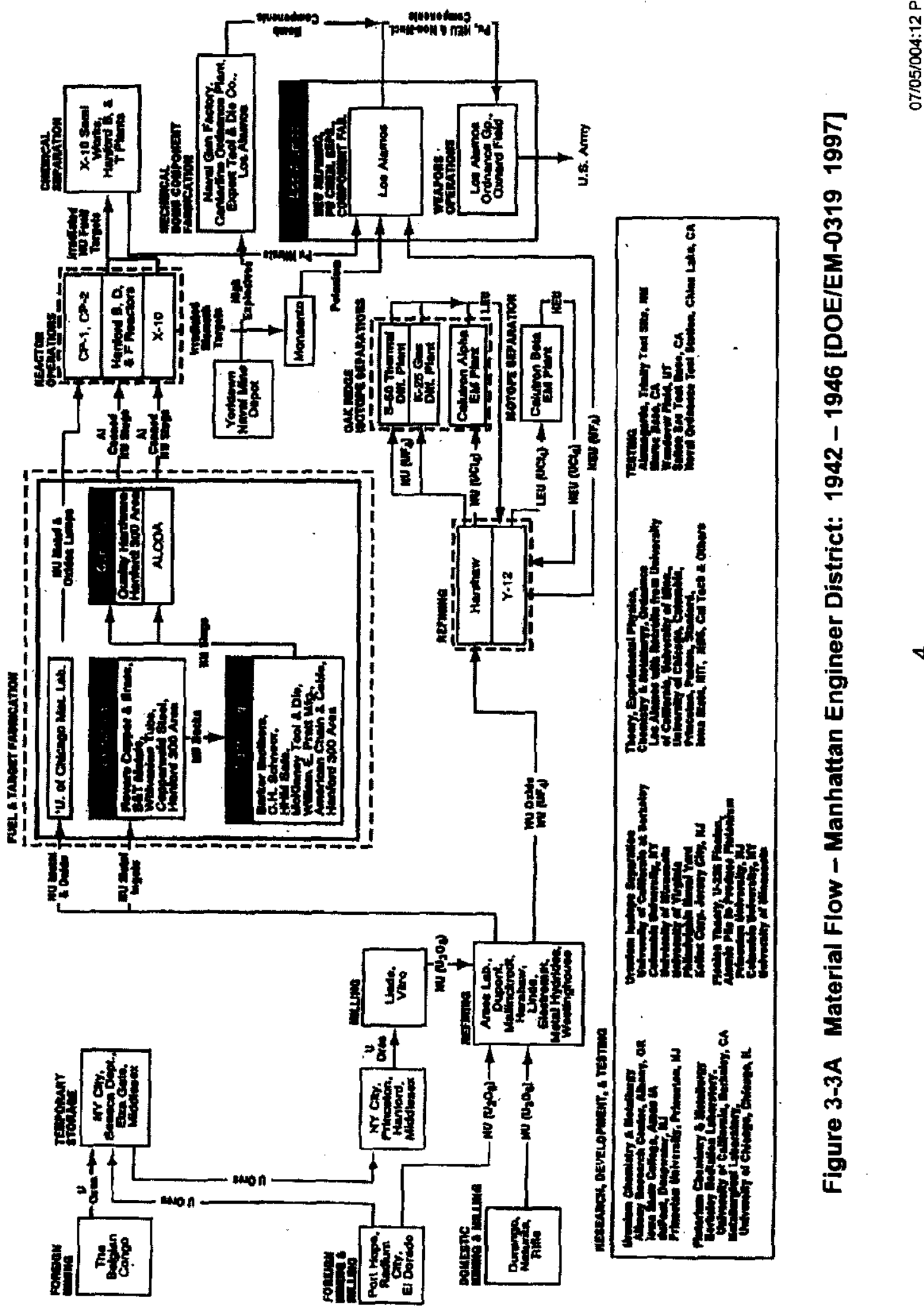

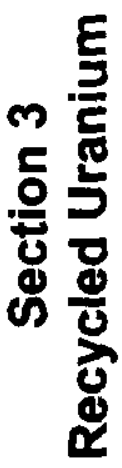

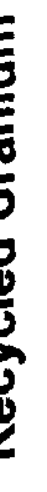




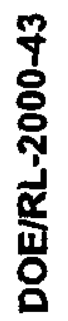

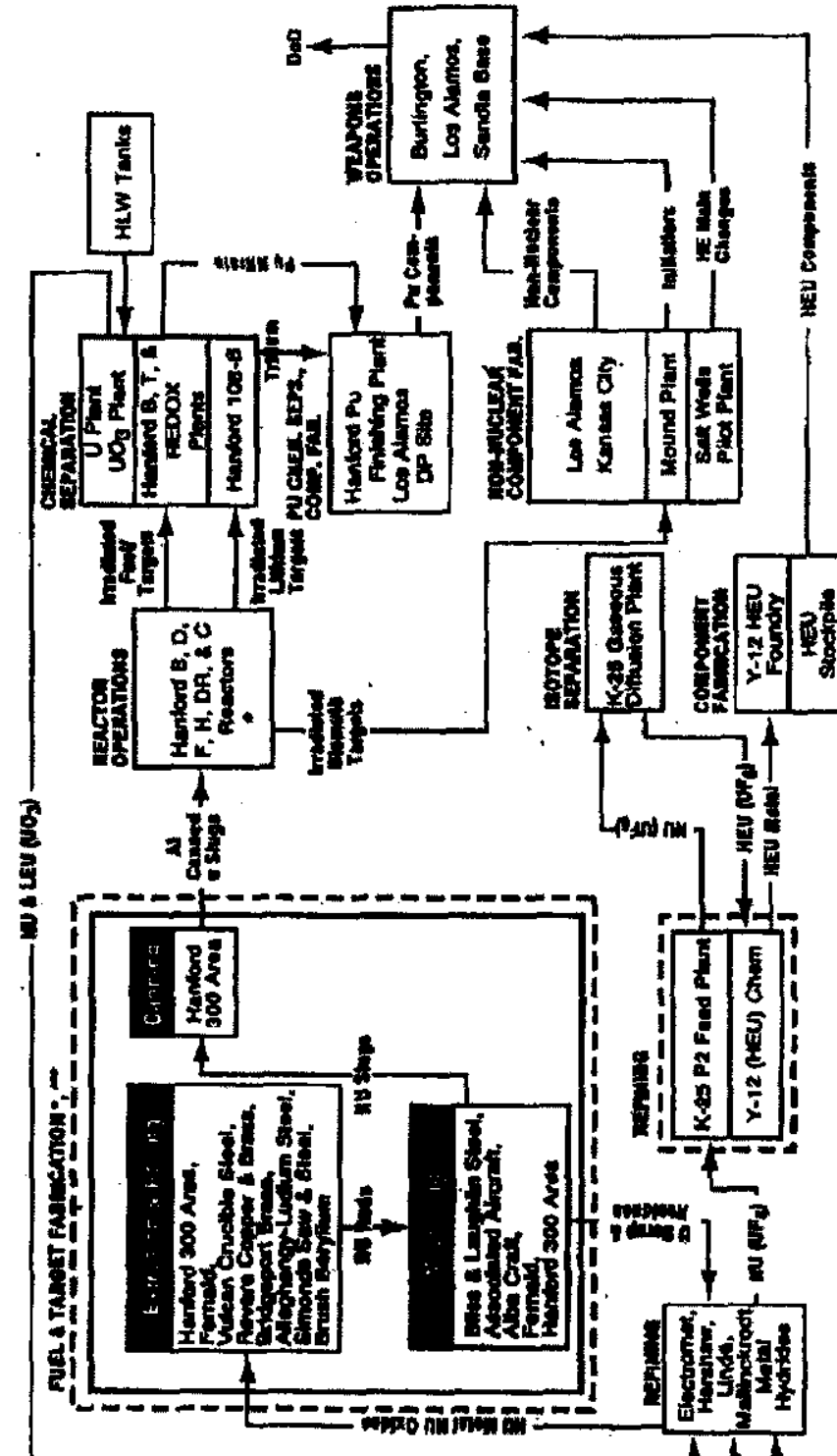

m $\frac{5}{3}$
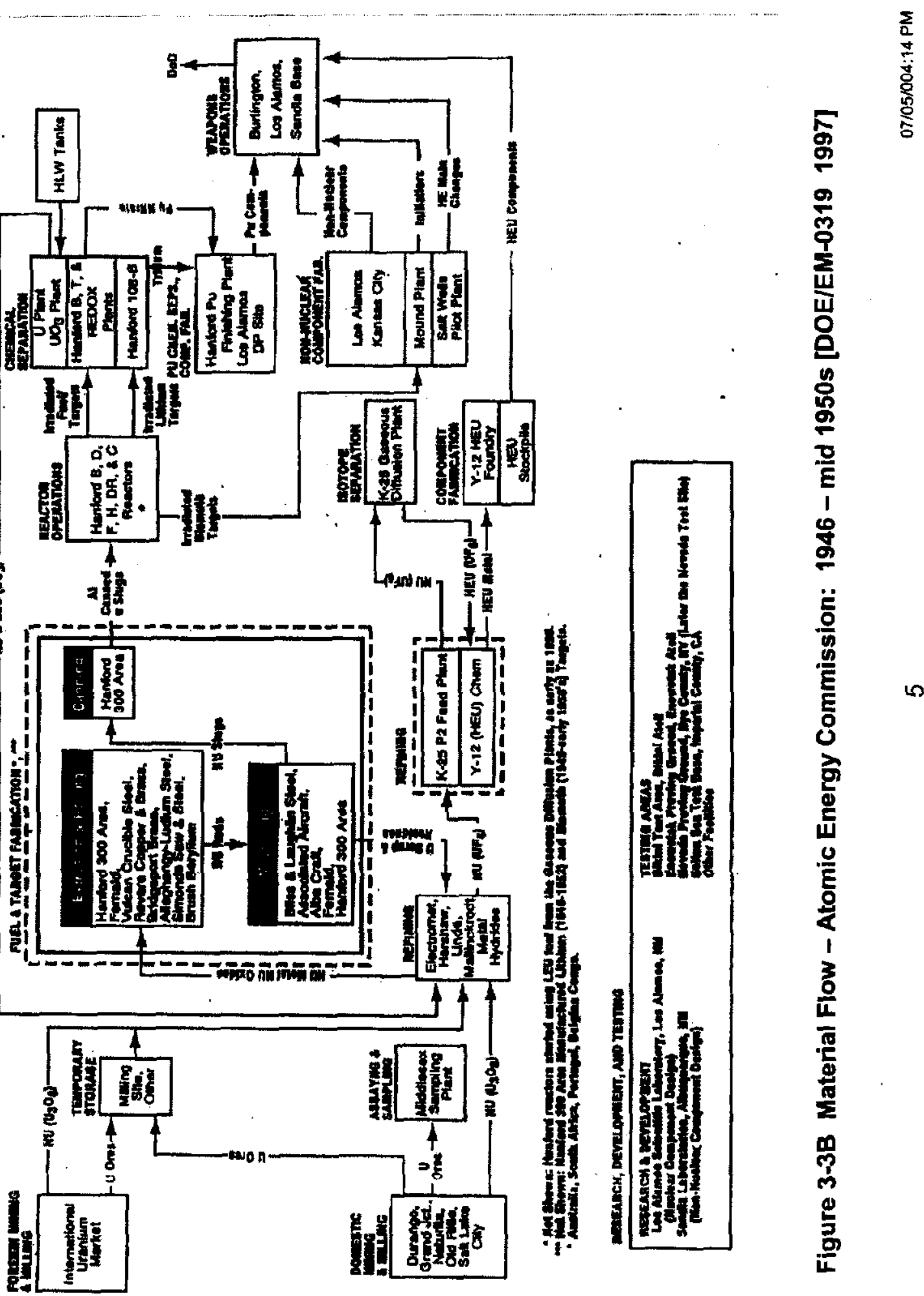

$\infty$ 


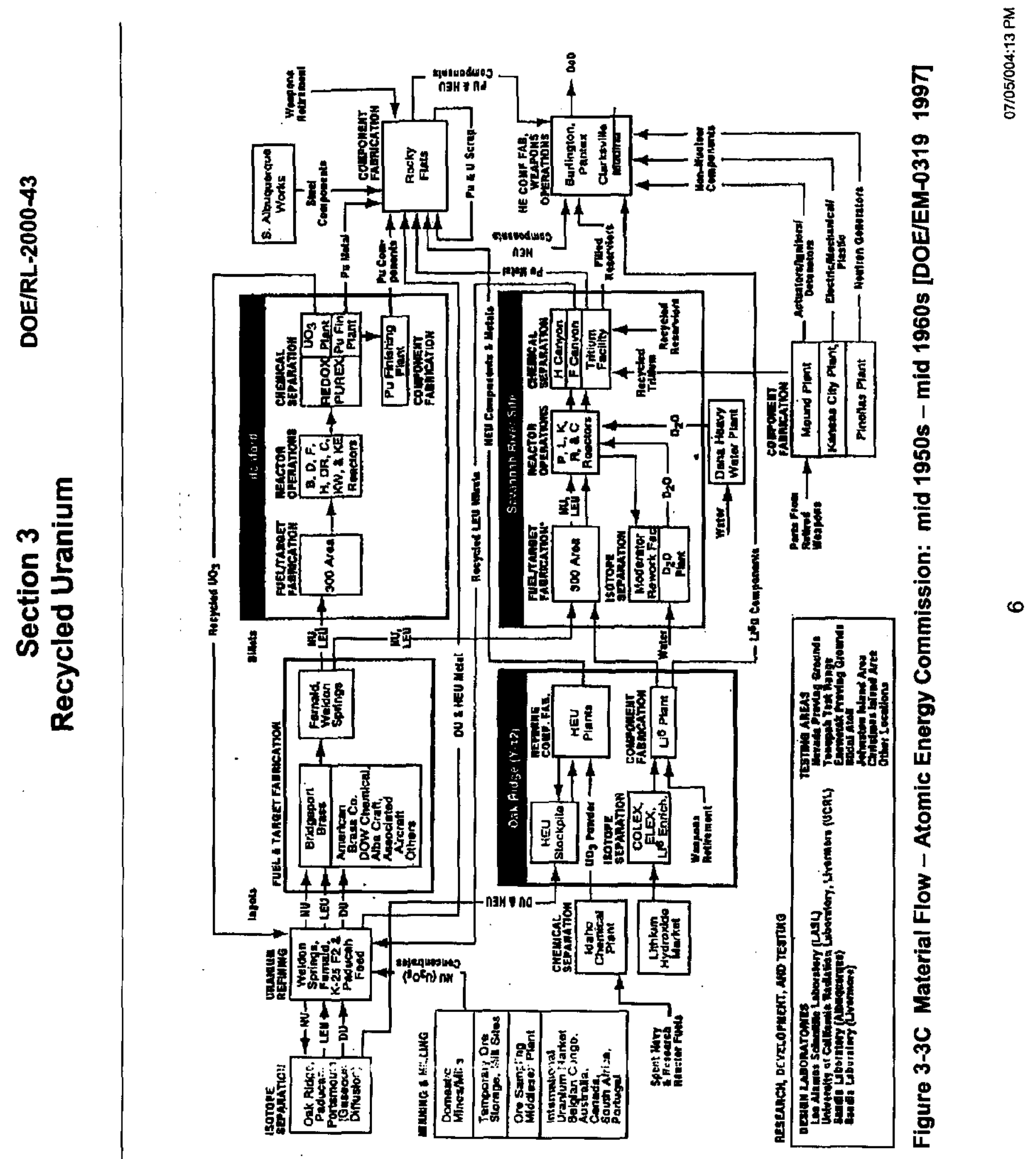


尔

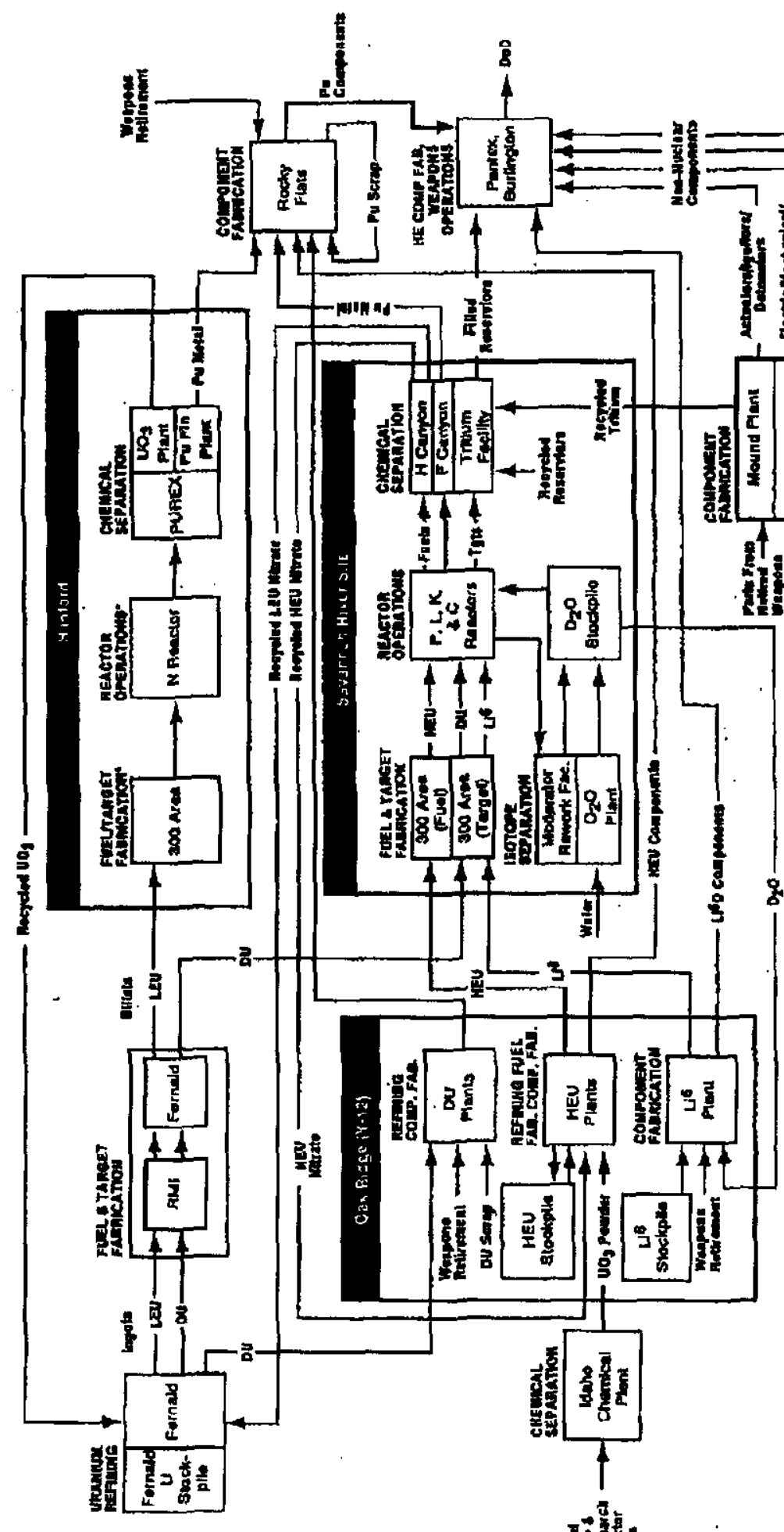

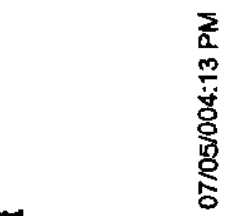

\% $\frac{5}{5}$

잉

웅형

。

홍

뜬 쁨

용ㅇㅁㅇ

禺

충요

旁

음 웅

E

충

UE

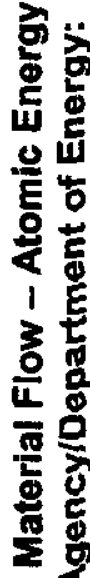

คै

옹 


\section{Section 3 \\ Recycled Uranium \\ DOE/RL-2000-43}

3.1.2 Beginning of Hanford In-Scope Recycled Uranium Transactions

3.1.2.1 Key Hanford Historical Dates for Recycled Uranium

Beginning of Recycled Uranium Shipments OUT of Hanford:

\begin{tabular}{|c|c|c|}
\hline $\begin{array}{l}\text { Depleted Uranium: } \\
\text { Normal Uranium: }\end{array}$ & $\begin{array}{l}\text { Mar } 1952 \\
\text { July } 1952\end{array}$ & $\begin{array}{l}\mathrm{UO}_{3} \text { product to Oak Ridge K- } 25 \\
\text { Metal scrap returns to offsite fuel } \\
\text { reprocessors }\end{array}$ \\
\hline $\begin{array}{l}\text { Enriched Uranium: } \\
\text { Enriched Uranium: }\end{array}$ & $\begin{array}{l}\text { July } 1952 \\
\text { Mar } 1959\end{array}$ & $\begin{array}{l}\text { Research \& development quantities } \\
\text { UO }{ }_{3} \text { LEU product to Oak Ridge K-25 } \\
\text { (Production Channel) }\end{array}$ \\
\hline
\end{tabular}

Beginning of Recycled Uranium Receipts INTO Hanford:

$\begin{array}{lcl}\text { Depleted Uranium: } & \text { July } 1952 & \begin{array}{l}\text { Hanford } \mathrm{UO}_{3} \text { heels in returned drums } \\ \text { from Oak Ridge K-25 }\end{array} \\ \text { Normal Uranium: } & \text { July } 1952 & \begin{array}{l}\text { Metal billets from offsite fuel fabricators } \\ \text { Enriched Uranium: }\end{array} \\ \text { Enriched Uranium: } & \text { July 1952 } 1960 & \begin{array}{l}\text { Research and development quantities } \\ \text { Metal LEU billets from Fernald } \\ \text { (Production Channel), at parts per trillion } \\ \text { Pu (from cascades) } \\ \text { Metal LEU billets from Fernald } \\ \text { (Production Channel) } \\ \text { (at parts per billion Pu) }\end{array}\end{array}$

\subsubsection{Production Channel Material Transactions}

\subsection{Shipments}

For $\mathrm{UO}_{3}$ finished product from the Hanford production channel, the first lot of $\mathrm{UO}_{3}$ was rail shipped to K-25 on January 25, 1952 and consisted of 8 drums of Lot 001 [Richards 1952b]. The second shipment (Lot 002, 7 drums) was shipped to K-25 on February 11, 1952 [Richards 1952]. Both of these lots were produced from natural uranium and contained no fission products. They were "cold" test runs to validate the $\mathrm{UO}_{3}$ conversion process. This material was shipped to K-25 to make sure the physical (particle size) and metallic impurities were within Oak Ridge acceptance criteria. As the "cold" $\mathrm{UO}_{3}$ was examined and found acceptable, Hanford began spiking the feed stream with UNH from irradiated fuel.

Production records indicate shipment of recycled uranium trioxide product to the Oak Ridge K-25 GDP first occurred on March 10, 1952. Examples of the historical transfer documents, with attendant analytical data, are shown in Figures 3-4, 3-5, and 3-6. This March $1952 \mathrm{UO}_{3}$ shipment is consistent with Hanford production history indicating $\mathrm{UO}_{3}$ test runs in January 1952 and full operation in February 1952. 


\title{
Section 3 Recycled Uranium
}

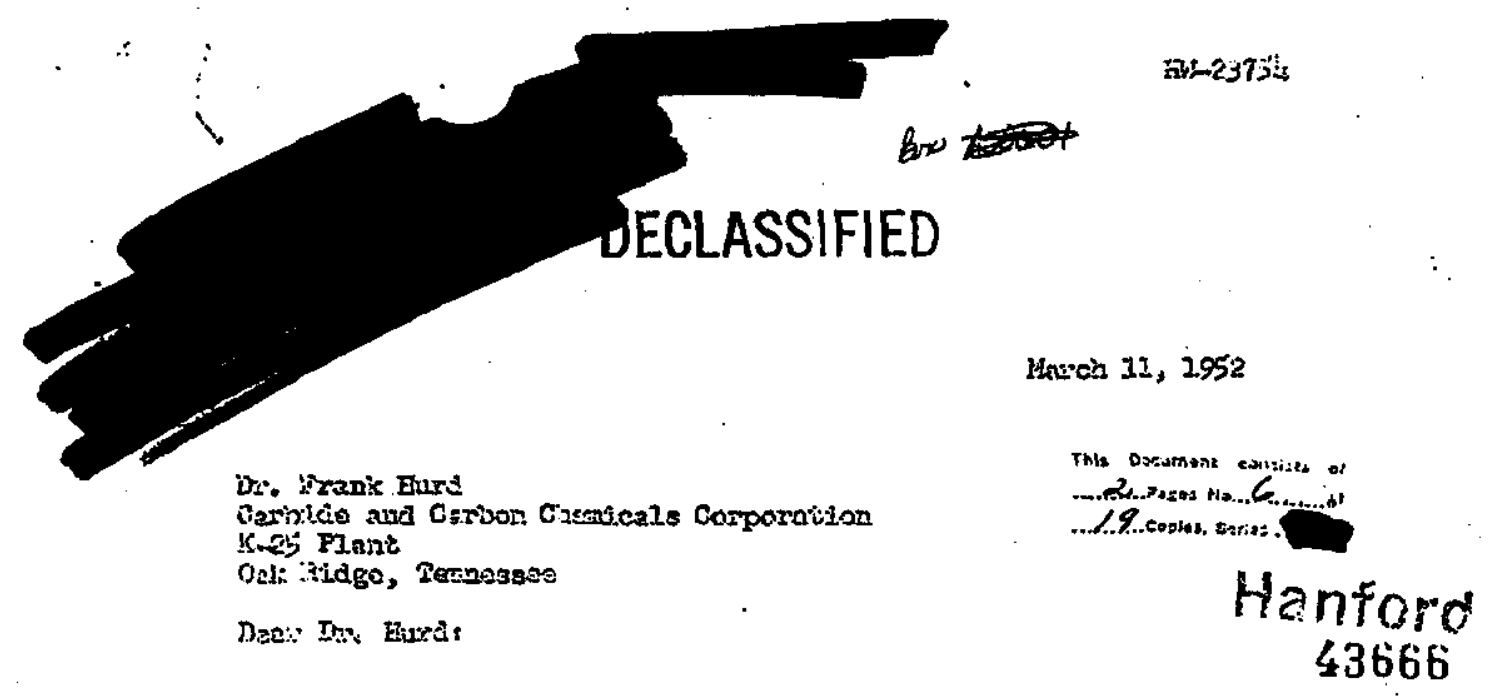

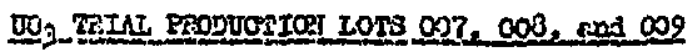

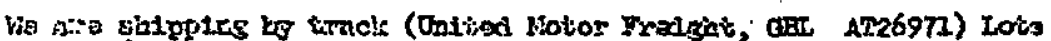

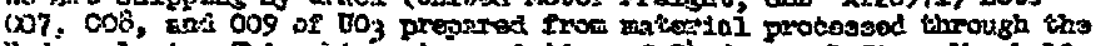

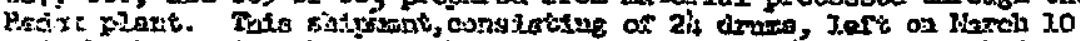

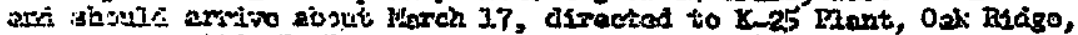

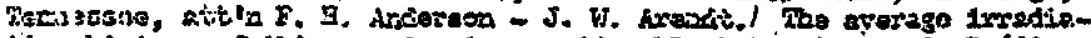

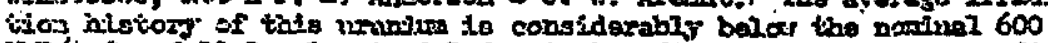

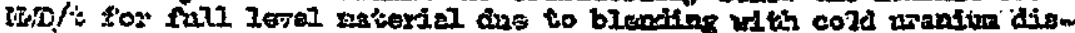

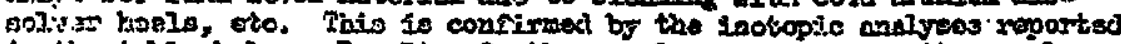

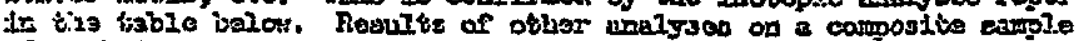

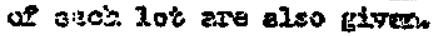

laestilication cancelied (Change to

\section{UNCLASSIFIED}

y A thorky ol $R 2 D-C 6-5$

zetan $2,7,3,1$

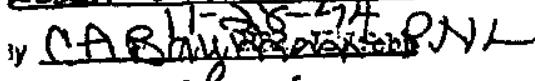

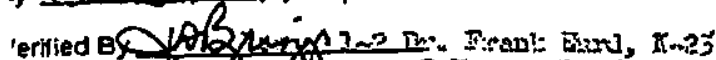

$$
\begin{aligned}
& \text { wh co } \\
& \text { III } 14 / 94
\end{aligned}
$$

3 AF ELiDer, $\mathrm{x}-25$

4 this Eurses, $3-25^{5}$

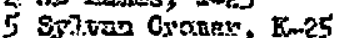

Li: hit in: IC Storgee

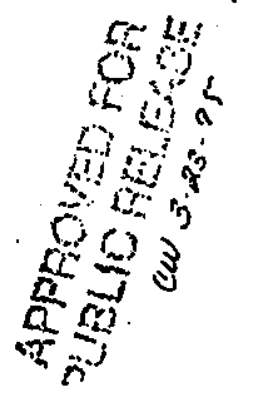

8 AD Graringa: .. GI Groszey

9 JE laidar - NI Hewf

Io IS EOII . TR Crapres

13 vD Dosibse

32 Je

i3 $\mathrm{Fi}$

IL RE

15 IN Alibaugh - hit Easbog

I6 $300 \mathrm{File}$

37700 rille

is Piste

in Fise:

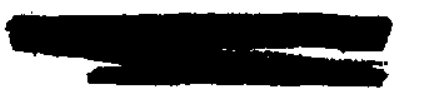

DECLASSIFIED

\section{Figure 3-4A First Hanford Shipment of $\mathrm{UO}_{3}$ Containing Transuranics \& Analytical Data} [Richard 1952a] 


\section{Recycled Uranium}

\begin{tabular}{|c|c|c|c|c|c|}
\hline \multirow{2}{*}{ 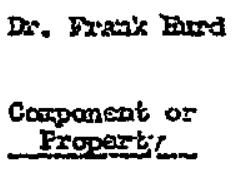 } & \multicolumn{2}{|c|}{$-2-$} & \multicolumn{2}{|c|}{ Karch 12, I95? } & \\
\hline & $\begin{array}{l}\text { Resportad } \\
\text { Re }\end{array}$ & $\begin{array}{l}\text { Lot } \\
\cos 2 .\end{array}$ & $\begin{array}{l}\text { Lot } \\
006 \\
\end{array}$ & $\begin{array}{l}205 \\
009 \\
\end{array}$ & $\therefore$ \\
\hline $\mathrm{wO}_{3}$ & 2 & 97.9 & 97.7 & 97.13 & \\
\hline $\mathrm{B}_{2} \mathrm{O}$ & $"$ & 0.21 & 0.23 & 0.25 & \\
\hline $\mathrm{HO}_{3}$ & $\mathrm{SWO}_{3}$ & 0.05 & 0.61 & 0.55 & \\
\hline$v_{3} O_{3}$ & 3 & 0.12 & 0.1 & 0.21 & \\
\hline $\mathrm{Mn}$ & ppm & 3000 & 3000 & 2500 & \\
\hline $\mathrm{FO}_{4}$ & $n$ & 2500 & 2500 & 1500 & \\
\hline Fe & $n$ & 700 & 950 & 550 & \\
\hline Hit & " & 20 & 20 & 30 & \\
\hline Ho & $n$ & 50 & 50 & $<50$ & \\
\hline $\mathrm{C} \pi$ & $n$ & $a$ & 2 & 5 & \\
\hline$\theta$ & $n$ & $<200$ & $<100$ & $<100$ & \\
\hline S:L & " & 10 & 10 & 50 & \\
\hline $\mathbf{B}$ & $\pi$ & $<0.2$ & $<0.2$ & $<0.2$ & \\
\hline$s$ & $n$ & 27 & 8 & $<1$ & \\
\hline i & $"$ & 5000 & 5000 & 5000 & \\
\hline Particio Siso & Fi bra do besia & $98 . ?$ & 99.0 & 97.7. & \\
\hline Burl Dosoits & $E_{*} / \mathrm{ce}$ & 3.099 & 2.07 & 1.75 & \\
\hline Surineo hea & s. $\mathrm{m} . / \mathrm{B}$ & 1.3 & 1.035 & 2.2 & \\
\hline Ex & Fob & $<5$ & $<5$ & $<5$ & \\
\hline S-p, sotilnitiyg, & $\#$ & $<5 \%$ & $<5 \%$ & $=30 \%$ & \\
\hline 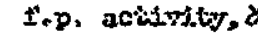 & 3 & $<70$, & $<100 \%$ & $<56 \%$ & \\
\hline $\mathrm{D}_{235}$ & 8 of 0 & 0.68 & 0,68 & 0.67 & \\
\hline
\end{tabular}

Figure 3-4A (Continued) First Hanford Shipment Containing

Transuranics and Analytical Data

[Richards 1952a] 


\section{Recycled Uranium}

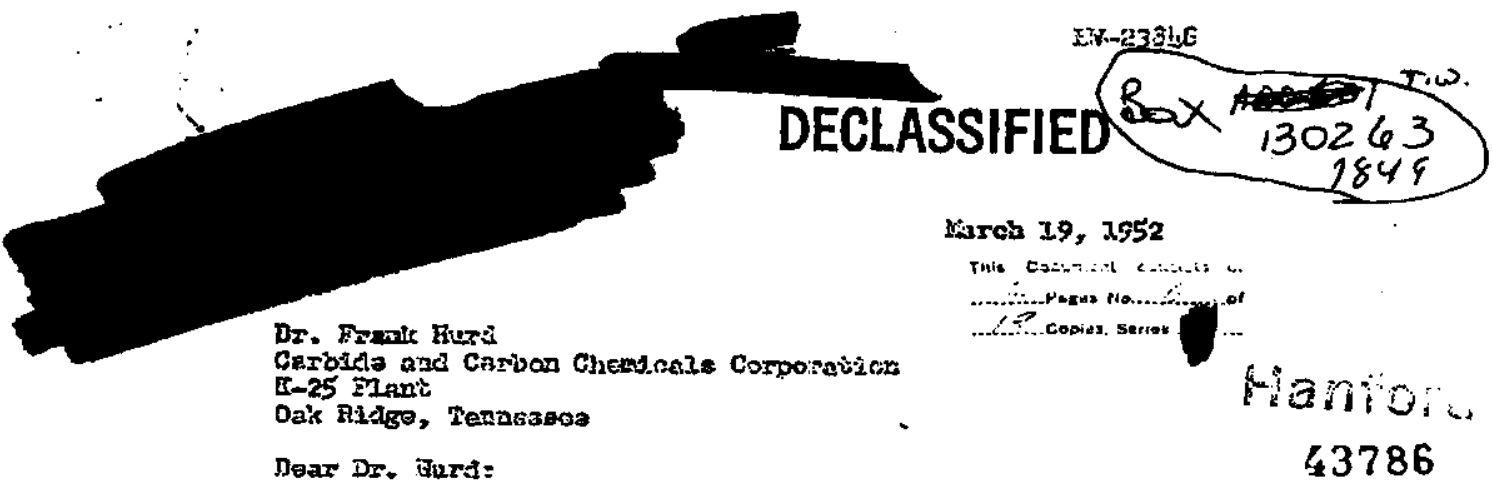

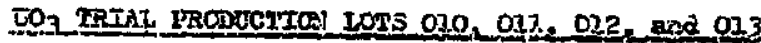

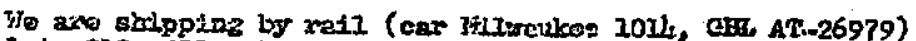

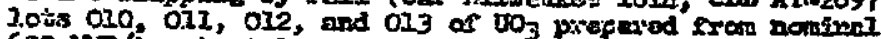

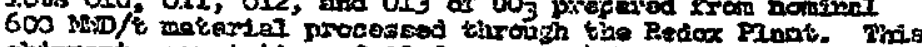

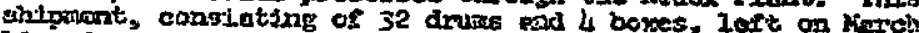

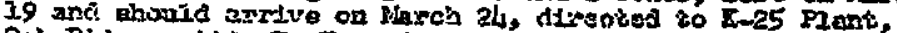

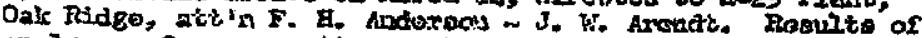

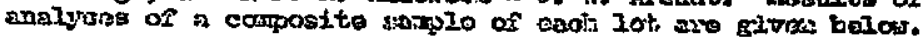

Classification cancelled (Change to

UNCI ASSIFIED

By A:thorty of RLO-CG-S

$5 . \operatorname{tin} 1.4 .3$

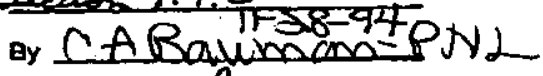

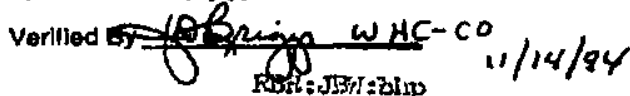

bec: In-2 Dr. Frate Find, Tim?

3 AP Ftuluar, B- -3

4 VIS Hrises, Kn-25

5 Sylven cromar, kwes

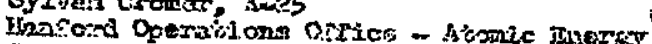

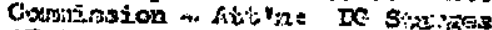

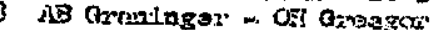

JE Jas̃ar - Th Thens:

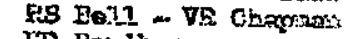

iD Dolitivea

it Worth - Ro Richarcis

IN boodriens

1) $m$ ind

1!

1.

18 pint

19 Toग7.6\%
Yours verg tring.

R. B. Ris whinda, Managor

3apuiztions Techrolost OnIt

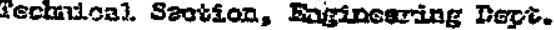
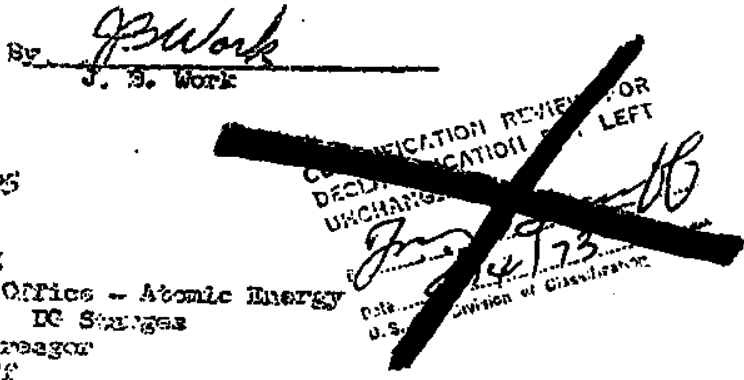

APPROVED FOR

T RELEASE

$-23.45$

MATERIALS Kar.i.

\section{DECLASSIF!:-}

Figure 3-4B Second Hanford Shipment Containing Transuranics and Analytical Data [Work 1952] 


\section{Section 3 \\ Recycled Uranium}

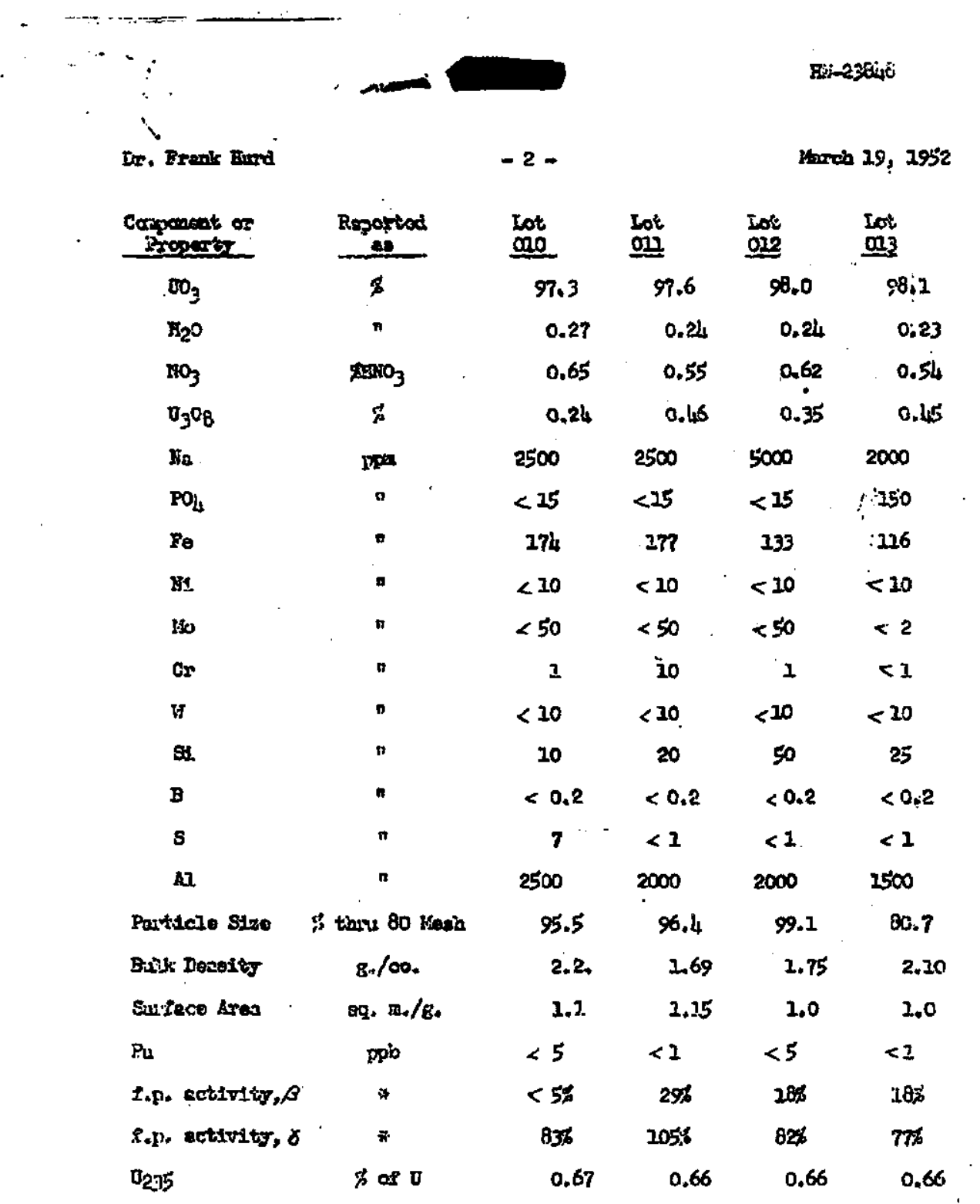

Figure 3-4B (continued)

Second Hanford Shipment of $\mathrm{UO}_{3}$ - Analytical Results

[Work 1952] 


\section{Section 3 Recycled Uranium}

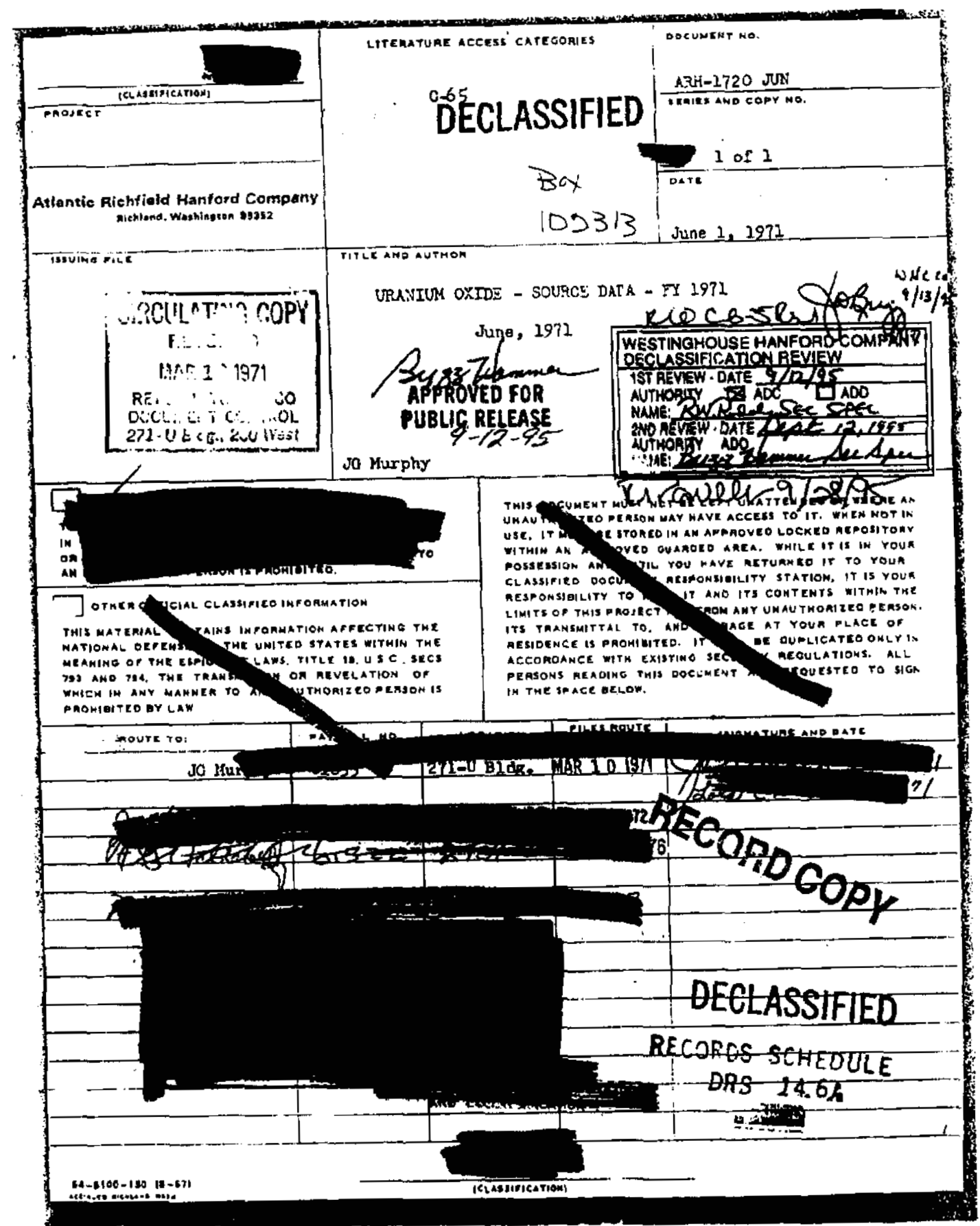

Figure 3-5 Example of Historical Transfer Forms-Cover Page 


\section{Section 3 Recycled Uranium}

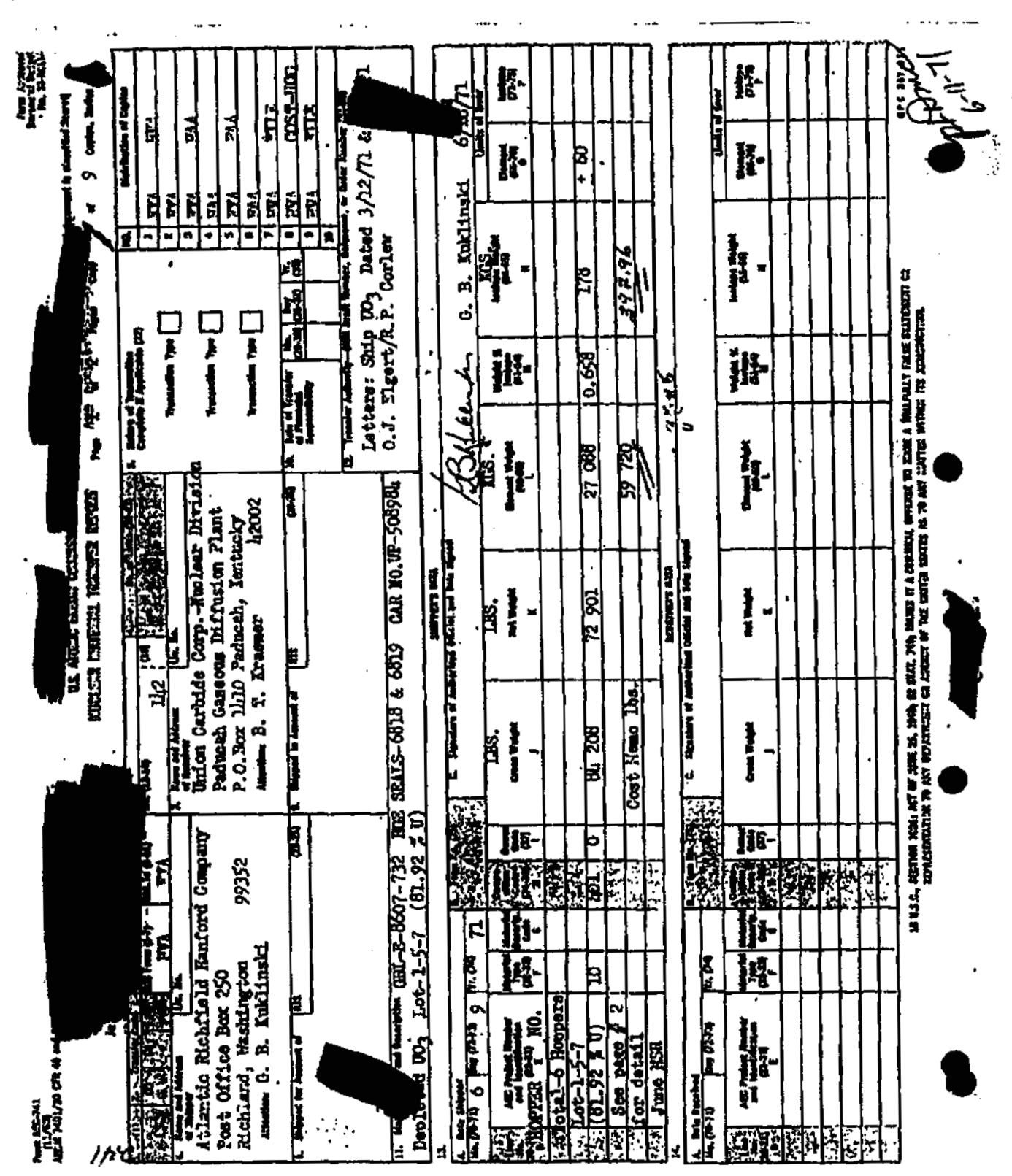

Figure 3-5 (Continued) Example of Historical Transfer Form for Shlpment from Hanford to Paducah (circa 1971) 


\section{Section 3 Recycled Uranium}

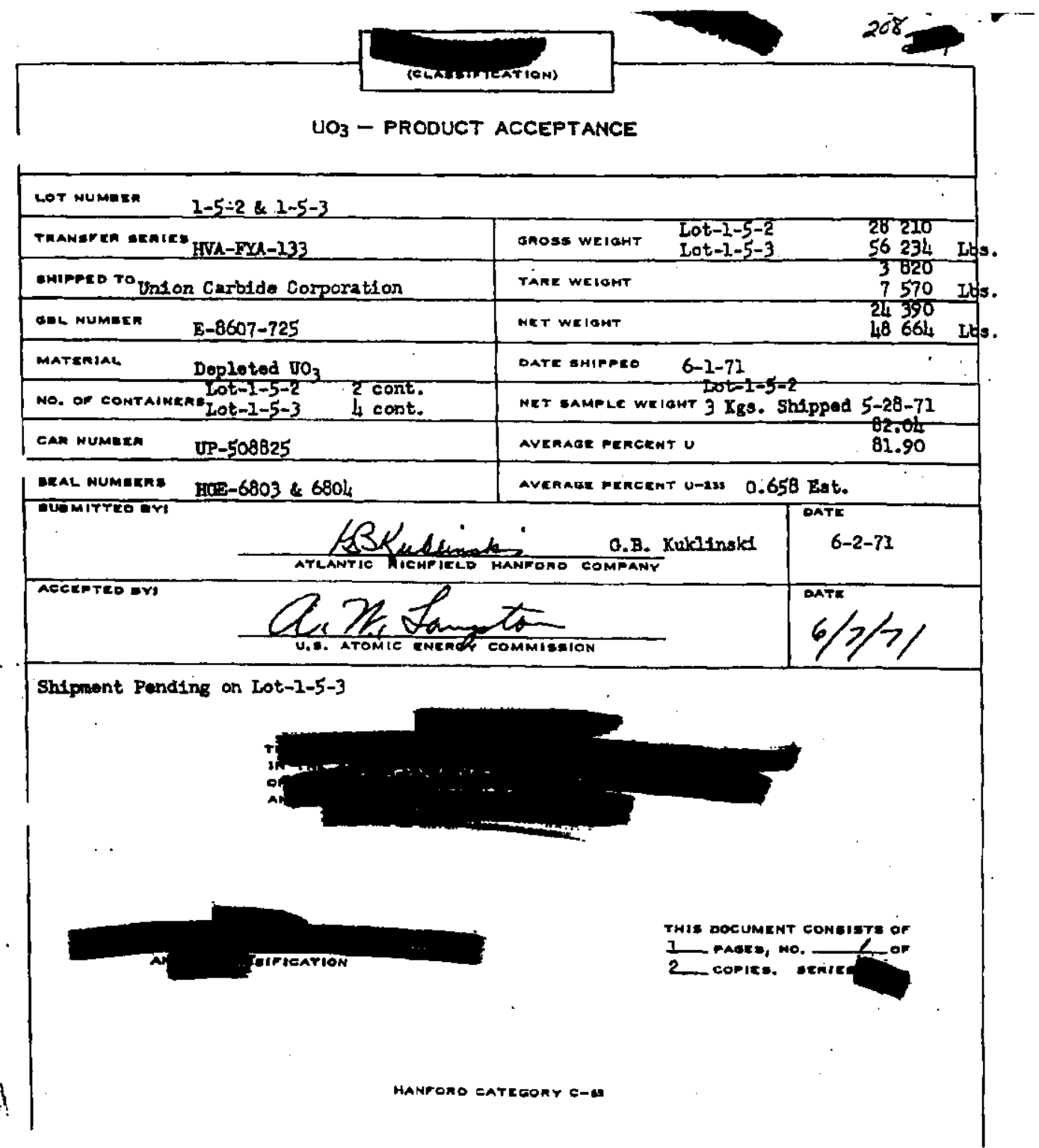

Figure 3-6 Example of Historical Product Acceptance Form Hanford Depleted $\mathrm{UO}_{3}$ to Paducah (circa 1971) 


\section{Section 3 Recycled Uranium

In March 1959, General Electric was authorized by the AEC to begin routine shipments of low-enriched $\left(0.94 \%{ }^{235} \mathrm{U}\right.$ before irradiation) $\mathrm{UO}_{3}$ to the $\mathrm{K}-25$ facilities in Oak Ridge [Gifford 1959]. Hanford LEU UO 3 shipments began soon thereafter. From this March approval-to-ship to the end of June 1959, Hanford produced and shipped approximately $288 \mathrm{MTU}$ of the low-enriched $(0.85 \%) \cup \mathrm{O}_{3}$ to Oak Ridge. Although the $\mathrm{K}-25$ facility was the first recipient of Hanford recycled uranium, the vast majority of the $\mathrm{UO}_{3}$ product was shipped to the Paducah site beginning in FY 1954 through FY 1972.

The third major recipient of Hanford recycled $\mathrm{UO}_{3}$ was the Fernald site, which began receiving research quantities of depleted $\mathrm{UO}_{3}$ in $\mathrm{FY}$ 1953. Although Fernald received small quantities of Hanford depleted $\mathrm{UO}_{3}$, they were the major recipient of Hanford lowenriched recycled $\mathrm{UO}_{3}$ beginning in the early 1960 s through March 1989. These shipments originated from the Hanford chemical processing contractors (GE, Isochem, $\mathrm{ARHO}, \mathrm{RHO}, \mathrm{WHC}$ ). Some small quantities of Hanford $\mathrm{UO}_{3}$ which did not meet K-25 acceptance criteria for non-radioactive chemical purity were sent to Harshaw for purification. The majority of Hanford $\mathrm{UO}_{3}$ shipped from Hanford to the $\mathrm{K}-25$ plant was later shipped from K-25 to Paducah.

\subsection{Receipts}

Beginning in the late 1940s, Hanford received uranium product to support fuel fabrication activities. Metal feedstock was received from Mallinckrodt (St Louis and Weldon Spring, Missouri), and Simonds. Fuel samples were exchanged with many sites as this new technology was rapidly growing. With the Fernald Plant coming on line in March 1953, an increasing quantity of uranium was received and shipped between Hanford and Fernald. Hanford receipt of recycled uranium is assumed to begin in July 1952 (FY 1953) as material shipped from Hanford offsite between March through June 1952 could not have reasonably been received, reprocessed, and retumed as feedstock from offsite until that time. In discussions with Fernald staff, normal (recycled) uranium metal feedstock initially received at Hanford could be expected to have contained only parts-per-trillion quantities of plutonium. Further discussions concerning the Hanford receipts are detailed in Section 3.2. Figure 3-7 (based on a 1949 document) shows the flow of uranium received into Hanford's 300 Area Fuel Fabrication facilities.

\subsubsection{Out-of-Scope Uranium Transactions}

\subsubsection{Hanford Production Channel}

Prior to March 1952, uranium shipments were confined to natural uranium scrap from Hanford's 300 Area Fuel Fabrication activities or metallurgical and process research involving UNH solutions. Natural uranium metal rods were received, principally from the New York Operations Office contractors, and processed at the 300 Area. The unirradiated scrap generated, in various forms, was sent offsite for reclamation. The finished fuel, termed "slugs" were "canned" and sent to the Hanford reactors for subsequent irradiation. Significant effort was made at Hanford in the early 1950 s to reclaim and reuse as much of the generated uranium scrap due to the shortage of 


\section{Section 3 \\ Recycled Uranium}

feedstock within the production complex. The fuel fabrication process had no input points at which transuranics could be introduced into the unirradiated fuel manufacturing process. There has been no evidence of any transuranic contaminants being introduced into the fuel within the Hanford manufacturing process.

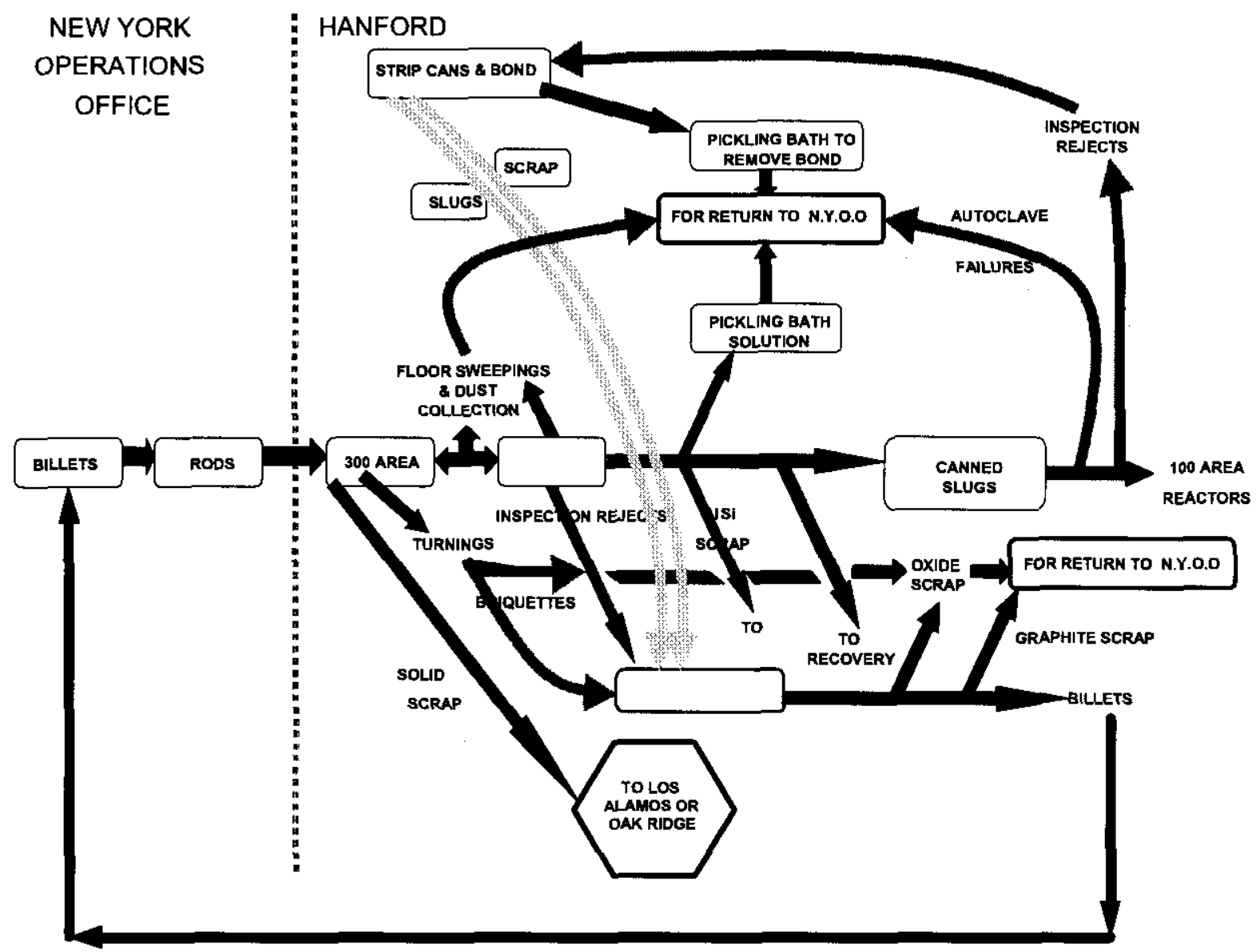

Figure 3-7 1949 Schematic Diagram Showing Uranium Flow in 300 Area (based on HAN-25257, dated May 25, 1949)

\subsubsection{Out-of-Scope Research and Development Programs}

As the development for increased uranium fuel productivity and chemical integrity continued during the late 1940 s and early 1950 s, small amounts of uranium were diverted from the production channels for research and development. The three areas of R\&D were 1) Exponential Pile Program; 2) Fuel Development Metallurgy; and 3) Separations Technology. One such research program, referred to as the Pile Enrichment program, involved transfers of unirradiated slugs between the Y-12 Plant 


\section{Section 3 \\ Recycled Uranium}

DOE/RL-2000-43

and Hanford. Hanford received the bare slugs from the Y-12 Plant, canned them, and returned slugs, scrap metal, and reject slugs to $Y-12$. There is no indication that these slugs contained recycled uranium, and are therefore considered out-of-scope transactions.

A subsequent part of the R\&D program sent irradiated slugs to the Idaho Chemical Processing Plant (ICPP). These $\mathrm{J}-1$ slugs were also irradiated at $\mathrm{H}$ reactor and the $\mathrm{J}-2$ slugs at $\mathrm{C}$ reactor. The " $\mathrm{C}$ " slugs were irradiated at $\mathrm{C}$ and $\mathrm{H}$ reactor. As the ICPP came on line, shipments of these "J" irradiated slugs began in late calendar year 1951 and were reported in a 1952 Material Balance Report, FTS-953 [Donihee 1952]. As spent fuel, the irradiated slugs sent to Idaho are considered out-of-scope for this project.

Another mid-1960 AEC research program, termed the Plutonium Credit Activity, involved shipment of Hanford irradiated fuel to Nuclear Fuel Services (NFS) in West Valley, New York [DOE 1999]. Uranium contained in this spent fuel is also considered out-of-scope for this study.

\subsubsection{Recycled Uranium Timeframe Summary}

Summaries of recycled uranium transfers at Hanford have been separated into two distinct timeframes. The period from January 1952 through June 1970 (FY 1970) represents the initiation of Hanford processing of recycled uranium from one or more separation plants. (In 1967, REDOX (S-Plant) shut down.) The second period from July 1970 through the present (March 1999) represents a period in which the PUREX plant (when operating) was the sole separation plant for Hanford's Defense missions. This later period is also one in which Hanford supported multiple non-defense missions, such as the Fast Flux Test Facility, under multiple Hanford contractors.

Quantities of uranium shipped and received are presented in Sections 3.2 and 3.3 and further detailed in Appendix B.

\subsubsection{Data Presentation - Isolation of Specific Timeframes}

This narrative section is prepared to explain the Hanford Recycled Uranium Project team's approach to quantitatively define recycled uranium materials that were shipped into and out of the Hanford Site since its inception in 1943 until March 30, 1999. To simplify reporting, Hanford shipments and receipts include the aggregate of the fuel fabrication/reactor operations contractors (Douglas United, UNI) and the chemical processing contractors (Isochem, ARHO, Rockwell, Westinghouse, Fluor) after contractor turnover from General Electric (GE, 1965-66 turnover). The Pacific Northwest National Laboratory (PNNL) and its predecessors offsite shipments and receipts are addressed separately.

In an effort to simplify the data investigation, the team chose to separate the Hanford Site uranium transactions to correspond to the following four timeframes: 


\section{Section 3 Recycled Uranium

- Late 1940s - December 31, 1951: Hanford Site external shipments and receipts from December 1947-December 31, 1951 encompasses the General Electric Company (GE), which solely operated the fuel fabrication, reactors, and chemical separations plants. This first timeframe was isolated to define a demarcation between In-Scope and Out-of-Scope uranium transactions. All transactions within this timeframe have been evaluated as Out-of-Scope to this project. These transactions, detailed in Section 3.2 and 3.3, were almost exclusively natural uranium product and scrap transfers between the New York Operations Office (NYOO) and its contractors and Hanford's Fuel Fabrication facilities.

- January 1,1952 - June 30,1965: This timeframe represents the beginnings of Hanford transactions involving recycled uranium under a single GE Company contractor. This period also represents a high production timeframe. As the research for safer and more efficient plutonium production continued, more offsite facilities become recipients and suppliers for recycled uranium into and out of Hanford. In the early 1950s, the major NYOO contractors were replaced primarily by the Fernald and Weldon Spring (Mallinckrodt) facilities as the major suppliers of Hanford metal feedstock and recyclers of Hanford scrap.

- July 1, 1965 - June 30,1970: This timeframe represents a transitional period of Hanford contractor turnover from the GE Company to multiple contractors and the beginnings of implementation of a DOE-wide Nuclear Materials Management and Safeguards System (NMMSS). PNL, assumed the management of Hanford Laboratories in 1965 as an independent research entity from Hanford Operations.

- July 1, 1970 - March 30, 1999: This timeframe includes the period when the PUREX Plant became the sole producer of UNH for Hanford. The NMMSS MC\&A system became operational (complex-wide). Recycled uranium transactions between Hanford and Paducah and Oak Ridge were minimal, and the vast majority of transactions for Hanford were with Fernald (NLO, FMPC, FEMP) and Reactive Metals Incorporated (RMI, Ashtabula Extrusion Plant).

\subsubsection{Hanford Historical Timeline References}

In tracing the historical transfers, the key activities and timeframes listed below were identified as potentially significant for the purposes of this study. (A more complete Hanford historical timeline of events is provided in Appendix $\mathrm{H}$.)

- Events Related to Hanford:

1950: $\quad$ Paducah Gaseous Diffusion Plant sited

1951: $\quad$ Savannah River Plant sited

1951: Fernald Feed Materials Production Plant (Ohio) sited

1952: Fernald production begins

1953: Paducah GDP becomes operational 


\section{Section 3 \\ Recycled Uranium}

DOE/RL-2000-43

- Hanford Contractor timeline:

December 21, 1942: Du Pont signed to construct/operate atomic plants

September 1, 1946: General Electric Company (GE) assumes control as overall Site Contractor

1965 to 1966: $\quad$ GE replaced by multiple contractors

September 1965 - Fuel Fabrication \& Reactor Operation:

1973

Douglas United Nuclear (DUN-joint venture subsidiary of

Douglas Aircraft Co. and United Nuclear Corp.)

1973-1979 United Nuclear Industries

1979-1987 United Nuclear Corporation (UNC)

1987-1996 Westinghouse Hanford Operations (WHC)

October 1996 - Fluor Hanford Incorporated (FHI)

Current

January 1966 -

September 1967

Chemical Separations, Processing \& Production Isochem (joint venture subsidiary of U.S. Rubber Co. and Martin Marietta Corp.)

September 1967 - Atlantic Richfield Hanford Company, chemical October 1967 processing operations

October 1977- Rockwell Hanford Company, chemical processing July 1987 operations

July 1977 -

October 1996

Westinghouse Hanford Operations, reactor operations and chemical processing

October 1996 - Fluor Hanford Incorporated (FHI)

Current

January 1965 - Battelle Memorial Institute (BNWL) (became PNL)

1977

1977 - Current Pacific Northwest Laboratory (PNL)(became PNNL) 


\section{Section 3 \\ Recycled Uranium}

DOE/RL-2000-43

- Government Agencies Having Control of Hanford Site:
$1943-1946$
U. S. Army, Manhattan Engineer District
$1947-1974$
Atomic Energy Commission (AEC)
1/1/75 - 9/30/77 Energy Research and Development Administration (ERDA)
10/1/77 - Current
U. S. Department of Energy (DOE)

\subsubsection{Key Dates/Assumptions for Uranium Transactions}

May 5, 1950: $\quad$ First shipment of unirradiated EU "J" slugs to $\mathrm{Y}-12$

January 1952: $\quad$ First recorded shipments of irradiated EU slugs to Idaho ICPP

January 1952: $\quad$ Depleted $\mathrm{UO}_{3}$ product was shipped (no fission products)

March 10, 1952: First recorded shipment of $\mathrm{UO}_{3}$ product to $\mathrm{K}-25 \mathrm{GDP}$ with fission products

July 1952: $\quad$ First assumed return of recycled uranium into Hanford

July 1958 Scheduled start of enriched $\mathrm{UNH}$ input into $\mathrm{UO}_{3}$ Plant [Gustafson 1957]

March-June, 1959: First production and shipment of enriched $\mathrm{UO}_{3}$ to $\mathrm{K}-25$

\subsubsection{Beginning Shipment of Recycled Depleted Uranium Trioxide $\left(\mathrm{UO}_{3}\right)$}

As previously noted, the first shipment of recycled $\mathrm{UO}_{3}$ produced at Hanford was shipped to Oak Ridge, Tennessee on March 10, 1952. Trial Production Lots 007, 008, and 009 were prepared from nominal $600 \mathrm{MWD} / \mathrm{t}$ material processed through the REDOX Plant. This initial truck shipment consisted of 24 drums and was sent to the K25 Plant. The analytical results of composite samples for each lot were also provided [Richards 1952] and are shown in Figure 3-4. Further discussion of Hanford analytical data and product quality is detailed in Section 4.0.

\subsubsection{Initial Shipments of Recycled Low-Enriched Uranium Trioxide $\left(\mathrm{UO}_{3}\right)$}

The first shipments of low-enriched $\left(0.8-0.9 \%{ }^{235} \mathrm{U}\right) \cup \mathrm{O}_{3}$ to Oak Ridge were approved by the AEC on March 3,1959 . Shipments were initially to be made to the K-25 Facility [Gifford 1959]. 


\section{Error}

An error occurred while processing this page. See the system log for more details. 


\section{Section 3 Recycled Uranium}

DOE/RL-2000-43

- Enriched Uranium: July 1952 research and development quantities

- Enriched Uranium: July 1960 metal LEU billets from Fernald from production channel (Pu in parts per trillion $\mathrm{U}$ ) (from cascades)

- Enriched Uranium: October 1963 metal LEU billets from Fernald (Pu in parts per billion $U$ )

\subsubsection{Receipts Prior to July 1952 (Out-of-Scope)}

In the late 1940s, Hanford receipts were natural uranium billets and rods from various metal fabricators under the management of the New York Operations Office (NYOO). Many of these same contractors were the recipients of Hanford shipments of scrap generated during the fuel fabrication activities and are detailed in Section 3.3. In the late 1940s and early 1950s, a majority of the Hanford billets were supplied by Mallinckrodt Chemical Works (MCW) and originated from three types of MCW cast ingots which included 1) ingots cast from natural uranium derbies; and 2) ingots recast from ingot croppings; and 3 ) ingots recast from reject slugs, rod ends, and rolling mill scrap [Greninger 1953]. Any uranium received at Hanford before July 1952 would not have contained reactor-produced fission products or radionuclides. There would have been $n{ }^{236} \mathrm{U}$ in these uranium receipts but would have contained the same distribution of uranium isotopes as present in natural or enriched uranium from a GDP cascade.

\subsubsection{Beginning Receipts of Recycled Uranium at Hanford}

The beginning receipts of metal feed stock with trace transuranics into the 300 Area is assumed to begin in July 1952 (FY 1953). This assumption is based on the logic that transuranics in the March $1952 \mathrm{UO}_{3}$ shipped offsite, could not have reasonably been processed and re-introduced into the returning metal billets until July 1952. Throughout the 1950s, Hanford continued to receive substantial metal feedstock from the NYOO contractors (Mallinckrodt Chemical Works, Simonds Saw \& Steel, etc.). The largest shipper of metal feedstock during the mid-1950s and until the 1980s was the National Lead of Ohio Company (NLO) plant in Fernald, Ohio. NLO was renamed the Feed Materials Production Center (FMPC) in the 1950s. FMPC is now managed by the Westinghouse Materials Company of Ohio. FMPC is a Major Tier 1 site, being both the recipient of Hanford fuel fabrication scrap and $\mathrm{UO}_{3}$ product and the supplier of metal billet feedstock. FMPC produced, via plants 6 and 9 , normal and low-enriched ingots that were finished into billets at Reactive Metals Inc. (RMI) and shipped to Hanford's 300 Area. Informal discussions with Fernald staff, indicate that there were no input points at RMI that could introduce transuranic contaminants into the billets shipped to Hanford. RMI was essentially a heat treating and extruding facility.

\subsubsection{Quantities of Recycled Uranium Received from July 1952-March 30, 1999}

The summary of in-scope recycled uranium received at the Hanford contractor(s) starting in July 1952 until March 31, 1999 totaled approximately 109,200 metric tons. Of 


\section{Section 3 \\ Recycled Uranium}

DOE/RL-2000-43

this total, approximately $85 \%$ was received from the three Major Tier 1 sites $(-92,800$ MTU). Yearly summaries for these three Major Tier 1 sites are detailed in Tables 3-1, 3-2, and 3-3. Summary fiscal year tables for all receipts by Hanford contractors are provided in Appendix B, Tables 3.2.1 through 3.2.8. These Appendix tables are divided into distinct timeframes to simplify transactions associated with the Hanford contractor turnover which occurred continually from 1965 onward. Summarized in Table 3-1below is the total recycled uranium received from offsite sources at Hanford.

Table 3-1 Total Recycled Uranium Received from Offsite Sources

\begin{tabular}{llrc} 
Timeframe: & $\begin{array}{c}\text { MTUs Received: } \\
\text { All Offsite Sources: }\end{array}$ & $\begin{array}{r}\text { MTUs Rec'd } \\
\text { Malor Tier 1: }\end{array}$ & $\begin{array}{c}\text { MTUs Rec'd } \\
\text { Minor Tier 1: }\end{array}$ \\
\hline FY 1953-FY 1965 & $77,603.7$ & $72,869.5$ & $4,734.2$ \\
FY 1966-FY 1970 & $19,119.5$ & $19,109.6$ & 9.9 \\
FY 1971-3/31/99 & $12,420.4$ & 788.0 & $11,632.4^{*}$ \\
\hline & $109,143.6$ & $92,767.1$ & $16,376.5$
\end{tabular}

"The majority of post FY 1971 receipts were from RMI Extrusion Plant (FTA) which supplied the Hanford fuel fabricator (United Nuclear, HXA).

\subsubsection{Hanford Receipts of Recycled Uranium from Paducah}

Hanford received residual $\mathrm{UO}_{3}$ in returned containers from FY 1954 through FY 1964. The receipts from Paducah are detailed in Table 3-2.

\subsubsection{Hanford Receipts of Recycled Uranium from Fernald and RMI (Ashtabula)}

Hanford received metal billets from Fernald and Reactive Metals Incorporated (RMI), Ashtabula. Hanford also received residual $\mathrm{UO}_{3}$ in returned shipping containers from Fernald. In 1983, incoming materials into the 300 Area were primarily $0.95 \%$ and $1.25 \%{ }^{235} \mathrm{U}$ billets from RMl in Ashtabula, Ohio. The receiving rate was nominally $41 / 2$ loads per month at 18 metric tons uranium per load [Heaberlin 1983]. The receipts from Fernald are summarized in Table 3-3.

\subsubsection{Hanford Receipts of Recycled Uranium from Oak Ridge}

Hanford received relatively small quantities of $\mathrm{UO}_{3}$ as heels in returned shipping containers and uranium metal for research programs. These receipts are summarized in Table $3-4$.

\subsection{Recycle Uranium Shipments}

\subsubsection{Recycled Uranium Streams Shipped Offsite:}

Two major recycle uranium streams were shipped offsite from Hanford's beginnings until March 1999. The first of the two major streams was byproduct from the fuel 


\section{Error}

An error occurred while processing this page. See the system log for more details. 


\section{Error}

An error occurred while processing this page. See the system log for more details. 


\section{Error}

An error occurred while processing this page. See the system log for more details. 


\section{Section 3 \\ DOE/RL-2000-43 \\ Recycled Uranium}

fabrication activities in the 300 Areas. The other major stream was the $\mathrm{UO}_{3}$ product produced at the $\mathrm{UO}_{3}$ Plant in the 200 West Area.

Hanford $\mathrm{UO}_{3}$ shipped after March 10, 1952 contained recycled uranium. The Major Tier 1 sites of Paducah, Fernald, and Oak Ridge received the vast majority of Hanford recycled uranium. Paducah received the majority for these three sites with approximately 74,500 MTU shipped out of Hanford from FY 1952 through FY 1973. After FY 1973, the majority of recycled uranium was sent to Fernald. Table 3-5 provides a brief summary of recycled uranium shipments from Hanford. Tables 3-6, 37, and 3-8 show these shipments to the Major Tier 1 sites in detail. Appendix B Tables 3.3.1 through 3.3.8 show the details of Hanford shipments to all off-site locations.

Table 3-5 Summary of Recycled Uranium Shipments from Hanford

\begin{tabular}{llll} 
Timeframe: & $\begin{array}{l}\text { MTUs Shipped } \\
\text { All Offsite Sites }\end{array}$ & $\begin{array}{l}\text { MTUs Shipped } \\
\text { Major Tier 1 }\end{array}$ & $\begin{array}{c}\text { MTUs Shipped } \\
\text { Minor Tier 1 }\end{array}$ \\
\hline March 1952-FY65 & $\mathbf{6 7 , 7 4 0 . 4}$ & $64,593.0$ & $3,147.4$ \\
FY 1966-FY 1970 & $28,292.4$ & $28,289.6$ & 2.8 \\
FY 1971-3/31/99 & $13,759.6$ & $11,263.6$ & $2,496.0$ \\
\hline Recycle Total & $\mathbf{1 0 9 , 7 9 2 . 4}$ & $\mathbf{1 0 4 , 1 4 6 . 2}$ & $\mathbf{5 , 6 4 6 . 2}$
\end{tabular}

\subsubsection{Uranium Shipments from 300 Area Fuel Fabrication Activities}

Specific uranium forms being removed from the fuel fabrication shops included reject metal rods, uranium oxide, "eggs", "slugs", metallic chips and fines, and floor sweepings. As much uranium was recovered as was possible in the early years due to shortages in uranium feedstock supply. "Eggs" were a term for metal samples cut off from the ends of newly arrived billets and tested for impurities before the billets were fabricated into fuel elements. "Slugs" were an early term for uranium fuel elements in the form of short cylinders clad or encased in corrosion-resistant metals. The 1949 schematic in Figure 3-4 shows the various flows of the generated scrap from the fuel fabrication activities. The four major NYOO sites receiving Hanford scrap were Mallinckrodt Chemical Works (Simonds Saw \& Steel (Lockport, New York), Vitro Manufacturing (Cannonburg, Pennsylvania), and Harshaw Chemical (Cleveland, Ohio)). Simonds performed metal rolling of the uranium billets, Mallinckrodt reprocessed sweepings, metal solids, "eggs", and rejected slugs. Vitro reprocessed Hersey Bag Filters (from $\mathrm{UO}_{3}$ plant) and miscellaneous scrap oxides. Uranium billets and metal turnings were also shipped to National Lead of Ohio (NLO).

Beginning in 1952, Aluminum-Silicon (Al-Si) alloy scrap (from the fuel Fabrication process) was also shipped to the U.S. Bureau of Mines (Albany, Oregon) because that facility had developed a method for recovering the tin. The tin crystals contained uranium. 


\section{Error}

An error occurred while processing this page. See the system log for more details. 


\section{Error}

An error occurred while processing this page. See the system log for more details. 


\section{Error}

An error occurred while processing this page. See the system log for more details. 


\section{Section 3 Recycled Uranium}

DOE/RL-2000-43

In the late 1940s, as part of Uranium Sample Exchange Programs, Hanford shipped metal billets to Mallinckrodt Chemical Works (St. Louis) for metallic impurity comparisons [Rebol 1949].

Until the end of June 1952, all Hanford outbound shipments were of unirradiated natural uranium scrap or research materials generated at the 300 Area Fuel Fabrication or Hanford research laboratories. The primary recipients for the reprocessing of this scrap were Mallinckrodt Chemical Works, Simonds Saw \& Steel Company, Vulcan Crucible Steel, Joslyn Manufacturing, and Vitro Manufacturing. The majority of the receipt sites were under the management of AEC's New York Operations Office (NYOO). As the metallurgical and chemical refinements to the Hanford fuel cycle continued, small quantities of unirradiated natural uranium were also sent to various laboratories for research. Shipments to the New York contractors was phased out in the early 1950s as the Oak Ridge-managed plants at Oak Ridge, Tennessee and Fernald, Ohio became the primary recipients of the fuel fabrication scrap. All production channel shipments of natural uranium from the late 1940s through June 1952 are therefore assumed to be out-of-scope for this report.

For the purposes of this project, it was assumed that offsite scrap shipments of recycled uranium from fuel fabrication activities began in July 1952 (FY 1953). This is based on the assumption that transuranics from $\mathrm{UO}_{3}$, or within irradiated slugs shipped offsite, could not have been processed and re-introduced into the returning metal billets until July 1952.

In the 1980's, all the Fuel Fabrication scrap was sent to National Lead of Ohio (NLO). Scrap forms included sludges, fines, and burned oxide (began in 1984). Approximately 181 MTU of $0.95 \%$ and 26 MTU of $1.25 \%$ as scrap was forecasted to be generated per year. A scrap generation rate of $21 \%$ of input was forecasted [Heaberlin 1983].

\subsubsection{Hanford Shipments of Recycled Uranium in Trioxide Product}

\subsubsection{1 $\mathrm{UO}_{3}$ Finished Product}

For $\mathrm{UO}_{3}$ finished product, the first shipment of $\mathrm{UO}_{3}$ was rail shipped to $\mathrm{K}-25$ on January 25, 1952 and consisted of 8 drums of Lot 001 [Richards 1952b]. The second shipment (Lot 002, 7 drums) to K-25 was shipped on February 11, 1952 [Richards 1952]. Both of these lots were produced from natural uranium and contained no fission products. They were "cold" test runs to validate the $\mathrm{UO}_{3}$ conversion process. This material was shipped to $\mathrm{K}-25$ to make sure the physical (particle size) and metallic impurities were within Oak Ridge acceptance criteria. As the "cold" $\mathrm{UO}_{3}$ was examined and found acceptable, Hanford began spiking the feed stream with UNH derived from irradiated fuel.

\subsubsection{Introduction of Fission Products}

The introduction of fission products into the $\mathrm{UO}_{3}$ product is indicated in production records that show a March 10, 1952 beginning for truck shipments, in drums, of 


\section{Section 3 Recycled Uranium

recycled uranium trioxide product to the Oak Ridge K-25 Gaseous Diffusion Plant (GDP). (Copies of these historical transfer documents, with attendant analytical data, were previously shown in this report as Figures 3-4 and 3-5.) This March $1952 \mathrm{UO}_{3}$ shipment is consistent with Hanford production history indicating $\mathrm{UO}_{3}$ test runs in January 1952 and full operation in February 1952. The primary recipient of early 1950s Hanford $\mathrm{UO}_{3}$ was to be the Harshaw Plant [Sturges 1952], but shipments were diverted to Oak Ridge facilities as their feedstocks became depleted. In March 1959, General Electric was authorized by the AEC to begin routine shipments of low-enriched $(0.94 \%$ ${ }^{235} \mathrm{U}$ before irradiation) $\mathrm{UO}_{3}$ to the $\mathrm{K}-25$ facilities in Oak Ridge [Gifford 1959]. Hanford $\mathrm{LEU} \mathrm{UO}_{3}$ shipments began soon thereafter.

\subsubsection{Out-of-Scope Research and Development Spent Fuel}

The irradiated fuel research and development program, referred to as the Pile Enrichment program, involved the receipt of unirradiated slugs from $Y-12$, irradiation in Hanford reactors, and shipment to Idaho.

The J-1 slugs were irradiated at $H$ reactor and the $\mathrm{J}-2$ slugs at $\mathrm{C}$ reactor. The " $\mathrm{C}$ ' slugs were irradiated at $\mathrm{C}$ and $\mathrm{H}$ reactor. Early in calendar year 1952, as the Idaho Chemical Processing Plant (ICPP) came on line, shipments of these " $\mathrm{J}$ " irradiated slugs began [Sturges 1953]. These transactions between Hanford and Idaho are considered out-ofscope for this study.

Prior to and continuing into 1952, Hanford also transferred small research quantities of aqueous uranyl nitrate hexahydrate, processed through REDOX and U.Plant, to Mallinckrodt Chemical Works and the Oak Ridge K-25 facility for subsequent conversion to $\mathrm{UO}_{3}$ [Richards 1950]. Although uncommon, UNH solutions were shipped offsite by rail in tanker cars. In 1952, Hanford shipped UNH to Brush Beryllium Company in Luckey, Ohio [Freitag 1952]. This company stored the UNH until it could be transferred to Harshaw for conversion to $\mathrm{UO}_{3}$.

\subsubsection{Post Fiscal Year 1970 Shipments}

After FY 1970, Hanford shipments continued to Fernald. In the early 1970s, Hanford missions also became more diversified with uranium materials being allotted by Defense Programs to support Research and Development projects such as the Fast Flux Test Facility (FFTF). Additionally, some of the Hanford recycled legacy metal and scrap was shipped outside the United States to support Mutual Defense Agreements and Hanford environmental management missions. Approximately 1,000 MTU were shipped abroad between 1993 and 1996 to support these governmental agreements [De-Minimis 2000].

\subsubsection{Shipment Packaging and Scheduling}

In the early $1950 \mathrm{~s}, \mathrm{UO}_{3}$ product was shipped in steel 55-gallon drums via both truck and rail. Beginning in 1956, T-Hoppers based on a Union Carbide Nuclear Company design 


\section{Error}

An error occurred while processing this page. See the system log for more details. 


\section{Section 3 \\ Recycled Uranium}

DOE/RL-2000-43

In the $1980 \mathrm{~s}, \mathrm{UO}_{3}$ process pipeline storage capacity was 45.6 tons of $\mathrm{UO}_{3}$. Yard storage of $\mathrm{UO}_{3}$ in 55 -gallon drums or T-Hoppers was virtually unlimited (>1,500 MTU). Loading could keep up with maximum production rates.

\subsubsection{Transaction Material Control and Accountability (MC\&A):}

Beginning in the early 1950s, shipment and receipt requests were approved through AEC correspondence. This correspondence was as both letters and teletypes between the various field offices. Transactions were recorded on AEC 101 forms. In later years, this form evolved into the current DOE $\mathbf{7 4 1}$ form but the basic function has remained unchanged. An example of the transfer forms and product acceptance forms are shown in Figures 3-4, 3-5, and 3-6 respectively. Key portions of the form included transfer authority, material type and description, authorized shipper signature, and authorized receiver signature. Accountability values were based on the net weight of the $\mathrm{UO}_{3}$ which were, in turn, determined by chemical analysis of composite samples with the ${ }^{235} \mathrm{U}$ content determined by mass spectrometry analysis of the representative composite samples. As the planning for shipments evolved, any Hanford shipments which Hanford testing indicated were out-of-specification were reviewed, by formal correspondence, by the receiver site and approved prior to any physical transfers.

In the early 1980s, as the Rockwell Hanford contractor readied for the restart of the PUREX Plant and UNH shipments to the $\mathrm{UO}_{3}$ Plant, the PUREX Material Control and Accountability Plan [Larson 1982] was prepared in which three analytical quality control programs were implemented for the laboratory measurement systems. The three systems were:

- Maintenance of control charts for each laboratory system

- Strict adherence to the Control of Analytical Measurement Systems (CAMS)

- Statistical tracking and evaluation per the Laboratory Accountability Measurement Program (LAMP) [RHO-MA-138 1978]

\subsubsection{Sample Exchange Programs and Sample Shipments}

In the late 1940s, the AEC understood the need for establishing a complex-wide set of uranium specifications and measurement methodology. Early specifications for depleted $\mathrm{UO}_{3}$ were led by Oak Ridge and concurred with by Mallinckrodt, Harshaw, Hanford and NLO. As detailed in Section 4.1, early Hanford laboratory analyses were performed in accordance with HW-24403 (sections 472.2, 285.1, 660.22, 845.10, \& 845.14) [McIntosh 1952]. Specifications for enriched $\mathrm{UO}_{3}$ were based on $\mathrm{K}-25$ operating experience and implemented at Hanford [Smith 1959].

Early in the 1950s, samples were exchanged for comparison and standardization. A triad of measurement programs provided standards and limits for the uranium 


\section{Section 3 \\ Recycled Uranium}

DOE/RL-2000-43

transactions. The three programs included 1) the AEC-wide Measurements Program; 2) Fissionable Standards Samples Committee; and 3) Sample Exchange Program.

In the 1950s, Hanford's $\mathrm{UO}_{3}$ Plant Control Laboratory composited samples of each ten (10) drum lot for each carload of $\mathrm{UO}_{3}$ product shipped. Samples were analyzed at Hanford and one-half of each sample was sent to the receiving site for check analysis. About 25-30 samples monthly were exchanged with K-25 and Harshaw [Hauff 1952].

For inbound billets in the 1950s, uranium metal quality control of non-radioactive constituents was maintained through an analytical checking arrangement with Mallinckrodt with up to 10 samples per month exchanged. Hanford sampling of metal occurred before it was placed into storage [Hauff 1952]. The Hanford specification [Groot 1952] for receipt of uranium metal was strictly enforced with "...no deviations from these specifications will be accepted without prior approval" [McCullough 1952].

\subsection{Recycle Uranium Scrap, Waste, and Conversion}

\subsubsection{Introduction}

In the sub-sections below are summaries of Hanford's past waste handling activities that are relevant to recycled uranium. Also included is a discussion of the uranium consumed in the production reactors. Waste and scrap streams from the 300 Area Fuel Fabrication facilities, the separations plants and the $\mathrm{UO}_{3}$ Plant are discussed. Each of these processes has been previously described in Section 2.0

The uranium waste streams were examined for possibilities of disposition and uranium content. Overall, less than two percent of the uranium handled in all aspects of operation was discharged as waste or local environmental releases.

\subsubsection{Reactor Fuel Element Fabrication}

Uranium-containing wastes were generated during the fabrication of reactor fuel elements. For the majority of the fuel fabrication activities, uranium slugs received at Hanford were first cleaned and then canned in aluminum cans. For a short time period, Hanford received metal ingots that were extruded, rolled, and cut into slugs or "cored" fuel rods for canning. With the start-up of Fernald, Hanford received billets that were coextruded, sectioned to specified lengths, and finished. The various unit operations included a number of cleaning, degreasing, acid leaching, and autoclave operations using nitric acid, hydrofluoric acid, sulfuric acid, organic solvents, and water. The liquid streams from these operations were treated to recover uranium. The uraniumcontaining sludge recovered from the treatment activities was processed to recover uranium. After treatment, these liquid wastes were routed to ponds and trenches. During 1984, the reported amount of uranium discharged, via liquid waste, was 0.004 percent [Hillesland 1984]. 


\section{Section 3 \\ Recycled Uranium}

Scraps in the form of chips and turnings from the lathes, rejected fuel slugs and the "butts" from the extrusion processes were salvaged and recycled. The chips and turnings were sorted, broken into smaller pieces, washed, dried, and pressed into briquettes. Initially, the filtered solids and dust were put into an oxide burner and converted to oxide. Later the chips and fines were drummed and sent to Fernald for recycle. Some of the fines and dust were cemented in drums and sent to solid waste disposal. (Additional information on scrap handling can be found in Sections 2.2.7.2, 2.2.8.5, and in Appendix F.)

Airborne effluents from uranium sawing and lathe operations were exhausted through an exhaust system equipped with a water spray scrubber to remove uranium particles, chemical vapors, gases, fumes and smoke particles. A typical annual emissions report from the 333 Building [Riches 1979] stated that the uranium concentration from the cutoff saw exhaust was $4.6 \times 10^{-9} \mathrm{lb} / \mathrm{ft}^{3}$ in a total air volume of $2.9 \times 10^{9} \mathrm{ft}^{3}$.

Solid uranium wastes, which included materials in failed and replaced equipment and normal line-generated process waste, were sent to Hanford burial grounds in the 300 and 600 Areas.

The description which follows, is based on the DOE Environmental Assessment [DOE/EA-0030 1980] and provides summary level information of scrap and waste streams from the 300 Area Fuel Fabrication facilities.

Uranium processing and effluent streams follow four principal material flow paths as related to fuel manufacturing. These are finished fuel, in-process storage, scrap returned to National Lead of Ohio (Fernald) for recovery, and waste streams. These streams are shown in Figure 3-10. 


\section{Section 3 \\ Recycled Uranium}

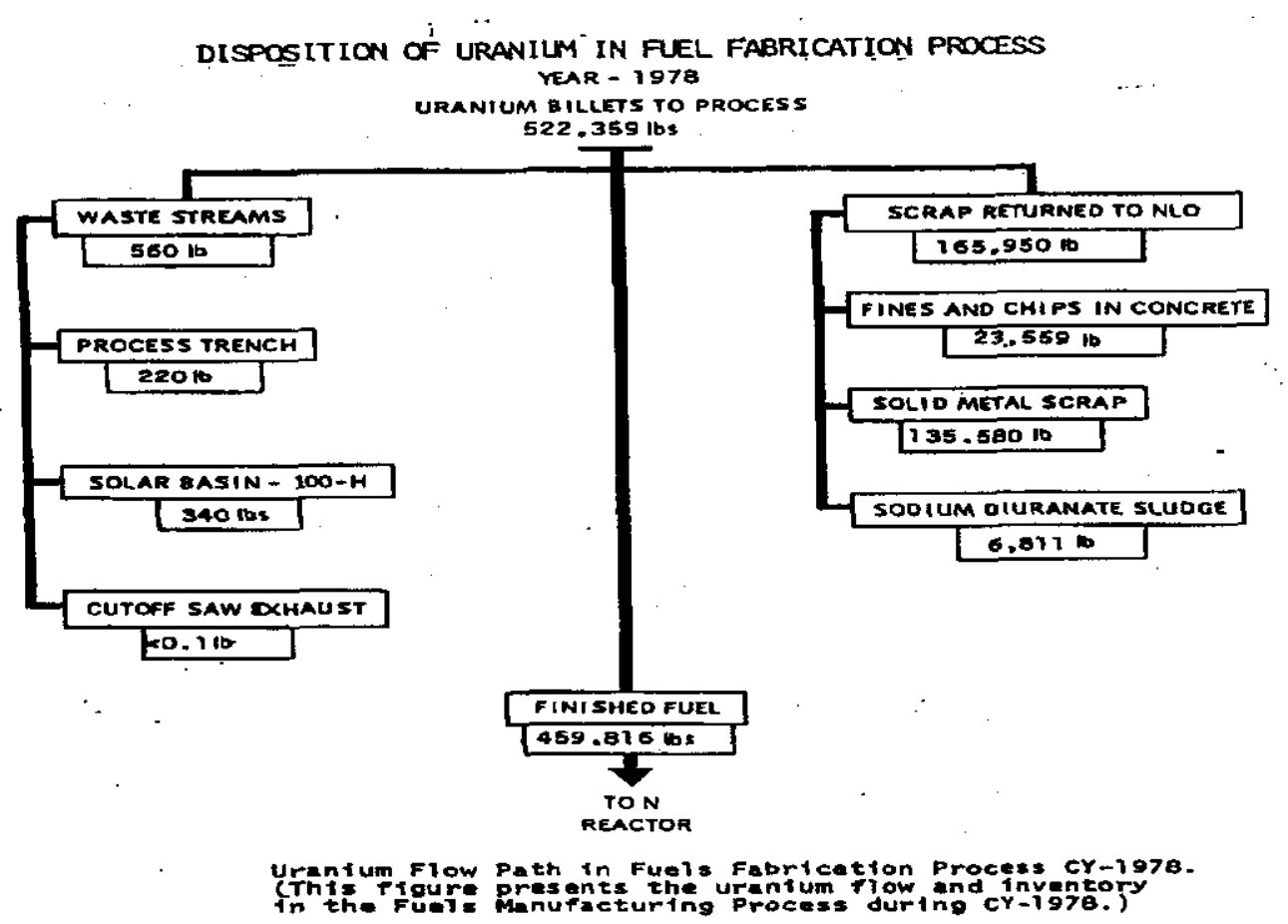

Figure 3-10 Uranium Flow and Inventory in Fuels Manufacturing Process (CY1978) [DOE/EA-0030 1980]

\subsubsection{Scrap Returned to Femald}

Uranium metal scrap and sludge from uranium-bearing acids were returned to Fernald for reprocessing. Uranium scrap sources included uranium chips and saw fines, solid metal scrap, and sodium diuranate sludge.

\subsubsection{Liquid Effluent - Chemical Waste Containing Uranium}

A chemical waste system was used in the 300 Area to receive and dispose of all concentrated liquid chemical wastes, including three liquid waste streams containing uranium. As shown in Figure 3-11, the system provided for collection, neutralization, and transportation of the wastes to concrete basins in the 100-H Area where the liquids would evaporate to form a solid salt cake. Later, as part of the Hanford Site response to the Comprehensive Environmental Response, Compensation and Liability Act of 1980 (CERCLA ) the residual material was stabilized, removed, and buried at the Hanford Environmental Restoration Disposal Facility (ERDF). 


\section{Section 3 Recycled Uranium

The only routine chemical wastes and uranium particulates to enter the process sewer from Buildings 313 and 333 were from process sewer rinse tanks, air scrubbers, wash stations, cut-off saws, and the concretion facility in the 304 Building.

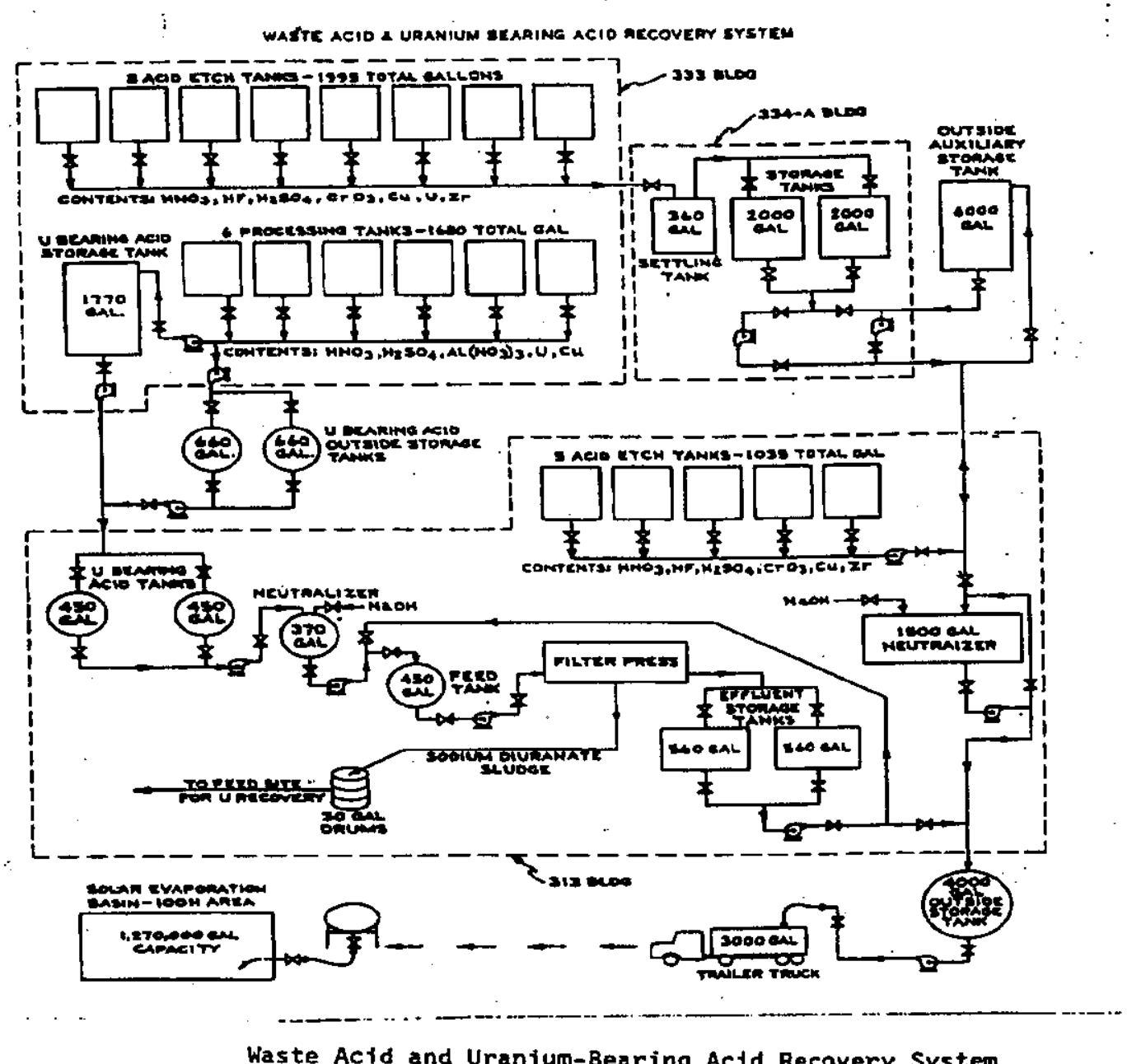

Figure 3-11 Waste Acid and Uranium-Bearing Acid Recovery System [DOE/EA-0030 1980]

Chemical solutions that contained appreciable amounts of uranium were collected in holding tanks, pumped to Building 313 and neutralized with sodium hydroxide. The precipitate was shipped to Fernald for recovery. 


\section{Section 3 Recycled Uranium}

DOE/RL-2000-43

Chemicals used and transferred were controlled, and liquids discharged to the process sewer were neutralized. Neutralized waste storage tanks (surrounded by dikes) held 10,000 gallons of liquid waste.

\subsubsection{Airborne Effluents}

All plants had filtered ventilation and air monitoring devices to assure safety of personnel and that atmospheric releases were controlled. It is noted that prior to 1948, T-Plant and B-Plant did not have exhaust filters and had to restrict dissolution activities to periods when atmospheric conditions would permit maximum dilution of the radioactive and non-radioactive off-gases. Ventilation systems were provided at process locations to collect and remove airborne uranium particulates and smoke and to discharge the filtered air outside the buildings.

\subsubsection{Solid Waste}

Solid waste contaminated with uranium was packaged for transfer, by truck, to the burial sites in the 200 and 600 Areas. Some of the solid burial sites in the 600 Area contain unreported quantities of uranium waste. The Waste Information Data System maintained by the Environmental Restoration Contractor has information on each waste site on the Hanford Project. Included in the description of each site is the concentration, when known, of the chemical and radionuclide concentration.

\subsubsection{300 Area Process Trenches}

The chemical wastes and uranium within the process water that entered the process sewer from fuel fabrication were diluted in the sewer before being discharged into the two process sewer trenches.

\subsubsection{Hanford Separation Plants}

T-Plant, B-Plant, and the REDOX, U-Plant, and PUREX separations plants routinely discharged uranium in a number of waste streams to the environment, waste storage tanks, and to the solid waste burial ground. Plant operations were designed to minimize loss of product and for protection of workers and the environment. As earlier stated, both the T-Plant and B-Plant processed irradiated fuel to recover plutonium from the uranium and fission products, which were transferred to underground tanks. REDOX and PUREX recovered both plutonium and uranium as primary products. U-Plant reclaimed the uranium from the waste that had been discharged from the $T$ - and B-plants.

Solid wastes, such as failed equipment and line-generated wastes, were sent to the Hanford Burial Grounds. 


\section{Section 3 \\ Recycled Uranium}

\subsubsection{Recovery of Uranium in the U-Plant}

After uranium had been removed in the TBP process at U-Plant, residual liquid was returned to the waste tanks and chemically struck to cause precipitation of the fission products. Clarified liquid was then pumped to the BC cribs located just south of the 200 East Area. Approximately thirty million gallons of waste liquors containing about 5,700 kgs of uranium were thus disposed.

Other wastes from the TBP process were disposed to the liquid and solid waste pathways described in Section 3.4.6.

\subsubsection{Uranium Trioxide $\left(\mathrm{UO}_{3}\right)$ Plant}

The major unit operations performed at the $\mathrm{UO}_{3}$ Plant were concentration of uranyl nitrate hexahydrate $(\mathrm{UNH})$, calcination of $\mathrm{UNH}$ to $\mathrm{UO}_{3}$, packaging of the $\mathrm{UO}_{3}$ product, and nitric acid recovery. Uranium-containing wastes were generated during routine operation. The waste streams included solid wastes which were buried, the liquid effluents discharged to the ground, and gaseous effluents released to the atmosphere.

The $\mathrm{UO}_{3}$ process condensates were pumped to the $216-\mathrm{U}-12$ Crib, though some went to the acid absorber tower for use as reflux water. Uranium-contaminated liquid wastes including steam condensate, chemical sewer, and cooling water were discharged to the U-10 pond.

The vapors leaving the concentrators contained water and very dilute nitric acid which were condensed and discarded as waste. Calcination of the UNH produced oxides of nitrogen, oxygen and water. The gaseous products were drawn through an off-gas scrubber, a gas cooler, and an absorption tower before being discharged to the atmosphere. A portion of the recovered nitric acid was circulated back through the acid scrubber and the remainder was pumped to storage for shipment back to the PUREX Plant. The nitric acid had a low residual level of UNH. The flowsheet [Raab 1978] indicated that the $\mathrm{UO}_{3}$ content of the scrubber off-gas was negligible. The $\mathrm{UO}_{3}$ product was conveyed to a cyclone separator where the $\mathrm{UO}_{3}$ powder and the transporting air were separated. The air was filtered first through two bag filters and then a final filter before discharge to the atmosphere.

Solid contaminated uranium waste, consisted typically of failed equipment and normal line-generated process waste. These solid wastes were buried in the 200 Area waste burial grounds.

Gaseous wastes from concentration, calcination powder handling, and acid recovery operation were filtered and discharged to the atmosphere. Radioactive elements in this stream included uranium. 


\section{Error}

An error occurred while processing this page. See the system log for more details. 


\section{Section 3 Recycled Uranium}

200 Area is based on an estimated $77.9 \mathrm{Ci}$ of uranium discharged to cribs and trenches [Diediker 1999]. An earlier estimate [TRAC-0151-VA 1991] reported 143 MTU based on an estimate of $137 \mathrm{Ci}$ of uranium in the liquid waste. The quantity of uranium in solid waste is based on the reported estimate in each burial ground as of the end of 1998 [Hagel 1999]. The estimate includes a small contribution from solid uranium bearing waste from offsite. The quantity of uranium in liquid wastes to the ground for the 300 Area is based on the data reported in the 1988 hazards ranking report [Stenner 1988]. The waste in the North and South ponds has been excavated and shipped to the Environmental Restoration Disposal Facility. The quantity of uranium in solid waste in the 300 Area is based on data provided by the Environmental Resource Center and reported in the Waste Information Data System. The 300 Area generated solid U waste was actually buried in or moved to the 600 Area burial. Several of the sold waste burial sites in the 600 Area contain unreported quantities of uranium waste.

\subsubsection{Uranium Losses Through Transmutation and Fission}

Uranium fuel fabricated in the 300 Area Fuel Fabrication Facility was irradiated in one of nine reactors that were operated at Hanford. The reactors primarily produced plutonium for the Defense Program, but a number of other products were produced to support ongoing Defense and Nuclear Energy Programs. During reactor operations uranium was fissioned to produce fission products and uranium was transmuted to other radionuclides, including plutonium.

An estimate of the quantity of uranium consumed in the reactors has been made on the basis of the quantity of plutonium produced at Hanford, the change in the percentage of ${ }^{235} \mathrm{U}$ in the uranium fuel to the reactors, and the percentage of ${ }^{235} \mathrm{U}$ in the uranium fuel discharged from the reactors. Between 1945 and 1989 Hanford produced 67.4 MT Pu. [DOE DP-0137 1996] This would have required the consumption of an equivalent quantity of ${ }^{238} \mathrm{U}$. Normal uranium $\left(0.711 \mathrm{wt} \%{ }^{235} \mathrm{U}\right)$ or low enriched uranium $(0.94-1.25$ wt $\%{ }^{235} \mathrm{U}$ ) was the feed to the reactors. The uranium recovered from processing was slightly depleted in ${ }^{235} \mathrm{U}$. Assuming that $10 \%$ of the uranium received at Hanford for fuel fabrication was returned as fabrication scrap without cycling it through the reactors, an estimated $66 \mathrm{MT}$ of ${ }^{235} \mathrm{U}$ was fissioned in the reactors. If it is also assumed that $10 \%$ of the plutonium produced was also fissioned or transmutated, then $\sim 140$ MTU was consumed in the reactors. This calculation results in a net loss of uranium in the overall uranium site balance.

\subsection{Overall Recycled Uranium Site Mass Balance}

In the attempt to segregate out the Hanford Site recycled uranium component, a mass balance including both in-scope and out-of scope uranium was developed. Development of this material balance was very complex because uranium transactions internal to Hanford activities needed to be clearly separated from non-Hanford transactions. In establishing a mass balance, both the Hanford Site contractors and the Pacific Northwest National Laboratory (PNNL) needed to be integrated into the calculations. Two issues related to shipper/receiver correlation of historical transactions 


\section{Section 3 Recycled Uranium}

make a precise mass flow extremely difficult. The first issue is that while MC\&A records indicate shipments to offsite locations, it was not uncommon for shipments to be diverted, during transit, to secondary locations to address feedstock shortages. Secondarily, for fiscal year transaction reconciliation between sites, quantities leaving one site near the end of a fiscal year may not be received and entered into the receiver site's MC\&A records (booked values) until the next fiscal year. Further difficulties with establishing precise mass flows at Hanford are in establishing the accuracy of estimates for normal operational losses (NOL), accuracy of measured discards, accuracy of estimated discards, reconciliation of Inventory Differences (ID) from continual contractor turnovers, accuracy of past decay calculations, and accuracy of Material Unaccounted For (MUF) explanations. An example of one difficulty was when Hanford, within a semiarid environment, shipped $\mathrm{UO}_{3}$ powder to the southeast. During transit and upon arrival at the southeast receipt location, the $\mathrm{UO}_{3}$ absorbed moisture, resulting in larger receipt quantities measured than were reported shipped from Hanford.

Table 3-10 and Figure 3-12 summarize these mass flows. At the right of each entry in Table 3-10 is a reference number which maps to the index below for further details to entered quantities and attendant reference documents. As the table indicates, approximately $115,955.4$ metric tons of uranium (all types) were received at Hanford (Hanford and PNNL) from January 1948 through March 30, 1999. Approximately 112,287.3 metric tons were shipped within this same period. Approximately 4,006 MTU remains in the Material Control and Accountability (MC\&A) inventory and approximately 2,314 MTU was lost to waste and reactor consumption. This leaves a difference of about 664.1MTU between receipts, on-site holdings, uranium consumed, and shipments. This difference is primarily attributed to uncertainties in the quantities of uranium in waste, that which was consumed in the reactors, and the limited data from the pre-1948 operating period. As indicated in Figure 3-12, the recycled uranium component of the receipt total is approximately 109,143.6 MTU ( 94\%). The recycled component of the shipment total was approximately 109,792 MTU ( 98\%).

Approximately 6,180 MTU is at the Hanford site in the form of current inventory or waste. An additional approximately $140 \mathrm{MTU}$ was fissioned or transmutated in the production reactors.

Index Mapping for Summary Table 3-10:

\begin{tabular}{|c|c|}
\hline Entry \# & $\begin{array}{l}\text { Table Reference } \\
\text { (Receipts) }\end{array}$ \\
\hline 1. & Appendix B, Table 3.2.1 \\
\hline 2. & Appendix B, Table 3.2.1 \\
\hline 3. & Appendix B, Table 3.2.1 \\
\hline 4. & Appendix B, Table 3.2.2 \\
\hline 5. & Appendix B, Table 3.2 .3 \\
\hline 6. & Appendix B, Table 3.2 .4 \\
\hline & Appendix B, Table 3.2.5 \\
\hline & $\begin{array}{l}\text { Appendix B, Table 3.2.6 } \\
\text { Appendix B, Table 3.2.7 }\end{array}$ \\
\hline 7. & Appendix B, Table 3.2.8 \\
\hline
\end{tabular}

\begin{tabular}{ll} 
Entry \# & $\begin{array}{c}\text { Table Reference } \\
\text { (Removals) }\end{array}$ \\
\hline 8. & Appendix B, Table 3.3.1 \\
9. & Appendix B, Table 3.3.2 \\
10. & Appendix B, Table 3.3.3 \\
11. & Appendix B, Table 3.3.4 \\
& Appendix B, Table 3.3.5 \\
& Appendix B, Table 3.3.6 \\
12. & Appendix B, Table 3.3.7 \\
13. & Appendix B, Table 3.3.8 \\
14. & Section 5, Table 5.1.1 \\
15. & Section 5, Table 5.1.2 \\
15. & Section 3.4
\end{tabular}




\section{Section 3 \\ Recycled Uranium}

DOE/RL-2000-43

Table 3-10 Hanford Mass Balance-Total In-Scope \& Out-of-Scope

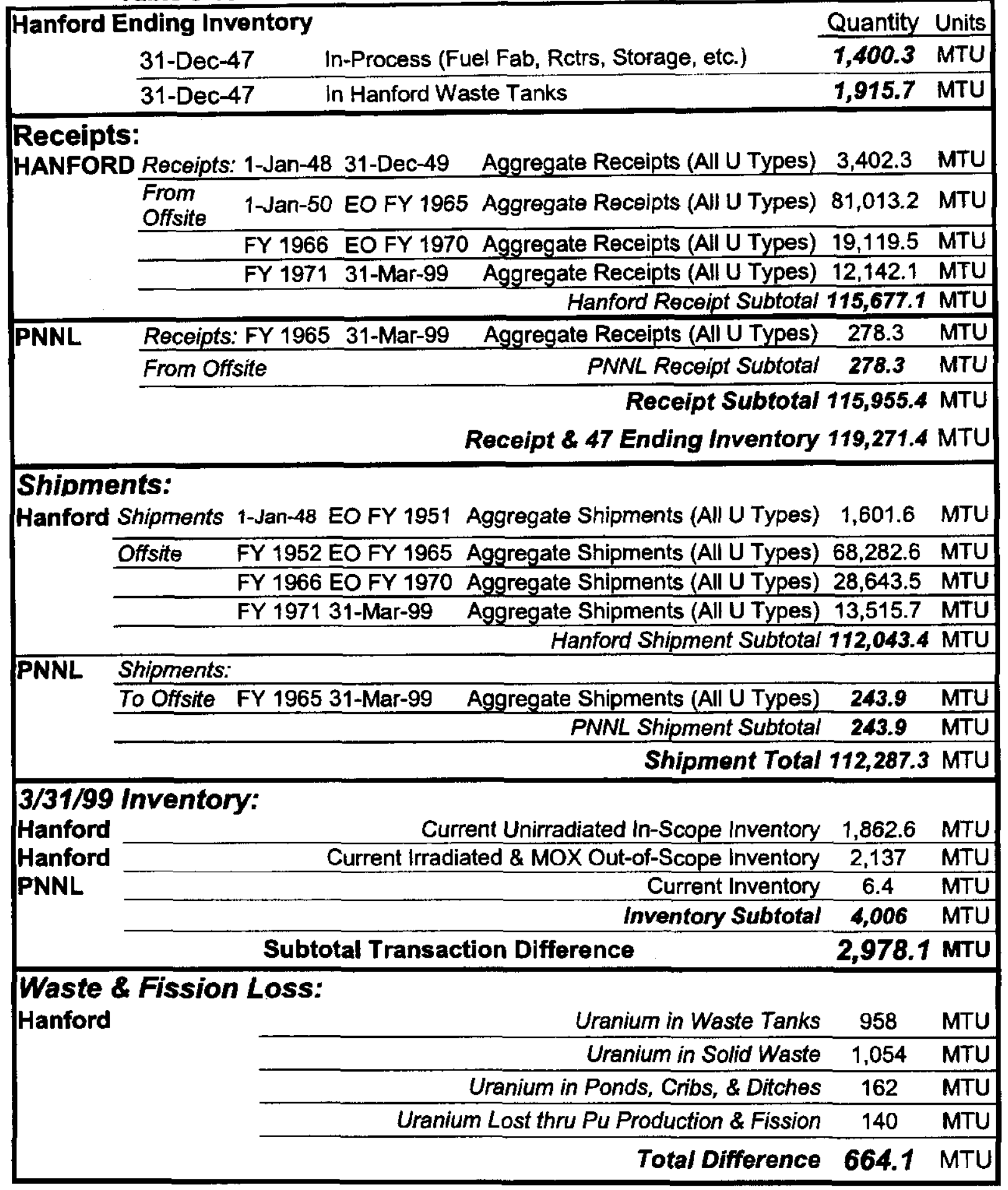




\section{Section 3 \\ DOE/RL-2000-43 \\ Recycled Uranium \\ (This page intentionally left blank)}




\section{Error}

An error occurred while processing this page. See the system log for more details. 


\section{Section 3 \\ Recycled Uranium}

DOE/RL-2000-43

\section{References}

ARH-1721M4

PUREX Month-End Reports - FY 1971, April through June, 1971, April1, 1971

Burge 1965 (classified)

HAN-92119, Burge, GE, to U.S. AEC Richland, Source and Special Nuclear

Materials Balance Reports, July 15, 1965

Byland 1963 (classified)

HAN-85615, J. N. Byland, GE, to U.S. AEC Richland, Source and Special

Nuclear Materials Balance Reports, July. 16, 1963

Byland 1964

HAN-88957, J. N. Byland, GE, to U.S. AEC Richland, Source and Special

Nuclear Materials Balance Reports, July 17, 1964

Christy 1968

Memo CPD-00144, J. T. Christy, Scheduled $\mathrm{UO}_{3}$ Shipments to Fernald, November 8, 1968

Christy 1969

Memo CPD-00344, J. T. Christy, Depleted UO ${ }_{3}$ Shipments to Fernald, December 11, 1969

De-Minimis 2000 (classified)

- RL2000-I-00002 Receipts, NMMSS to RL, Receipts by Calendar Year, Receiver, Material Type, Shipper, COEI Code, February 17, 2000

- RL2000-1-00002 Shipments, NMMSS to RL, Shipments by Calendar Year, Receiver, Material Type, Shipper, COEI Code, February 17, 2000

- RLSR00-00009 Recelpts, NMMSS to RL, Receipts by Calendar Year, Receiver, Material Type, Shipper, COEl Code, February 9, 2000

- RLSR00-00009 Shipments, NMMSS to RL, Shipments by Calendar Year, Receiver, Material Type, Shipper, COEI Code, February 9, 2000

Diediker 1999

HNF-1744, L. P. Diediker, Radionuclide Inventories of Liquid Waste Disposal

Sites on the Hanford Site, August 1999

DOE DP-0137 1996

DOE/DP-0137, Plutonium: The First 50 Years, February 1996

DOE 1999

DOE Report, Office of Defense Programs, Plutonium and Uranium Recovery from Spent Fuel Reprocessing by Nuclear Fuels services at West Valley, New York from 1966 to 1972, November 1999 


\section{Section 3 \\ DOE/RL-2000-43 \\ Recycled Uranium}

DOE/EA-0030 1980

DOE/EA-0030, Revision 1, Section II.2, Operation of N-Reactor and Fuel Fabrication Facilities, August 1980

Donihee 1949

HW-15-701, V. D. Donihee, GE, to U.S. AEC Richland, Source and Fissionable Materials Inventory, January 7, 1949

Donihee 1949a

FTS-668 (HW-15-757), V. D. Donihee, GE, to U.S. AEC Richland, Source and Fissionable Materials Inventory, July 8, 1949

Donihee 1951

FTS-670-DEL (HW-15-1017), V. D. Donihee, GE, to U.S. AEC Richland, Source and Fissionable Materials Inventory, January 10, 1951

Donihee 1951a

FTS-845-DEL (HW-15-1327), V. D. Donihee, GE, to U.S. AEC Richland, Source and Fissionable Materials Inventory, July 11, 1951

Donihee 1952

FTS-953-DEL, V. D. Donihee, GE, to U.S. AEC Richland, Source and

Fissionable Materials Inventory, July 16, 1952

Donihee 1953

FTS-1085-DEL, V. D. Donihee, GE, to U.S. AEC Richland, Source and Fissionable Materials Balance Reports, July 15, 1953

Donihee 1954 (classified)

FTS-1311 V. D. Donihee, GE, to U.S. AEC Richland, Source and Fissionable Materials Inventory, July 15, 1954

Donihee 1957

FTS-1980-DEL, V. D. Donihee, GE, to U.S. AEC Richland, Source and Special Nuclear Materials Balance Reports , July 17, 1957

Doninee 1958

FTS-CLVI-463-DEL (CLY1-431), V. D. Donihee, GE, to U.S. AEC Richland, Source and Special Nuclear Materials Balance Reports, July 16, 1958

Donihee 1959

HAN-72720-DEL (HW-61013), V. D. Donihee, GE, to U.S. AEC Richland, Source and Special Nuclear Materials Balance Reports, July 16, 1959 


\section{Section 3 \\ Recycled Uranium}

DOE/RL-2000-43

Donihee 1960

HAN-75996-DEL (HW-66018), V. D. Donihee, GE, to U.S. AEC Richland, Source and Special Nuclear Materials Balance Reports, July 18, 1960

Donihee 1961

HAN-79125-DEL (HW-70179), V. D. Donihee, GE, to U.S. AEC Richland, Source and Special Nuclear Materials Balance Reports, July 19, 1961

Donihee 1962

HAN-82406-DEL HW-74167), V. D. Donihee, GE, to U.S. AEC Richland, Source and Special Nuclear Materials Balance Reports, July 17, 1962

Elgert 1968

Memo CPD-00109, O. J. Elgert, RL, Shipment of $\mathrm{UO}_{3}$ to Paducah,

October 9, 1968

Freitag 1952

Teletype TT-04459, H. R. Freitag, AEC, to F. M. Belmore, NYOO, Tank CarsUNH Materials, September 19, 1952

Gifford 1959

Letter HAN-71497, A. T. Gifford, AEC/RL, to V. P. Donihee, GE, Enriched $\mathrm{UO}_{3}$, March 3, 1959

Greninger 1953

Letter HW-27296, A. B. Greninger, GE, to D. G. Sturges, AEC/RL, Uniformity of Uranium Metal Composition, March 3, 1953

Groot 1952

HW-25757, C. Groot to Files, Status of the Flouride Volitility Processes, October 17, 1952

Gustafson 1957

HW-53366, L. D. Gustafson, Definitive Scope of a Facility for E-Metal Product Segregation at the $\mathrm{UO}_{3}$ Plant, Project CG-767, November 4, 1957

Hagel 1999

HNF-EP-0125-11, D. L. Hagel, Summary of Radioactive Solid Waste Received in the 200 Areas During Calendar Year 1998, May 1999

Handshuh 1966

HAN-95170-DEL (RL-GEN-1068-DEL), J. W. Handshuh, GE, to U.S. AEC

Richland, Source and Special Nuclear.Materials Balance Reports, June 1966, July 18, 1966 


\section{Section 3 \\ Recycled Uranium}

DOE/RL-2000-43

Handshuh 1966a

HAN-96413-DEL (RL-GEN-133-1), J. W. Handshuh, GE, to U.S. AEC Richland, Nuclear Materials Balance Report, December 31, 1966

Handshuh 1967

HAN-98198, J. W. Handshuh, GE, to U.S. AEC Richland, Nuclear Materials Balance Report, June 1967, June 301967

Hauff 1952

Letter HW-26138, T. W. Hauff, GE, to D. G. Sturges, AEC, General Analytical Control Program I, November 5, 1952

Heaberlin 1983

UNI-03254, J. O. Heaberlin, UNC Nuclear Industries, Operational Analysis for Uranium and Plutonium Flows, October 1, 1983

Hillesland 1984

UNI-278 REV 10, D. S. Hillesland, Factor Weights for N Fuel Elements, Effective October 1, 1984, October 1, 1984

Kupfer 1999

HNF-SD-WM-TI-740, Rev. OC, M. J. Kupfer, et al., Standard Inventories of

Chemicals and Radionuclides in Hanford Site Tank Wastes, March 2, 1999

Larson 1982

6-I-47-17, M. P. Larson, RHO, to G. J. Miskho, RL, PUREX Material Control and Accountability Plan, Contract DE-AC06-77RLO1030, RHO-CD-1475) June 21, 1982

Maxfield 1979

RHO-CD-0673, Volumes I, II, \& III, H. L. Maxfield, Handbook, 200 Area Waste Sites, April 1, 1979

McCullough 1952

Letter HAN-46781, McCullough, GE, to G. W. Wunder, NLO, Hanford Uranium Specifications, dated September 25, 1952

McIntosh 1952

HW-24403, J. D. McIntosh, Hanford Works Analytical Manual for the Plutonium Separations and Metal Fabrication Processes, August 1, 1952

Murphy 1966

HAN-95136-DEL (ISO-378-DEL, J. G. Murphy, Isochem, to U.S. AEC Richland, Material Balance Report-June 1966, July 14, 1966 


\section{Section 3 \\ Recycled Uranium}

DOE/RL-2000-43

Murphy $1966 \mathrm{a}$

HAN-96400-DEL (ISO-665-DEL), J. G. Murphy, Isochem, to U.S. AEC Richland, Material Balance Report-December 1966, January 13, 1967

Murphy 1967

HAN-98196-DEL (ISO-973-DEL), J. G. Murphy, Isochem, to U.S. AEC Richland, Material Balance Report-June 1967, July 17, 1967.

Murphy 1968

HAN-99439-DEL (ARH-314-DEL), J. G. Murphy, Atlantic Richfield Hanford

Company, to U.S. AEC Richland, Material Balance Report-December 1967, January 15,1968

Murphy 1968a

ARH-699-DEL, J. G. Murphy, Atlantic Richfield Hanford Company, to U.S. AEC

Richland, Material Balance Report-June 1968, July 12, 1968

Murphy 1969

ARH-1036-DEL (SSSM-246), J. G. Murphy, Atlantic Richfield Hanford Company, to U.S. AEC Richland, Material Balance Report-December 1968, January 15, 1969

Murphy $1969 a$

ARH-1099-6-DEL, J. G. Murphy, Atlantic Richfield Hanford Company, to U.S.

AEC Richland, HVA Material Balance Report-June 1969, July 10, 1969

Murphy 1970.

ARH-1099-12-DEL (SSSM-646), J. G. Murphy, Atlantic Richfield Hanford

Company, to U.S. AEC Richland, HVA Material Balance Report-December 1969, January 12,1970

Murphy 1970 a

ARH-1540-6-DEL, J. G. Murphy, Atlantic Richfield Hanford Company, to U.S.

AEC Richland, Material Balance Report-June 1970, July 13, 1970

Prudich 1966

HAN-95171-DEL (DUN-1303), T. Prudich, Douglas United Nuclear, to U.S. AEC

Richland, Material Balance Report-June 1966, July 14, 1966

Prudich 1967

HAN-96419-DEL (DUN-1916), T. Prudich, Douglas United Nuclear, to U.S. AEC

Richland, Material Balance Report-December 1966, January 16, 1967

Prudich 1967a

HAN-98194-DEL (DUN-2777), T. Prudich, Douglas United Nuclear, to U.S. AEC

Richland, Material Balance Report-June 1967, July 12, 1967 


\section{Section 3 \\ Recycled Uranium}

DOE/RL-2000-43

Prudich 1968

HAN-99434 (DUN 3624-DEL), T. Prudich, Douglas United Nuclear, to U.S. AEC

Richland, Material Balance Report-December 1967, January 11, 1968

Prudich 1968a

DUN-4436, T. Prudich, Douglas United Nuclear, to U.S. AEC Richland, Material Balance Report-June 1968, July 12, 1968

Prudich 1968b

DUN-5250, T. Prudich, Douglas United Nuclear, to U.S. AEC Richland, Material Balance Report-December 1968, January 15, 1969

Prudich 1969

SSM-644 (DUN-5942-DEL), T. Prudich, Douglas United Nuclear, to U.S. AEC

Richland, Material Balance Report-June 1969, June 30, 1969

Prudich 1969a

DUN-6557, T. Prudich, Douglas United Nuclear, to U.S. AEC Richland, Material Balance Report-December 1969, December 31, 1969

Prudich 1970a

DUN-7049, T. Prudich, Douglas United Nuclear, to U.S. AEC Richland, Material Balance Report-June 1970, June 30, 1970

Raab 1978

RHO-CD-519, G.J. Raab and W. C. Schmidt, Uranium Trioxide $\cup_{3}$ ) Plant Chemical Flowsheet, November 1978

Rebol 1949

HAN-27519, E. W. Rebol, AEC, Hanford Analytical Results Uranium Sample Exchange Program, August 22, 1949

RHO-MA-138 1978

RHO-MA-138, RHO to DOE RL, Analytical Laboratories Operating Instructions, 1978

Richards 1950

HW-19496, R. B. Richards, GE, Conversion of UNH to $\mathrm{UO}_{3}$-Progress Report, November 9, 1950

Richards 1952 (classified)

Letter HW 23509, B. B. Richards, AEC/RL, to Dr. Hurd, Shipment of UO3-Lot 002, February 15, 1952 


\section{Section 3 \\ Recycled Uranium}

DOE/RL-2000-43

Richards $1952 a$

Memo HW-23754, R.B. Richards, $\mathrm{UO}_{3}$ Production Lots 007,008, 009,

March 11, 1952

Richards 1952b

Letter HW-23379, R. B. Richards, AEC, to F. W. Hurd, OR, First Trial Production Lot, $\mathrm{UO}_{3}$, January 28,1952

Riches 1979

Letter, J. W. Riches to O.J. Elgert, N-Reactor Environmental Assessment, UNI1313 Environmental Report on the Operation of N Reactor and Fuels Fabrication Facilities, May 9, 1979

SD-CP-SAR-002 1983

SD-CP-SAR-002, Rev. 1, Rockwell Hanford Operations, $\mathrm{UO}_{3}$ Plant Safety Analysis Report, September 1983

Shortess 1955

FTS-1481-DEL, C. J. Shortess, GE, to U.S. AEC Richland, Source and Special Nuclear Materials Balance Reports, July 19, 1955

Shortess 1956

FTS-1644-DEL, C. J. Shortess, GE, to U.S. AEC Richland, Source and Special Nuclear Materials Balance Reports, July 18, 1956

Smith 1959

HW-59136, R. E. Smith, Product Specifications Uranium Trioxide (Depleted E-

Metal) for Off-Site Shipment, February 18, 1959

Stenner 1988

PNL - 6456 Vol I, R. D. Stenner, et al., Hazard Ranking System Evaluation of CERCLA Inactive Waste Sites at Hanford, October 1988

Sturges 1953

Memo HAN-53121, D. G. Sturges, Shipments of Irradiated Enriched Uranium from Hanford to ARCO, December 21, 1953

TRAC-0151-VA 1991

TRAC-0151-VA, Historical Perspective of Radioactively Contaminated Liquid and Solid Wastes Discharged or Buried in the Ground at Hanford, April 1991

Work 1952

$\mathrm{HW}-23848$ (Hanford 43786), J.B. Work, $\mathrm{UO}_{3}$ Trial Production Lots 010,011, 012, and 013, March 19,1952 


\section{Section 4 \\ DOE/RL-2000-43 Contaminants in Recycled Uranium}

\subsection{Contaminants in Recycled Uranium}

The earliest specifications on $\mathrm{UO}_{3}$ product for recycle required analyses to be performed for chemical and physical properties before it left the Hanford Site. Typical analyses included beta and gamma activity as a percent of aged natural uranium, metal impurities, density, particle size, plutonium, and sulfur. Prior to initiating the addition of sulfur, a chemical reactivity measurement was included to predict the effectiveness of the conversion of $\mathrm{UO}_{3}$ to $\mathrm{UF}_{4}$ in subsequent processing. Neptunium-237 analysis was not requested on the $\mathrm{UO}_{3}$ product until about 1978 and technetium-99 was not included in analysis requirements until 1985. Although specification threshold concentrations were proposed, neither isotope was included in the specifications. As a result, there is a wide variation in the quantity of data available for $\mathrm{Pu},{ }^{237} \mathrm{~Np}$, and ${ }^{99} \mathrm{Tc}$ contaminants in Hanford $\mathrm{UO}_{3}$. This section focuses on the concentration of the three primary constituents of concern, $\mathrm{Pu},{ }^{237} \mathrm{~Np}$, and ${ }^{99} \mathrm{Tc}$, although concentration data for other constituents are discussed.

\section{4. $1 \mathrm{UO}_{3}$ Process Specifications}

Processing specifications of the $\mathrm{UO}_{3}$ Plant interacted with those of the separations plants (U-Plant, REDOX, and PUREX) because the UNH product from the separations plants was the feed to $\mathrm{UO}_{3}$ Plant. The UNH did not leave the separations plant if chemical analyses showed the product to be outside the threshold concentrations in any constituent of concern unless the $\mathrm{UO}_{3}$ Plant manager granted prior approval. These threshold values were generally consistent through the years of $\mathrm{UO}_{3}$ operation and are described below.

\subsubsection{Feed Specifications}

Feed specifications for the initial operation of the $\mathrm{UO}_{3}$ Plant are provided in the $\mathrm{UO}_{3}$ flowsheet included in Section 2.2.4.3. They indicate that the feed material from REDOX and U-Plants were tightly controlled, as the $\mathrm{UO}_{3}$ process provided no further purification of the uranium. The need for process control was recognized in the late 1940s and early $1950 \mathrm{~s}$, before the $\mathrm{UO}_{3}$ Plant came on line. Once decisions were made in the late 1940 s to "enrich the depleted uranium back to normal concentrations" [Greenwalt 1947], questions were raised about "firm specifications for the final uranium product to be delivered from either the REDOX and the TBP Plants or an uranyl nitrate-oxide conversion plant at the Hanford works" [Greninger 1950]. The separation plants were originally designed on the basis that the recovered uranium would be sufficiently decontaminated with respect to $\mathrm{Pu}$ and gross beta and gamma activity to permit essentially direct physical handling of the final product in its last form at Hanford. It was also recognized at this early stage that subsequent processing at other plants might result in fractionation or concentration of either fission products or $\mathrm{Pu}$ and cause a need for more highly specific or greater decontamination than would be required at Hanford. A Pu concentration limit was defined in 1948 [Gamertsfelder 1948] based on the 


\section{Section 4 \\ DOE/RL-2000-43 \\ Contaminants in Recycled Uranium}

tolerance level in breathing air. The conclusion was stated "that material with a purity limit of one part in $\mathbf{1 0 0}$ million parts uranium could be handled essentially as natural uranium." In a 1951 letter [Gamertsfelder 1951], the limit was again considered and it is stated that "reclaimed uranium should contain no more than one part plutonium in $7.8 \mathrm{X}$ $10^{6}$ parts uranium" in order that the hazard due to breathing air contaminated with reclaimed uranium should be no more than $10 \%$ greater than for ordinary uranium. This value allowed a $10 \mathrm{ppb}$ limit to be established and maintained throughout the history of the Hanford production era with greater than a ten fold conservatism factor built in.

\subsubsection{Product Specifications}

Threshold concentrations of constituents in UNH were included in technical manuals for both REDOX and U-Plants based on expected performance of the processes to purify the $\mathrm{UO}_{3}$ product. Both manuals set Pu concentration levels at $100 \mathrm{ppb}[\mathrm{HW}-18700$ 1951 and HW-19140 1951] but these threshold concentrations were not accepted by Oak Ridge, the Site responsible for setting standards for the $\mathrm{UO}_{3}$ Receiver Sites. Only product meeting the $10 \mathrm{ppb}$ Pu specification were to be shipped. Negotiations continued between the sites into 1953 by which time the processes demonstrated the ability to meet a more stringent quality requirement.

Although firm specifications were reissued many times, (see Table 4-1) and changes were made in the beta, gamma, chemical reactivity, and metal impurities thresholds, the approved $\mathrm{Pu}$ specification value did not change. In 1951, Hanford proposed a Pu specification of $50 \mathrm{ppb}$ but Oak Ridge held firm in maintaining the $10 \mathrm{ppb}$ limit [Sapirie 1951]. Communications between Oak Ridge and Hanford continued into 1953 with adjustments to accept metal impurities up to $200 \mathrm{ppm}$ with stipulations, but "in regards to the plutonium content, the specification of less than $10 \mathrm{ppb}$ should not be exceeded and, if possible, the plutonium level should be even lower. Oxide received from Hanford has, in general, contained less than 5 parts per billion plutonium" [Sapirie 1953].

The product specifications for the $\mathrm{UO}_{3}$ Plant provided chemical and radiological requirements that had to be met. In 1953, based on operating experience, Hanford and Oak Ridge representatives agreed upon the properties of the Hanford $\mathrm{UO}_{3}$ to be included in a firm specification. These properties included fission product activity, $\mathrm{Pu}$ content, purity (uranium content), particle size, and volatile impurity content. "The maximum acceptable Pu concentration shall be ten parts of plutonium per billion parts of uranium. Plutonium shall be determined on each carload composite" [Smith 1953]. Table 4-1, $\mathrm{UO}_{3}$ Process Specifications, provides a list of the firm specification documents in place during the life of the $\mathrm{UO}_{3}$ Plant. The information in these documents show that the required $\mathrm{Pu}$ concentration specification remained unchanged.

\subsubsection{Proposed Specifications}

Product specifications for ${ }^{233} \mathrm{U},{ }^{232} \mathrm{U},{ }^{237} \mathrm{~Np}$, and ${ }^{99} \mathrm{Tc}$ were also discussed but not adopted. In 1962, it was proposed that the maximum concentration of ${ }^{233} U$ be set at 90 ppm on a ${ }^{235} U$ basis, and ${ }^{232} U$ be set at 1.10E-2 ppm on a ${ }^{235} U$ basis [Judson 1962]. In 


\section{Error}

An error occurred while processing this page. See the system log for more details. 


\section{Section 4 \\ Contaminants in Recycled Uranium

transferred from the separations plants to the $\mathrm{UO}_{3}$ Plant with prior approval if the $\mathrm{UO}_{3}$ Plant had material on hand that could be blended to bring the out-of-specification material to within specification concentration.

Figure 4-1, an example page from one of the specification documents, is included for completeness. It defines the threshold quantity of impurity that was allowed and the analytical method that was used to generate the result.

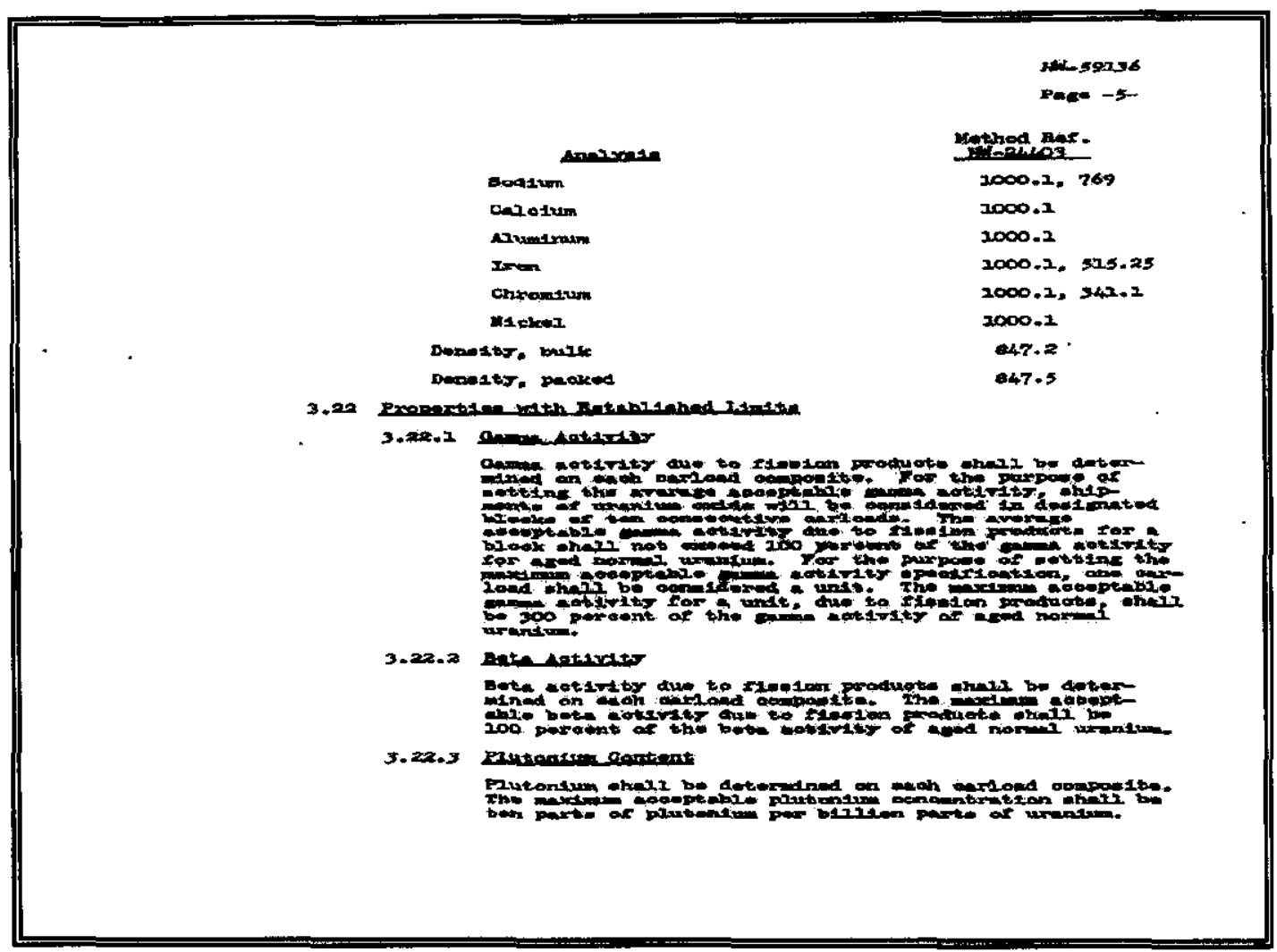

Figure 4-1 Example Page of Specifications for $\mathrm{UO}_{3}$ Plant

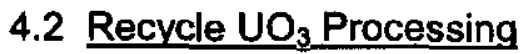

Each of the separations processes (i.e. U-Plant, REDOX, PUREX) sampled the UNH product prior to sending it to a load-out tank for transfer to the $\mathrm{UO}_{3}$ Plant. This internal transfer was not made until the analytical results were completed. If the UNH material was out of specifications in any respect, the material was recycled back to the partitioning cycle and reworked before being transferred to the $\mathrm{UO}_{3}$ process [HW-25744 1952]. Weekly and monthly reports contain several examples of this rework being necessary during the early years of Hanford operations. In the REDOX process, this rework was most commonly necessary to reduce the fission product activity rather than 


\section{Section 4 \\ DOE/RL-2000-43 \\ Contaminants in Recycled Uranium}

for reducing the levels of the three primary constituents of concern. There was a final silica gel extraction for removal of zirconium/niobium-95 $\left({ }^{95} \mathrm{ZrNb}\right)$, if those radionuclide concentrations were found to be high. This step was omitted if the UNH was found acceptable without employing this process step. Laboratory oriented, research and engineering flowsheet improvements were provided on a continuous basis through the operational life of each process. In addition, Process Engineering Support monitored and evaluated process operations on a daily basis. A few examples of these activities are recorded in the weekly and monthly reports and are included below to demonstrate the attention that was paid to UNH product quality in the separations plants and the $\mathrm{UO}_{3}$ product. In spite of this strict adherence to UNH specifications, five references have been found that document the shipment of $\mathrm{UO}_{3}$ product with $\mathrm{Pu}$ concentrations outside the $10 \mathrm{ppb}$ limit. These citations are included in Section 4.2.1. Although Hanford documents indicate these shipments were made after approval was obtained from of the receiver site, copies of receiver site acknowledgement of these notifications have not been located.

\subsubsection{Processing Issues}

During processing at the separations operations (REDOX, PUREX, U-Plant), upsets occurred that caused the UNH product to be outside the acceptable specifications in one or more constituents. Provisions were made during the construction of these facilities for taking remedial actions without exacerbating the entire process. Provisions were made for storage and rework of the UNH prior to transfer to the final loadout tanks. The U-Plant process provided alternative decontamination of REDOX UNH from impurities prior to transfer to the $\mathrm{UO}_{3}$ process. There are also records that document the transfer of UNH produced in the U-Plant process to REDOX for decontamination of ${ }^{95} \mathrm{ZrNb}$. In PUREX, provisions were made for rework of the UNH prior to transfer to the staging tanks if the product was found to be outside the specification.

\subsubsection{Typical Hanford Responses}

The following items are presented to provide examples of the types of issues addressed by the Process Operations and the laboratory-oriented Research and Engineering organizations: (These items are not listed in chronological order and only items that pertain to UNH product quality have been included. All items found addressing $\mathrm{Pu}$ issues have been included.)

- Provisions were made to "ship all $\mathrm{UO}_{3}$ which fails to meet specifications for impurities, other than radioactive contaminants, to the Harshaw Chemical Company" [Shaw 1952]. A number of railcar shipments (numbers 77-87, 90, 93, $94,96,98$ ) are recorded from July through September 1953) as being sent under this directive. Sodium contamination was a continuing problem in the UNH recovered from the waste tanks by the U-Plant. Iron concentrations above acceptable thresholds from corrosion were a recurring issue. These recurring non-conformance issues continued throughout the $1950 \mathrm{~s}$. 


\section{Section 4 \\ DOE/RL-2000-43 \\ Contaminants in Recycled Uranium}

- In 1953, a weekly report for REDOX [Christy 1953] states that six batches of $\mathrm{UNH}$ in excess of gamma specifications were sent to storage for decay of ${ }^{237} \mathrm{U}$.

- A firm specification was included in the REDOX and PUREX process operations that limited the concentration of plutonium allowed in the UNH product. Several references are recorded that indicate UNH transfers were held up awaiting analytical results on the process samples to verify that the product met the specification [HW-50584-DEL 1957].

- Several examples were encountered of $\mathrm{UO}_{3}$ produced from PUREX UNH that was outside the acceptable threshold for iron concentration [HW-48835-DEL 1957]. The excessive iron contamination in the final $\mathrm{UO}_{3}$ was found to originate in the $\mathrm{UO}_{3}$ Plant rather than in PUREX.

- An extensive investigation of analytical methods was initiated to resolve an apparent discrepancy of plutonium values in uranium as reported by REDOX and PUREX Laboratories. Subsequently, a real discrepancy was found to exist between results obtained by two different methods employed in the different laboratories. An analytical procedure was accepted that both laboratories subsequently used [HW-48835-DEL 1957].

- Conversion of $\mathrm{UNH}$ to $\mathrm{UO}_{3}$ was frequently hampered by foaming in the pot calciners. The identified source of this issue was the organic extractant, used in the U-Plant process, that contaminated the aqueous UNH feed. This issue was resolved when the continuous calciners were put into service.

- A shipment (carload \#8) was made to Harshaw that contained $30 \mathrm{ppb}$ Pu in 1952 [Richards 1952d].

- Three cars of continuous calciner powder were outside shipping specifications, however, they were accepted by the customer prior to shipment. The reason one car (UA-16) contained $16 \mathrm{ppb}$ plutonium concentration was unexplained since the UNH feed was determined to be within the $10 \mathrm{ppb}$ limit [HW-48835DEL 1957]. An investigation was initiated that resulted in a modified procedure [HW-50584-DEL 1957] that eliminated the bias due to neptunium coextracting with the plutonium in the final uranium analyses. The quantity of powder represented is not given specifically but (at this time) the usual shipment contained 10 drums, each containing 900 pounds, which comprised one carload. These shipments were made prior to use of T-Hoppers which contained 4.5 metric ton of $\mathrm{UO}_{3}$. The $\mathrm{UO}_{3}$ in one car exceeded the iron limit of $50 \mathrm{ppm}$ and the third car exceeded the particle size specification of $98 \%$ passing a 40 mesh screen.

- In December 1953, a shipment of $\mathrm{UO}_{3}$ product was made to Paducah, after acceptance by Oak Ridge, with $19 \mathrm{ppb} \mathrm{Pu}$ [Christy 1954]. 


\section{Contaminants in Recycled Uranium}

- In January 1954 an additional two cars, numbers 148 and 149 , of $\mathrm{UO}_{3}$ product were shipped to Paducah with 13 and $12 \mathrm{ppb}$ Pu respectively. Lot 148 resulted from poor quality REDOX UNH and Lot 149 resulted from poor U-Plant UNH [Christy 1954a].

- A T-Hopper (T 58) was returned to the Hanford Site with residual material from the shipment of GDP tails from Paducah to Fernald. Typical quantities of residue in these containers is approximately two kilograms. Information from Fernald indicates that the ash heel in this T-Hopper was 900 grams, was $40.69 \mathrm{wt} . \%$ uranium, and contained $\sim 7,760 \mathrm{ppb}$ plutonium, and $\sim 25,300 \mathrm{ppb}$ neptunium on a uranium basis. T-Hopper $\mathrm{T} 58$ was subsequently refilled with $\mathrm{UO}_{3}$ and is in storage at Hanford.

\subsection{Analytical Laboratories}

In the Hanford separations areas, buildings with the designation of "222" were laboratory facilities (222-B, - T, -S, and -U Labs) that supported the separations facility with the corresponding letter designation. As the only laboratory incorporated into its process building, the PUREX laboratory did not carry its own building designation. Analytical services for the $\mathrm{UO}_{3}$ Plant were provided by the 222-S Laboratory after the Metal Recovery and TBP processes were discontinued and the U-Plant laboratory was closed. These measurements continued in 222-S Laboratory until the $\mathrm{UO}_{3}$ process was put in standby in 1972. During restart of the $\mathrm{UO}_{3}$ process in 1983, the Plutonium Finishing Plant (PFP) Laboratory provided analyses for a short period until the testing could resume at the 222-S Laboratory. It continued there until the $\mathrm{UO}_{3}$ process was closed again in the late 1980s. The exception to this statement is that all uranium isotopic analyses and total metal impurities measured by emission spectroscopic analyses were performed at the PFP laboratory.

\subsection{1 $\mathrm{UO}_{3}$ Product Sampling and Subsampling}

Reliable analytical measurements were dependent on the adequacy of sampling and subsampling of the stream to be characterized. A new continuous sampler was designed for use when the continuous calciners were installed [Gustafson 1957]. This sampler was to replace a screw-type, continuous sampler used in the 224-UA unloading system to sample material produced in the pot calciners. A proportional sample was collected for analysis while each T-Hopper or pallet of four drums was being filled with $\mathrm{UO}_{3}$ product.

Continuous collection is generally recognized as an appropriate methodology for reliably sampling a stream that may have variability in composition. By collecting a portion of the bulk product as it is made or moved, variations in any constituent of concern will be sampled in relation to the extent that the constituent is present in the overall product.

When a sample arrived at the laboratory, it was placed on a tumbler-mixer and thoroughly homogenized before any aliquots were extracted for any purpose. After 


\section{Section 4 \\ DOE/RL-2000-43 \\ Contaminants in Recycled Uranium}

homogenization, a subsample was removed from each sample to build a composite representing a "lot" of material. A "lot" normally represented ten T-Hoppers or sixty drums of $\mathrm{UO}_{3}$ powder. This composite was again tumbled to effect thorough mixing before any subsampling was performed for either archive or analyses. In addition, a subsample of each sample was collected, sealed to exclude moisture, and stored separately for archive. Analytical measurements were then made of subsamples taken from the lot composite.

\subsubsection{Analytical procedures}

Procedures were developed for monitoring impurity levels and product quality through the separations processes while flowsheet testing of those processes was in progress. These procedures were transferred to the analytical laboratory supporting each process. Changes to these procedures were controlled and implemented only after closely controlled tests were conducted to verify performance. New methods of analysis were implemented to provide improved productivity or quality over the method being replaced. As higher resolution instrumentation became commercially available, especially for radionuclide characterization, these instruments were placed in use only after rigorous acceptance testing and approval of the change by the Process Engineering of the $\mathrm{UO}_{3}$ Plant. The original procedures to be used were collected in a procedure manual [Mclntosh 1952]. That document replaced a preliminary manual, HW-12864, 1950. The Product Specifications documents identified the analytica! procedures to be used for monitoring the product quality of $\mathrm{UO}_{3}$ shipped off-site, as shown in Table 4-1. The process control laboratories for REDOX, U-Plant, and PUREX were allowed to modify the procedures used on the UNH with technical justification but not without complex wide acceptance. Procedure differences were present between the laboratories and generally, the $\mathrm{UO}_{3}$ Laboratory procedures were the last to be changed because of the time required to obtain approvals.

Uranium concentrations were measured in UNH feed by density and nitric acid concentration. Because the UNH was very uniform, and had low impurity levels, the concentration was directly proportional to the density. This measurement method was very precise and accurate as long as the stream was within accepted impurity concentration thresholds. Other methods were used in the separations processes, such as $X$-ray photometer and spectrophotometry. These methods provided a more robust measurement in the event the uranium concentration did not meet the specifications or impurities were unexpectedly found by other analyses to be significant and affect the density methodology.

A gravimetric analysis was performed on the $\mathrm{UO}_{3}$ product in which the $\mathrm{UO}_{3}$ was converted to $\mathrm{U}_{3} \mathrm{O}_{8}$. This treatment eliminated contributions from water and corrections were made to account for the total metal impurities and sulfur associated with this compound.

The analysis methodology used for plutonium contamination was included in the original document [HW-12864 1950] although in 1960, this method was modified to improve the 


\section{Section 4 \\ DOE/RL-2000-43 \\ Contaminants in Recycled Uranium}

separation of plutonium from uranium and other alpha emitters [HW-65402 1960]. The formal mechanics of these methods are shown in a letter recommending substitution of an improved plutonium method from the previous accepted methodology [Harmon 1957]. This modification was included in the $1960 \mathrm{UO}_{3}$ process specification. Most (but not all procedures) of the established specification analyses were later documented in ARH-85 1970.

Plutonium was isolated from other alpha emitters and interferences by extracting it into thenoyl-trifluoro-acetone from a mildly acidic sample. The method is dependent on plutonium being in the extractable +4 oxidation state. The separation from uranium is effected by washing the extracted uranium from the organic phase with high concentration nitric acid. Alpha activity from ${ }^{237} \mathrm{~Np}$ contributed to the plutonium alpha activity which was measured for determining the plutonium content. This resulted in a high-biased plutonium analysis. An estimate of the potential bias introduced can be calculated using the ratio of specific activities of ${ }^{239} \mathrm{Pu}(1.30 \mathrm{E} 11)$ and ${ }^{237} \mathrm{~Np}(1.56 \mathrm{ES})$ and the relative concentrations of each (10 ppb and $500 \mathrm{ppb}$ respectively). The Np could have introduced a high bias to the $\mathrm{Pu}$ result by as much as 30 percent if the $\mathrm{Np}$ came through the procedure quantitatively. If the Pu concentration was already near the 10 ppb limit, this contribution could be considered significant. A modification was made to the method in 1960 to improve separation of plutonium from neptunium. The modification included a reduction step that also reduced the oxidation state of neptunium and only the plutonium was reoxidized for extraction. The basic technology of the analytical method remained consistent throughout the rest of the history of the $\mathrm{UO}_{3}$ process.

Prior to the mid-1950s, beta and gamma activity of $\mathrm{UO}_{3}$ powder was determined using a Geiger-Mueller tube with a mica end window. During the gamma measurement, the beta activity was shielded out with an aluminum-lead-aluminum absorber. This provided a best estimate relationship of beta activity to gamma emissions. The Shonka instrument, a high-pressure ionization chamber, replaced the G-M tube. Absolute measurements were not possible on a control basis with the Shonka. Empirical controls and relationships to aged natural uranium were re-established to define relative changes in product quality. It was assumed at that time, based upon process knowledge, that product $\mathrm{UO}_{3}$ would exceed the gamma activity threshold before reaching the beta threshold. Results from these instruments were likely biased high due to decay daughters of strontium-89 and strontium-90, if present, because of their high energy beta emission. In 1966, a modification was presented for measurement of beta and gamma activity with instrumentation that could attribute the gamma activity to specific fission products. Gamma scintillation counters replaced the Shonka after negotiations were concluded between Hanford and the recipients of the $\mathrm{UO}_{3}$ product [Knights 1966]. In 1967, the $\mathrm{UO}_{3}$ product specification established an upper limit of 15 $\mathrm{uCi} / \mathrm{lb}$. U for ${ }^{95} \mathrm{ZrNb}, 50 \mathrm{uCi} / \mathrm{lb}$. for the combination of ${ }^{103} \mathrm{Ru}^{106} \mathrm{RuRh}$, and $2 \mathrm{uCi} / \mathrm{lb}$. for all other isotopes excluding ${ }^{99} \mathrm{Tc}$. Ten lot average values were also established with the values for ${ }^{95} \mathrm{ZrNb},{ }^{103} \mathrm{Ru}$, and ${ }^{106} \mathrm{RuRh}$ and others limited to 10,25 , and 0.5 , respectively [Knights 1966]. 


\section{Contaminants in Recycled Uranium}

Introduction of the Beckman, Wide Beta $\|{ }^{\circledR}$ Counter, provided the ability to measure beta activity directly rather than calculating the beta activity from the beta/gamma measurements. Since ruthenium isotopes produced the majority of beta activity, the beta specification threshold was eliminated as a routine measurement. Although the Wide Beta $\|^{\Phi}$ instruments exhibited superior sensitivity to the prior instruments, the beta measurements did not adequately represent the Tc concentration in the sample. Chemical separations were required to isolate the ${ }^{99} \mathrm{Tc}$ from all other beta emitters before quantitation. This was not requested until the restart of the $\mathrm{UO}_{3}$ Plant in 1984. In later tables of this section, both the previous beta/gamma percent and specific radionuclide activities are presented.

Neptunium and technetium methods were not included in the original Hanford Works documents, nor are there single accepted methods for the measurements available today. For that reason, technologies developed at the on-site laboratories were applied after extensive testing and application to the UNH matrix. Reliable neptunium measurements were not made on $\mathrm{UO}_{3}$ until 1969 and technetium analyses were not performed until 1985 . Chemical standards with the isotope were included during the analyses to verify method performance.

An emission spectrograph provided the total metal impurities measurements on all $\mathrm{UO}_{3}$ product. This methodology was originally procured for quantitation of Pu product in the PFP and when the need for analyses of $\mathrm{UO}_{3}$ arose, aliquots were sent to PFP for analyses. The same logic was used for the uranium isotopic analyses that were also performed at PFP.

\subsubsection{Analytical Methods and Errors}

Each analytical method has an uncertainty associated with the measurement that can be attributed to either random or fixed errors. Both types must be considered and with appropriate data can be evaluated individually using statistical methods. The total uncertainty of a measurement is the combination of the two types. Fixed errors are those usually associated with the chemistry of the method such as extraction coefficients, volumes of vessels, and sampling. Random errors are those that are not repetitive such as degradation of chemicals used in the measurement and inadvertent use of incorrect supplies.

Combining both types of errors provides an error band that estimates the minimum and maximum concentration of a measured constituent that may be present in a sample. Certain of these parameters are easy to assess, but others are much more difficult to establish and monitor over time. During the development of a procedure, the fixed error contribution is defined and documented. The method is only put into service if it meets the measurement criteria established to support the use of the resulting data.

Early analyses of Pu were biased high from the effect of $\mathrm{Np}$ being coextracted during the separation of Pu from the sample matrix. This contribution was small when the $\mathrm{UO}_{3}$ was not recycled and the ${ }^{237} \mathrm{~Np}$ concentration was small compared to the concentration 


\section{Contaminants in Recycled Uranium}

of $\mathrm{Pu}$. As preparations were made to separate ${ }^{237} \mathrm{~Np}$ as a co-product, its contribution increased. The accuracy of the plutonium measurement was estimated to be $100 \pm$ $20 \%$ at the $99 \%$ confidence interval. Radioanalytical precision available at the time ranged from plus or minus 2 to $4 \%$ for gross beta, and plus or minus $0.2 \%$ to $10 \%$ for gross gamma depending on sample size [HW-19140 1951]. Emission spectrographic instrumentation provided data that was reliable within step ranges (20-50 ppm, 50-100 ppm), for each element. Unique quantitation values were not available on multi-element instrumentation until inductively coupled plasma atomic emission spectrometry became available in the late $1960 \mathrm{~s}$. Consequently, there are variations in early documented metal impurity data that may not be reproducible with current instrumentation.

\subsubsection{Quality Assurance}

Analytical procedures were written that implemented the standard methods documented in the manuals HW-12864, HW-24403, and HW-65402, cited earlier. Although laboratory-specific procedures were given different identification numbers, the technology remained the same. Details were modified to conform to specific instructions from the $\mathrm{UO}_{3}$ Process Engineering organization, implementation of new instrumentation, or to provide more specificity to the measurement.

\subsubsection{Quality Assurance Program}

An extensive quality assurance program was developed for use by the laboratories performing specification analyses in support of the $\mathrm{UO}_{3}$ process. This program was primarily focused on the measurement of uranium, but included very limited standards data to monitor the performance of analytical methods for other constituents as well. The program consisted primarily of blind standards and in-house referee analyses. The percent average recovery and precision of the average $(95 \mathrm{CL})$ was reported and used by the nuclear material control organization to apply a bias correction to the uranium shipment data if necessary [Rochon 1972]. The uranium measurement threshold limit for percent average recovery was about $100 \pm 0.5$ percent, but concern was raised if the result exceeded $100 \pm 0.1$ percent. A chemist was assigned to oversee and approve all results generated by the laboratory technicians. This methodology was directly applicable to the $\mathrm{UNH}$ received by the $\mathrm{UO}_{3}$ Plant.

The measurement for uranium in $\mathrm{UO}_{3}$ was sufficiently reliable that it did not require monitoring. Temperature and laboratory balances used were routinely calibrated according to accepted standards of the time. However, in 1961-1962, there were shipper-receiver discrepancies recorded in the uranium analyses. Investigation of the discrepancy was resolved by finding that hygroscopic $\mathrm{UO}_{3}$ picked up water during shipment and storage before the measurement was made at the receiver site. These differences were less than one percent but resulted in a significant bias in uranium material balance. 


\section{Section 4 \\ Contaminants in Recycled Uranium \\ DOE/RL-2000-43}

\subsubsection{In-House Standards Program}

An in-house standards program included synthetic UNH solutions (UNH from natural uranium) to which known quantities of the impurities of concern were added. These standard solutions were analyzed as a sample at a periodicity that would provide statistically significant quantities of data within the monitoring period, normally one month. During high production periods, these standard results were plentiful, however as the process was shut down for extended periods, data were not generated in sufficient numbers to be statistically evaluated for all constituents. Although sample preparation was performed in a laboratory room dedicated to uranium, analytical instruments were shared with other operations of the analytical laboratory. Standards results were not necessarily exclusive to the $\mathrm{UNH}$ or $\mathrm{UO}_{3}$ product. The percent average recovery of the Pu measurements was maintained at $100 \pm 10$ percent at the 95 percent confidence interval. Neptunium quantitation was held to $95 \pm 15$ percent.

Early in the 1950s, samples were exchanged for comparison and standardization. A triad of measurement programs provided standards and limits for the uranium transactions. The three programs included: 1) AEC-wide Measurements Program; 2) Fissionable Standards Samples Committee; and 3) Sample Exchange Program. These programs were supported by the AEC and its contractors and provided different emphasis. They continued until sufficient reliability was demonstrated that significant differences in analytical results would not be encountered.

Also in the early 1950s, Hanford continued to support quality assurance efforts to validate both the measurement techniques and product quality. Early correspondence between the New York Operations Office (NYOO) and Hanford indicates that $\mathrm{UO}_{3}$ data between Oak Ridge and Hanford correlated very closely in that:

- For both labs, the precision of mass spectrometry was $0.006 \%$.

- For both labs, the sampling was by aliquot and was nearly foolproof.

- Comparison between Hanford General Electric (HGE) and Carbide and Carbon Chemicals (CCC K-25 Oak Ridge) shipment analysis showed five cases of agreement at $0.64 \%$; one case of agreement at $0.65 \%$; and two cases of difference of $0.01 \%$. Averaging the above shows that in eight cases there is a difference of $0.00250 \%$ between the two laboratories. This represented 9.48 pounds of ${ }^{235} \mathrm{U}$ out of $399,699.06$ pounds of $\mathrm{UO}_{3}$ shipped. The conclusion is that HGE analyses for Harshaw shipments are of the same reliability as above.

An independent referee program was continued throughout the uranium recycling effort to monitor the analytical processes at the participating sites. The program established that aliquots of each container and lot composites were prepared and sent to the Site receiving the lot shipment. Since analytical measurements were performed at the receiver's site on material from the same composite, this effected a double-blind 


\section{Section 4 \\ DOE/RL-2000-43 \\ Contaminants in Recycled Uranium}

external referee program. Shipper-receiver differences were tracked by the Nuclear Materials Accountability personnel. If there were significant differences, the event was investigated at both locations and the differences resolved. Limited data is available that shows some differences in concentrations of plutonium were present on individual lots as expected, but were probably within the combined (two site) error band of the measurement. This inter-site comparison has not been performed.

Agreement on the Pu concentration between Hanford and Oak Ridge was more problematic in the 1952-1953 time period [HW-27314 1953]. Hanford generated data was apparently significantly lower than the Oak Ridge analysis of the same $\mathrm{UO}_{3}$ powder. However, in one sample of four, the Pu concentration agreed. Documentation with resolution of this issue was not found.

\section{$4.4 \mathrm{UO}_{3}$ Analyses:}

Production of $\mathrm{UO}_{3}$ product for recycle was continuous from inception in 1952 until the PUREX and $\mathrm{UO}_{3}$ Plant were placed in stand-down in 1972. By the time these processes were restarted in 1983, additional measurements were made that included ${ }^{237} \mathrm{~Np}$ and ${ }^{99} \mathrm{Tc}$ although there was no threshold specification on the allowable concentration. Data is separated in the following sections only because of the discontinuity of operations. The sources of data used in the following subsections are gleaned from records as near to the final $\mathrm{UO}_{3}$ shipment report as possible. The only data sources available prior to 1984 for ${ }^{237} \mathrm{~Np}$ and ${ }^{99} \mathrm{Tc}$ concentrations are the specifications imposed on the process facilities, REDOX or PUREX, and a few special analyses performed on $\mathrm{UNH}$ at the $\mathrm{UO}_{3}$ Plant.

\subsubsection{Impurity Concentrations in UNH}

As described earlier, the $\mathrm{UO}_{3}$ process made no significant changes in the impurity concentrations of the incoming UNH. Sulfur was added to the UNH after the mid-1950s to improve the conversion of $\mathrm{UO}_{3}$ to $\mathrm{UF}_{4}$ at the receiving site. The concentration was varied from about 300 to as much as 3000 parts sulfur per million parts uranium according to the requests of the receivers. Radioisotopes and volatile compounds were present in the UNH feed to the $\mathrm{UO}_{3}$ Plant. Some minor concentrations of ruthenium and other volatile fission products were volatilized during the calcination process strictly due to their volatility. The conversion of $\mathrm{UNH}$ to $\mathrm{UO}_{3}$ evolved large quantities of nitrogen oxides. The majority of volatilized $\mathrm{NO}_{\mathrm{x}}$ and some fission products were collected in the off-gas treatment system and returned to the PUREX Plant. Low concentrations of fission products were also included in wastewater discharged to the soil column. Constituents that were not volatilized remained in the $\mathrm{UO}_{3}$ product.

\subsubsection{Analyses Performed and Results}

After conversion of $\mathrm{UNH}$ to $\mathrm{UO}_{3}$, chemical analyses were performed on each lot, representative samples from which consisted of ten containers (when using T-Hoppers) or sixty drums. During heavy production, when both REDOX and PUREX were 


\section{Error}

An error occurred while processing this page. See the system log for more details. 


\section{Section 4 \\ DOE/RL-2000-43 \\ Contaminants in Recycled Uranium}

with a maximum of $7.5 \mathrm{ppb}$ and minimum of $<1 \mathrm{ppb}$. The average gamma percent for this UNH was $87 \%$ of aged natural uranium. These are limited data, but they indicate the ability of the U-Plant Process to produce UNH that comfortably met the $10 \mathrm{ppb}$ specification.

\subsubsection{Storage of $\mathrm{UO}_{3}$ at Hanford}

Due to shutdown of facilities producing $U_{6}$ at Paducah, Hanford-produced depleted $\mathrm{UO}_{3}$ was stored at Hanford [Sloat 1964]. The enriched (nominal $0.8 \mathrm{wt} \%{ }^{235} \mathrm{U}$ ) was milled and packaged in T-Hoppers while the depleted (nominal $0.6 \mathrm{wt} \%{ }^{235} \mathrm{U}$ ) was packaged in $\mathbf{5 5}$ gallon drums for storage when the T-Hoppers were not available.

Plutonium and fission product concentrations on lots of depleted $\mathrm{UO}_{3}$ packaged in drums and stored at Hanford are summarized in Table 4-3; more detailed reports are presented in the Appendix C, Table 4-3. A data package [ISO-877 1967] provided this product information for the time period from May 1964 through June 1967. The data covers 352 lots of drummed material that were processed during the 32-month period. The average plutonium concentration for the 352 lots was $2.2 \mathrm{ppb}$ uranium with a low of $<1 \mathrm{ppb}$ and a high of $8 \mathrm{ppb}$. It should be noted that the plutonium concentration exceeded $5 \mathrm{ppb}$ on only six lots out of the 352 and these were only $6,6,6,7,7$ and 8 ppb. None exceeded the $10 \mathrm{ppb}$ specification.

The data package includes concentrations of specific radioisotopes, and gross beta and gamma radiation levels during periods when the measurements were made. The average beta radiation for 317 lots for which data is available was $6.53 \%$ of the beta radiation level of aged natural uranium and ranged from a low of $0.31 \%$ to a maximum of $36.5 \%$. The average gamma radiation level was $78.2 \%$ that of aged natural uranium and ranged from a low of $3.9 \%$ to a maximum of $212 \%$.

The gross beta and gamma data were not included for the last 35 lots; however, activity levels for specific isotopes $\left({ }^{95} \mathrm{ZrNb},{ }^{103} \mathrm{Ru}\right.$ and $\left.{ }^{406} \mathrm{RuRh}\right)$ were documented for the last 52 lots in the data package. The average ${ }^{95} \mathrm{ZrNb}$ activity was $4.58 \mu \mathrm{Ci} / \mathrm{lb}$ of uranium with a range of 1.23 to $38.76 \mu \mathrm{Ci} / \mathrm{b}$. It should be noted that the data is fairly consistent except for two entries that appear to be calculation errors that are off by a factor of ten. If these two entries ( 38.76 and 20.18 ) are corrected, the average activity becomes 3.56 $\mu \mathrm{Ci} / \mathrm{lb}$ of uranium and the range is 1.23 to $7.04 \mu \mathrm{Ci} / \mathrm{b}$. The average ${ }^{103} \mathrm{Ru}$ activity was $0.29 \mu \mathrm{Ci} / \mathrm{lb}$ and the range was from unmeasurable to $2.79 \mu \mathrm{Ci} / \mathrm{lb}$. For ${ }^{106} \mathrm{RuRh}$, the average activity was $0.44 \mu \mathrm{Ci} / \mathrm{lb}$ of uranium and the range was from unmeasurable to $1.78 \mu \mathrm{Ci} / \mathrm{lb}$.

This material whose analytical results are presented in Table 4-3 and some LEU was shipped by truck and rail to Paducah between 1969 to 1971 . Gamma isotopic data (where available) are presented in this table in addition to the beta and gamma percentages (although a direct correlation can not be drawn without the calculations used to report the beta and gamma percent of aged natural uranium). $\mathrm{UO}_{3}$ produced 


\section{Error}

An error occurred while processing this page. See the system log for more details. 


\section{Error}

An error occurred while processing this page. See the system log for more details. 


\section{Section 4}

DOE/RL-2000-43

\section{Contaminants in Recycled Uranium}

prior approval from the receiving site, very few if any of the lots with unrecovered data exceeded the $10 \mathrm{ppb}$ threshold. Using the LEU data from 1962 through 1967, when only REDOX was processing LEU spent fuel, it is obvious that the REDOX process was well able to produce the UNH within the specification limit. Likewise using the analyses of depleted fuel from 1964 forward, PUREX was also capable of meeting the UNH plutonium specification. Consequently, there is a basis for predicting with assurance that nearly all shipments of $\mathrm{UO}_{3}$ met the plutonium specification.

\subsection{5 $\mathrm{UO}_{3}$ Processed In/After 1984 Restart of PUREX/UO ${ }_{3}$ Plants}

When the PUREX and $\mathrm{UO}_{3}$ operations resumed in 1983, after about 10 years of standdown, the $\mathrm{UO}_{3}$ process support analyses were performed for the three impurities $\mathrm{Pu}_{\mathrm{u}}$, ${ }^{237} \mathrm{~Np}$, and ${ }^{99} \mathrm{Tc}$ and results of these analyses are summarized in Table 4-4. There is less consistency in these data because the measurement systems were inactive for the extended down period from the previous operating period. These data were also generated by two different laboratories on site. Data that has been found is included in Table 4-4 in its entirety. Data recorded in Table 4-5 is a special processing of 177 drums of $\mathrm{UO}_{3}$ that is atypical in the ${ }^{235} \mathrm{U}$ content, but is included for completeness.

\subsection{Neptunium-237}

\subsubsection{Neptunium Concentration in Recycled Uranium}

From the earliest records of uranium production at the $\mathrm{UO}_{3}$ facility, plutonium analyses were required, however the same was not true for neptunium. Production of ${ }^{237} \mathrm{~Np}$ in the Hanford reactors was modeled based on reactor power levels and uranium isotopic data.

\subsubsection{Neptunium-237 Formation}

${ }^{237} \mathrm{~Np}$ was formed in the Hanford production reactors by several possible neutron capture reactions in uranium. In natural uranium, the formation of ${ }^{237} \mathrm{~Np}$ was due to two distinct reactions:

$$
\begin{aligned}
& \text { 1. }{ }^{238} U(n, 2 n) \rightarrow{ }^{237} U(\beta) \rightarrow{ }^{237} \mathrm{~Np} \\
& \text { 2. }{ }^{235} U(n, \gamma) \rightarrow{ }^{236} U(n, \gamma) \rightarrow{ }^{237} U(\beta) \rightarrow{ }^{237} \mathrm{~Np}
\end{aligned}
$$

The generation of ${ }^{236} \mathrm{U}$ in uranium recovered for recycle, materially added to the production of ${ }^{237} \mathrm{~Np}$. The ${ }^{236} \mathrm{U}$ reaction [Nilson 1961, Gestson 1967] was:

$$
\text { 3. }{ }^{236} \mathrm{U}(\mathrm{n}, \gamma) \rightarrow{ }^{237} \mathrm{U}(\beta) \rightarrow{ }^{237} \mathrm{~Np}
$$




\section{Error}

An error occurred while processing this page. See the system log for more details. 


\section{Error}

An error occurred while processing this page. See the system log for more details. 


\section{Section 4 \\ DOE/RL-2000-43 \\ Contaminants in Recycled Uranium}

installation of the Neptunium Recovery System and the Neptunium Purification System. During this cyclical operations mode, the ${ }^{237} \mathrm{~Np}$ concentration in the recovered uranium varied by as much as an order of magnitude. Data presented in Table 4-4 shows this variability with concentrations ranging from 20 to $490 \mathrm{ppb}$.

The ${ }^{237} \mathrm{~Np}$ is separated from the uranium by taking advantage of the relatively large differences in extractability of the two elements. The separation is further enhanced by deliberately saturating the organic solvent with uranium and maintaining a controlled uranium "loss" to the aqueous waste corresponding to about five percent of the input to the system. The organic uranium product stream normally contains less than five parts of plutonium and 100 parts of ${ }^{237} \mathrm{~Np}$ per billion parts of uranium [Matheison 1968].

Analytical measurements of ${ }^{237} \mathrm{~Np}$ in UNH were not routinely performed at the $\mathrm{UO}_{3}$ Plant prior to 1969. Initial analyses were performed on the REDOX and PUREX UNH before shipment to the $\mathrm{UO}_{3}$ for conversion of the $\mathrm{UNH}$ to $\mathrm{UO}_{3}$. Neptunium concentrations in the $\mathrm{UO}_{3}$ powder shipped offsite were not routinely reported until the mid-1980s.

At the Paducah GDP, measurements were made after FY 1957 on monthly composite samples of received $\mathrm{UO}_{3}$ [Smith 1984]. The average concentration of ${ }^{237} \mathrm{~Np}$ in uranium oxide received from Hanford and Savannah River prior to FY 1967 was $240 \mathrm{ppb}$ with a range of 10 to $600 \mathrm{ppb}$. For Hanford material after FY 1967 the average concentration of ${ }^{237} \mathrm{~Np}$ was $120 \mathrm{ppb}$ with a range of 50 to $270 \mathrm{ppb}$. The concentration of ${ }^{237} \mathrm{~Np}$ in recovered low enriched $\mathrm{UO}_{3}$ from Hanford was slightly lower, $50 \mathrm{ppb}$ with a range of 10 to $110 \mathrm{ppb}$.

In 1978, the $\mathrm{UO}_{3}$ chemical flowsheet included a proposed threshold for the neptunium content of incoming UNH to the $\mathrm{UO}_{3}$ Plant. The value is given in grams/gallon and includes a minimum uranium threshold of $2.12 \mathrm{M}$. By calculation, the allowed concentration is 210 parts ${ }^{237} \mathrm{~Np}$ per billion parts uranium. Table 4-7 lists available neptunium concentrations measured in the incoming UNH from PUREX to the receiver tank at $\cup \mathrm{O}_{3}$ Plant in 1969 and 1970. These values agree with the limited data generated and reported at Hanford on $\mathrm{UO}_{3}$ product produced in 1985-1986.

Available data [Smith 1984] suggests that ${ }^{237} \mathrm{~Np}$ concentrations in $\mathrm{UO}_{3}$ remained within the same wide range of values before and after recovery of ${ }^{237} \mathrm{~Np}$ was initiated in 1959 as a co-product. Recovery of the ${ }^{237} \mathrm{~Np}$ occurred within approximately the same time period that the ${ }^{236} \mathrm{U}$ concentration in reactor fuels was enhanced. There was therefore little net effect on the quality of $\mathrm{UO}_{3}$ product.

In addition, analyses were reported from Paducah [Ritter K/ETO-30 (no issue date)] reports average $\mathrm{Np}$ receipts by year. The estimated $\mathrm{Np}$ received at Paducah with $\mathrm{UO}_{3}$ was $18.4 \mathrm{Kg}$ from 1953-1976 (no receipts shown for the years 1965-1968 and 1971). The annual quantity for the years 1953-1956 was estimated rather than measured but from 1956-1976 the quantity was measured. Assuming the quantity of reactor tails received is reported in English tons, the average Np concentration from 1953-1964 is $239 \mathrm{ppb} \pm 1 \mathrm{ppb}$. From 1969-1976 the average Np concentration varies from $11 \mathrm{ppb}$ to 


\section{Error}

An error occurred while processing this page. See the system log for more details. 


\section{Section 4 \\ DOE/RL-2000-43 \\ Contaminants in Recycled Uranium}

ppm implied specification but above the proposed specification of $0.4 \mathrm{ppm}$. Special studies were performed in 1964 in which ${ }^{99} \mathrm{Tc}$ concentrations were found to be $1.74 \mathrm{E} 5$ $\mathrm{d} / \mathrm{m} / \mathrm{gram}$ in PUREX-produced UNH and $2.9 E 4 \mathrm{~d} / \mathrm{m} / \mathrm{gram}$ in REDOX UNH. This calculates to $450 \mathrm{ppb}$ in PUREX and $760 \mathrm{ppb}$ in REDOX UNH [Christy 1964]. The range of ${ }^{99} \mathrm{Tc}$ concentrations in the $\mathrm{UO}_{3}$ in T-Hoppers currently stored at Hanford is between 2.3 to $12.4 \mathrm{ppm}$. In a review of the radiological effects of a $\mathrm{UO}_{3}$ release scenario in the interim safety basis [Goldberg 1998], it was noted that ${ }^{99}$ Tc was not included in the original source term calculations. A concentration of 0.001 weight percent ${ }^{99} \mathrm{TC}$ "supplied by the customer" was ascribed to the stored $\mathrm{UO}_{3}$, consistent with the measured values.

\subsubsection{Paducah Measurements of Technetium-99 in Recycled Uranium from Hanford}

Measurements on "depleted reactor tails" received from Hanford were made at Paducah from 1959 onward [Smith 1984]. The ${ }^{99} \mathrm{Tc}$ data clustered in the range of 4 to $10 \mathrm{ppm}$ on a uranium basis. The ${ }^{99} \mathrm{Tc}$ average was $7 \mathrm{ppm}+1-30 \%$. The few analyses reported for recovered enriched uranium showed an average ${ }^{99} \mathrm{Tc}$ concentration of $16 \mathrm{ppm}$ with a range of 11-27 ppm.

\subsubsection{Fernald Measurements of Technetium-99 in Recycled Uranium from Hanford}

Measurements at Fernald on $\mathrm{UO}_{3}$ lots from Hanford shipped in the 1980 s are consistent with measurements at Hanford and Paducah and are in the range of 3 to $12 \mathrm{ppm}$ [Lower 1995].

\subsection{Uranium Isotopic Composition}

\subsubsection{Natural Uranium}

Natural uranium contains three isotopes ${ }^{238} \mathrm{U},{ }^{234} \mathrm{U}$, and ${ }^{235} \mathrm{U}$ which are present in the weight percentages $99.28 \%, 0.005 \%$ and $0.711 \%$ respectively. Irradiation of uranium in the Hanford reactors resulted in the generation of other uranium isotopes, in particular ${ }^{236} \mathrm{U}$ and ${ }^{232} \mathrm{U}$. The preponderance of the uranium irradiated in the Hanford reactors was natural or normal and the remainder was low enriched uranium (LEU) primarily $0.94 w t \%$ or $1.25 w t \%{ }^{235} \mathrm{U}$. In the context of this document, natural uranium is uranium that has not been irradiated. "Normal" uranium is uranium that has been through a nuclear reactor and recovered from the spent fuel, but contains approximately the same concentration ${ }^{235} \mathrm{U}$ as occurs in nature. This ${ }^{235} \mathrm{U}$ concentration is attained either by blending uranium of different isotopic compositions or by processing in a GDP. Until normal $U$ entered the metal fabrication process, reactor generated fission products would not be present in the fuel fabrication operations. It is believed that "normal" uranium was not received at Hanford for fuel fabrication before the start up of National Lead of Ohio. One year after $\mathrm{UO}_{3}$ shipments from Hanford, the cascade feed at $\mathrm{K}-25$ was composed almost entirely of reactor depleted uranium and therefore the quantities of normal uranium hereinafter will almost surely vary from theoretical isotopic ratio of $0.711 \%{ }^{235} \mathrm{U}$. In a letter [Gifford 1963], a statement is made that "...the next billets to be 


\section{Section 4 \\ Contaminants in Recycled Uranium \\ DOE/RL-2000-43}

received from the feed material sites for NPR fuel elements will be recycle material." These billets were being produced at NLO.

\subsubsection{Normal Uranium}

Normal uranium received for reactor fuel tended to have a low concentration of ${ }^{236} \mathrm{U}$, the ${ }^{235} \mathrm{U}$ concentration was depleted to only around $0.64 \mathrm{wt} \%$ due to the short irradiation time. The ${ }^{236} \mathrm{U}$ isotope and concentration did not build up very rapidly. In the gaseous diffusion process, the ${ }^{235} U$ isotope is partially separated from other $U$ isotopes and blended to produce the desired product isotopic composition.

\subsubsection{Low Enriched Uranium (LEU)}

LEU shipped to Hanford for fabrication into fuel elements was recycled uranium. The recycled uranium contained varying amounts of ${ }^{236} U$ depending on the number of times it had been recycled through the reactors and the exposure time in the reactor. From 1975 through 1979 , the $0.94 \%$ enriched fuel contained ${ }^{236} \mathrm{U}$ mostly in the range of 400 to $500 \mathrm{ppm}$ and the $1.25 \%$ enriched fuel contained between 350 to $400 \mathrm{ppm}$. From 1981 through 1986 the ${ }^{236} U$ was mostly between 500 and $600 \mathrm{ppm}$ for 0.947 enriched fuel and 500 to $800 \mathrm{ppm}$ for $1.25 \%$ enriched fuel [Schmitroth 1995].

\subsubsection{Typical Recovered LEU Uranium Oxide}

The approximate isotopic content of LEU uranium oxide from N-Reactor operations contained $79-154 \mathrm{ppb}^{232} \mathrm{U}, 0.009 \mathrm{wt} \%{ }^{234} \mathrm{U}, 0.88 \mathrm{wt} \%{ }^{235} \mathrm{U}$, and $0.07 \mathrm{wt} \%{ }^{236} \mathrm{U}$ [Millward 1993]. Based on analytical measurements taken between 1972 and 1988, the recovered LEU contained an average of $0.0093 \mathrm{wt} \%{ }^{234} \mathrm{U}$ with a range of 0.008 to 0.011 wt $\%{ }^{234} \mathrm{U}, 0.860 \mathrm{wt} \%{ }^{235} \mathrm{U}$ with a range of 0.748 to $0.957 w t \%{ }^{235} \mathrm{U}$, and $0.071 \mathrm{wt} \%{ }^{236} \mathrm{U}$ with a range of 0.06 to $0.08 w \%{ }^{236} \mathrm{U}$. Table 4-8 presents typical uranium isotopic

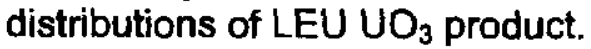

Table 4-9 shows a significant decrease in the ${ }^{236} U$ concentration in depleted uranium in the ${ }^{235} U$ concentration. These three lots are much different in isotopic content and would have been classified as depleted by the GDPs. They are atypical of normal production at Hanford. These three lots represent 177 fifty-five gallon drums that were in the Hanford Site Inventory in 1992 but have since been buried [Salley 1992].

Measurements of the uranium isotopic content of the recovered $\mathrm{UO}_{3}$ produced at the $\mathrm{UO}_{3}$ Plant were made on every lot of material shipped from Hanford. As shown in Table 4-10, the average ${ }^{235} \mathrm{U}$ concentration of the depleted $\mathrm{UO}_{3}$ over the time period of 1952 through 1971 was $0.645 \mathrm{wt} \%$, with a range of 0.62 to $0.68 \mathrm{wt} \%$ based on currently available data. 


\section{Error}

An error occurred while processing this page. See the system log for more details. 


\section{Error}

An error occurred while processing this page. See the system log for more details. 


\section{Error}

An error occurred while processing this page. See the system log for more details. 


\section{Section 4 \\ DOE/RL-2000-43 \\ Contaminants in Recycled Uranium}

Area Spectrographic Laboratory from those included in the methods compendium HW24403 and in reports of the development documents [Daniel 1952]. This method development improved the measurement detection limits of three elements and added six elements that could be detected. It should be noted that the elements of concern were for those non-radioactive constituents that might perturb the nuclear reactivity of the fuel in the reactor, the physical characteristics of the fuel during fabrication operations, or form impurity inclusions in the fuel.

The importance of adhering to these critical specifications is apparent from the extensive "round robin" acceptance test program implemented in May 1951. This program was recommended by the Chief, Metal Branch, Production Division, NYOO, to the Hanford Operations Office (HO) in Richland [Morgan 1951]. These verification tests included selection, by the St. Louis Area Office, of two consecutive production lots (16 heats) each week. Samples from each of the 16 heats were to be sent to New Brunswick Laboratory (NBL), an AEC operated referee laboratory, where complete and precise analysis for all elements of concern was to be performed. The NYOO would collect the sample identification and coordinate shipment of the samples to Hanford where they would be analyzed. Data from both sites (NBL and HO) were to be collected and evaluated by the NYOO. "When sufficient information has been obtained to enable a reliable correlation to be made of the results, chemical analyses, and bare slug tests, an acceptance plan based on functional testing will be devised" [Morgan 1951].

Several letters issued in 1953 have been reviewed (between C. L. Karl and others) that address uranium metal specifications and uniformity of metal composition. Blending of feed materiais (scrap, virgin derbies, and briquettes) into the metal appeared to have value rather than relying on one feed source alone. Although routine sampling and testing protocols were established with assistance from the Hanford Research Division during this period, the Hanford Site accepted the shipper's data for impurities. No records have been found that indicate that routine impurity analyses were performed after the uranium metal was received at Hanford for fabrication as fuel.

\subsubsection{Metallographic Testing}

Extensive micrographic examinations were performed on the uranium metal after fabrication into fuel elements to evaluate heating, rolling, and quenching effects on the grain size and orientation. These metallographic examinations of uranium metal and uranium compounds were performed in the onsite laboratory facilities during the 1950 s [Bach 1950, Hartcorn 1954, Gardner 1956].

\subsubsection{Radiological Contaminants}

Prior to 1952, no uranium oxide was recycled and as a result, $\mathrm{Pu},{ }^{237} \mathrm{~Np},{ }^{99} \mathrm{Tc}$ and fission product contamination were not present in the metal received for fuel fabrication. Between 1952 and 1962, $\mathrm{UO}_{3}$ was processed through the gaseous diffusion plants, which significantly reduced the concentration of $\mathrm{Pu}$ and ${ }^{237} \mathrm{~Np}$ in the enriched product to 


\section{Section 4 \\ DOE/RL-2000-43 \\ Contaminants in Recycled Uranium}

levels reported to be in the parts per trillion. Special test measurements performed at Oak Ridge in 1973 estimated that approximately $85 \%$ of ${ }^{99} \mathrm{Tc}$ received with recycle $\mathrm{UO}_{3}$ is vaporized to the gaseous diffusion cascade. Measurements of the cascade tails suggests that essentially all ${ }^{99} \mathrm{Tc}$ entered the cascade. In 1963, a trap was installed to reduce the ${ }^{99} \mathrm{Tc}$ concentration in the cascade product, and the concentration was reduced in the enriched $U$ fraction from an average of $3.2 \mathrm{ppm}$ to an average of 0.15 ppm. Routine ${ }^{99} \mathrm{Tc}$ measurements were not initiated at Paducah until fiscal year 1972. In fiscal year 1974 the average ${ }^{99} \mathrm{Tc}$ concentration peaked at about six ppm and in 1982 the Paducah GDP product averaged below the detectable level of $0.01 \mathrm{ppm}$ [Smith 1984].

It can be assumed that the ${ }^{99} \mathrm{Tc}$ concentration in $U$ metal received at Hanford between 1953 and 1963 varied proportionally with the content of ${ }^{99} \mathrm{Tc}$ in the recycled $\mathrm{UO}_{3}$. After 1963, the ${ }^{99} \mathrm{Tc}$ content of the $U$ metal would have been lower, but dependent on the effectiveness of the trap installed to remove ${ }^{99} \mathrm{Tc}$ in the GDP cascade.

\subsubsection{Direct Blending}

In 1962, the Fernald Plant proposed blending LEU oxide from Hanford with oxide containing $1.2 \%{ }^{235} \mathrm{U}$ produced from $\mathrm{UF}_{6}$ from Paducah to produce metal for reactor fuel [Keller 1962]. This process was to supercede generating the desired ${ }^{235} \mathrm{U}$ content within the GDPs. This direct blending of $\mathrm{UO}_{3}$ containing the recycled radioisotopes would be expected to increase the radionuclide content of metal returned to Hanford from that produced only from GDP product. Since metal was produced by blending GDP enriched $\mathrm{U}$ and recycled $\mathrm{UO}_{3}$, the radionuclide content of metal could not exceed the radionuclide content in the $\mathrm{UO}_{3}$, since there were no concentration processes in the metal production.

The metal production site, Fernald, maintained a maximum acceptable concentration of $10 \mathrm{ppb}$ for $\mathrm{Pu}$, even though this was not included in the Hanford metal specifications. Concentrations of the $\mathrm{Pu},{ }^{237} \mathrm{~Np}$, and ${ }^{99} \mathrm{Tc}$ were not routinely monitored at Hanford on the received metal. One set of data (Transuranic Analyses for $0.95 \%{ }^{235} \mathrm{U}$ Enriched Ingot Composites) is presented in Table 4-11. These data reflect composites of metal in the Hanford inventory after Hanford reactor operations ceased.

Although these data are incomplete, they indicate that $U$ metal, even when produced by direct blending, remains below the $10 \mathrm{ppb}$ in Pu content and the $\mathrm{Np}$ content is within the range of concentrations documented on the $\mathrm{UO}_{3}$ product. The ${ }^{99} \mathrm{TC}$ concentrations appear to be lower than the accepted concentrations values on the limited $\mathrm{UO}_{3}$ data available.

Metal produced from natural uranium or normal uranium which has been processed through a GDP could be expected to have much lower concentrations of $\mathrm{Pu}$ and ${ }^{237} \mathrm{~Np}$. During the 10 year period 1972 through 1982, Smith [Smith 1984] reports average values of ${ }^{99} \mathrm{Tc}$ in Paducah GDP product from $<0.01$ to $6.1 \mathrm{ppm}$. That document also 


\section{Error}

An error occurred while processing this page. See the system log for more details. 


\section{Section 4 \\ DOE/RL-2000-43 \\ Contaminants in Recycled Uranium}

Hanford did not routinely measure the uranium metal receipts for the amounts of $\mathrm{Pu}$, $\mathrm{Np}$, and Tc constituents. Since Hanford has very little data on the constituent concentration in the uranium metal received for fuel fabrication, it was necessary to estimate concentration ranges of $\mathrm{Pu}, \mathrm{Np}$, and $\mathrm{Tc}$ in the received metal for this historical review, based upon data presented in Table 4-12, the Smith 1984 document, and communication with Fernald personnel during the course of this review. For the purpose of providing a rough estimate of the amount of constituents in the metal received at Hanford for fuel fabrication, the following ranges of constituents were used: Pu range of $0.01-6 \mathrm{ppb}$, with a mean of $3 \mathrm{ppb}$; Np range of $3-10 \mathrm{ppb}$, with a mean of $6.5 \mathrm{ppb}$; Tc range of $0.01-6 \mathrm{ppm}$, with a mean of $3 \mathrm{ppm}$. It is recognized that the selected range will have a significant impact on the amounts of constituents received, however refinement of these ranges would require a more thorough analysis of historical Hanford data in conjunction with an analysis of available analytical data from those sites who shipped uranium to Hanford. The ranges listed above were utilized in Tables $1-12,1-13$, and $1-14$ to estimate potential quantities of constituents in recycled uranium received at Hanford. 


\section{Section 4 \\ DOE/RL-2000-43 \\ Contaminants in Recycled Uranium}

\section{References}

ARH-85 1970

ARH-85, Analytical Methods, 1970

ARH-896 1969

ARH-896, Product Specifications Uranium Trioxide Depleted Normal (72), January 3, 1969

ARH-1396 1969

ARH-1396, Product Specifications Uranium Trioxide Depleted Normal (72) For Off-Site Shipment, October 10, 1969

ARH-1396 Rev 1969a

ARH-1396, Rev, Product Specifications Uranium Trioxide Depleted Normal (72) For Off-Site Shipment, May 22, 1970

ARH-1493 1970

ARH-1493, Specification for PUREX UNH Product, January 15, 1970

ARH-1763 1970

ARH-1763, Product Specification Uranium Trioxide (Enriched to Less Than 1\%

$\left.{ }^{235} U\right)$ for Off-Site Shipment, July 20,1970

Bach 1950

HW-15791 by J. H. Bach et al., Interim Report, Metallurgical Analysis of Induction Heat Treated Uranium, January 26, 1950

Christy 1953

HAN-61650, Weekly Report (Ending 4/5/53) from J. T. Christy to Donald G.

Sturges, April 7, 1953

Christy 1954

Monthly Report by J. T. Christy to File, 200 Area Monthly Report for December 1953, January 14, 1954

Christy 1954a

Monthly Report, HAN-62359-DEL, by J. T. Christy to File, 200 Area Monthly Report for January 1954, February 4, 1954

Christy 1964

Letter (OC:EAA), J. T. Christy, RL to T. R. Workinger, USAEC-HQ, UNH Product Specifications, November 12, 1964 


\section{Contaminants in Recycled Uranium}

Corlew 1971

AEC-2202 from R. P. Corlew to O. J. Elgert, Product Specifications, Hanford Uranium Trioxide, ARH-2051, Contract AT(45-1)-2130, September 3, 1971

Daniel 1952

HW-26445 by J. L. Daniel, Current Status of the Spectrographic Analysis of Uranium Billets, December 2, 1952

Gamertsfelder 1948

HW-10515 by C. C. Gamertsfelder to C. N. Gross, Plutonium and Fission

Product Contamination in Reclaimed Uranium July 19, 1948

Gamertsfelder 1951

Letter HW-20628 (HAN-36668) from C. C. Gamertsfelder to R. H. Beaton, Recent Changes Affecting the Specifications Concerming Activity Levels in Reclaimed Uranium, March 27, 1951

Gardner 1956

HW-43428:RD (56759) by H.R. Gardner and J. W. Riches, The Effect of Cooling Rate on the Nucleation and Growth of Beta-Uranium Hydride in Metallic Uranium, September 14, 1956

Gestson 1967

Letter HAN-98008-DEL from D. K. Gestson, Richland Neptunium Production, June 21, 1967

Gifford 1962

Letter HW-81837, A. T. Gifford to C. L. Karl, Shipment Of Enriched $\mathrm{UO}_{3}$ (Your Memo, 4-24 and 4-19-62 0:OJT \& Memo, 3-20-62, Sapirie To Kar OF:PJM), May 11,1962

Gifford 1963

Letter CO-541, A. T. Gifford to A. B. Greninger, Recycle of Normal Uranium, October 17, 1963

Gill 1963

HW-76155 by S. M. Gill, Chemical Specifications for Uranium Metal Billets for NPR Fuel Elements; by N-Reactor Department; January 10, 1963

Goldberg 1998

Letter HNF-2105, Rev 1, H. J. Goldberg, Calculational Note for the Radiological

Effects of a $\mathrm{UO}_{3}$ Release from the T-Hopper Storage Pad, January 27, 1998

Greenwalt 1947

RHTG-46,879, Meeting with Dr. C. W. Greenwalt on the Use of K-25 in

Connection with Hanford Operations, April 21, 1947 


\section{Contaminants in Recycled Uranium}

\section{Greninger 1950}

Letter HW-18871 (HAN-33844), A. B. Greninger to D. F. Shaw, Request for Recovered Uranium Specifications, September 18, 1950

Gustafson 1957

HW-53366, L. D. Gustafson, Definitive Scope of a Facility for E-Metal Product Segregation at the $\mathrm{UO}_{3}$ Plant, Project CG-767, November 4, 1957

Harmon 1957

Letter RWA 39700 from K. M. Harmon to J. W. Jordan, Improved Procedure for the Analysis of Plutonium, April 9, 1957

Hartcorn 1954

HW-33409 by L. A. Hartcorn, Trip Report on Meeting of Uranium Cooperative Metallographic Group, September 15 \& 16, at Battelle Memorial Institute;

October 13, 1954

HW-18700 1951

HW-18700 (HAN-40653), Redox Technical Manual, July 10, 1951

$H W-191401951$

HW-19140, Uranium Recovery Technical Manual, November 10, 1951

HW-25744 1952

HW-25744, PUREX Facility Project CA-513-II-Design Criteria, October 29, 1952

HW-27314 1953

HW-27314, Determination of Plutonium in UO3, March 5, 1953

HW-30654 Rev 1959

HW-30654, Rev, Product Specifications Uranium Trioxide (Depleted) for Off-Site Shipment, January 5, 1959

HW-35938 1955

$\mathrm{HW}-35938, \mathrm{RD}, \mathrm{UO}_{3}$ Product Specifications, March 28, 1955

HW-48835-DEL 1957

HW-48835-DEL (HAN-65144), Chemical Processing Department Monthly Report for January 1957, March 21, 1957

HW-50584-DEL 1957

HW-50584-DEL, Chemical Processing Department; PUREX Operation, May 1957 


\section{Section 4 \\ DOE/RL-2000-43 \\ Contaminants in Recycled Uranium}

$H W-591361959$

HW-59136, Product Specifications Uranium Trioxide (Depleted E Metal) for OffSite Shipment, January 16, 1959

HW-65402

Letter HW-65402 from R. A. Schneider, Uranium Trioxide Product Specification Analyses, February 9, 1960

HW-76155 1963

HW-76155, Chemical Specifications for Uranium Metal Billets for NPR Fuel Elements, January 10, 1963

HW-79219 1964

HW-79219, Product Specifications Uranium Trioxide (Depleted E Metal) for OffSite Shipment, February 5 1964, 1964

HW-79219 Rev 1964

HW-79215, Rev. Hanford Uranium Trioxide (from depleted E Metal) for Off-Site Shipment, July 6, 1964

HW-79219, Rev. 21965

HW-79219, Rev. 2, Product Specifications Uranium Trioxide (Depleted E Metal) for Off-Site Shipment, 1965

ISO-528 1967

ISO-528, Product Specifications Uranium Trioxide (Enriched to Less Than 1\%

${ }^{235} U$ ) for Off-Site Shipment, February 27, 1967

ISO-877 1964-1967

ISO-877, Drum Weight, Storage and Analysis, May 1964 through June 1967

Judson 1962

Letter (DDTS-Gen-1329) from Judson to J. T. Christy, Proposed Specification for Production Reactor Returns $\mathrm{UO}_{3}$ for Gaseous Diffusion Plant Feed, June 5, 1962

Keller 1962

Letter from C.A. Keller to J.P. Murray, KYD 1609, Slightly Enriched Uranium Metal Production Studies, January 19, 1962 and Slightly Enriched Uranium, April 20, 1962

Knights 1966

1SO-253 from Lee M. Knights to Winston Burkhardt, National Lead Company of Ohio, $\mathrm{UO}_{3}$ Fission Product Specifications, April 28, 1966 


\section{Contaminants in Recycled Uranium}

Lower 1995

Reference Fax from C. W Lower to S. A. Colby, Estimated Pu GMS \& KGS to

${ }^{99} \mathrm{TC}$ in Hanford's $\mathrm{UO}_{3}{ }^{99} \mathrm{TC}$ Co-Extraction Values from Fernald, Ohio), April 7, 1995

Madeen 1964

ISO-1092, M. L. Madeen, Uranium Oxide Subsection Car Shipment Summary Data Lot No. E-122 thru E-223, December 29, 1964

Matheison 1968

Letter ARH-214, W. E. Matheison and G. A. Nicholson, PUREX Chemical

Flowsheet Processing of Aluminum Clad Uranium Fuels, February 15, 1968

McClusky 1982

Letter from J. K. McClusky to G. J. Miskho, Uranium Product Specifications,

(Contract DE-AC06-77RL01030) August 2, 1982

McIntosh 1952

HW-24403, Hanford Works Analytical Manual for the Plutonium Separation and Metal Fabrication Process, August 1952

Mclntosh 1969

ARH-1378, J. D. Mcintosh to E. L. Kelley, Neptunium Analytical Data For C1

Tank UNH Transfers June 1 Through July 31, 1969, August 4, 1969

Mclntosh 1969a

ARH-1370, J. D. McIntosh to E. L. Kelley, Neptunium Analytical Data For C1

Tank UNH Transfers August 1 Through August 31, 1969, September 2, 1969

Mclntosh 1969b

ARH-1452, J. D. Mclntosh to E. L. Kelley, Neptunium Analytical Data For C1

Tank UNH Transfers October 1 Through October 31, 1969, November 5, 1969

Mclntosh 1970

ARH-1554, J. D. Mclntosh to E. L. Kelley, Neptunium Analytical Data For C1

Tank UNH Transfers December 1 Through December 31, 1969, January 7, 1970

McIntosh 1970a

ARH-1586, J. D. McIntosh, Neptunium Analytical Data For C1 Tank UNH

Transfers January 1 Through January 31, 1970, February 5, 1970

Mclntosh 1970b

ARH-1586-2, J. D. Mclntosh, Neptunium Analytical Data For C1 Tank UNH

Transfers February 1 Through February 28, 1970, March 12, 1970 


\section{Section 4 \\ DOE/RL-2000-43 \\ Contaminants in Recycled Uranium}

Mclntosh 1970c

ARH-1586-3, J. D. McIntosh, Neptunium Analytical Data For C1 Tank UNH

Transfers April 1 Through May 2, 1970, June 15, 1970

Millward 1993

Memorandum, G. Millward to G. Hulse, Physical Data of $\mathrm{UO}_{3}$ Powder Stored at the Plant, February 1, 1993

Miskho 1982

Letter from G. J. Miskho to General Manager RHO, Uranium Product

Specifications, August 11, 1982

Morgan 1951

Letter from J. P. Morgan to R. E. L. Stanford, Correlation Tests for Uranium Acceptance, May 11, 1951

Murphy 1971

ARH-2133, J. G. Murphy, Uranium Oxide - Operation SS Materials General Ledger - FY 1972, July 1. 1971

Nilson 1961

Letter HW-72074 from R. Nilson, Effect of Special Uranium Fuel on Hanford

Reactors, December 21, 1961

OSD-U-185-0001 1983

OSD-U-185-0001, Rev A-0, Uranium Oxide Plant Operating Specifications, April 18, 1983

OSD-U-185-0001 1986

OSD-U-185-0001, Rev B-8, Uranium Oxide Plant Operating Specifications, July 11,1986

OSD-U-185-0001 1992

OSD-U-185-0001, Uranium Oxide Plant Operating Specifications, 1992

Richards 1952

Letter HW-23754 (HAN-43666), R. B. Richards to Dr. F. Hurd, UO 3 Trial

Production Lots 007, 008, and 009, March 11, 1952

Richards 1952a

Letter HW-23848 (HAN-43786), R. B. Richards to Dr. F Hurd, $\mathrm{UO}_{3}$ Trial

Production Lots 010, 011, 012, and 013, March 19, 1952

Richards $1952 b$

Letter HW-24655 (HAN-45087), R. B. Richards to Dr. F. Hurd, Shipment of $\cup_{3}$ Lots 036 thru 045, June 3, 1952 


\section{Section 4 \\ DOE/RL-2000-43 \\ Contaminants in Recycled Uranium}

Richards 1952c

Letter HW-26310 (HAN-47864), R. B. Richards to Dr. F. Hurd, Shipment of

Special $\mathrm{UO}_{3}$ Lots, November 20, 1952

Richards 1952d

Letter HW-26378, R. B. Richards to Dr. G. R. Fernelius, Data on $\mathrm{UO}_{3}$ Shipments, November 25, 1952

Richards $1952 \mathrm{e}$

Letter HW-24528 (HAN-44743), R. B. Richards to Dr. F. W. Hurd, Shipment of $\mathrm{UO}_{3}$ Test Lots 005T, 006T, and 026 thru 035, May 20, 1952

Richards $1952 f$

Letter HW-24801 (HAN-45270), R. B. Richards to Dr. F. W. Hurd, Shipment of $\mathrm{UO}_{3}$ Lots 046 thru 057, June 20, 1952

Richards $1952 \mathrm{~g}$

Letter HW-25555 (HAN-46470), R. B. Richards to Dr. G. R. Fernelius, Technical Data on Hanford $\mathrm{UO}_{3}$ Lots 77 thru 88, September 5, 1952

Ritter (Not Dated)

KJETO-30, R. L. Ritter, et al, Neptunium Experience at PGDP, document not dated

Roberts 1971

Letter BNWL-B-49 from F. P. Roberts, Summary of Research on Tc, Rh, and Pd by Battelle-Northwest, January 11, 1971

Rochon 1972

Letter ARH-2133 (Mar) by D. J. Rochon, CPD Analytical Bias Summary for Nuclear Materials Accounting, March 1972

Salley 1992

Letter 9253330 from R. L. Salley to M. Lundberg, Depleted $\mathrm{UO}_{3}$ Inventory, May 5, 1992

Sapirie 1951 (Classified)

Letter from S. R. Sapirie to D. F. Shaw, Specification for Recovered ${\cup \mathrm{O}_{3}}$ January 25, 1951

Sapirie 1953 (Classified)

Letter from S. P. Sapirie to R. W. Cook, Review and Revision of Specifications for Hanford Produced $\cup_{3}$, May 1, 1953 


\section{Section 4 \\ Contaminants in Recycled Uranium

Schmittroh 1995

WHC-SD-WM-RPT-166, Rev. 0, F. A. Schmittroh, T. H. De Lorenzo, D. W.

Wootan and D.Y. Garbrick, Inventories for Low-Level Tank Waste, June 1995

Schneller 1968

Letter from M. R. Schneller to H. E. Parker, Neptunium Recovery Factor-PUREX

Separations Plant FY68, September 26, 1968

Shaw 1952

Letter HAN-47029 from D. F Shaw to W. E. Johnson, REDOX Uranium

Specifications, October 15, 1952

Sloat 1964

HW-82285 by R. J. Sloat, Product Specifications, Uranium Trioxide (Depleted)

for On-Site Storage, July 6, 1964

Smith 1953

HW-27990 by R. E. Smith, Summary of Oak Ridge Discussions Relative to

Hanford Uranium Trioxide Specifications, May 7, 1953

Smith 1984

Report KY/L-1239, R. F. Smith, Historical Impact of Reactor Tails on the

Paducah Cascade, Paducah Gaseous Diffusion Plant, March 1984

Watrous 1997

HNF-SD-WM-TI-794, Rev. 0, R.A. Watrous and D. W. Wootan, Activity of Fuel Batches Processed Through Hanford Separations Plants 1944 Through 1989, July 29, 1997

WHC-SP-0056 1987

WHC-SP-0056 (formerly UNI-M-22), Specification for Uranium-Metal Billets for N Reactor Fuel Elements, August 1987 


\section{Error}

An error occurred while processing this page. See the system log for more details. 


\section{Section 5 \\ DOE/RL-2000-43 \\ Current Inventory of Recycled Uranium}

(COEI) descriptors. As the table indicates the recycled uranium is stored at the 300 Area Fuel Fabrication complex and the $\mathrm{UO}_{3}$ Plant.

\subsection{Pacific Northwest National Laboratory Current Inventory of Recycled Uranium}

Battelle Memorial Institute (BMI), assumed management of the Pacific Northwest National Laboratory (PNL) research and development activities for Hanford in 1965. PNL later received national recognition and became the Pacific Northwest National Laboratory (PNNL). One of the significant projects of the 1960 s was PNL's design of the Fast Flux Test Facility (FFTF) in support of the Atomic Energy Commission's commercial nuclear power program. This project utilized uranium in the fabrication of mixed oxide fuel (MOX) containing uranium and fuel grade plutonium. The role of the PNNL in support of Defense missions has been significantly reduced from the 1960s. The narrative below provides a brief overview of the main PNNL project utilizing recycled uranium. The approximate 6.4 metric ton PNNL inventory is shown in Appendix D, Table 5.1.2. The receipts and shipments relating PNNL recycled uranium transactions with the three Major Tier 1 sites are shown in Section 3.2 and 3.3 tables.

The Kinetic Energy Projectile Project (KEPP) project is an ongoing project that started in 1974. This was an extension of work for others through Picatinny Arsenal, which supported other munitions prior to the depleted uranium (DU) phase. In 1974, the uranium used for PNNL research activities was DOE material. This feodstock started as green salt from Paducah, which was delivered to National Lead of Ohio (NLO/Fernald) for processing into the ingot stage. The ingots were then sent to Rocky Flats (RFETS) for alloying with titanium and processed into billet form. The billets were then shipped to PNNL for final processing and machining. Essentially all of the uranium involved in the project was and is DU alloyed with a small amount of titanium. This alloy is used because of its density and mechanical properties that provide strength to survive extreme launch conditions. After the research penetrators showed great promise for defeating current armor threats, production facilities had to be established. This led to facilities such as National Laboratory of Albany and NLO to produce production quantities. Continuing success led to the private sector getting involved through systems contractors such as Honeywell, etc. The initial private uranium producers were Nuclear Metals Inc and Aerojet Ordnance Company. Both private companies are involved in recycling of the penetrator alloy. The March 31, 1999 DU inventory at $306 \mathrm{~W}$ building is approximately 4.9 metric tons with a storage limit in the 300 Area limited to 10 MTU. (In the past this limit has been 30 MTU.)

The receipts and shipments of normal, and enriched uranium into and out of PNNL were primarily for experimental fuel development of MOX fuel in support of the Liquid Metal Fast Breeder Reactor (Fast Flux Test Facility (FFTF)) program. The uranium itself was mainly supplied to Nuclear Energy (NE), via the DOE allotment process, from Defense Programs recycled production channels. As such, the entire PNNL uranium inventory, including DU, is considered in-scope. 


\section{Section 6 \\ Discussion and Conclusions \\ DOE/RL-2000-43}

\subsection{Discussion and Conclusions}

Based on the review of the documents located, the RL Team concludes the following:

\subsection{Recycled Uranium Shipped and Received}

\subsubsection{Operating History}

Uranium recovery from irradiated fuel began at Hanford in 1952 using the REDOX process located in the 202-S Plant. Shortly thereafter, the U-Plant also began supplying uranyl nitrate hexahydrate (UNH) containing uranium recovered from the waste tanks. In 1956, the PUREX Plant came on line and also recovered uranium, as UNH, from irradiated fuel for calcination and recycle. The UNH product was piped from REDOX Plant and U-Plant and trucked from PUREX to the $\mathrm{UO}_{3}$ Plant. At the $\mathrm{UO}_{3}$ Plant the $\mathrm{UNH}$ was converted by calcination to $\mathrm{UO}_{3}$ powder. The powder was sampled and packaged into either drums or specially designed "T-Hoppers" for shipment.

\subsubsection{Recycled Uranium Specifications}

Hanford received recycled uranium metal billets for reactor fuel rod manufacture starting about mid-1952; however, the recycled uranium used to produce these billets had been processed through the gaseous diffusion plants (GDPs) and was reported to contain approximately 30 parts plutonium per trillion parts uranium. After about 1963, as a result of a process change at Fernald involving blending, their metal billet plutonium specification rose to a not to exceed 10 parts plutonium per billion parts of uranium level. Hanford did not routinely perform a radionuclide analysis on the incoming billets, but relied on the shipper.

\subsubsection{Recycled Uranium Shipments and Receipts}

In all, Hanford shipped approximately 109,792 metric tons (MTU) of recovered (recycled) uranium. Of this, 74,491 MTU were shipped (as $\mathrm{UO}_{3}$ ) to the Paducah GDP, 4,404 MTU were shipped to the K-25 GDP and Y-12 Plant, and 25,251 MTU were shipped to Fernald. Metal turnings and scrap produced during fuel rod manufacture were returned to Fernald for recovery into new fuel rod billets. Lesser quantities of recycled uranium were sent to Harshaw Chemical Co. and Mallinckrodt Chemical Works for further refining to remove non-radioactive contaminants. Additional recovered uranium, in minor quantities, was sent to over 100 other destinations to support various DOE missions.

Hanford received and processed approximately 109,144 MT of recycled uranium, with approximately $85 \%$ (92,767 MT) being received from Paducah, Fernald and Oak Ridge. Uranium metal received for fuel fabrication before 1952 was made from natural uranium and is out of scope for this report. With the exception of the material remaining at Hanford, the majority of this material was used for fuel, irradiated in the Hanford 


\section{Section 6 \\ DOE/RL-2000-43 Discussion and Conclusions}

reactors, processed in the separations facilities to recover the plutonium and uranium, and the recovered uranium shipped offsite for use or recycle.

\subsubsection{Current Inventory}

Excluding uranium in solid and liquid waste and releases to the cribs, Hanford currently has approximately.4,006 MTU remaining in various forms including metal received for fabricating fuel, unused fuel, irradiated fuel, unirradiated uranium in mixed oxide fuel at the Fast Flux Test Facility and at the Plutonium Finishing Plant, and recovered uranium as $\mathrm{UO}_{3}$ stored in $\mathrm{T}$-Hoppers awaiting final disposition. The recycled uranium in the irradiated fuel $(2,137 \mathrm{MTU})$ is outside the scope of this study.

958 MTU is mixed with fission products and other chemical wastes in high-level waste storage tanks. $\sim 1,054 \mathrm{MTU}$ is buried solid waste, and $\sim 162 \mathrm{MTU}$ was released to the environment through various cribs, ponds, and ditches.

\subsubsection{Shipper/Receiver Differences}

During and after the May 17, 2000 Uranium Mass Balance Project workshop at Oak Ridge, TN, the RL team worked with other site representatives to compare shipping and receiving quantities of recycled uranium. For the Hanford shipments to Paducah, the percent variance between 1952 through March 30, 1999, was approximately $0.02 \%$ of the approximate $74,491 \mathrm{MT}$ total. Percentage variances for shipments from Hanford to Fernald were approximately $0.7 \%$. Percentage variances for Hanford receipts from Fernald were approximately $0.2 \%$. Comparison between Hanford and Oak Ridge for shipments and receipts to the Oak Ridge aggregate of K-25 and the Y-12 will not be completed until the $\mathrm{Y}-12$ transactions are prepared. The percentage variance for Hanford shipments to Savannah River (DuPont) were approximately $0.3 \%$.

\subsubsection{Inventory Difference}

Hanford uranium shipments, receipts, and material in storage, and waste records indicate a small material difference of about $0.5 \mathrm{wt} \%$ of the uranium received remains unexplained based upon the reviewed records. The calculation of this material difference includes an estimate that $\sim 140 \mathrm{MTU}$ was consumed during reactor operations and the generation of plutonium. The material difference resides largely in the uncertainties associated with quantities of uranium in liquid and solid wastes in the waste tanks, and in the estimate of uranium fissioned and transmuted to operate the reactors and generate plutonium. 


\section{Section 6 Discussion and Conclusions \\ DOE/RL-2000-43}

\subsection{Typical Impurities and isotopic Composition}

\subsubsection{Plutonium}

Hanford participated in development of the recycled $\mathrm{UO}_{3}$ product specification starting in about 1950. By 1952, before commencement of uranium recovery operations, a preliminary specification requirement of less than 10 parts $\mathrm{Pu}$ per billion parts uranium was established. This limit was firmly established in 1953 and remained in place for the entire $\mathrm{UO}_{3}$ production period. The bulk of Hanford's shipments of recycled $\mathrm{UO}_{3}$ powder to the GDPs contained only trace amounts $(<10 \mathrm{ppb})$ of Pu. Based on the limited amount of historical documentation located, it still appears the preponderance of Hanford recycled $\mathrm{UO}_{3}$ powder contained $\leq 5 \mathrm{ppb}$. Six shipments were identified in Hanford documents as containing about $12,13,16,19,22$, and $30 \mathrm{ppb}$ average, respectively; however, records indicate receiver sites were typically notified of these out-of-specification conditions and accepted these materials prior to their shipment from Hanford. These shipments represented $-193 \mathrm{MTU}$ containing $\sim 3.4 \mathrm{~g}$ Pu. Information from Oak Ridge indicates that their site received four shipments from Hanford for which their analyses indicated Pu concentrations of 13,17, 17, and $28 \mathrm{ppb}$. These shipments are in addition to the shipment containing $22 \mathrm{ppb}$ mentioned above. Hanford analyses on these four shipments indicate the Pu concentrations were all $<10 \mathrm{ppb}$. Available documentation indicates that Hanford and Oak Ridge both acknowledged this discrepancy. This is further discussed in Section 6.4.3. These four shipments totaled $\sim 123 \mathrm{MTU}$ and contained $\sim 2.3 \mathrm{gPu}$. The limited analytical data located is insufficient for $\mathrm{RL}$ to determine the total quantity of plutonium shipped to the various GDPs; however, it appears that approximately $\mathbf{1 1 0}$ to $\mathbf{5 5 0}$ grams of plutonium were shipped with the $109,792 \mathrm{MTU}$, based upon an assumed average plutonium concentration range of one to five $\mathrm{ppb}$. The mean of this range of $\mathrm{Pu}$ concentrations is 330 grams of $\mathrm{Pu}$.

Hanford did not routinely analyze the incoming uranium metal for radioactive constituents, but relied on the shipper's guidelines for the metal product. It appears, based on the information available, that metal received prior to 1963 had been processed through the Paducah GDP and contained on the order of 10 parts or less plutonium per trillion parts uranium. Metal that was received in 1963 and beyond had been directly blended at Fernald and contained $<10 \mathrm{ppb} \mathrm{Pu}$.

\subsubsection{Neptunium and Technetium}

Hanford did not routinely analyze the $\mathrm{UO}_{3}$ product for neptunium or technetium before 1980 , as there were no related product specification requirements. For Hanford recycled $\mathrm{UO}_{3}$ powder, technetium and neptunium limits were not considered required. Until 1967. Hanford analyzed the recycled $\mathrm{UO}_{3}$ powder for total beta and gamma activity and conformed to the required specification levels of less than $100 \%$ of the beta activity of aged natural uranium and less than $300 \%$ of the gamma activity of aged natural uranium, respectively. In 1967, the beta and gamma measurements were dropped in favor of specific isotopic measurements $\left({ }^{95} \mathrm{Zr} / \mathrm{Nb},{ }^{103} \mathrm{Ru}\right.$, and $\left.{ }^{106} \mathrm{RuRh}\right)$ as 


\section{Section 6 Discussion and Conclusions

discussed in Section 4.3.2. Information provided by Fernald indicates that metal produced from recycled uranium contained ${ }^{99} \mathrm{Tc}$ ranging from $3-12 \mathrm{ppm}$ and ${ }^{237} \mathrm{~Np}$ with an upper bound of $500 \mathrm{ppb}$.

No uranium processing activities at Hanford have been identified that would increase the plutonium component of the recycled uranium after it was separated in the reprocessing plants. In the course of this study, no documentation has been found that reports concentration of constituents in areas accessed during maintenance activities. However, time has not been available to perform a detailed assessment of all uranium processing steps utilized at Hanford to assure that impurities in uranium were never concentrated. The $\mathrm{UO}_{3}$ Plant calciners, which converted the recovered $\mathrm{UNH}$ to $\mathrm{UO}_{3}$ powder did operate at elevated temperatures in an oxidizing environment. It is reasonable to believe that any volatile fission products which may have been present in the recycled uranium could have been released through the off-gas system, plated out on equipment surfaces, accumulated in off-gas scrubber solutions, or have been released to the environment. Documentation has been found to indicate that some of the ruthenium volatilized during UNH calcination, with decontamination factors (DF) ranging from $<1$ to 6 (see Appendix G, Section G.5). No operations in the fuel fabrication processes have been identified which would be expected to have further concentrated the constituents, other than the burning of metal fines to uranium trioxide.

\subsection{Activity Assessment and Occupational Potential Exposure}

The DOE-HQ mass balance project is a Department-wide effort to review each site that was involved with recycled uranium to provide an estimate of specific activities involving recycled uranium, and to develop a preliminary estimate of the approximate number of employees whose work subjected them to potential exposure from the constituents in the recycled uranium. The estimate of occupational potential exposure (OPE) is based on guidance developed during a workshop meeting held at the ORNL in May, 2000. This OPE criteria is listed at the bottom of Table 6-1. The recycled uranium activity and OPE assessment for Hanford is provided below.

The operations, maintenance and waste handling operations of the facilities described in Section 2 contributed to some personnel exposure and environmental releases. However, distinguishing any such personnel exposures to trace quantities of transuranics and fission products in recycled uranium from those associated with other Hanford operations which involved the handling and processing of significant quantities of irradiated fuel, high-level waste, and plutonium, would be very difficult. Assessment of personnel uranium exposure is further complicated by the practice of transferring personnel between facilities to meet ongoing work needs. The facilities at Hanford that had the highest potential for uranium exposure were the fuel fabrication facilities where large amounts of uranium metal and scrap were handled, and the $\mathrm{UO}_{3}$ Plant, which handled large quantities of dry $\mathrm{UO}_{3}$ powder. Other facilities involved with the handling of separated recycled uranium (as $\mathrm{UNH}$ ) and of any waste from recycled uranium processing also had the potential for contributing to some exposure. 


\section{Error}

An error occurred while processing this page. See the system log for more details. 


\section{Error}

An error occurred while processing this page. See the system log for more details. 


\section{Section 6 \\ DOE/RL-2000-43 \\ Discussion and Conclusions}

Time was insufficient to complete an in-depth activity and potential worker exposure assessment. However, a cursory estimate, utilizing assumptions of direct labor and maintenance staffing at the facilities of interest, was completed to provide an overview of recycled uranium work activities in these facilities and an OPE estimate.

The facilities that were identified to have involved the handling of recycled uranium included: (1) the 313-314 Building complex in the 300 Area which was primarily involved with the fabrication of aluminum-clad reactor fuels, (2) the 333 Building complex in the 300 Area which was involved in the fabrication of zirconium-clad reactor fuels, (3) the REDOX Chemical Separations Plant in the 200 West area where reactor fuels were dissolved for plutonium and uranium recovery (including transfer of the $\mathrm{UNH}$ to the $\mathrm{UO}_{3}$ Plant for calcination), (4) the U-Plant in the 200 West area where pre-1952 tank wastes were processed for uranium recovery, (5) the $\mathrm{UO}_{3}$ Plant in the 200 West area where uranium recovered as UNH was received, concentrated, calcined, and packaged for shipment and recycle, (6) the PUREX Plant in the 200 East area where irradiated fuels were dissolved for separation of plutonium and uranium (with the UNH being shipped by truck to the $\mathrm{UO}_{3}$ Plant for calcination), and (7) the 183- $\mathrm{H}$ solar basin in the $100-\mathrm{H}$ area that was used for a ten-year interval to evaporate dilute liquid wastes generated at the 300 area fuel fabrication plants.

The interval of operation for each of these facilities is illustrated in Figure 6-1, along with an estimate of probable direct labor staffing support. The staffing calculations were based upon estimates of the number of operators and craft personnel per shift, the number of shifts per week, and an estimate of the average length of time that an employee would work at the facility. This information was used to estimate the total number of people who worked at each facility during its operating lifetime. These staffing totals, by facility, were then used as inputs to Table 6-1 to allow an estimate of the number of people likely to have been exposed to various levels of constituents of recycled uranium. Below is a typical staffing estimate calculation for Figure 6-1:

As an example, consider the 313-314 Building complex which had a $P Q$ operations shift schedule and operated for 25 Years. It is estimated that the following operational information would apply to these facilities:

25 Operators/Shift; 10 Crafts/Shift; and an average Employee Time at Facility of -5 years.

Thus, the number of workers on any given shift that may have been in contact with uranium would be 25 fuel fabrication operators plus 10 maintenance craftsmen for a total of 35 . The "PQ" shift arrangement provided for Monday through Friday coverage of the 8AM to 4PM shift and the 4PM to Midnight shift. If the average worker remained at the job for 5 years then,

( 35 workers/shift) $\times(2$ shifts/day $) \times \frac{25 \text { years facility operation }}{5 \text { years at that facility for a typical worker }}$

$=350$ involved employees at that facility over the lifetime of the facility. 


\section{Error}

An error occurred while processing this page. See the system log for more details. 


\section{Section 6 Discussion and Conclusions

shown in Figure 6-1 to arrive at an estimate of the number of personnel who could have had some level of OPE. All of this information is presented in Table 6-1.

The data summarized in Table 6-1 indicates that a total of about 1,126 people are estimated to have worked in areas directly involving recycle uranium during the operational time of the Hanford Site. Using the given OPE assessment criteria, of the $-1,126$ staff personnel, it is estimated that -670 had "no significant exposure potential" while $\mathbf{4 5 6}$ had "moderate occupational exposure potential." It should be noted that this is only a rough estimate based upon limited data, engineering judgements and assumptions, and the application of some broad general OPE criteria which were established specifically for the mass balance project.

Since 1946, Hanford has had formal personnel monitoring programs in place which are designed to identify uptake of radioactive materials by personnel. Any employee who was assigned to a work location where contact with radioactive materials was judged to be possible was required to participate in the bioassay program. Each decision/request for bioassay evaluation on an individual or group of people represented a rather conservative contemporary judgement for protection of employees from radioactivity. Not all of those who were placed on the uranium bioassay program were expected to have direct contact with the radioactive material. It is therefore reasonable to suggest that the number of employees sampled on the uranium-specific bioassay program represents a conservative and upper bounding estimate of the number of individual workers potentially exposed to recycled uranium at Hanford.

Site records show that more than 50,000 employees were hired at Hanford over the operating period of the installation. In contrast, since the sampling program was established in 1946, only $\sim 4,200$ Hanford employees have been subjected to uraniumspecific bioassay sampling and evaluation. A preliminary review of the records of that program was conducted. Those records (which included estimates for the constituents of interest) identified no significant doses associated with the recycled uranium for any of the Hanford Uranium Bioassay program participants. Due to the eligibility criteria applied, it is considered highly improbable that any substantial number of un-assayed site employees could have had any significant uranium uptake. For this study on recycled uranium traffic at Hanford, the very brief and somewhat empirical staffing and timing models for the facilities that handled large quantities of recycled uranium suggests that $\sim 1,126$ of the 4,200 employees did in fact perform substantial duty in the facilities that included opportunities for rather close contact with recycled uranium. Of that number, perhaps $\sim 456$ individuals had "moderate occupation exposure potential" as assessed and defined in the criteria that was given.

For a more specific analysis of worker contact with recycled uranium at Hanford than that contained in this report, an examination of Hanford's uranium bioassay records, a more detailed review of plant-by-plant operations, abnormal events, maintenance, and facility upgrades, overlaid by staffing models and production intervals would be required. Corroboration of such an analysis by examination of various records and 


\section{Section 6 \\ DOE/RL-2000-43 \\ Discussion and Conclusions}

interviews of retired employees would be necessary, in order to validate the OPE estimates.

\subsection{Data Validation}

\subsubsection{Recycled Uranium Shipped from Hanford}

External validation of Hanford shipment and receipt quantities of recycled uranium were performed, to the extent possible, during and after the May 17, 2000 workshop previously described in Section 6.1.5. For those sites identified as Major Tier 1 sites (Paducah, Fermald, and Oak Ridge) in which comparison was possible, the percentage variances between Hanford and other site data was below $1 \%(0.02-0.7 \%)$ for transaction categories detailed in Section 6.1.5.

\subsubsection{Impurities Shipped with $\mathrm{UO}_{3}$ from Hanford}

As shown in Section 4, fairly complete analytical data for Pu contained in shipments of $\mathrm{UO}_{3}$ have been located for the years from 1963 to 1988. Data on shipments prior to 1963 are limited for the constituents of concern including $\mathrm{Pu}^{237} \mathrm{~Np}$, or ${ }^{99} \mathrm{Tc}$. Hanford data for the ${ }^{237} \mathrm{~Np}$ and ${ }^{99} \mathrm{Tc}$ were not available on a routine basis until 1984. In an attempt to reconstruct the quantity of constituents that were present in Hanford produced $\mathrm{UO}_{3}$, source documents from other sites were used to make the estimates, i.e. Smith 1984 and Ritter KJETO-30 and draft U Mass Balance reports of receipts from the Major Tier 1 receiver sites. The Smith and Ritter documents report the result of special studies performed at Paducah using Hanford $\mathrm{UO}_{3}$ as a starting material. Analyses were completed at these sites on hundreds of samples between 1959 to 1973 for $\mathrm{Pu},{ }^{237} \mathrm{~Np}$, and ${ }^{99} \mathrm{Tc}$.

Engineering estimates of the quantities of constituents ( $\mathrm{Pu}, \mathrm{Np}$, and $\mathrm{Tc}$ ) which were present in recycled uranium received, shipped, contained in waste, released to the environment, or contained in the current recycled uranium inventory at Hanford have been made. The detailed results of these estimates are provided in Appendix I of this report. Analytical data on the concentration of $\mathrm{Np}$ and Tc in Hanford recycled uranium is minimal, since there were no specification requirements for these elements.

Reasonable analytical data has been identified which indicates that recycled uranium shipped from Hanford typically contained $\mathrm{Pu}$ in the range of 1 to $5 \mathrm{ppb}$, and limited analytical data indicate $\mathrm{Np}$ ranged from 20 to $500 \mathrm{ppb}$, and Tc ranged from 3 to $12 \mathrm{ppm}$.

Since it is not possible to provide a complete historical assessment of the constituent levels in all recycled uranium Hanford, rough estimates of annual quantities of constituents in recycled uranium shipped each year were developed by assuming that the constituent levels during the years when analytical data is not available were the same as those for the years when analytical data is available. The annual estimates provided were based upon the low, mean, and high values for the constituent ranges mentioned above. Summaries of the total amount of constituents sent to Paducah, 


\section{Section 6 Discussion and Conclusions

Fernald, and Oak Ridge sites are shown in Figures 6-2, 6-3, and 6-4. The $-110,000 \mathrm{MT}$ of recycled uranium shipped from Hanford is estimated to have contained from $\sim 110$ to $\sim 550 \mathrm{~g} \mathrm{Pu}, \sim 2.2$ to $\sim 28 \mathrm{Kg} \mathrm{Np}$, and $\sim 330$ to $\sim 1,318 \mathrm{Kg}$ of Tc. In general, these estimated constituent quantities appear to be consistent with data from sites receiving Hanford recycled uranium.

\subsubsection{Discussion of Pu Data Differences Between K-25 and Hanford}

In the K-25 Uranium Mass Balance Preliminary Site Report, analytical data are presented that indicate the $\mathrm{Pu}$ concentrations of $\mathrm{UO}_{3}$.reported by $\mathrm{K}-25$ between January and April 1953 are significantly outside the $10 \mathrm{ppb}$ specification threshold. Hanford and Oak Ridge agree that data generated before and after the January to April 1953 time period are generally well within the $10 \mathrm{ppb}$ threshold. Analysis of source documents are not available from Hanford for shipment composites or lots during this time period. However, monthly and weekly reports for this time period do not indicate that $\mathrm{UO}_{3}$ shipments to Oak Rjdge or Harshaw were made of out-of-specification $\mathrm{UO}_{3}$ material in the Pu constituent. A reference [Schmidt 1953] recognizes that there was some discrepancy in the plutonium analytical results between Oak Ridge and Hanford. This reference also indicates other constituent data are in agreement. Communications were ongoing at that time to resolve the differences, specifically on shipments 18,19 , and 20. This reference states that Hanford reported less than $10 \mathrm{ppb}$ and Oak Ridge reported concentrations in the range of 15 to $20 \mathrm{ppb}$ on those three shipments. Both laboratories reported $22 \mathrm{ppb}$ on the shipment composite number 43.

In 1952, Hanford was analyzing each lot of material but reduced the analytical workload in November 1952 by only analyzing the carload composite for $P u$. The K-25 report apparently includes measurements of each lot. A lot represented eight drums, each drum contained about $300 \mathrm{Kg}$ of $\mathrm{UO}_{3}$, and a car shipment included 11 or 12 lots (about 31-32 MTU) but ranged from 5 to 12 lots. Hanford transfer records show $411 \mathrm{MTU}$ of $\mathrm{UO}_{3}$ and metal scrap were shipped to Oak Ridge during the January to June 1953 time period. On the graphic in the K-25 draft report, approximately $45-50$ data points are shown during the January to April 1953 time frame. Assuming each point represents the results of one lot reported, this indicates four shipments were made and would have contained about 120 to 150 MTU. This is consistent with the weekly and monthly reports for the time period. This represents about three percent of the uranium sent to Oak Ridge. During the same time period Hanford shipped approximately four times more material to Harshaw Chemical Co. than to Oak Ridge. The Harshaw product was shipped on to Oak Ridge after processing to remove non-radionuclide constituents. The Oak Ridge report indicates the Harshaw material met the Pu specification.

The reference, cited above, indicates that Oak Ridge was using an analytical procedure that was not included in the authorized procedure manual of that time. They added an aluminum nitrate "salting agent" that could enhance the extraction of Pu into the organic extractant. Hanford was using the procedure in the manual and this could account for the discrepancy in the constituent concentration. It is evident that the Hanford results 


\section{Error}

An error occurred while processing this page. See the system log for more details. 


\section{Error}

An error occurred while processing this page. See the system log for more details. 


\section{Error}

An error occurred while processing this page. See the system log for more details. 


\section{Section 6 \\ Discussion and Conclusions \\ DOE/RL-2000-43}

are biased low compared to the K-25 results. It is interesting to note that during the same time period that Oak Ridge reported receiving high Pu concentrations from Hanford, they also reported receiving slightly higher Pu levels from Harshaw than in preceding or succeeding periods. It seems that there would be a delay of a month or more in the receipt at Oak Ridge of Hanford produced $\mathrm{UO}_{3}$ while processing was performed at Harshaw. The potential of the Harshaw process to reduce the Pu concentration in $\mathrm{UO}_{3}$ product from Hanford is not known.

If Hanford data (less than $10 \mathrm{ppb}$ for all shipments except shipment number 43 which Hanford reported as being $22 \mathrm{ppb}$ ) are used, about 4.5 grams of Pu would have been included with the $\mathrm{UO}_{3}$ shipped during the January - April 1953 time period. If Oak Ridge's example data are extrapolated to the material shipped during this period and the average is $22 \mathrm{ppb}$, the $\mathrm{Pu}$ included with the $\mathrm{UO}_{3}$ is 9 grams. This represents a difference of 4.5 grams of Pu in approximately 120 to $150 \mathrm{MTU}$ of uranium.

In 1948 and again in 1951 the concentration of Pu allowable in recycled $\mathrm{UO}_{3}$ was established to limit the increase in potential hazard to personnel to no more than 10 percent of the hazard present from handling aged natural uranium in equilibrium with its decay daughters [Gamertsfelder 1948 and 1951]. The threshold established for Pu was $10 \mathrm{ppb}$ and included a large conservatism factor. In 1985, a task force re-evaluated the $10 \mathrm{ppb}$ limit against the then current air concentration guides and concluded that the 10 $\mathrm{ppb}$ value represented 3.5 percent of the concentration guide [DOE/OR-859 1985]. Therefore, with respect to personnel hazards from $\mathrm{Pu}$ impurities in recycled uranium, even the Hanford shipments which were above the specification of $10 \mathrm{ppb}$ were well within the concentration guidance as established both in 1951 and again when the guidance was re-evaluated in 1985. 


\section{Section 6 \\ DOE/RL-2000-43 \\ Discussion and Conclusions}

\section{References:}

DOE/OR-859 1985

DOE/OR-859, The Report of the Joint Task Force on Uranium Recycle Materials

Processing, Task Force Members Dick Egli et. al., September 1985

Gamertsfelder 1948

HW-10515 by C.C. Gamertsfelder to C.N. Gross, Plutonium and Fission Product

Contamination in Reclaimed Uranium, July 19, 1948

Gamertsfelder 1951

Letter HW-20628 (HAN-36668) from C.C. Gamertsfelder to R.H. Beaton, Recent Changes Affecting the Specifications Concerning Activity Levels in Reclaimed Uranium, March 27, 1951

Hauff 1952

Letter T. W. Hauff to Donald G. Sturges, General Analytical Control Program I, November 5, 1952

Smith 1953

HW-27990, Summary of Oak Ridge Discussions Relative to Hanford Uranium Trioxide Specification, R. E. Smith, May 5, 1953

Smith 1984

Report KY/L-1239, R. F. Smith, Historical Impact of Reactor Tails on the

Paducah Cascade, Paducah Gaseous Diffusion Plant, March 1984

Schmidt 1953

Letter HW-27314, H. R. Schmidt to L. M. Knights, Determination of $\mathrm{Pu}$ in $\mathrm{UO}_{3}$, March 5, 1953 
DOE/RL-2000-43

Appendix A

Glossary of Acronyms and Terms 


\section{Error}

An error occurred while processing this page. See the system log for more details. 


\section{Error}

An error occurred while processing this page. See the system log for more details. 


\section{Error}

An error occurred while processing this page. See the system log for more details. 


\section{Error}

An error occurred while processing this page. See the system log for more details. 


\section{Error}

An error occurred while processing this page. See the system log for more details. 


\section{Error}

An error occurred while processing this page. See the system log for more details. 


\section{Error}

An error occurred while processing this page. See the system log for more details. 


\section{Error}

An error occurred while processing this page. See the system log for more details. 
DOE/RL-2000-43

Appendix B

\section{Section 3 - Supplemental Information}


DOE/RL-2000-43

(This page intentionally left blank) 


\section{Error}

An error occurred while processing this page. See the system log for more details. 


\section{Error}

An error occurred while processing this page. See the system log for more details. 


\section{Error}

An error occurred while processing this page. See the system log for more details. 


\section{Error}

An error occurred while processing this page. See the system log for more details. 


\section{Error}

An error occurred while processing this page. See the system log for more details. 


\section{Error}

An error occurred while processing this page. See the system log for more details. 


\section{Error}

An error occurred while processing this page. See the system log for more details. 


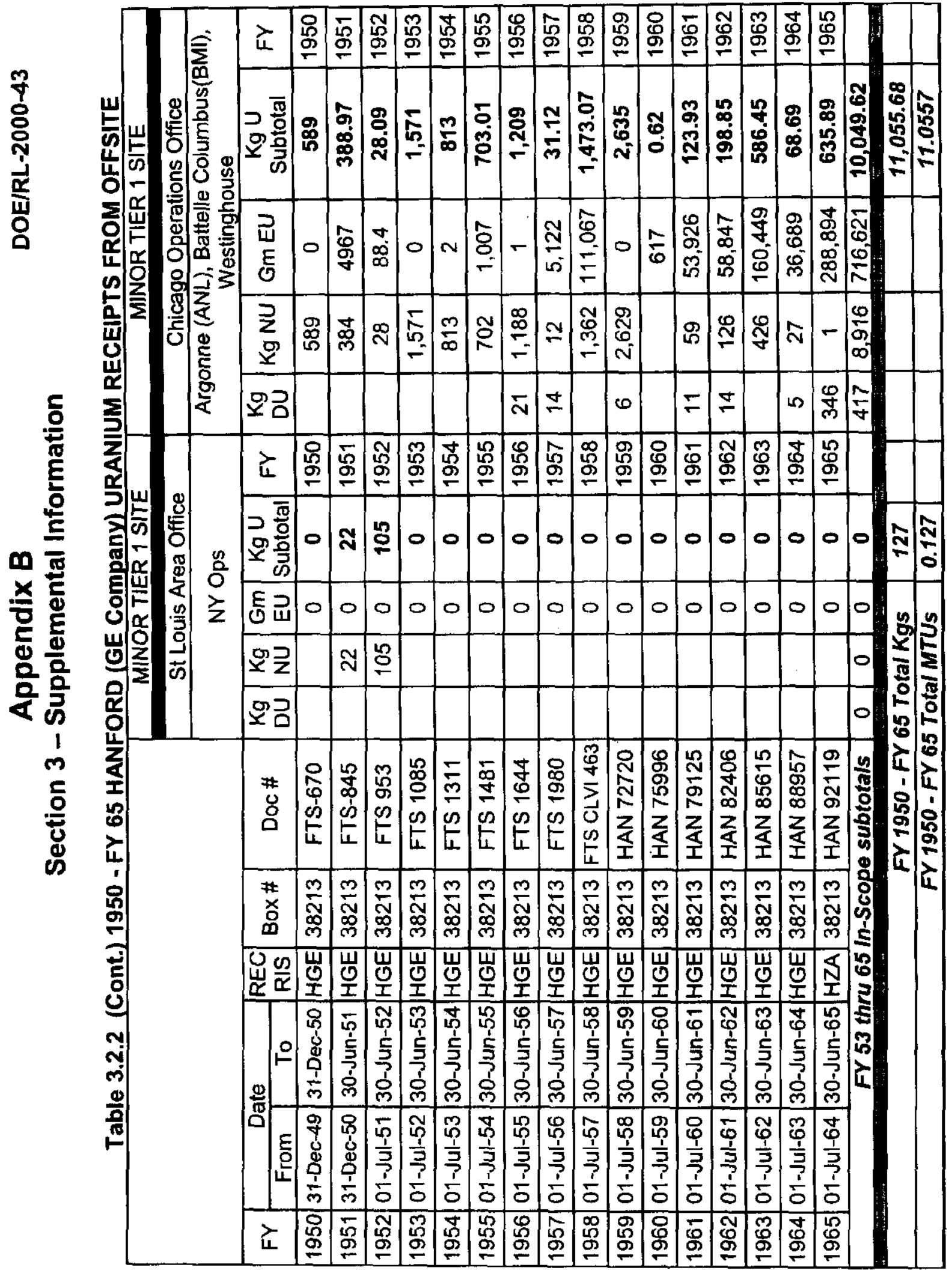




\section{Error}

An error occurred while processing this page. See the system log for more details. 


\section{Error}

An error occurred while processing this page. See the system log for more details. 


\section{Error}

An error occurred while processing this page. See the system log for more details. 


\section{Error}

An error occurred while processing this page. See the system log for more details. 


\section{Error}

An error occurred while processing this page. See the system log for more details. 


\section{Error}

An error occurred while processing this page. See the system log for more details. 


\section{Error}

An error occurred while processing this page. See the system log for more details. 


\section{Error}

An error occurred while processing this page. See the system log for more details. 


\section{Error}

An error occurred while processing this page. See the system log for more details. 


\section{Error}

An error occurred while processing this page. See the system log for more details. 


\section{Error}

An error occurred while processing this page. See the system log for more details. 


\section{Error}

An error occurred while processing this page. See the system log for more details. 


\section{Error}

An error occurred while processing this page. See the system log for more details. 


\section{Error}

An error occurred while processing this page. See the system log for more details. 


\section{Error}

An error occurred while processing this page. See the system log for more details. 


\section{Error}

An error occurred while processing this page. See the system log for more details. 


\section{Error}

An error occurred while processing this page. See the system log for more details. 


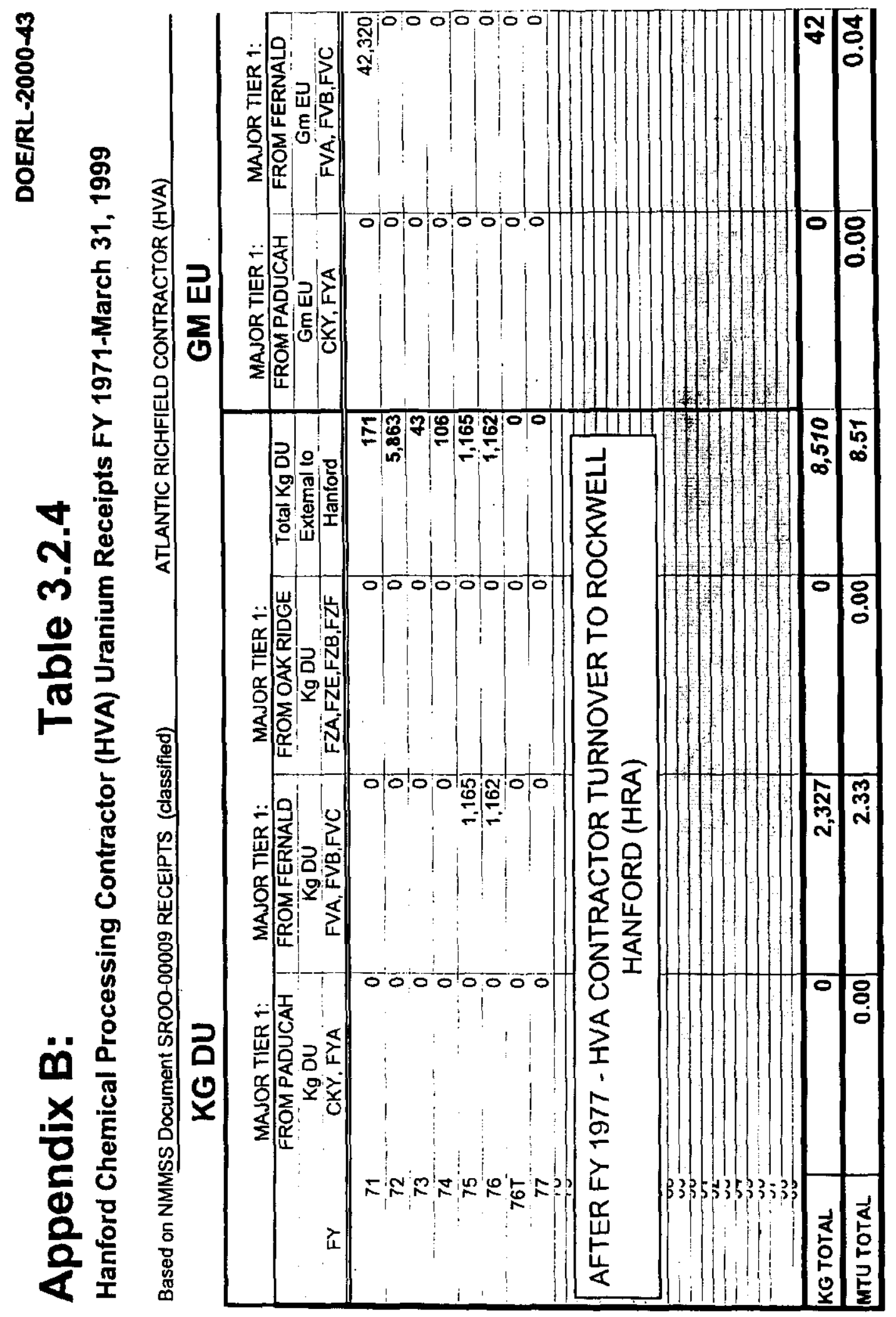




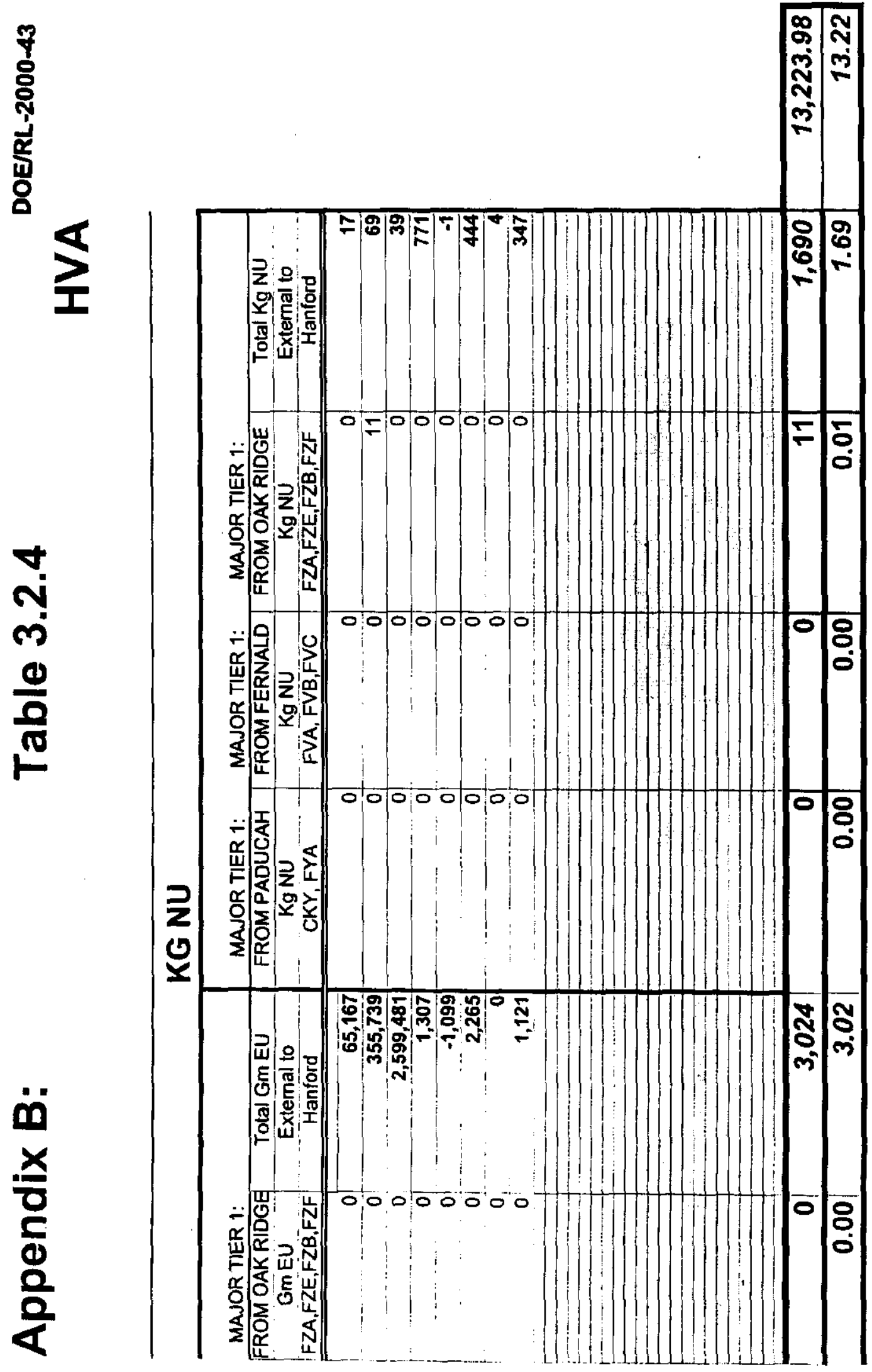




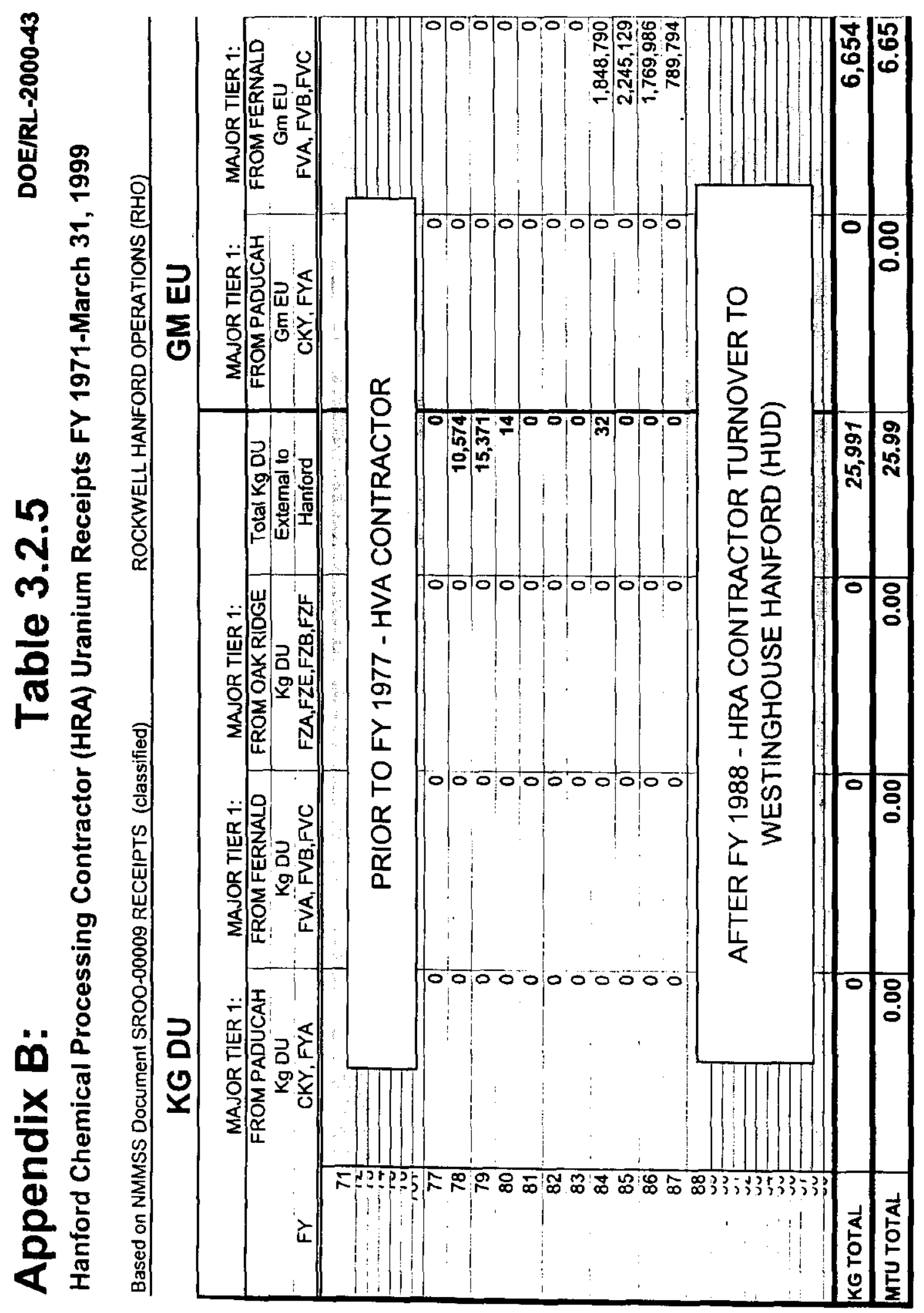




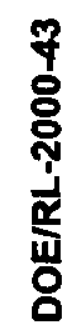
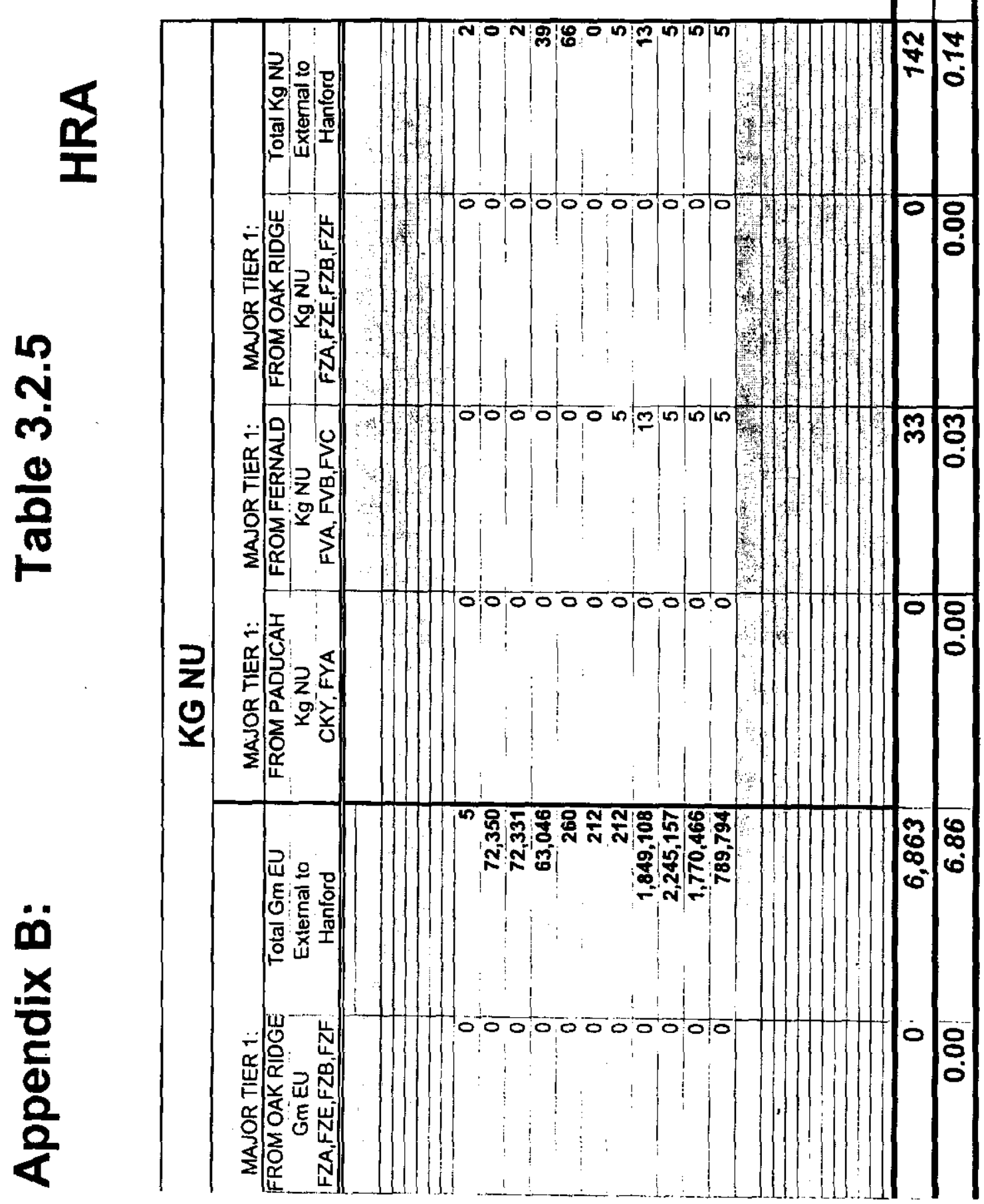


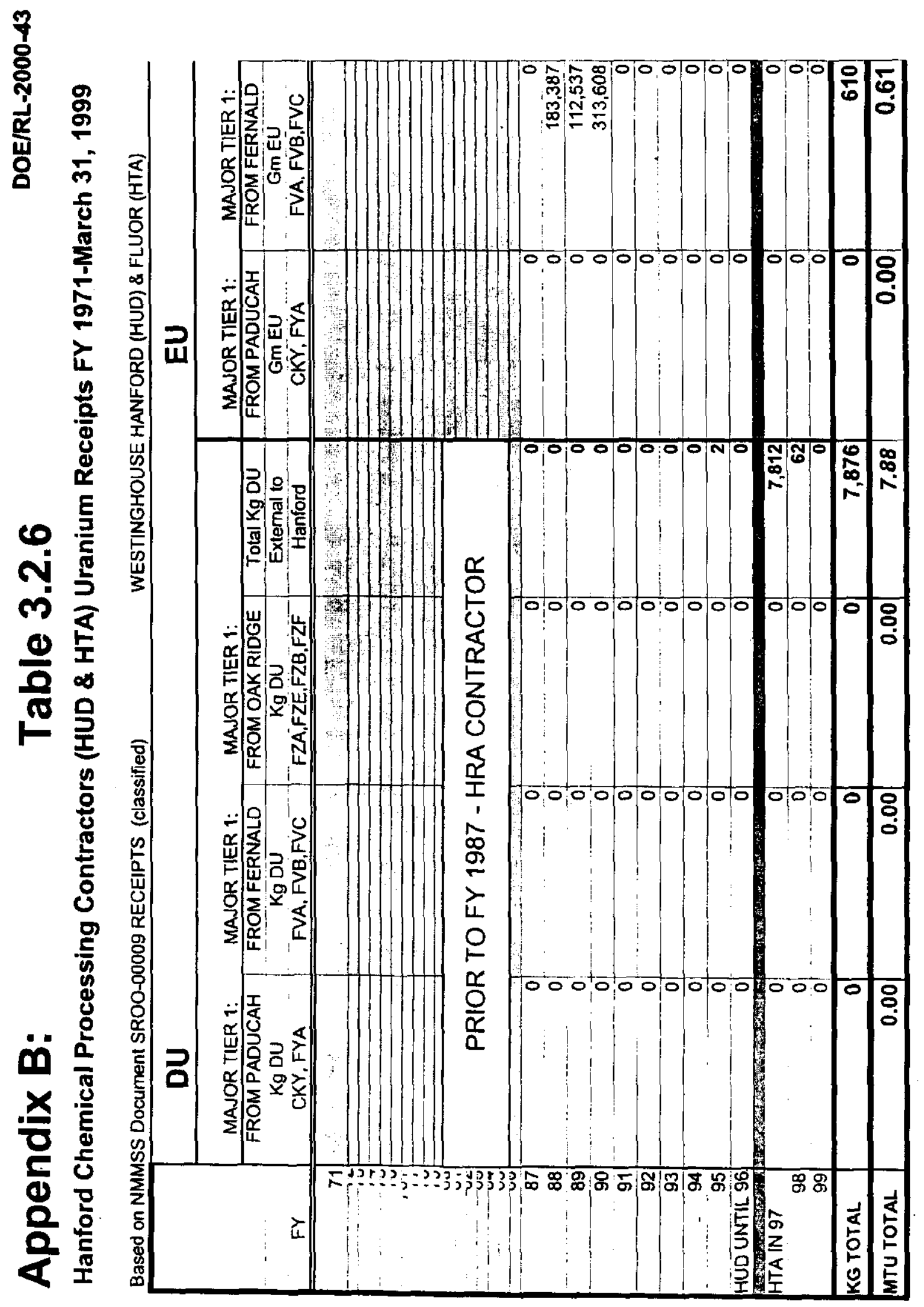




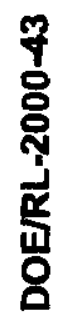

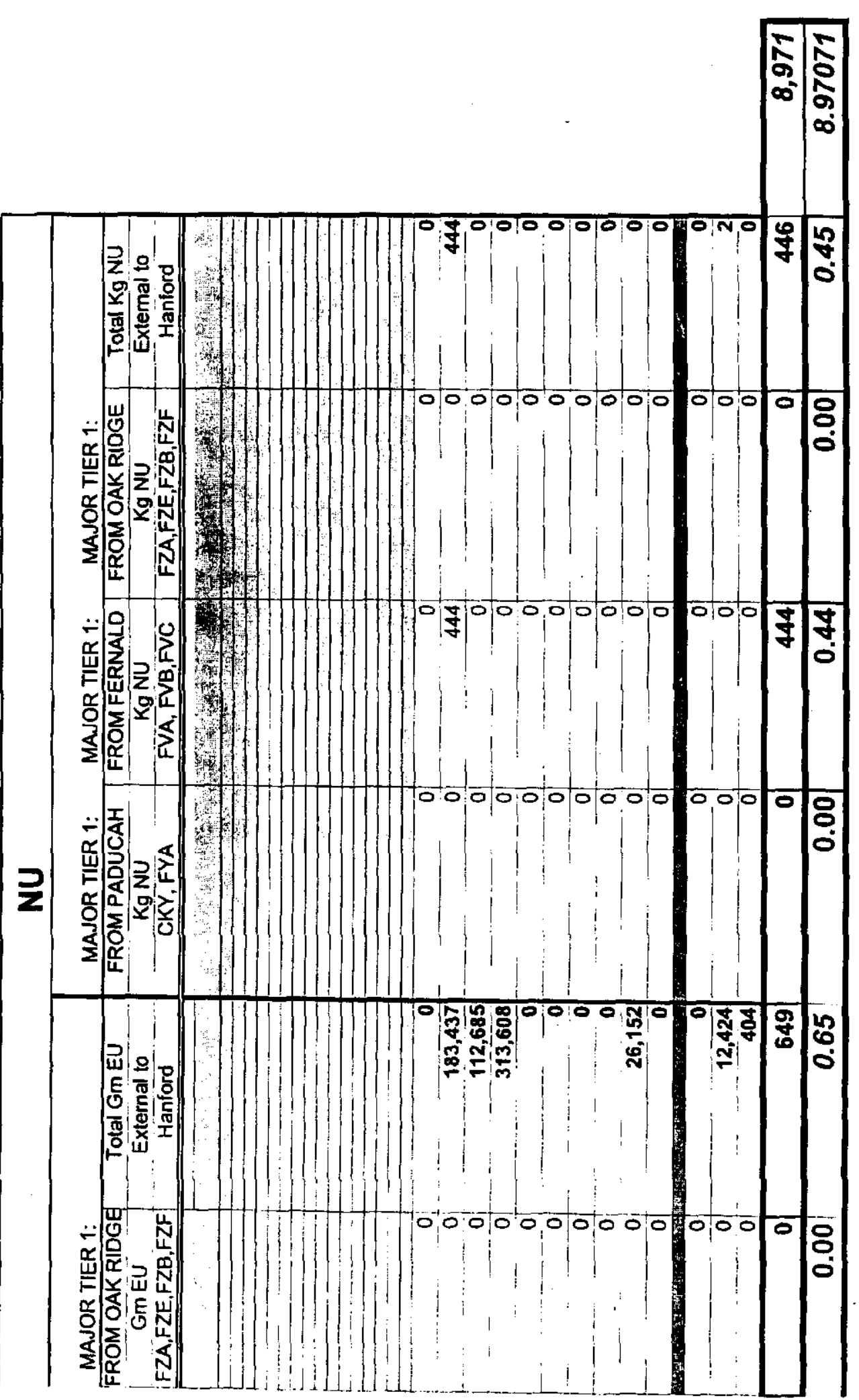




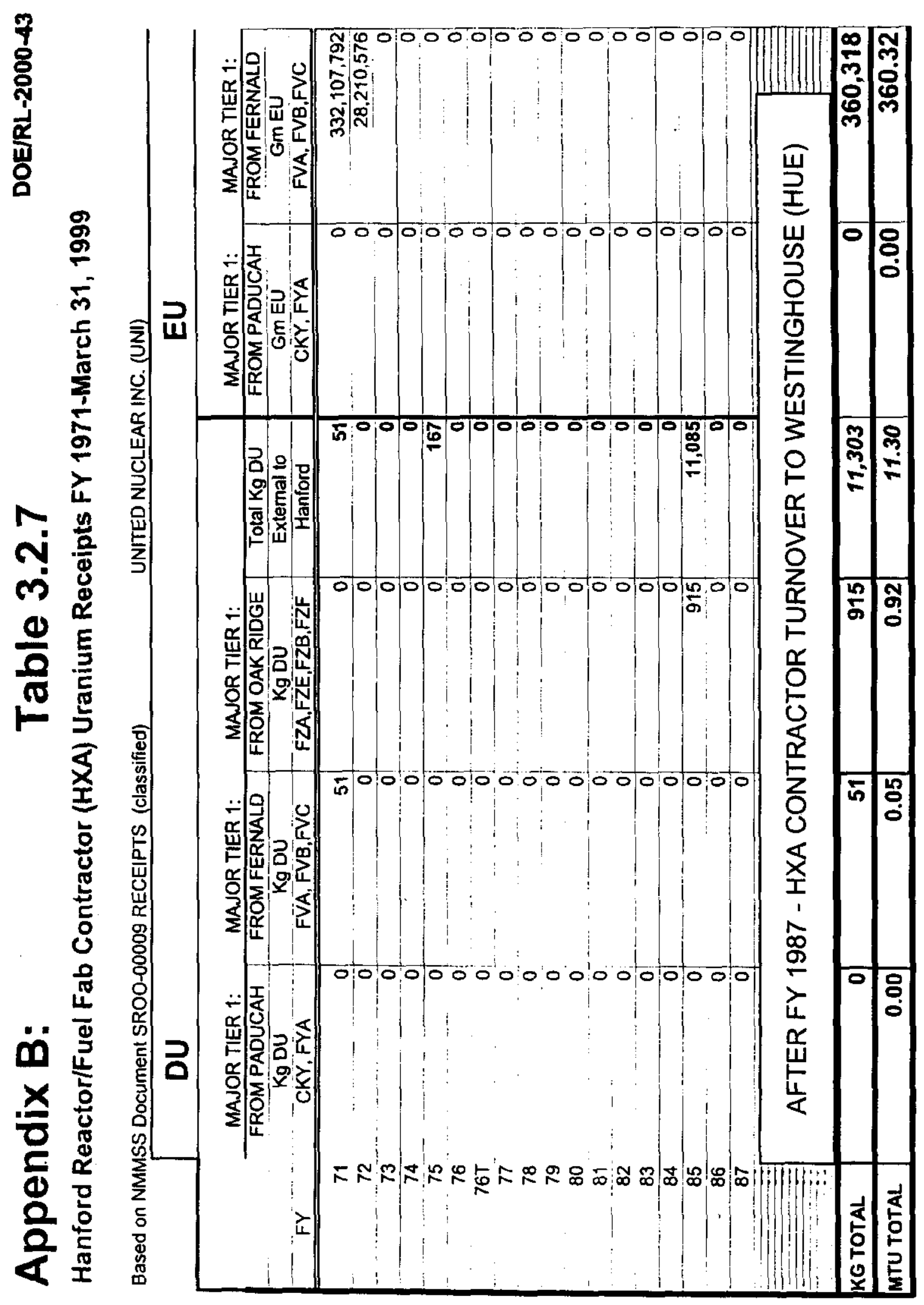




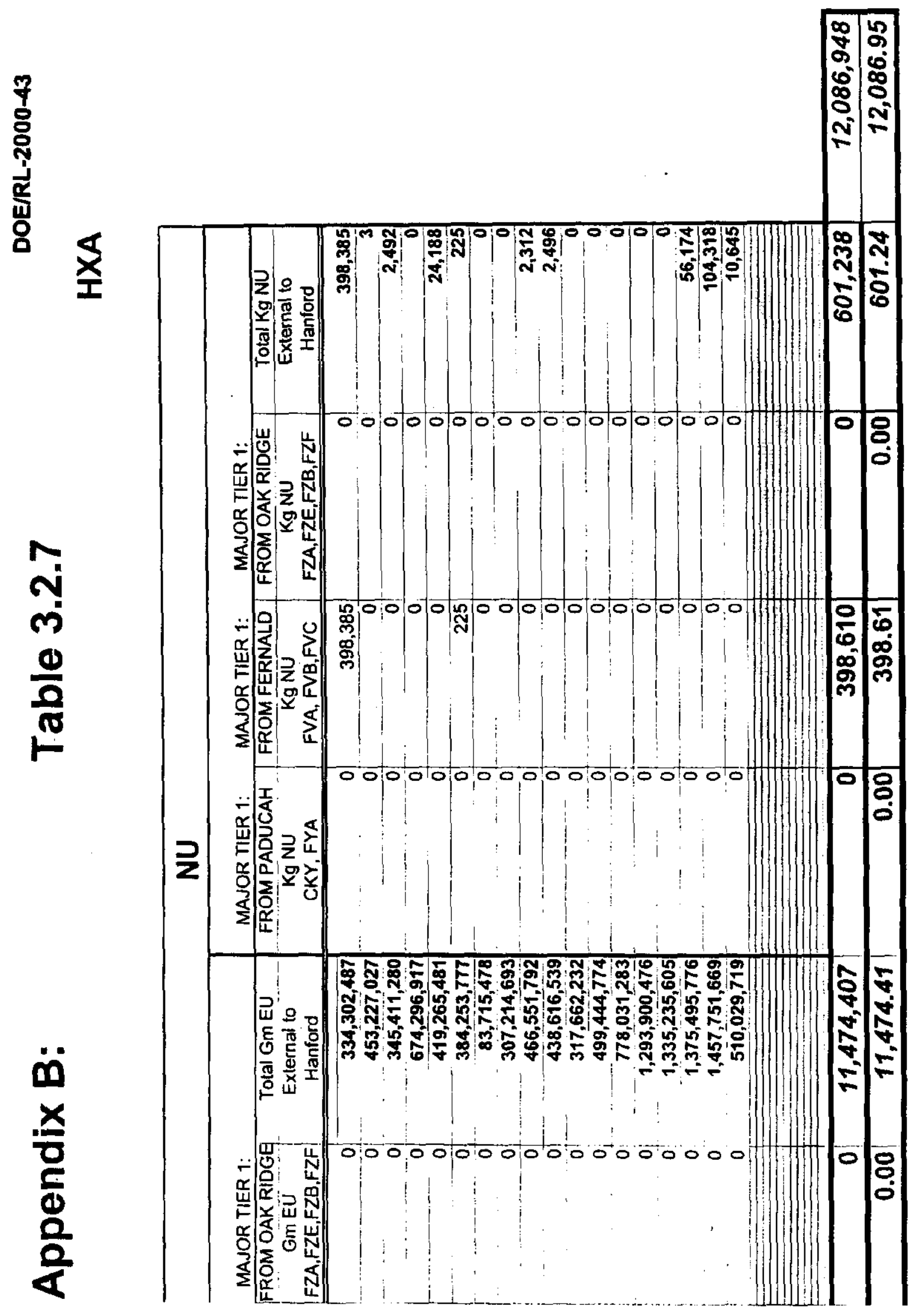




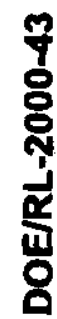

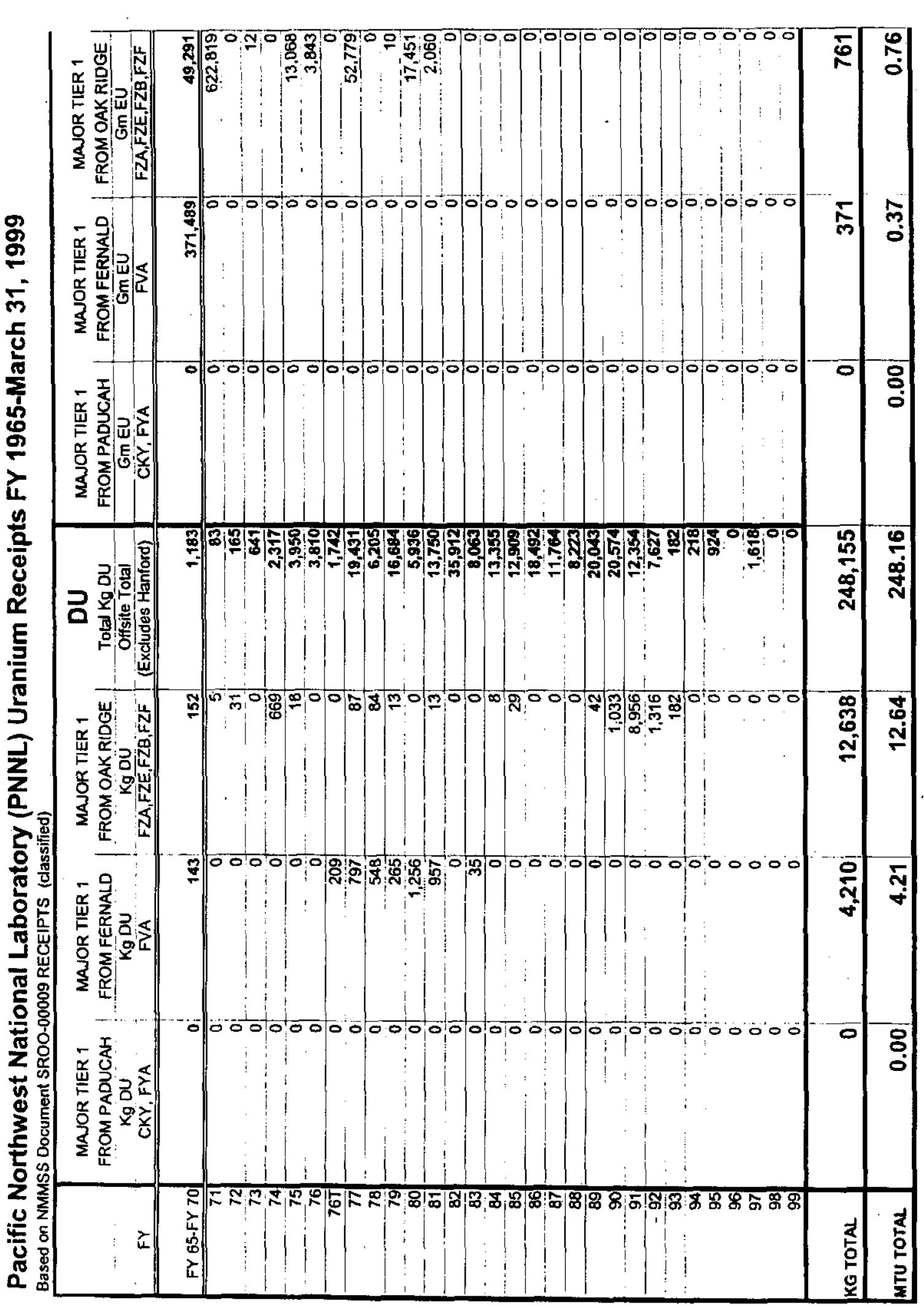




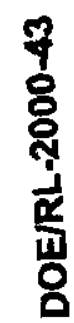

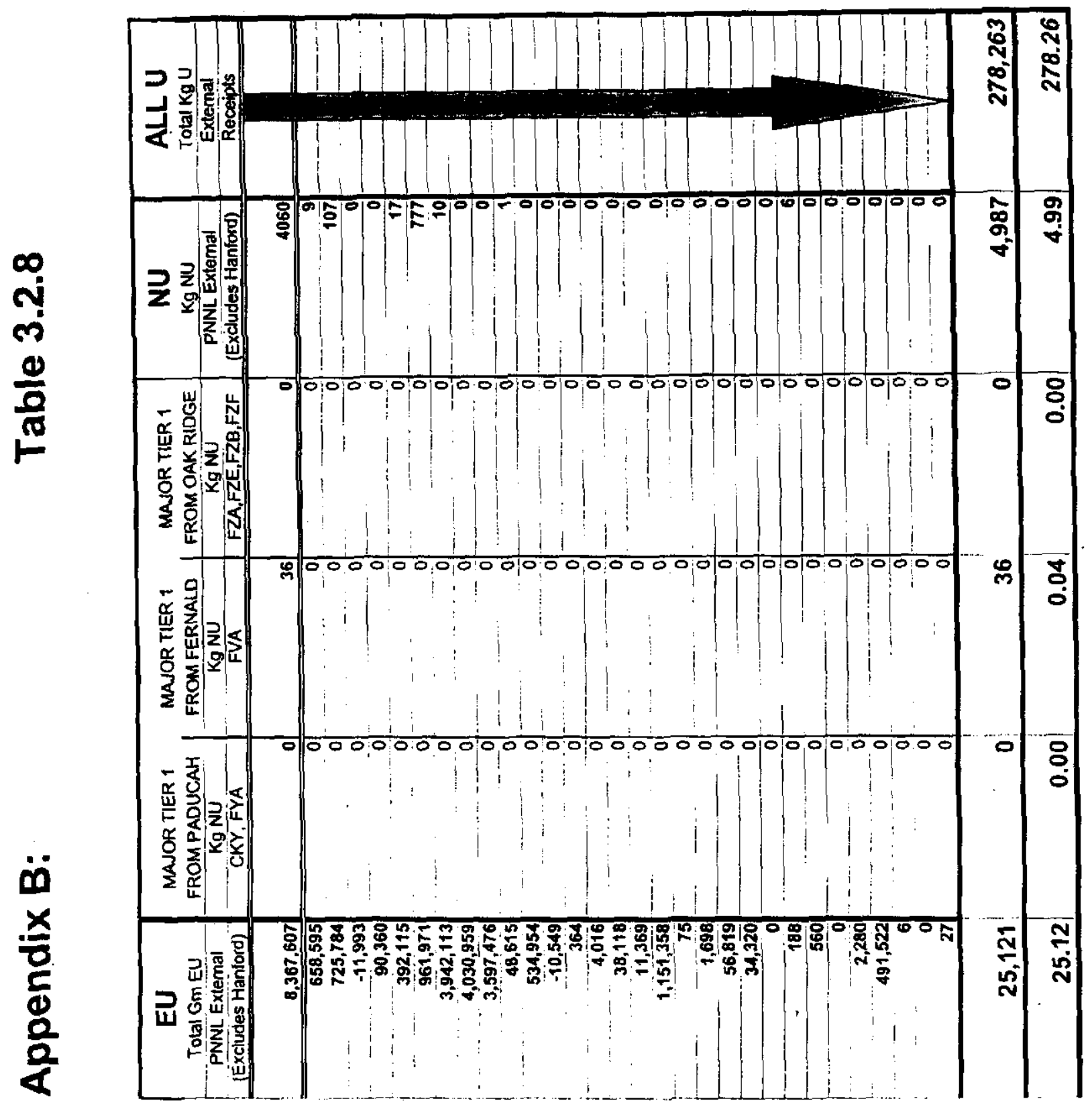


궁

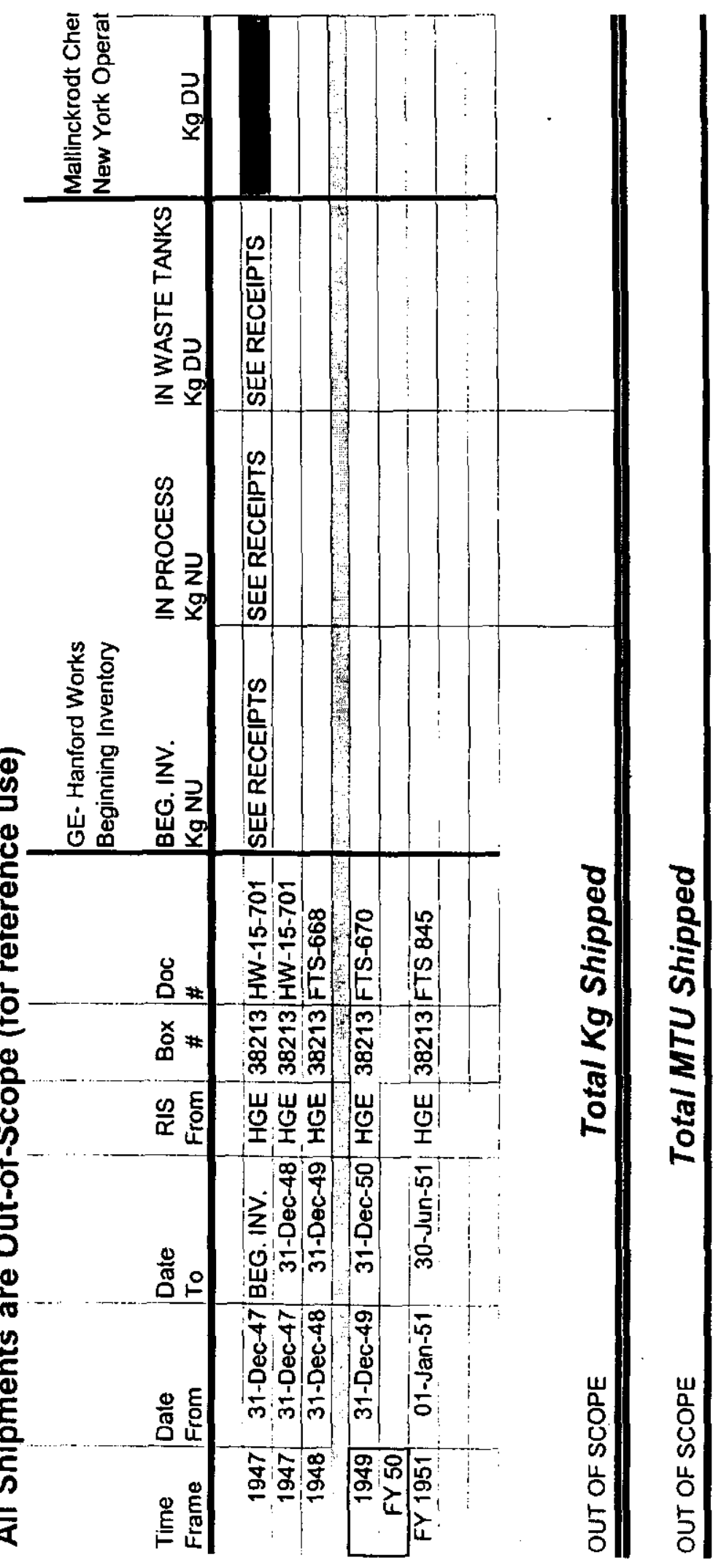


9
8
8
$\frac{8}{4}$
$\frac{\mathbf{x}}{\mathbf{W}}$
8

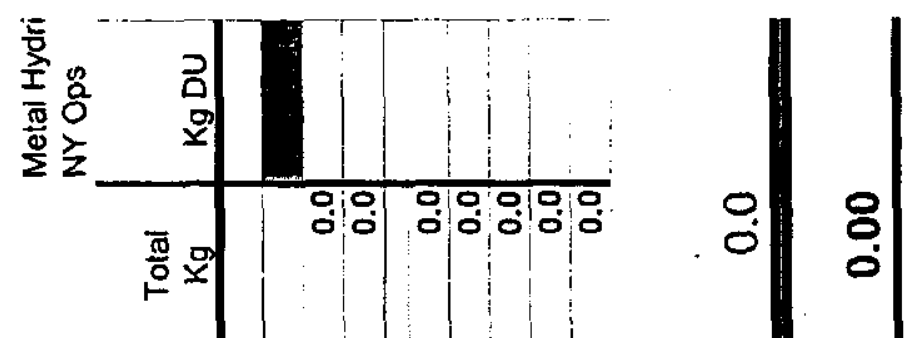

$\frac{m}{9}$

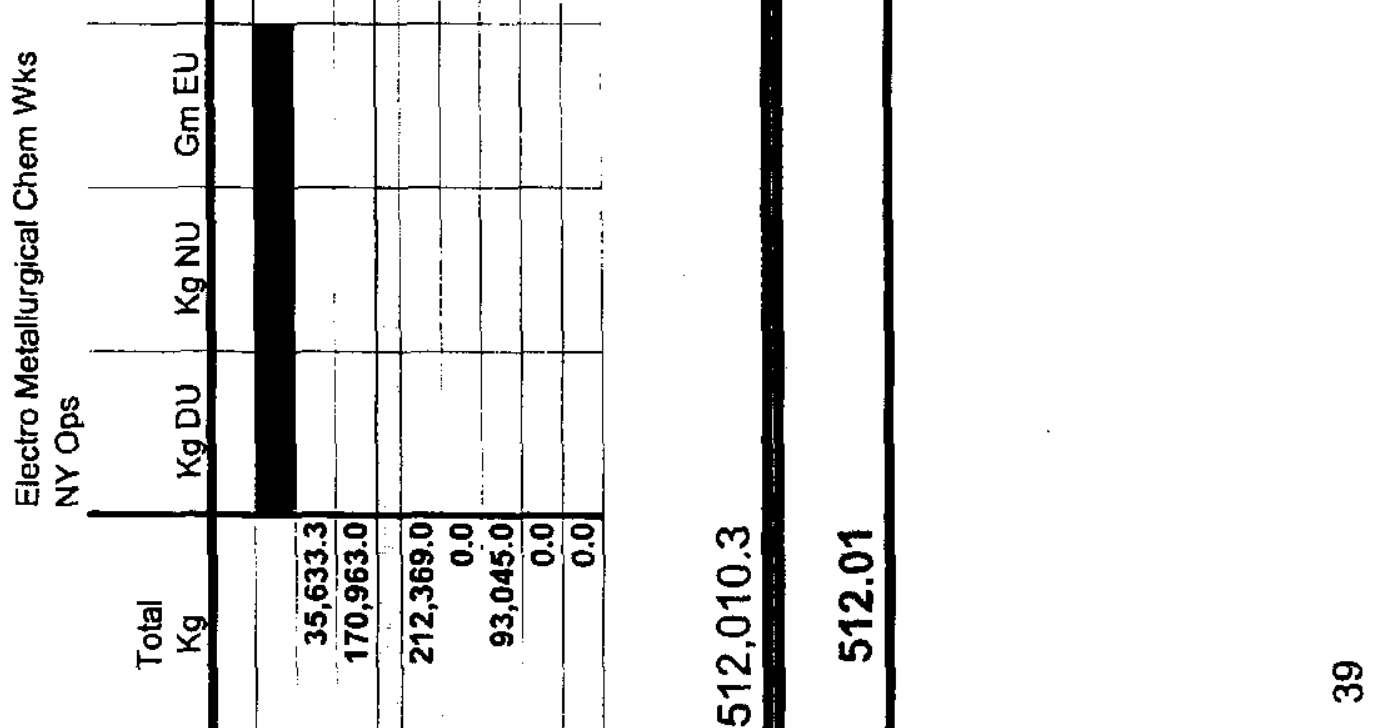

$\frac{\ddot{x}}{\frac{x}{0}}$
$\frac{\frac{1}{0}}{\frac{0}{2}}$

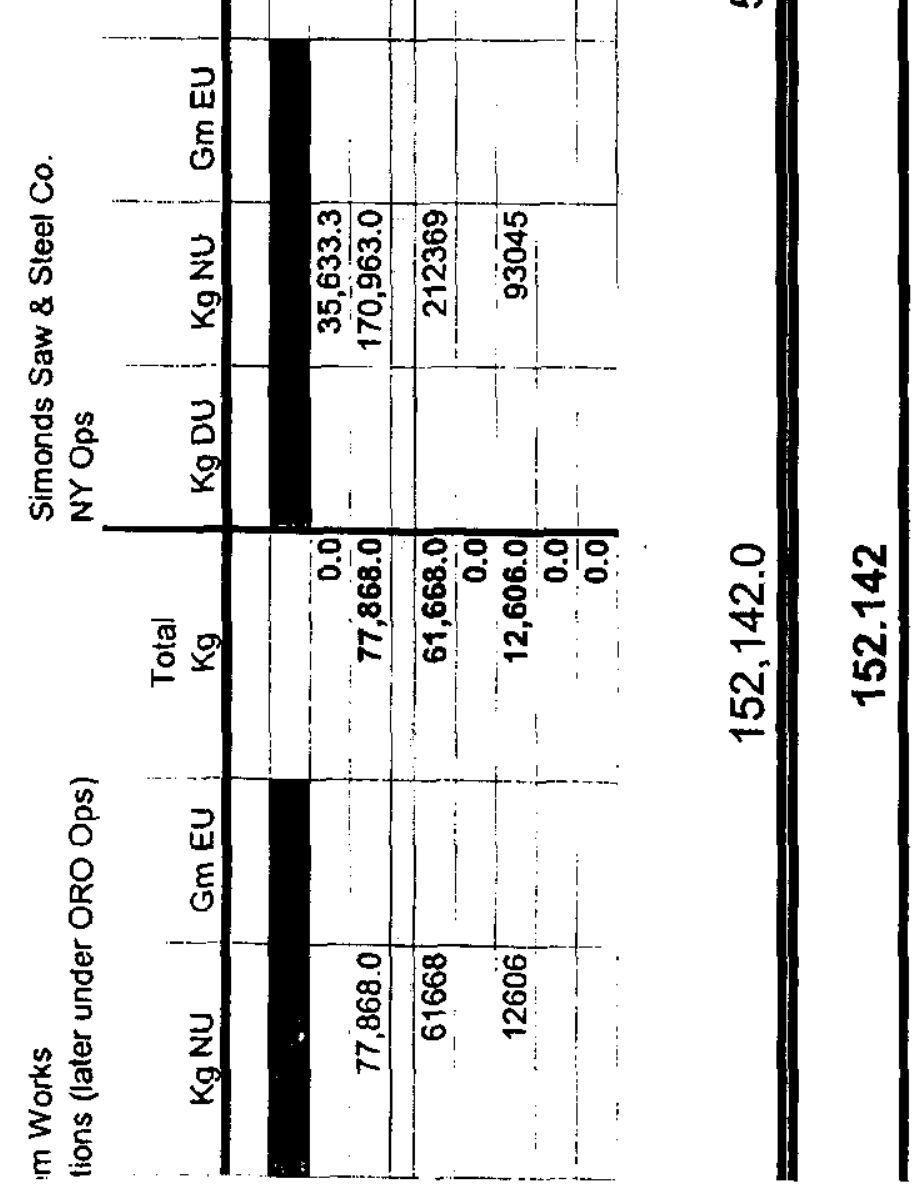




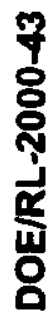

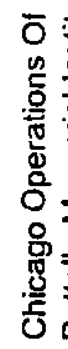

$\mid$

$\infty$
0
0
0

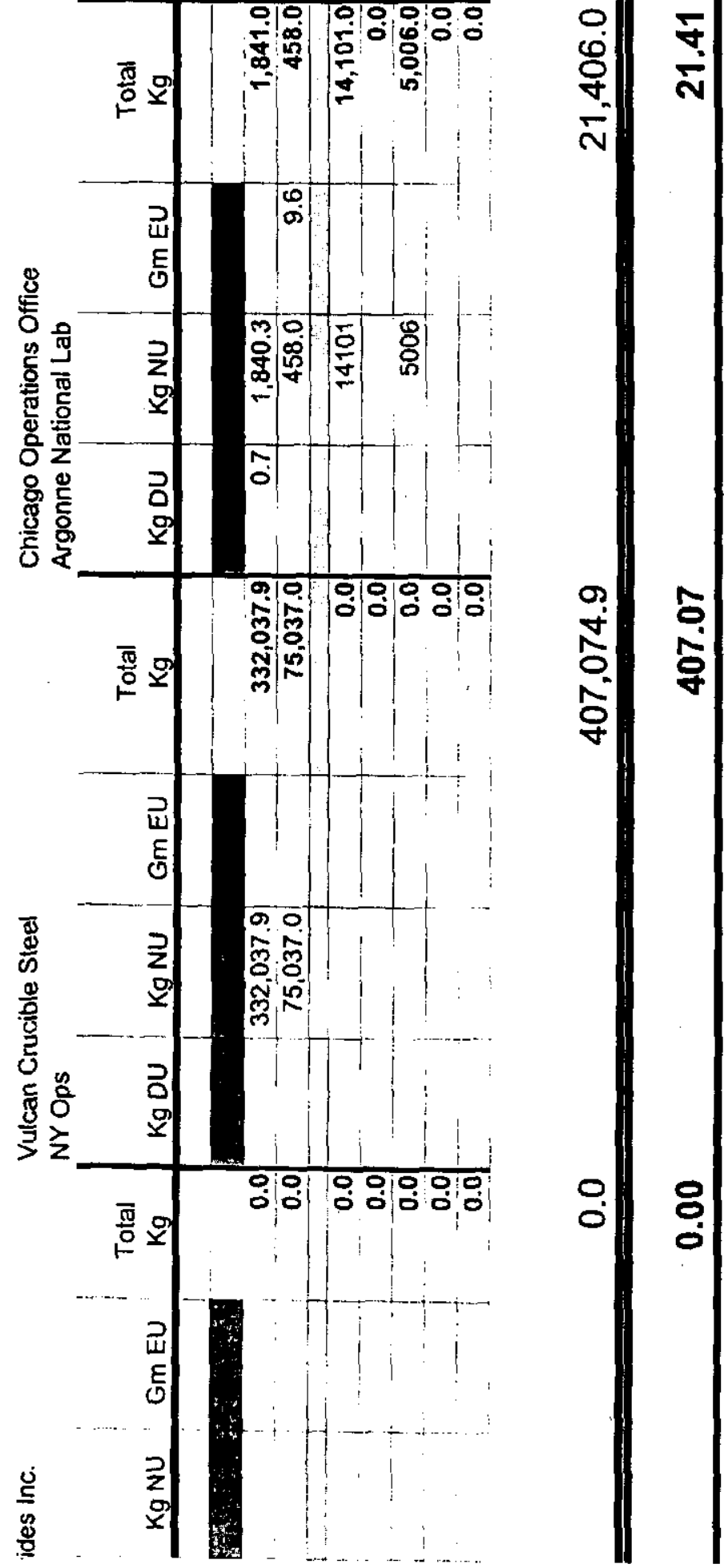




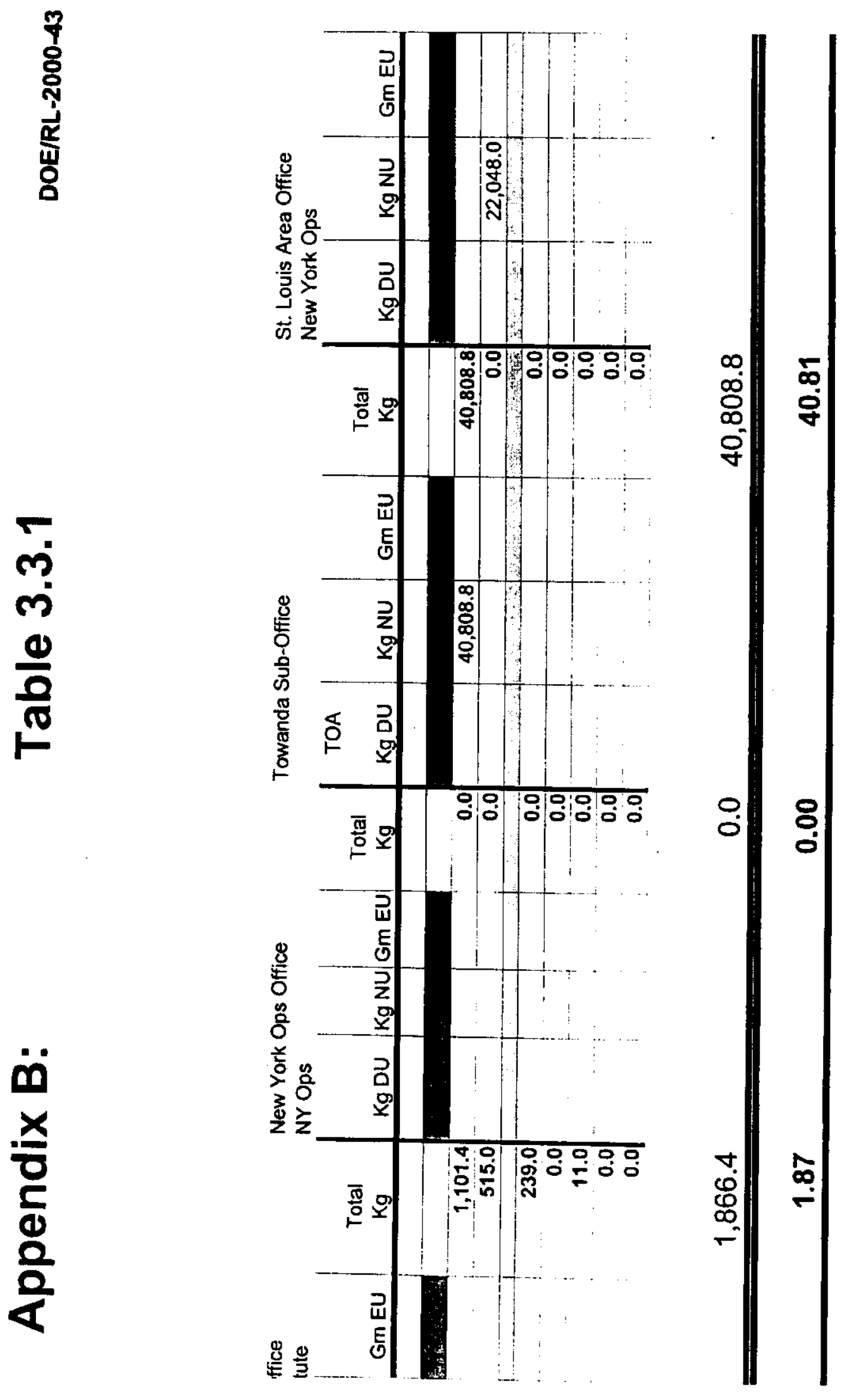




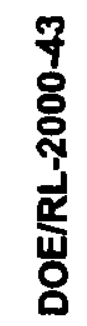

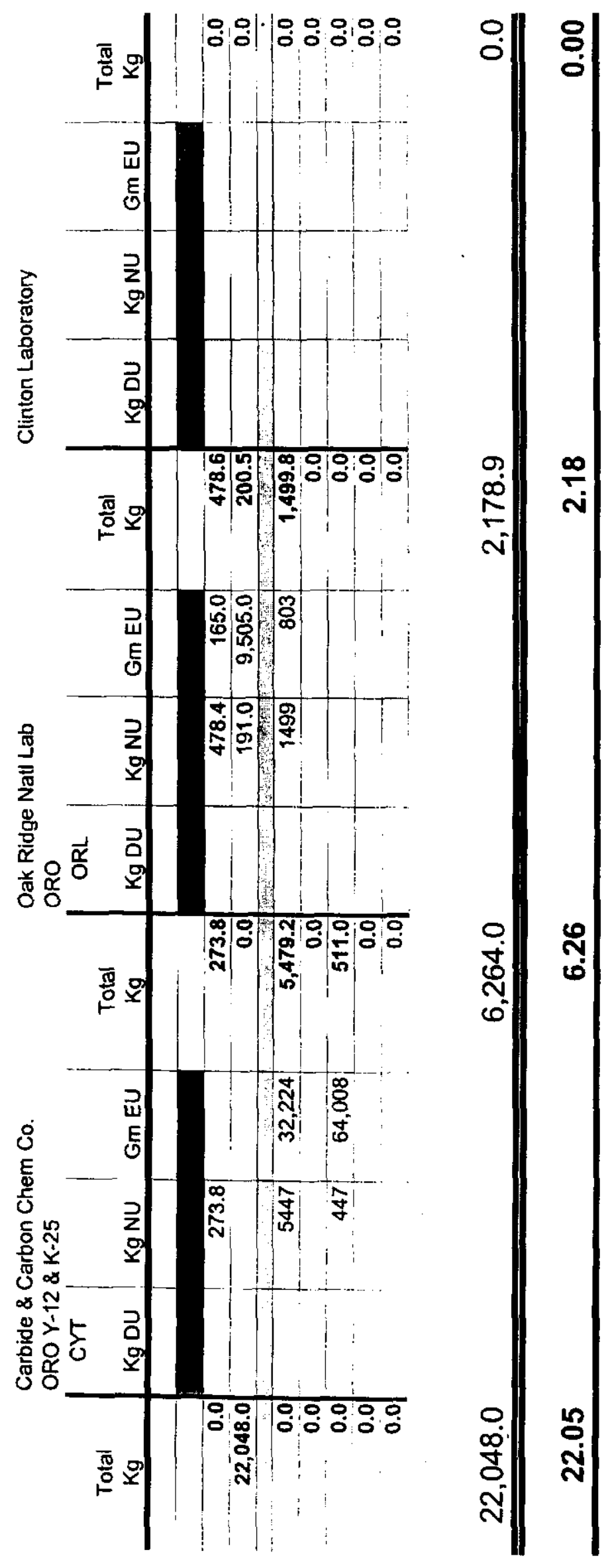

Y

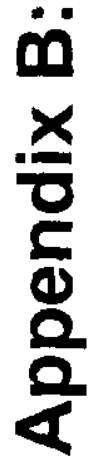




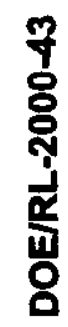

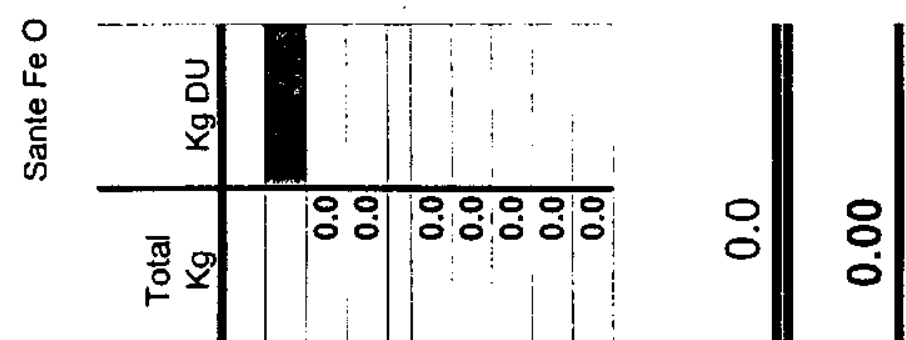

की

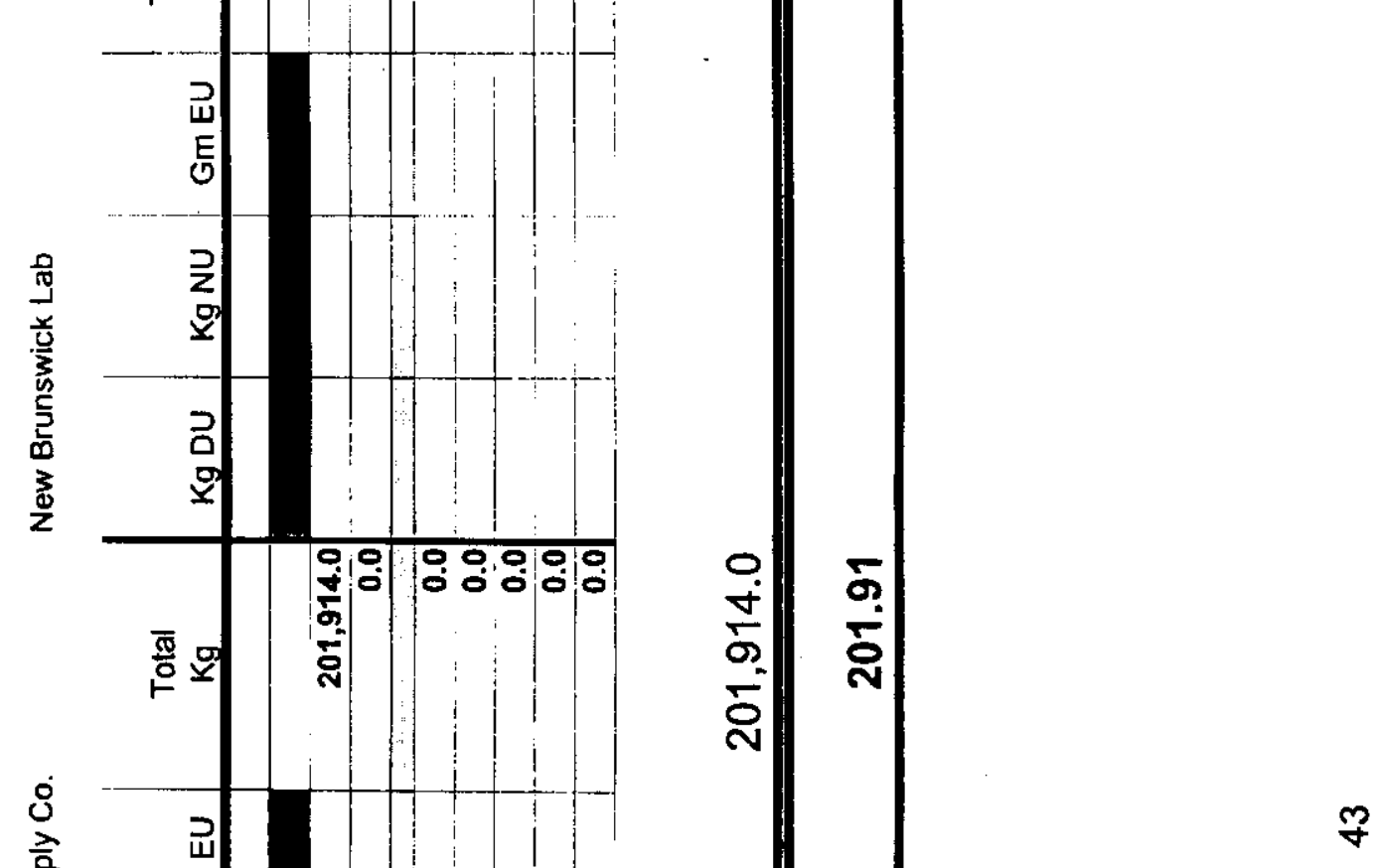




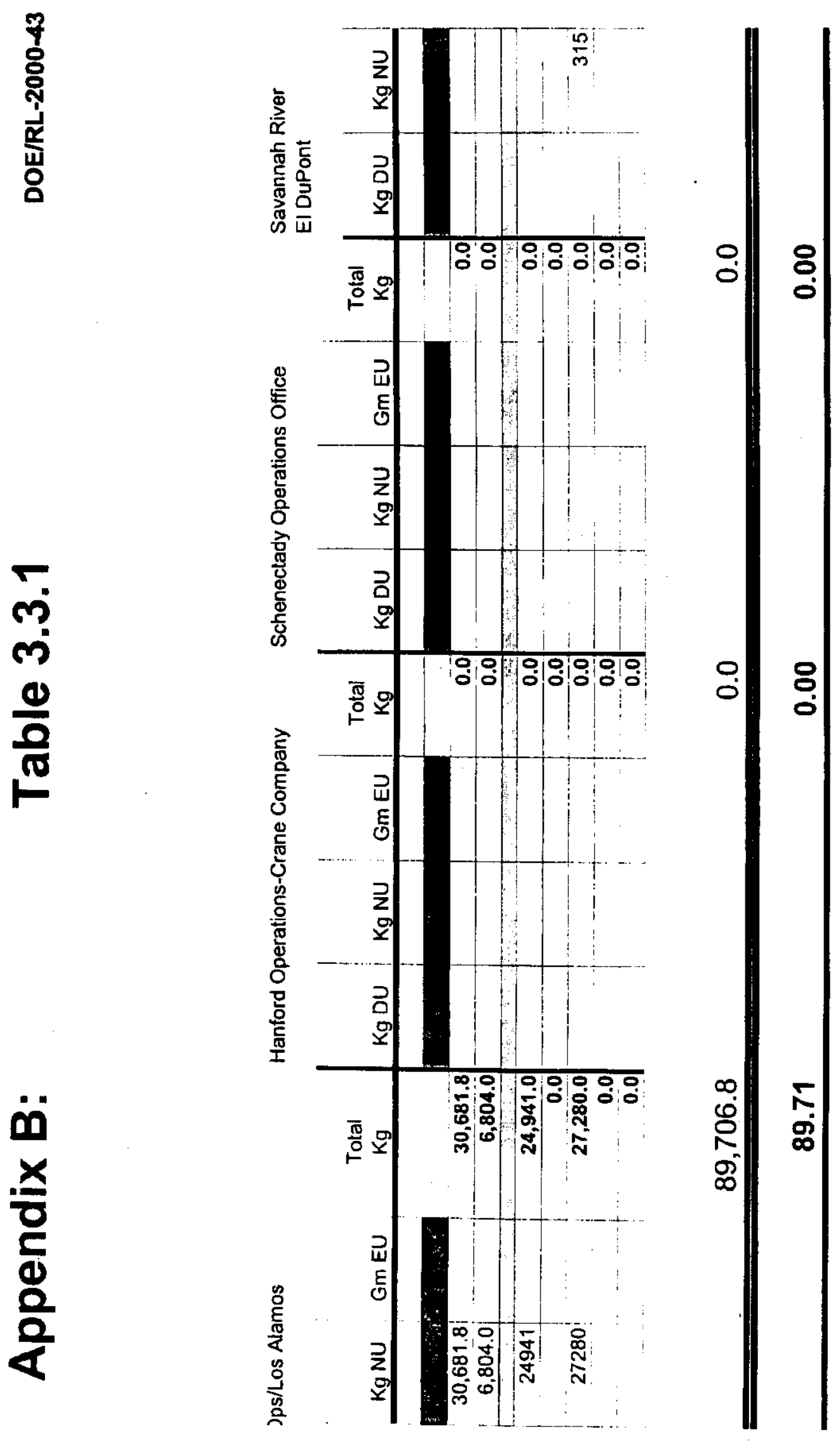




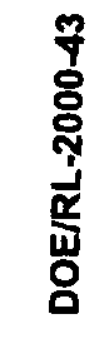
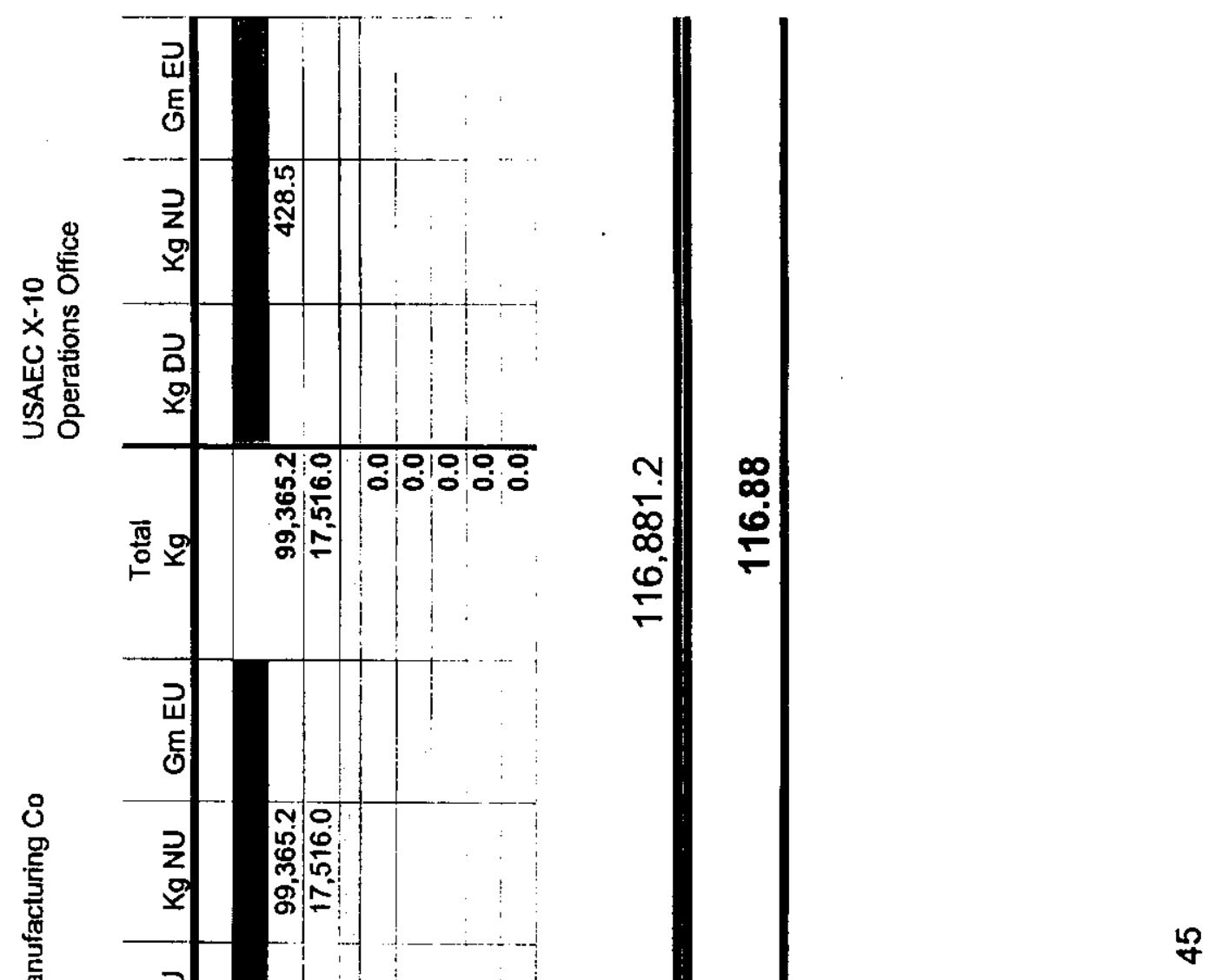

$\frac{0}{x}$

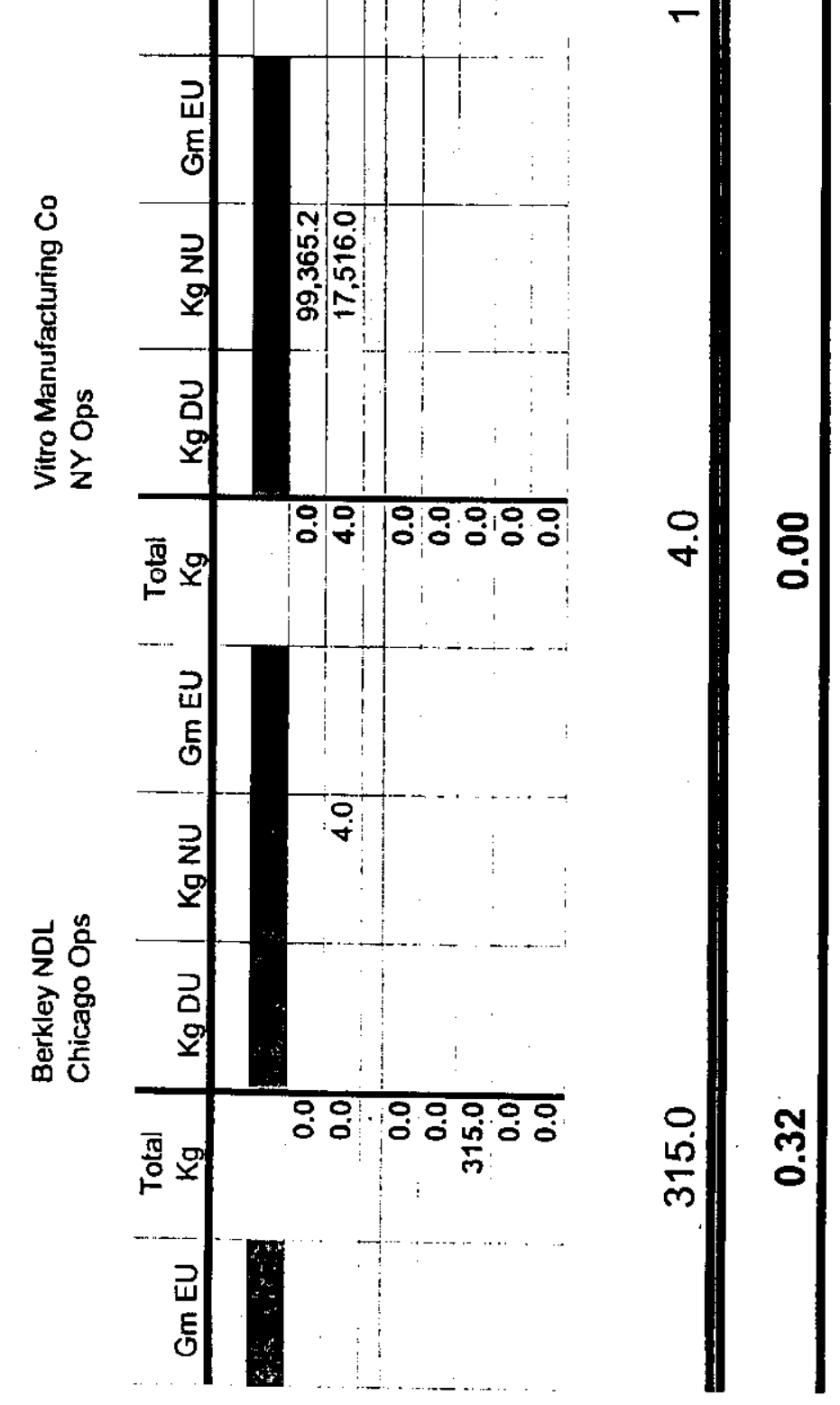


1<smiles>C1=C[As]=C1</smiles> 


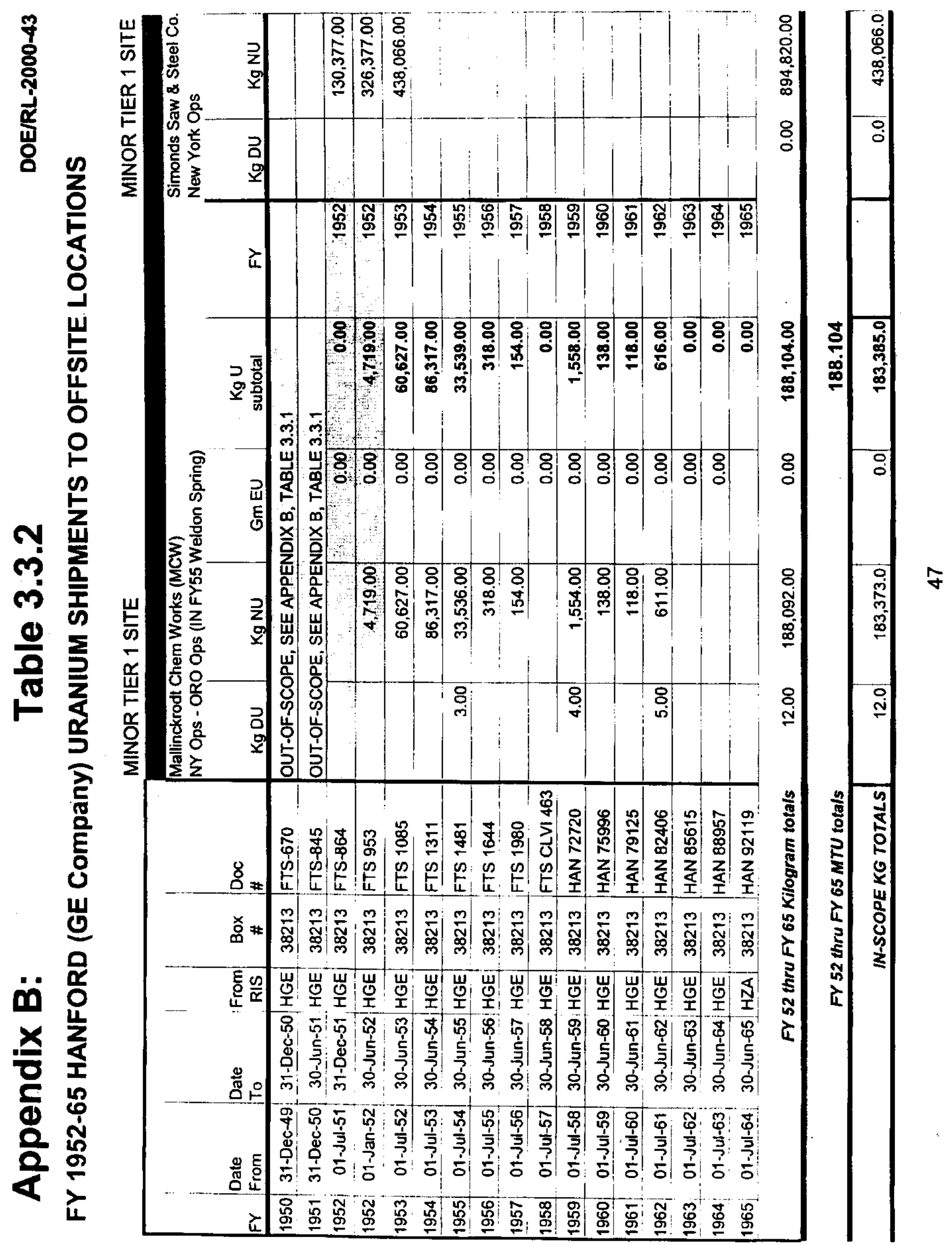




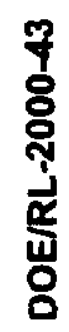

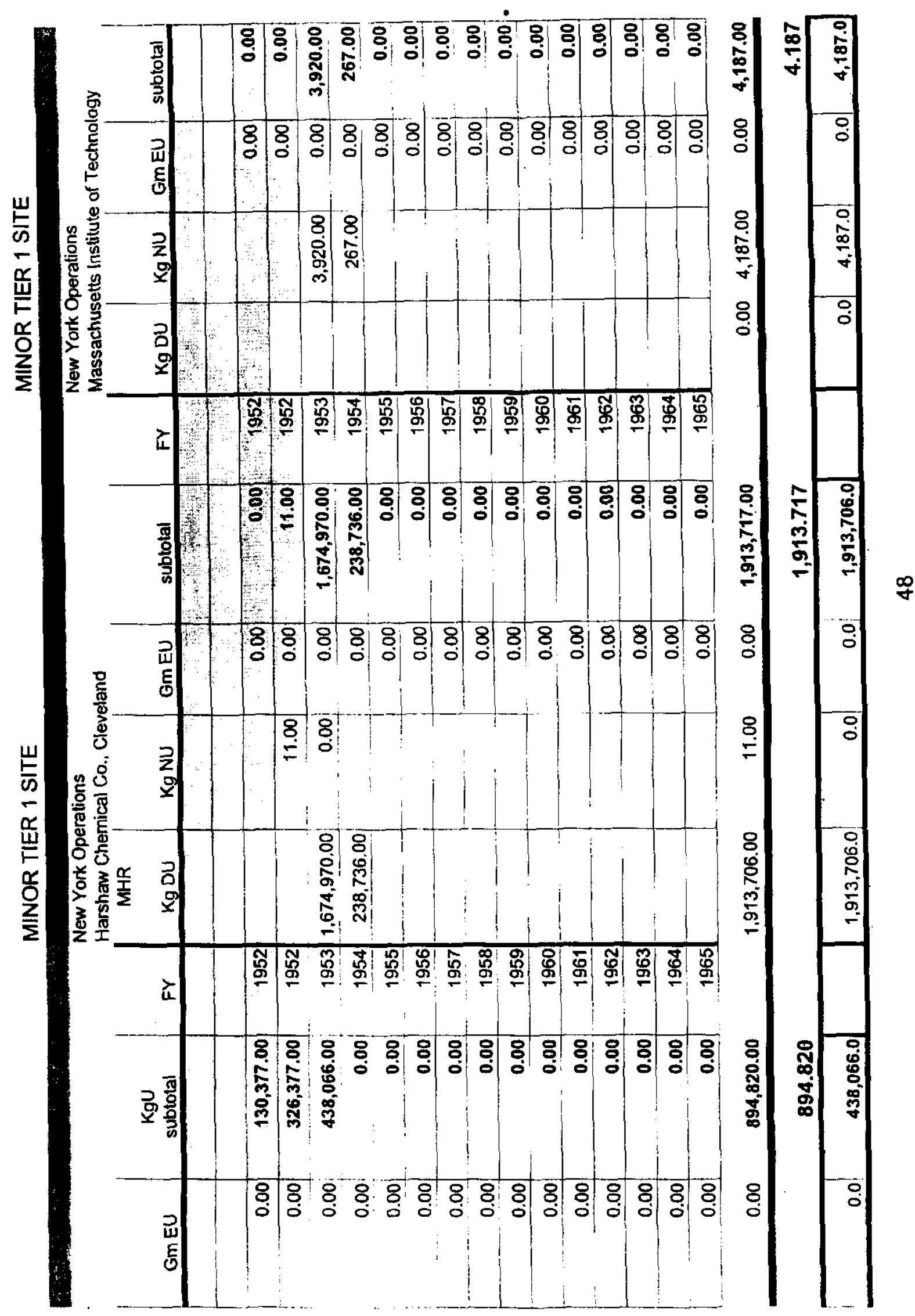




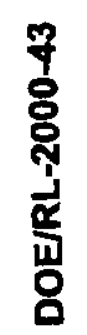

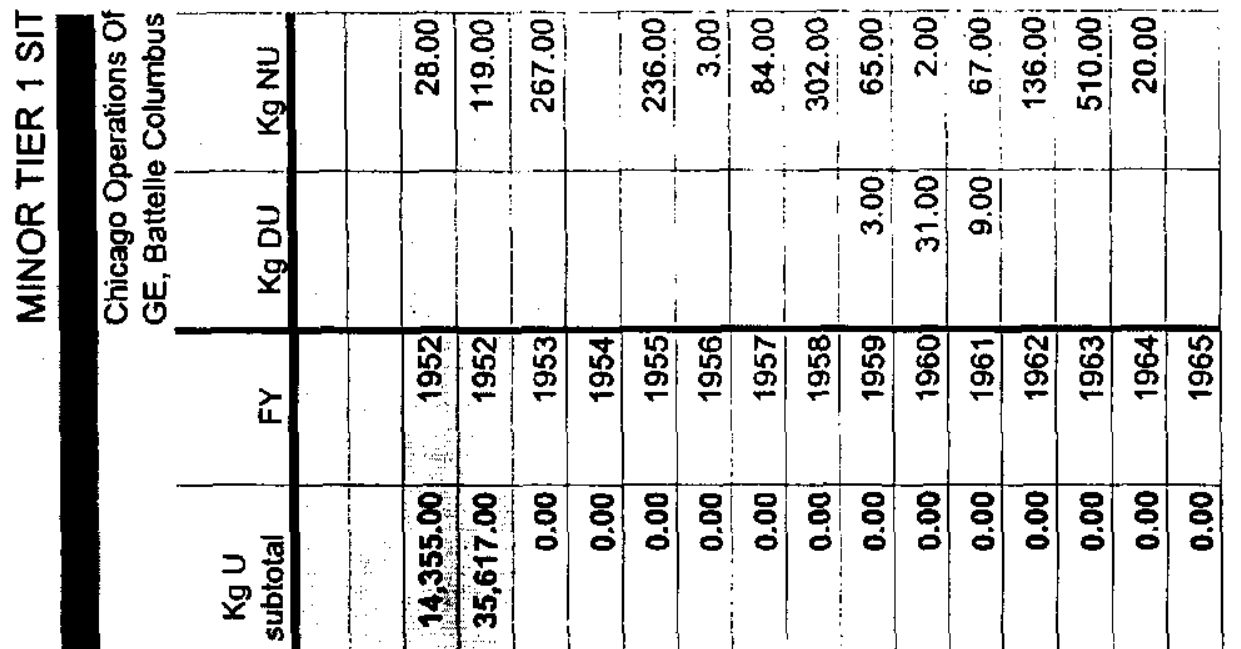

กั
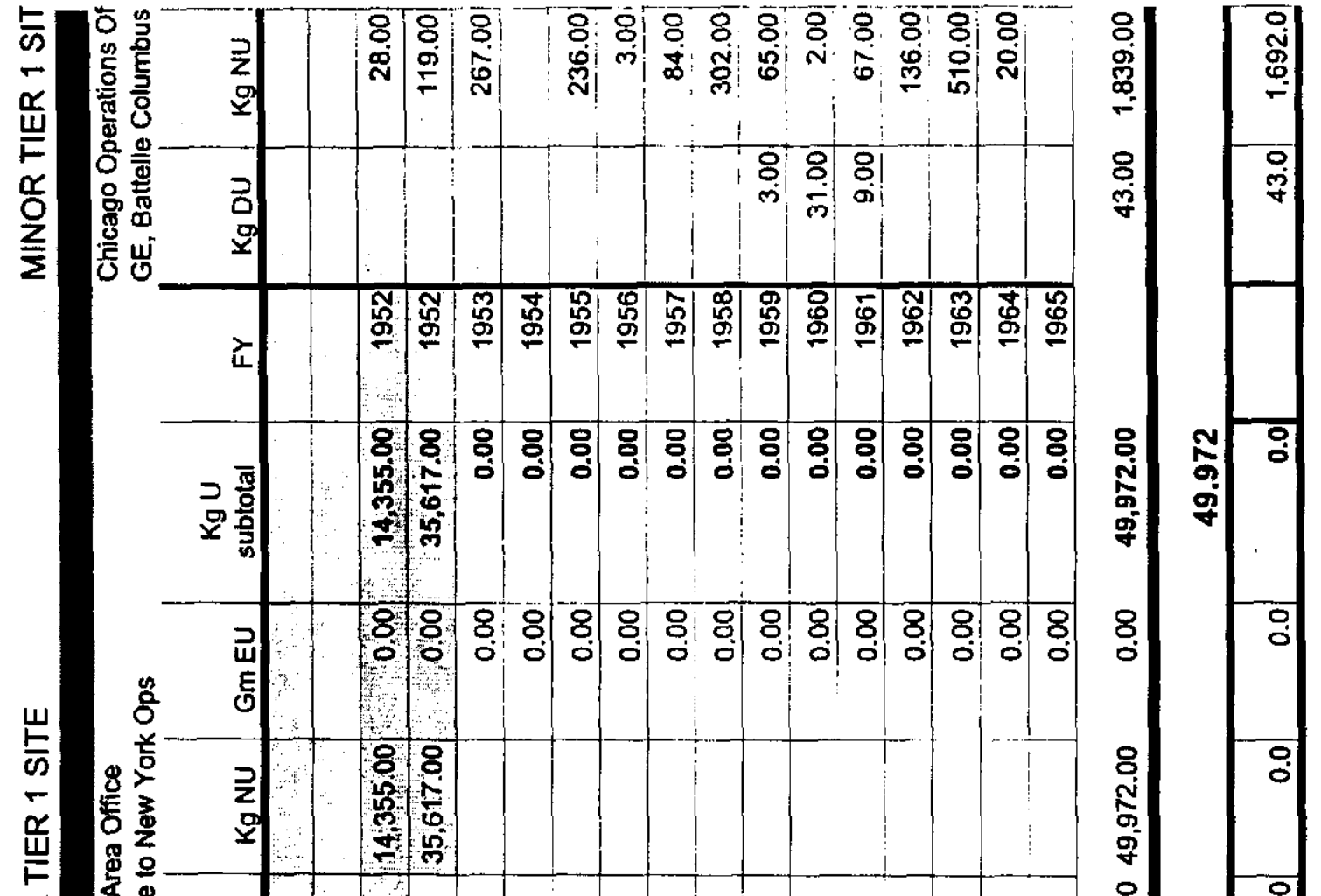

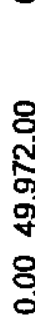

美总

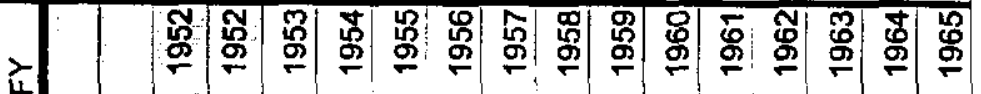

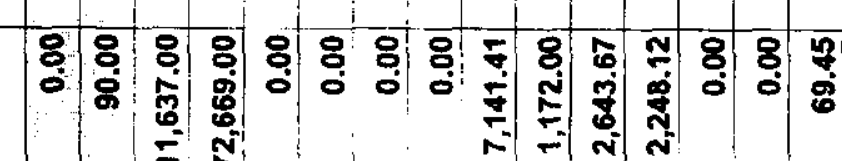

:

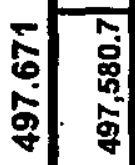

$\dot{0}$
$\times$
$\frac{8}{8}$
$\frac{0}{2}$

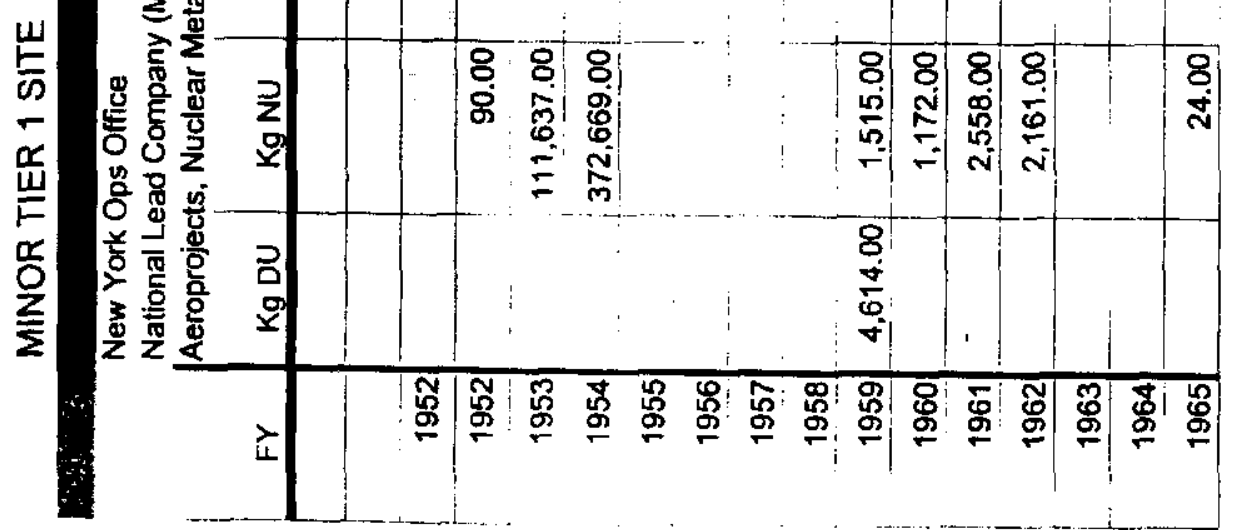




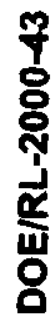
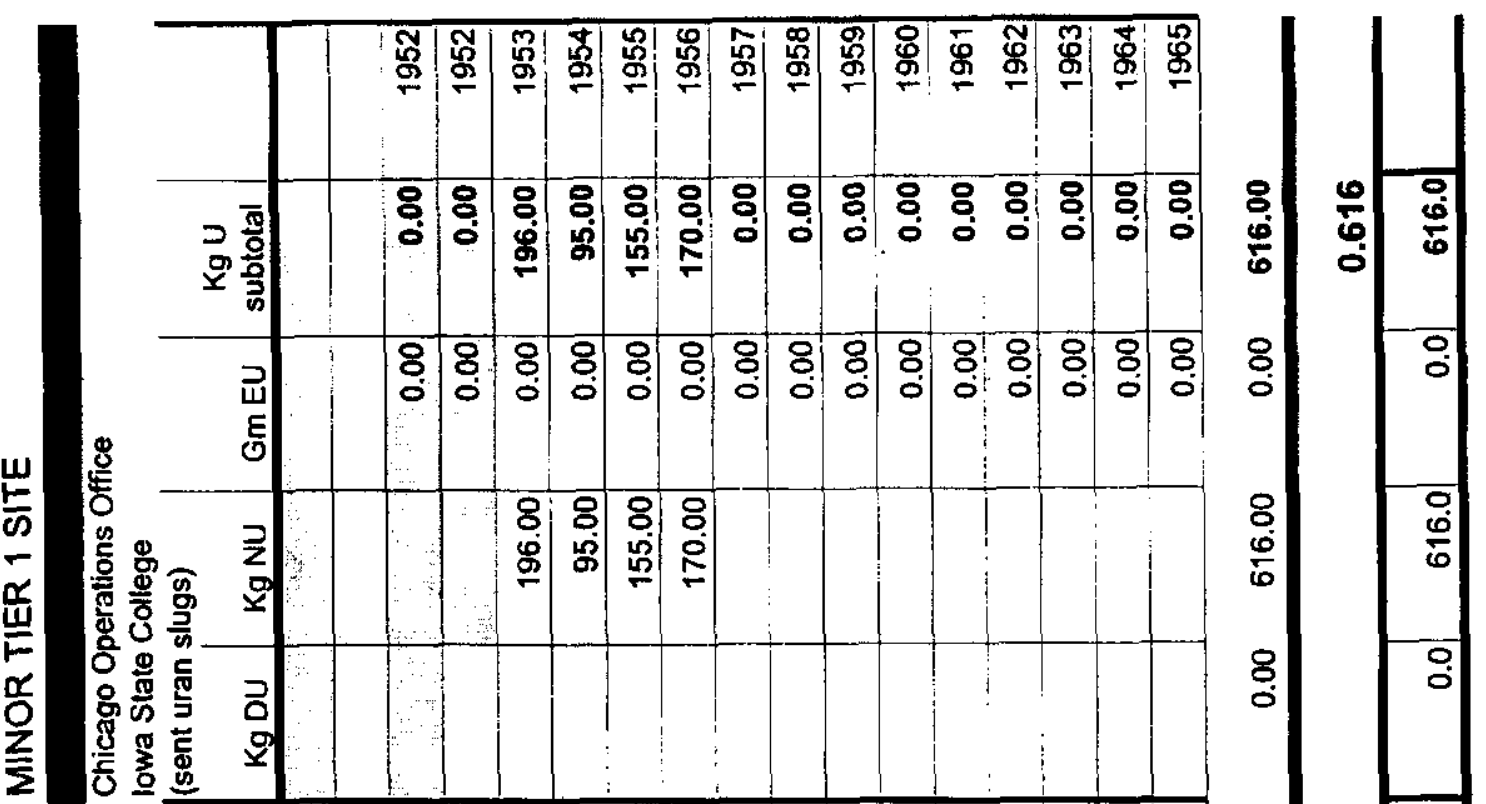

ñ
m
$\frac{0}{0}$

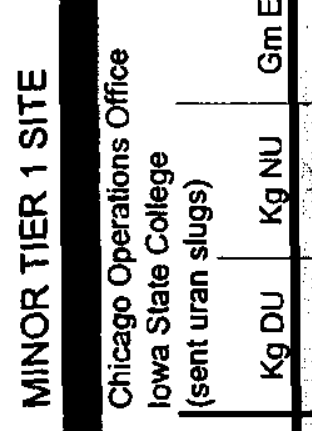

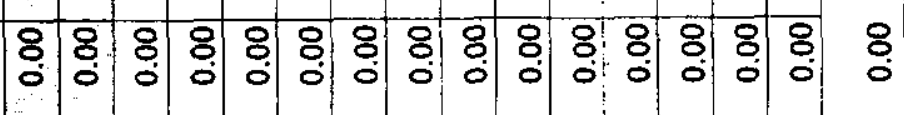

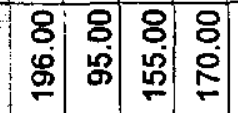

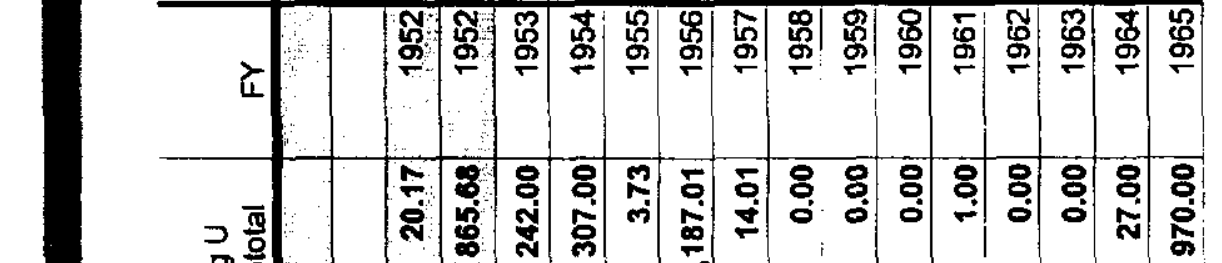

8
0
$\frac{6}{6}$

प्र

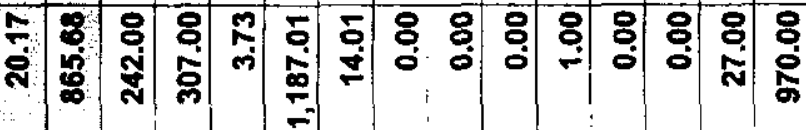

象

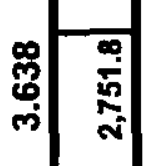

옹

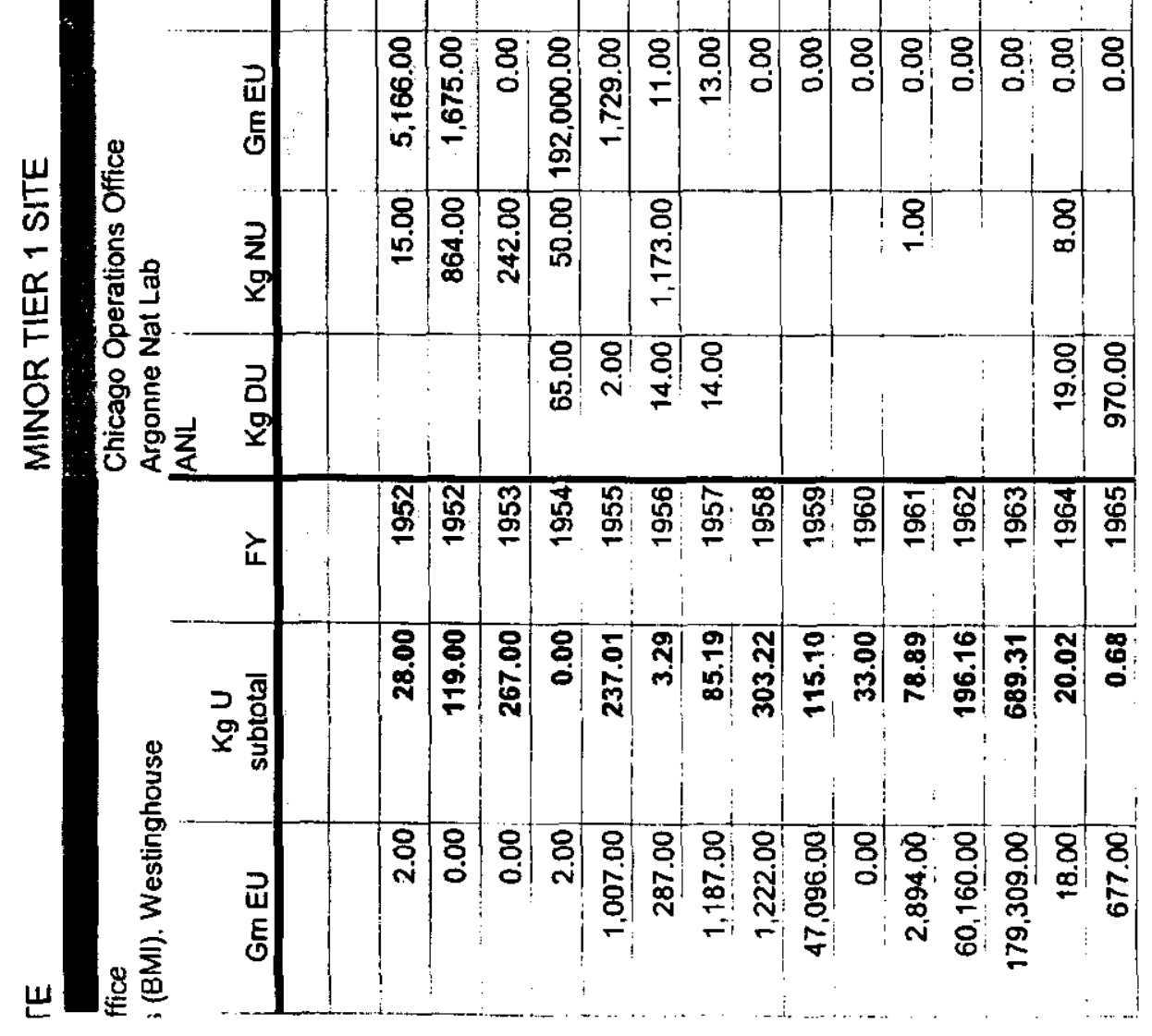

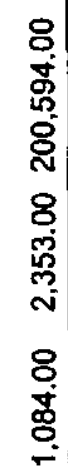

울

के

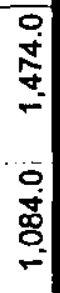

ค1

$\frac{x}{2}$

ఫ్

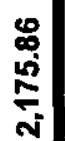

0

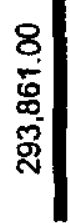

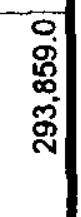




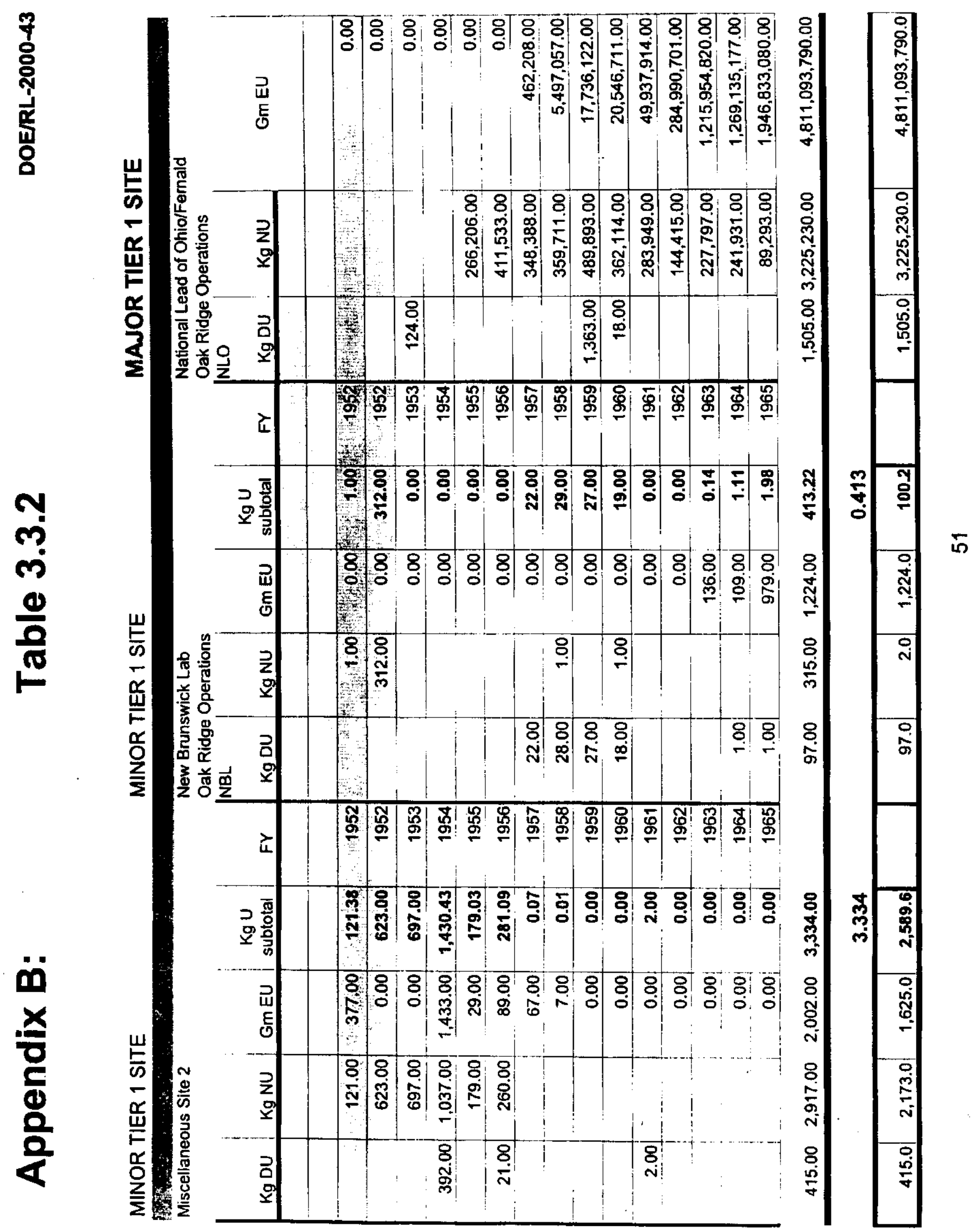




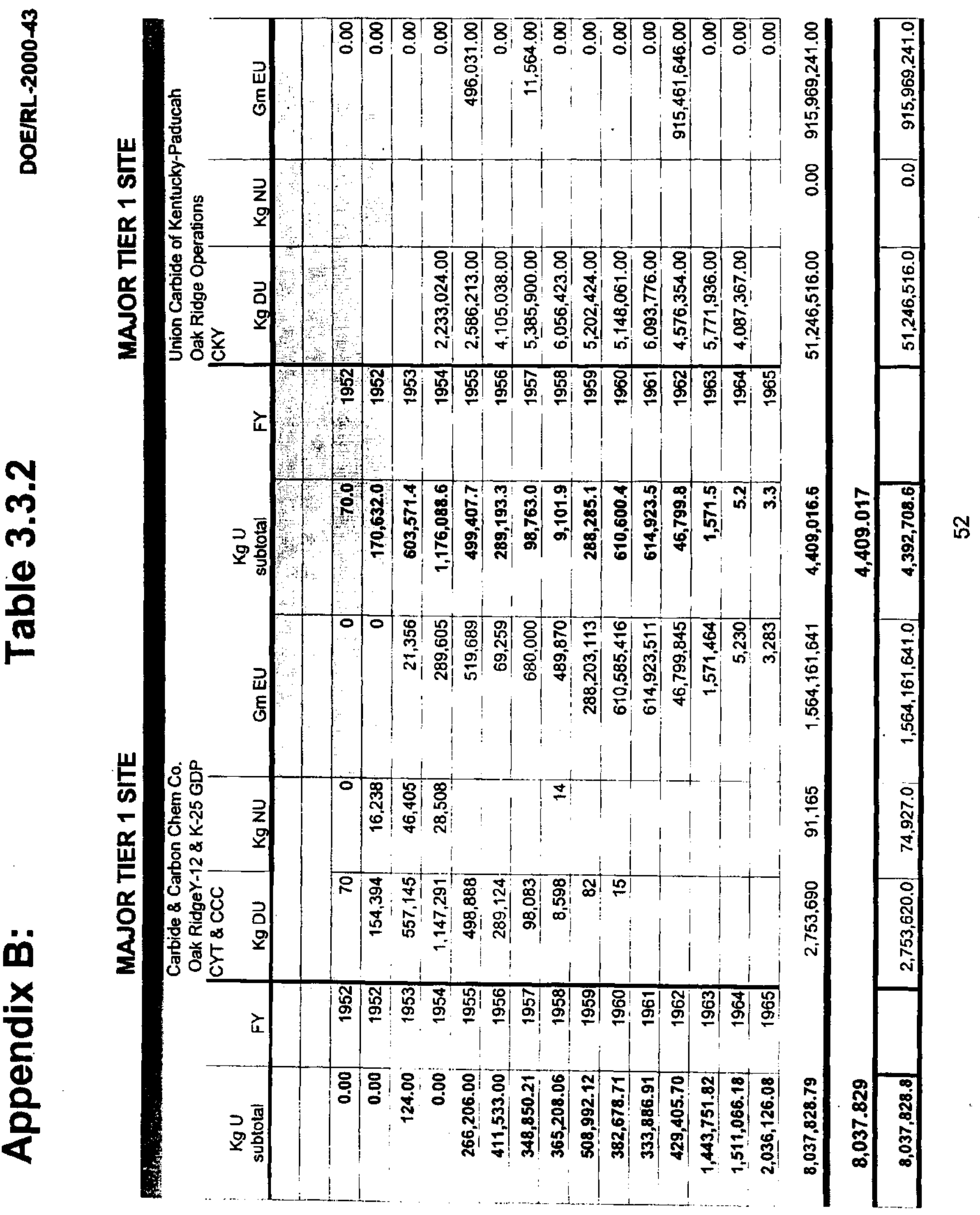




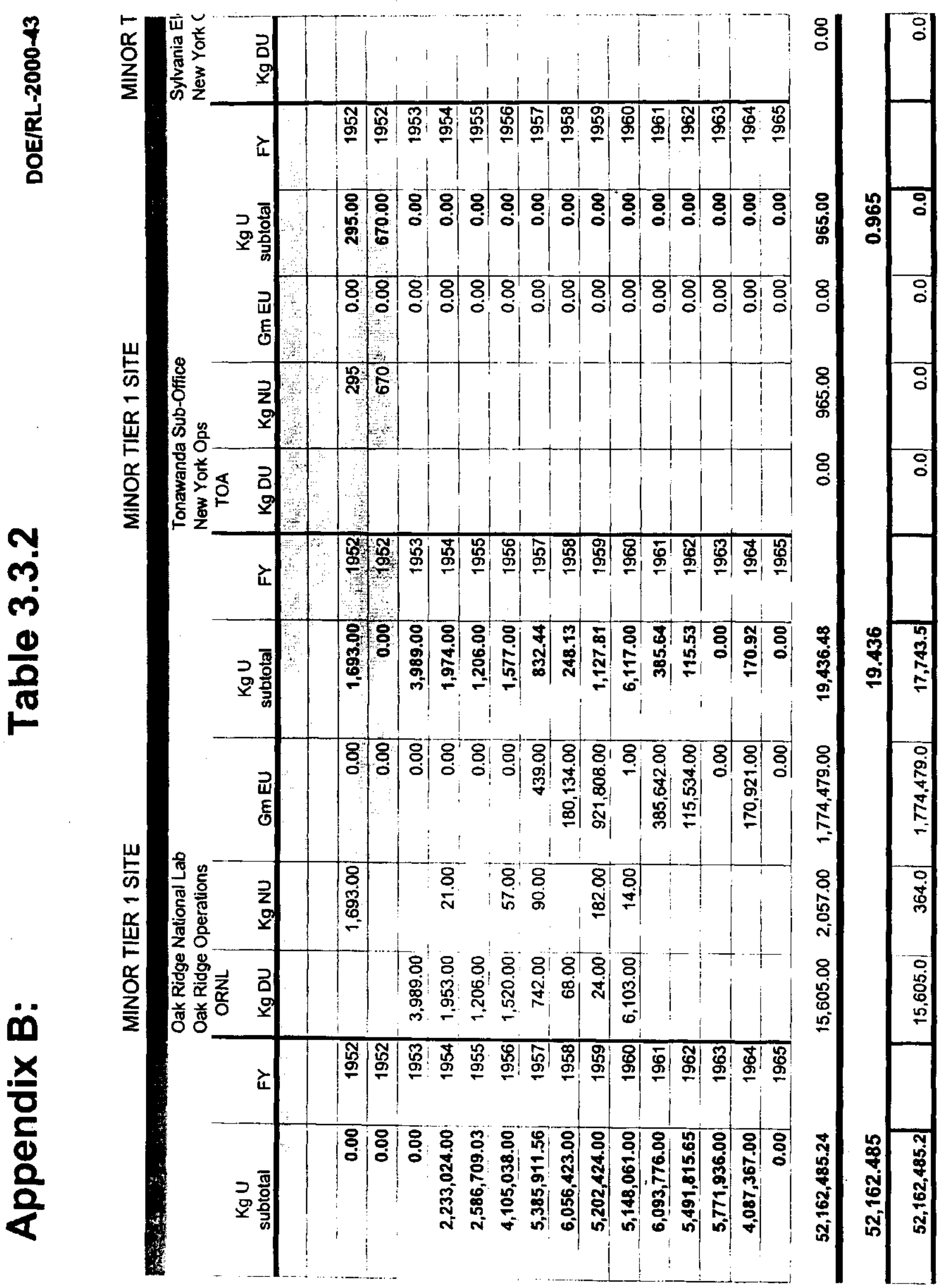


早

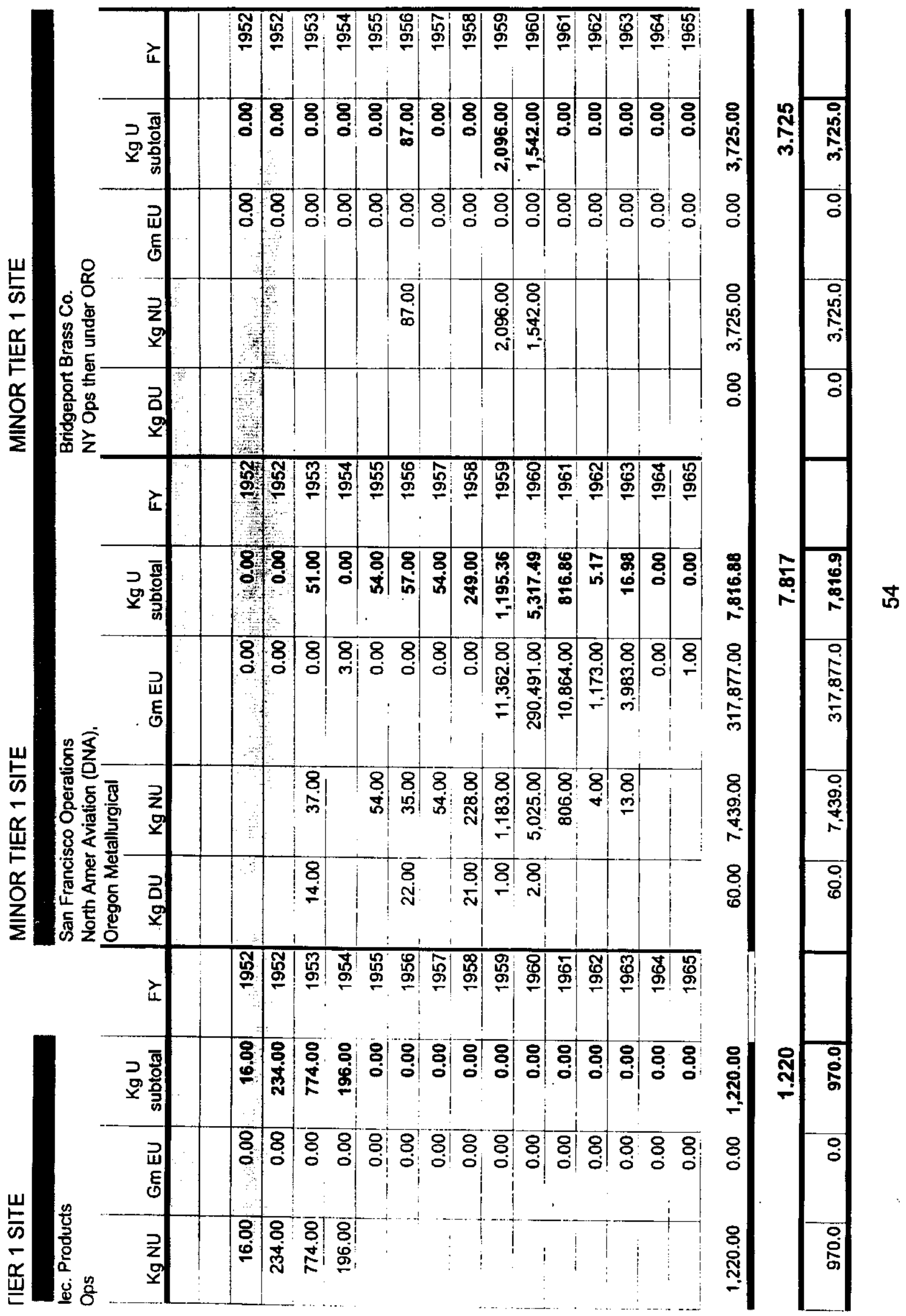




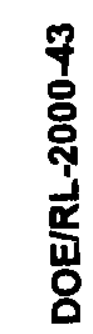
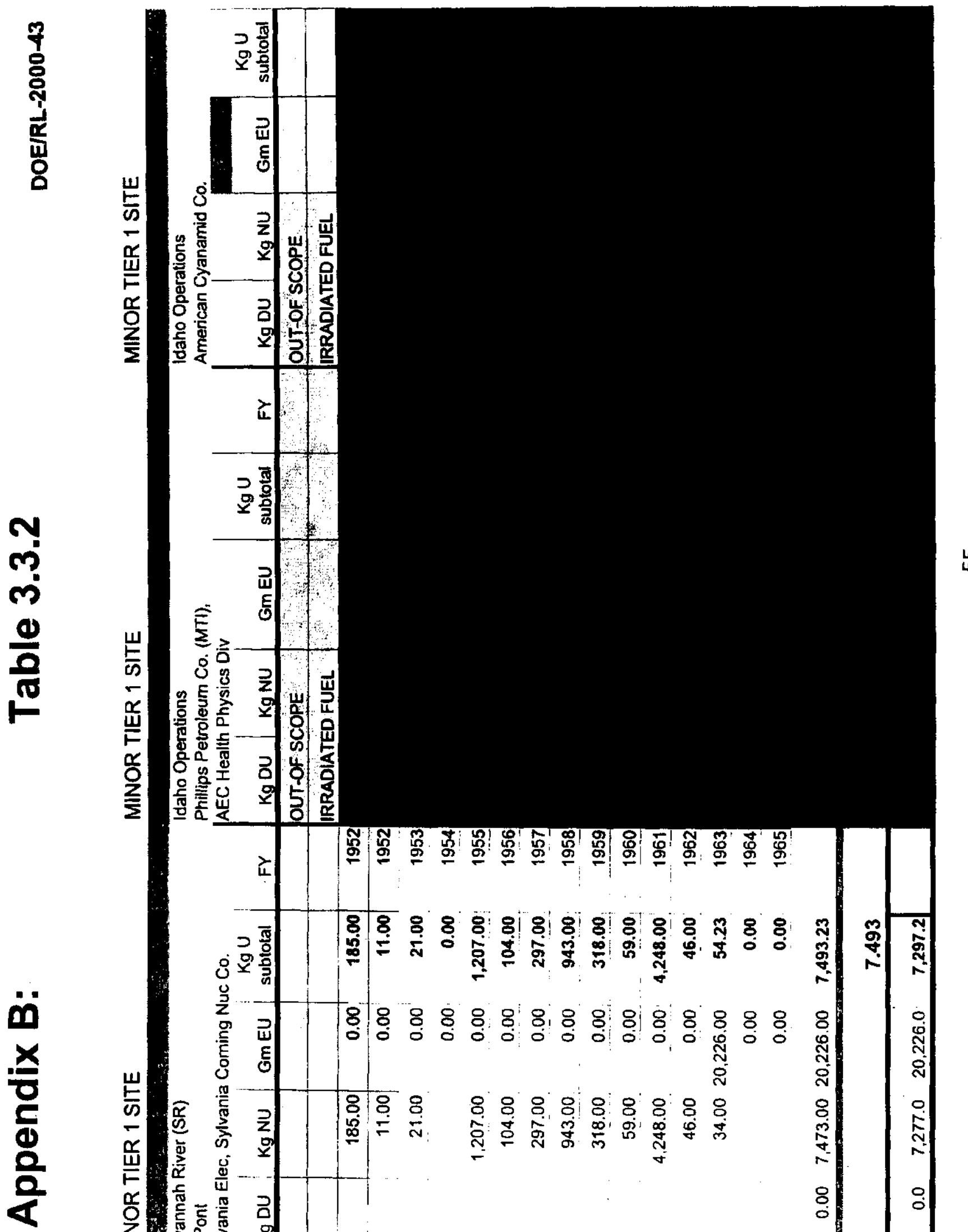

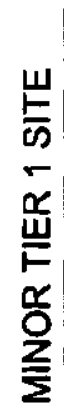

है $\quad$ ज

(1)

음

803

突究

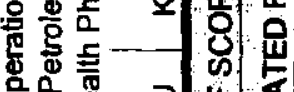

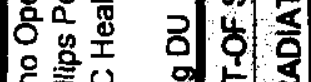

要言焉

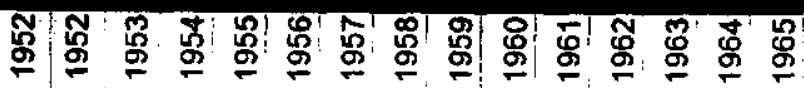

光 ১

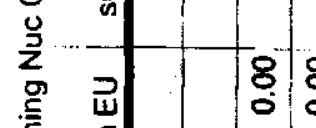

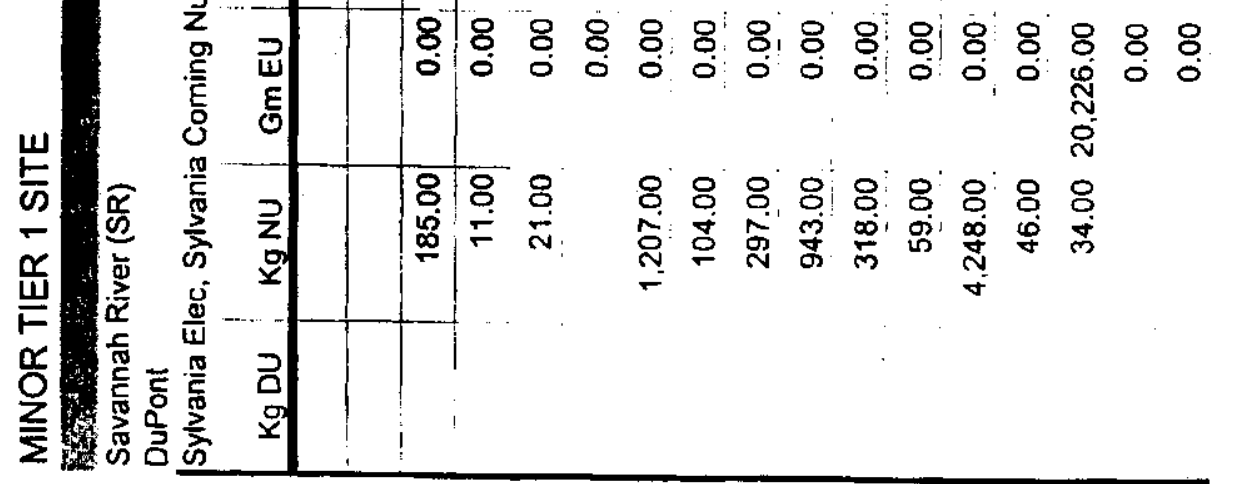




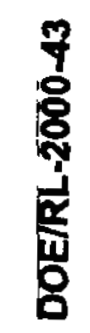
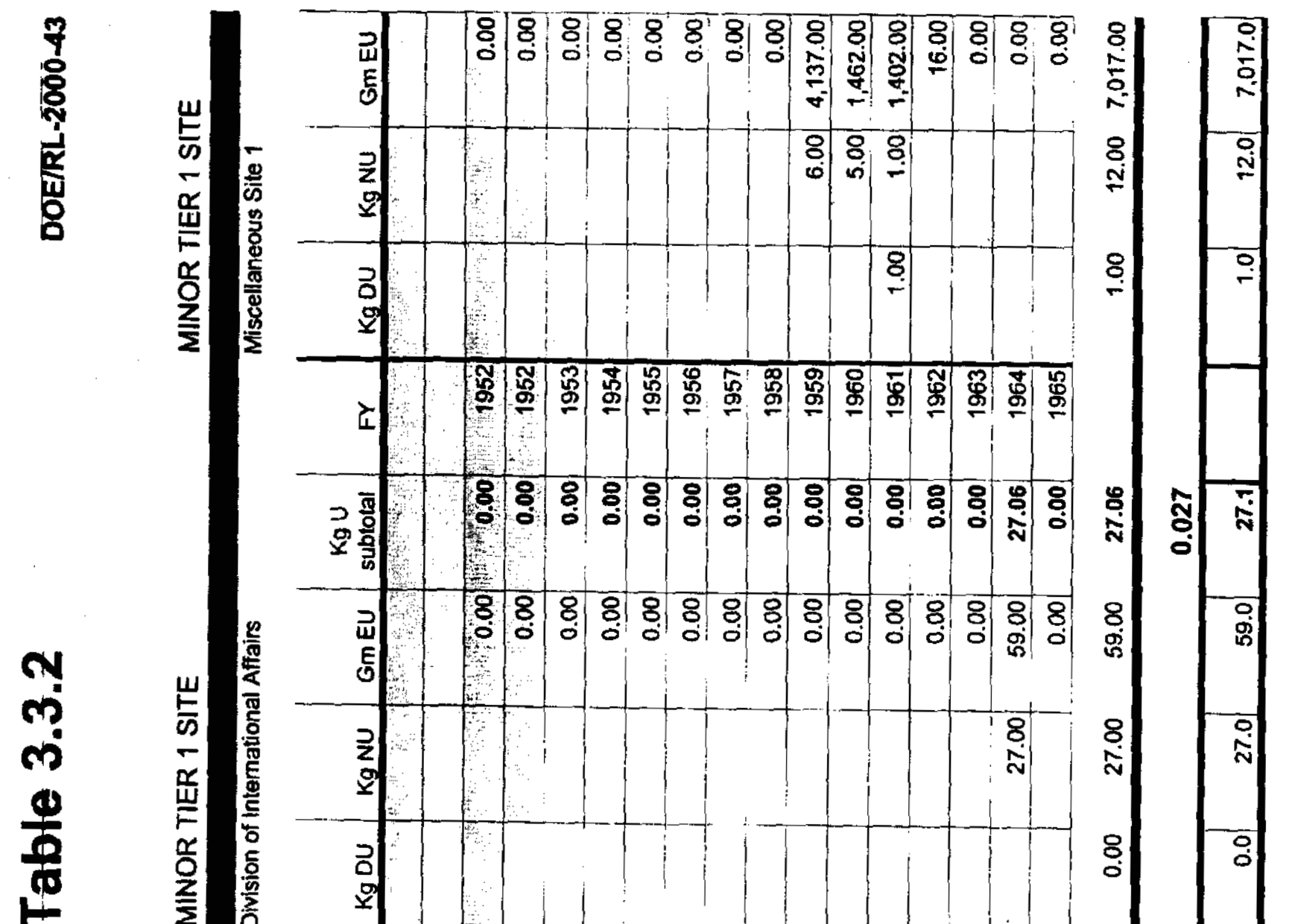

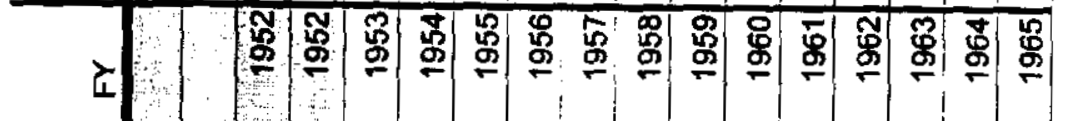

ᄀ

올

$\stackrel{\circ}{\text { กั }}$

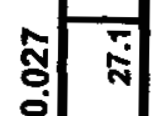

峁

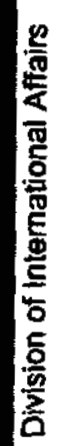

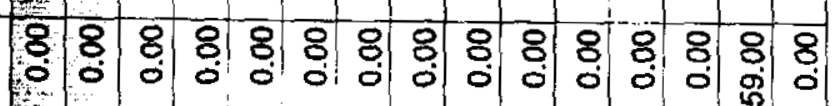

링.

.

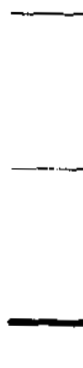

ㄱํำ

깅.

I

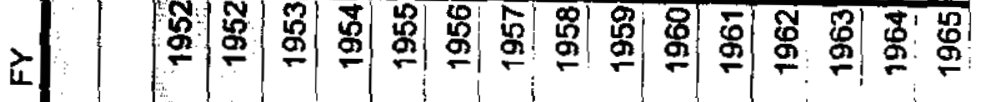

8

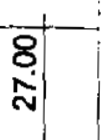

$\stackrel{8}{\stackrel{8}{~}}$

요

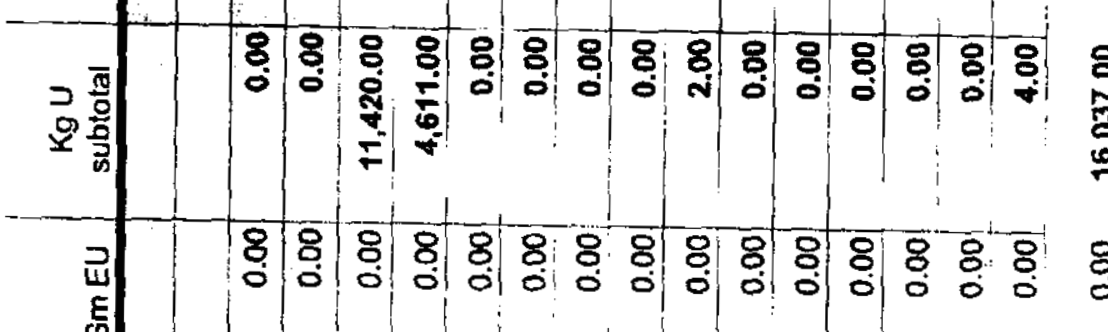

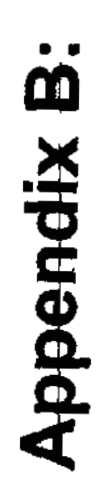
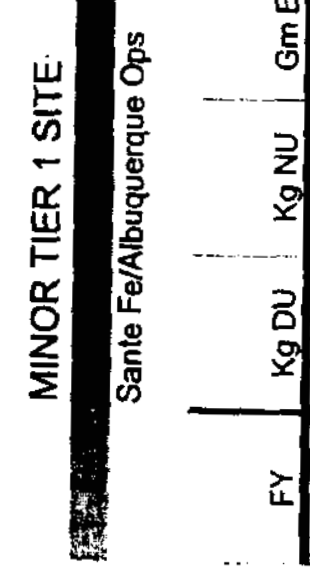


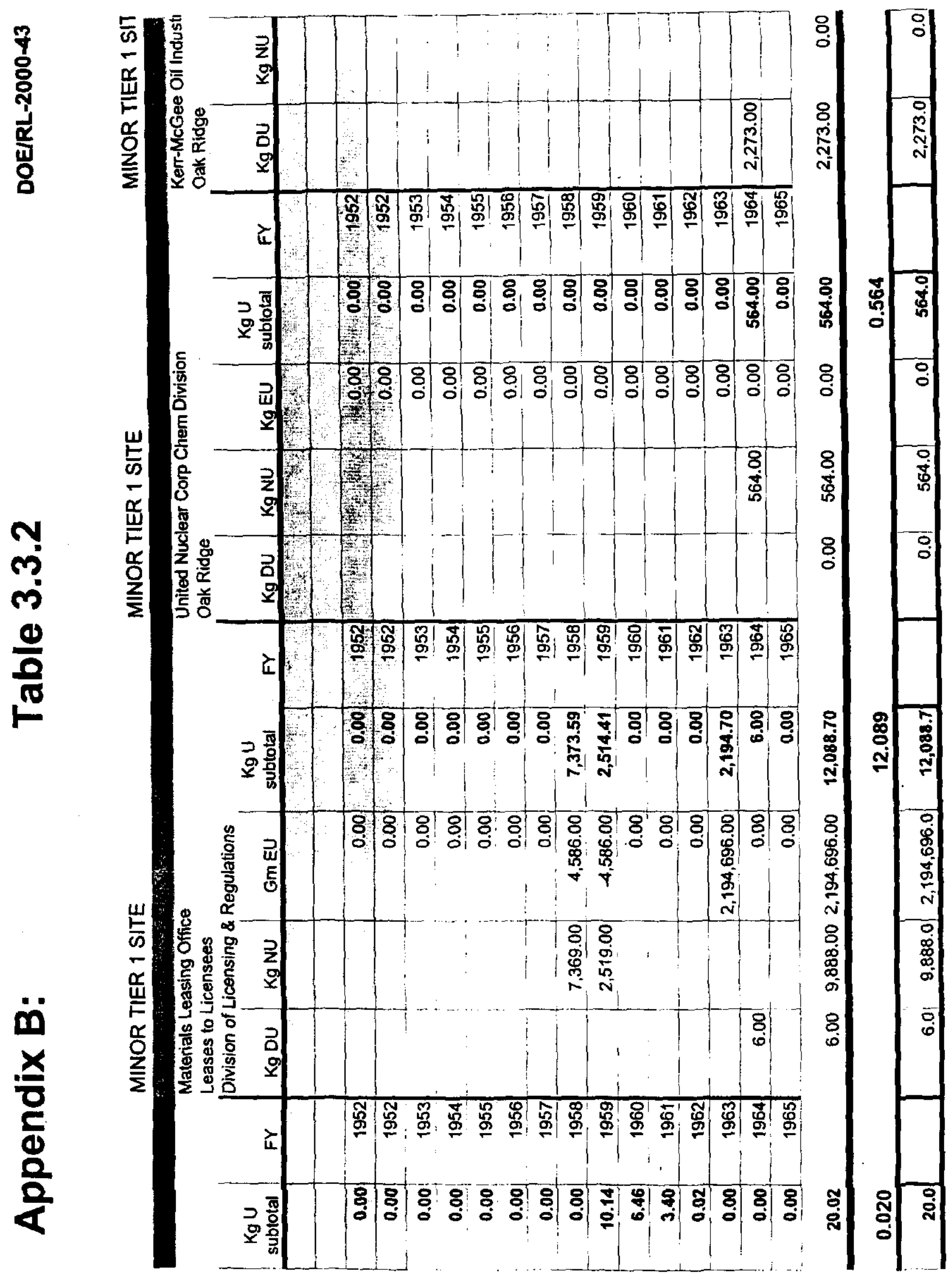




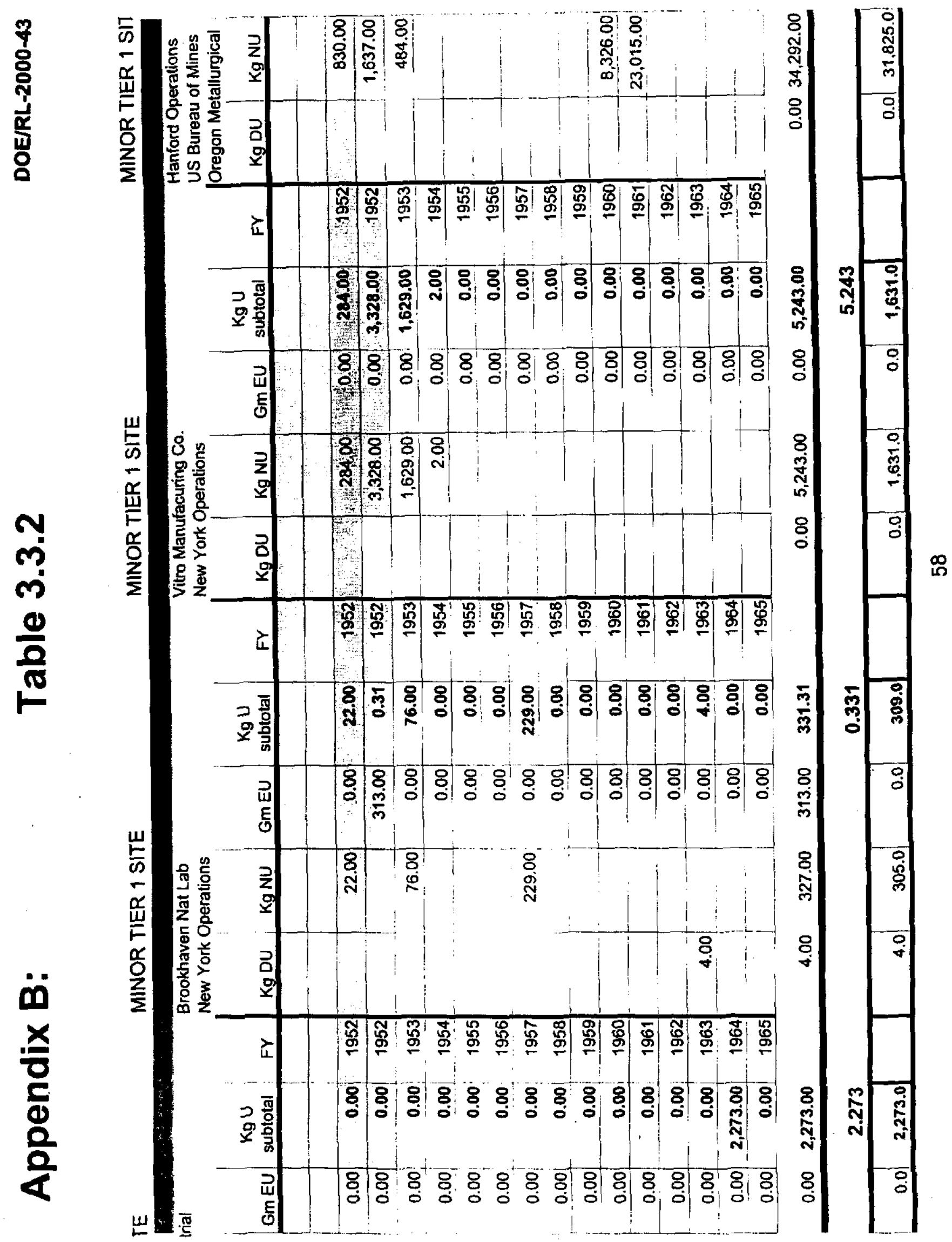




\section{Error}

An error occurred while processing this page. See the system log for more details. 
$\Upsilon$
8
8
$\frac{8}{3}$
$\frac{1}{0}$
8

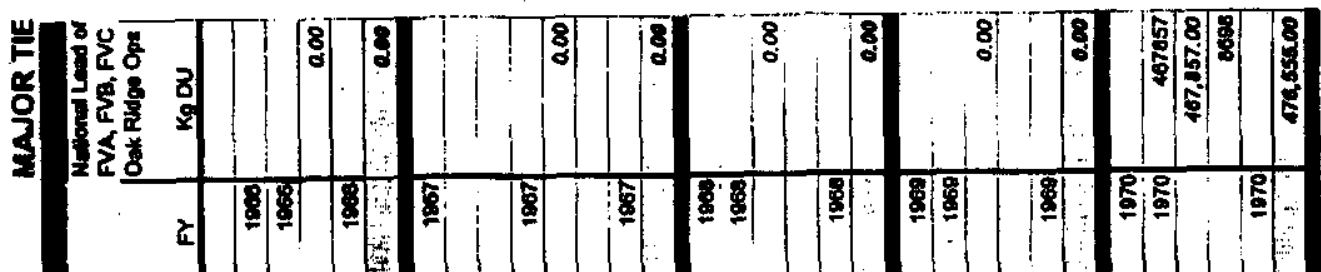
ว

임

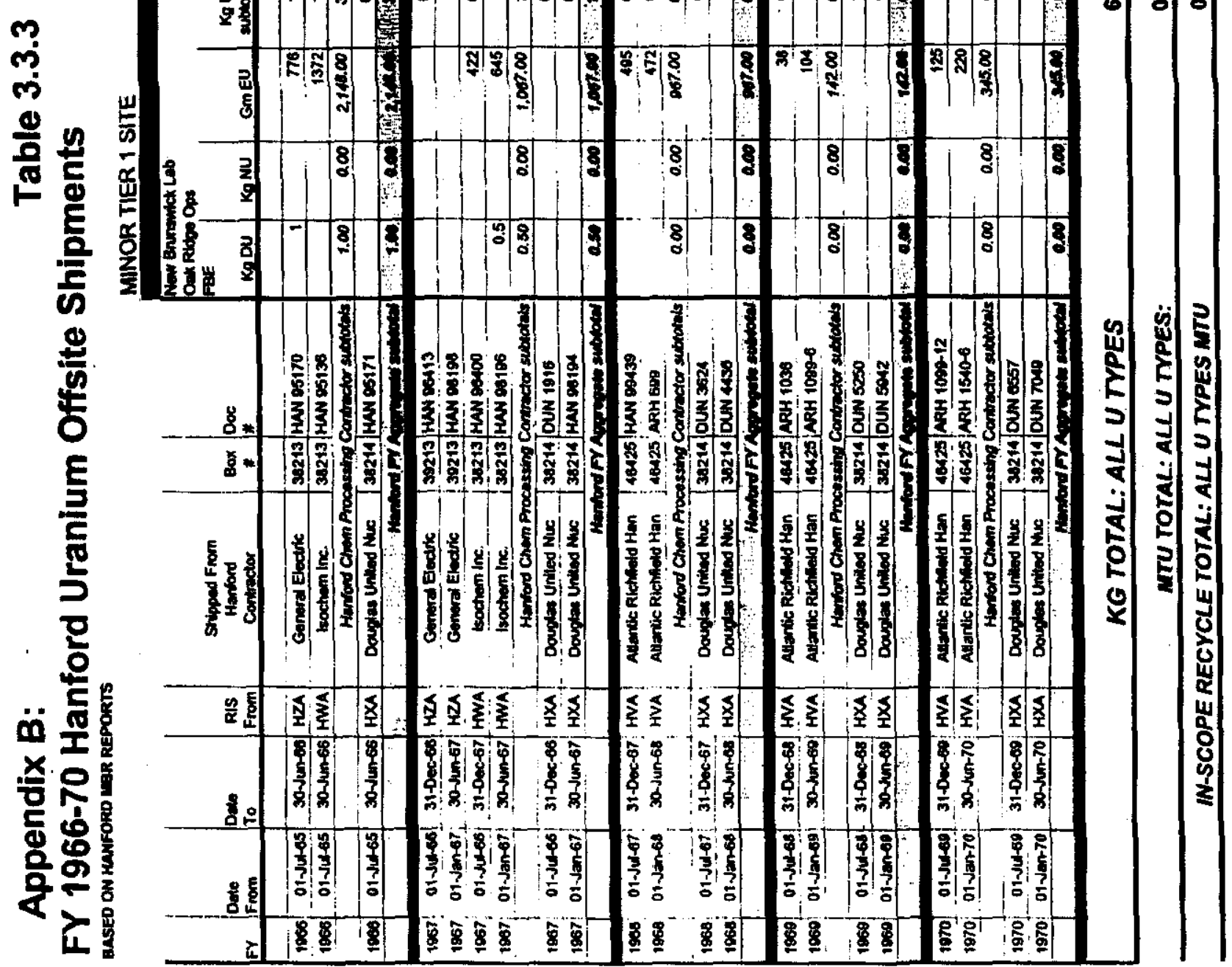




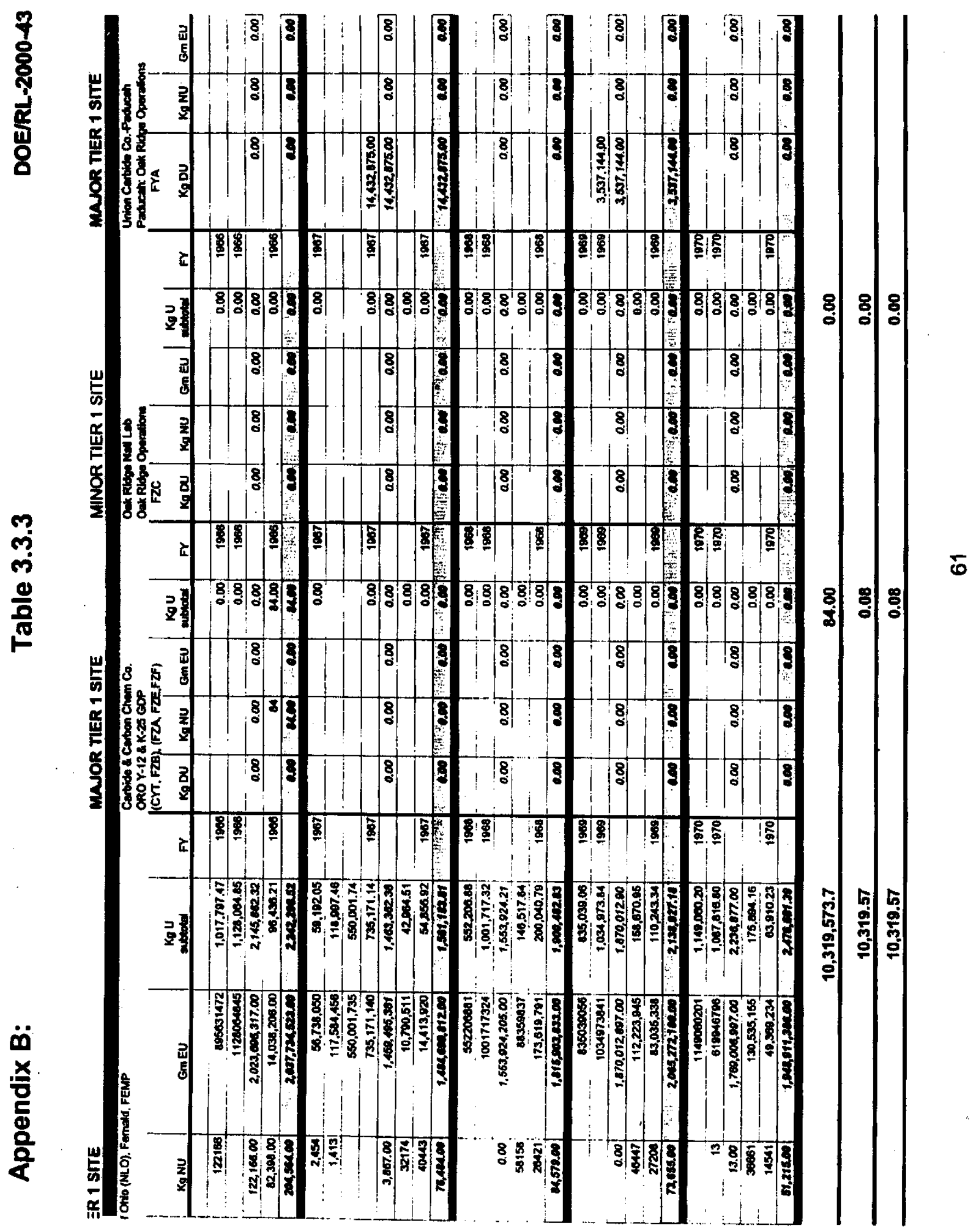


ถู้

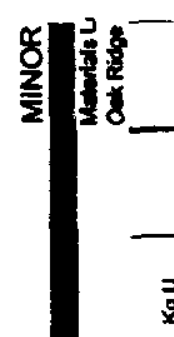

3:

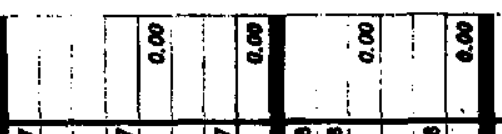

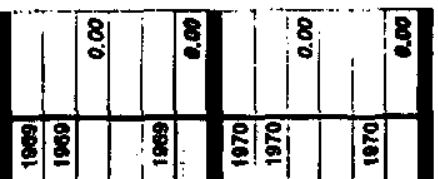

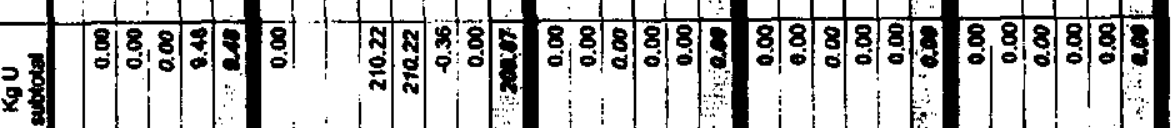

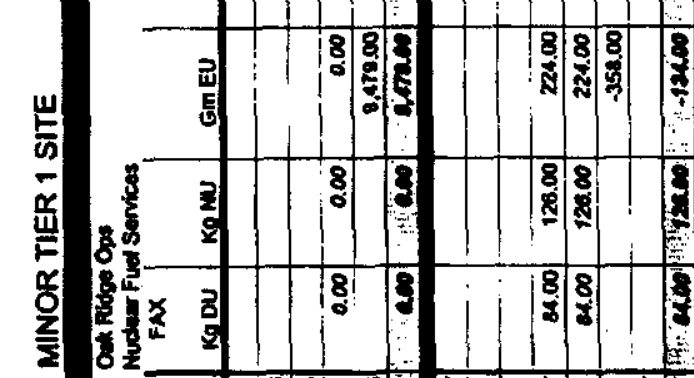

\begin{tabular}{lll|l|l|l}
\hline 8 & 8 & 8 & 5 & 8 & 8
\end{tabular}

ำ: 총

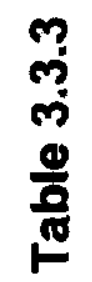

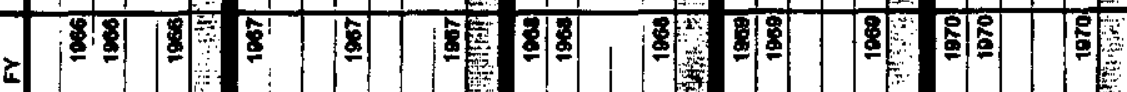

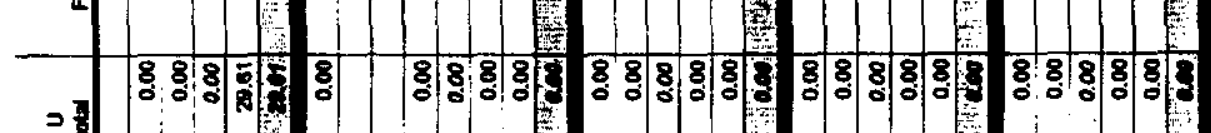

สิ:

它

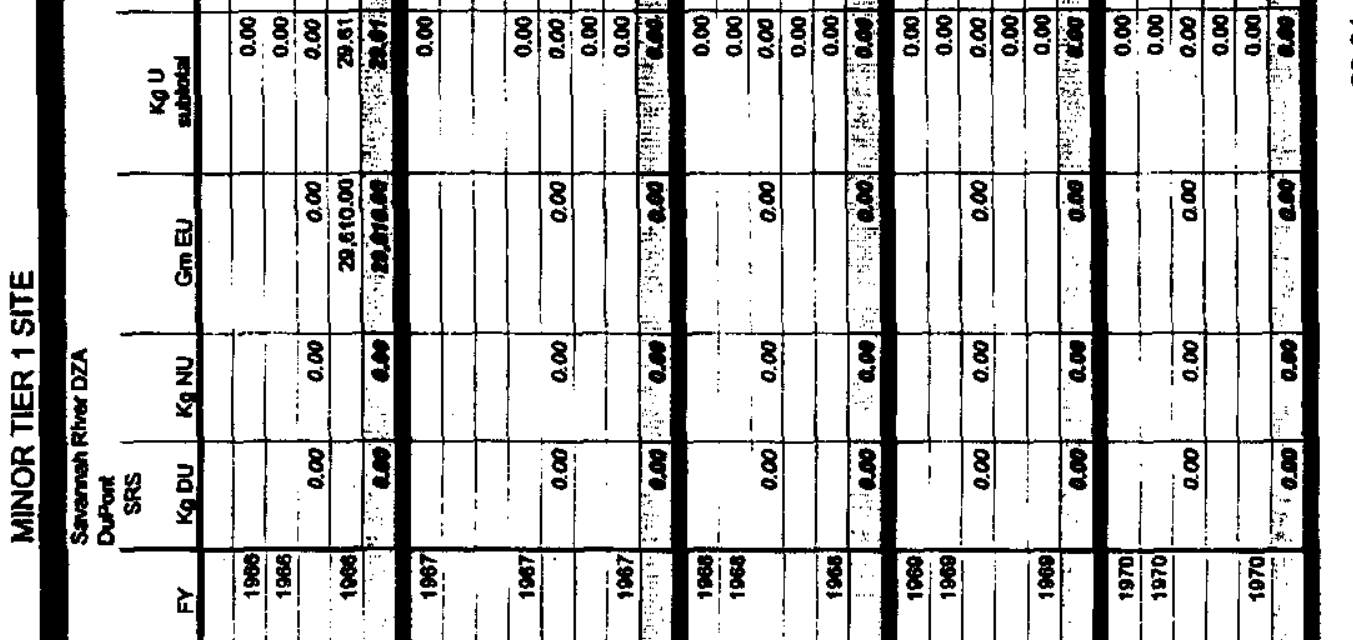

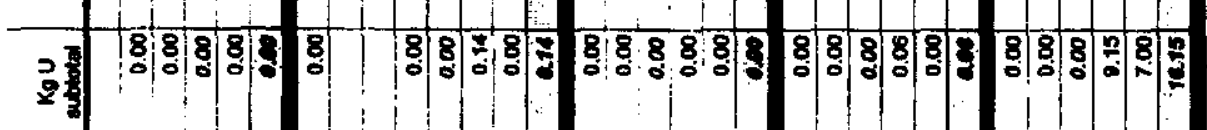

象

虍

(1)

落. 8

I

8

(8) क्षे

8 : 8

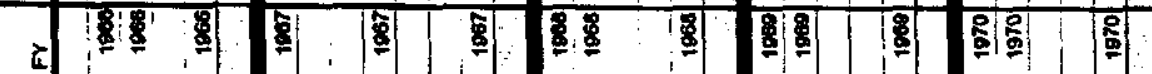

흥.

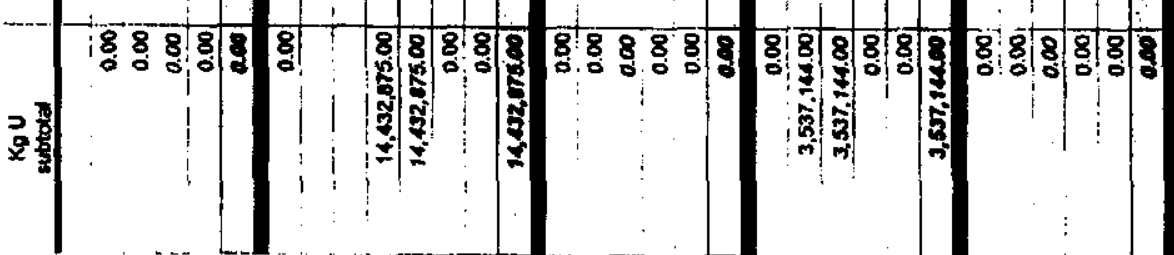

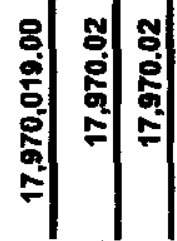


9
8
8
8
8
8
8
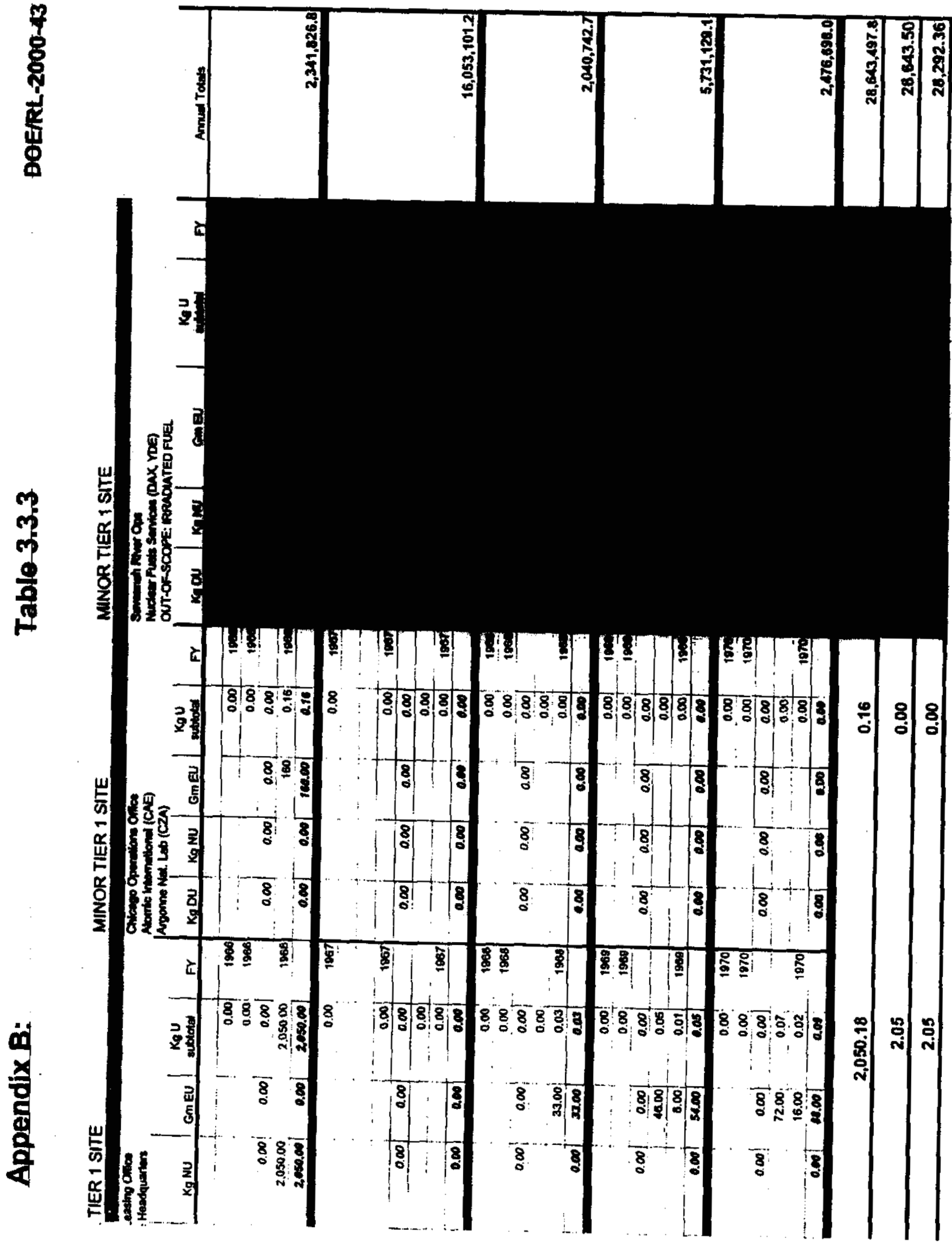


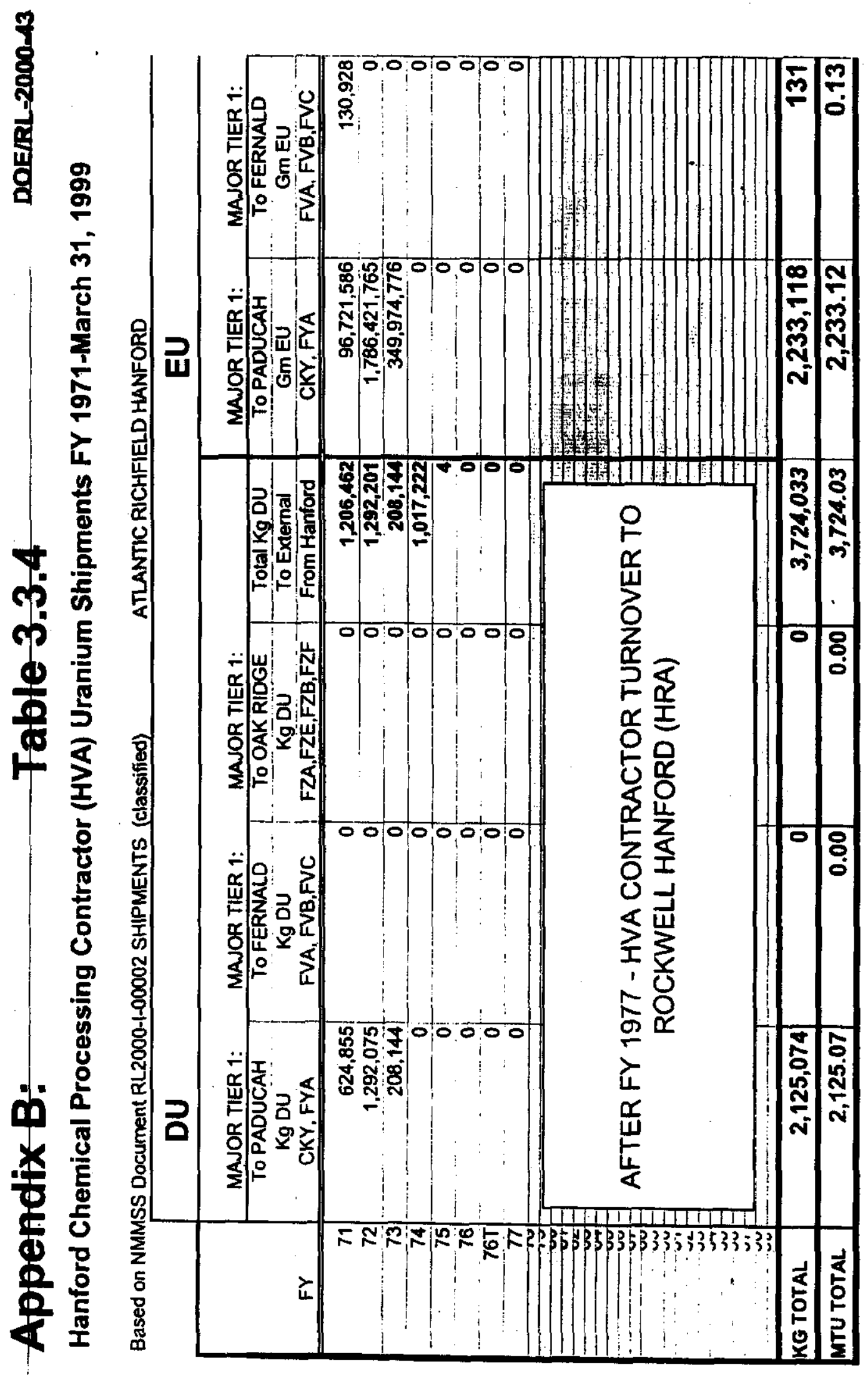

ष 


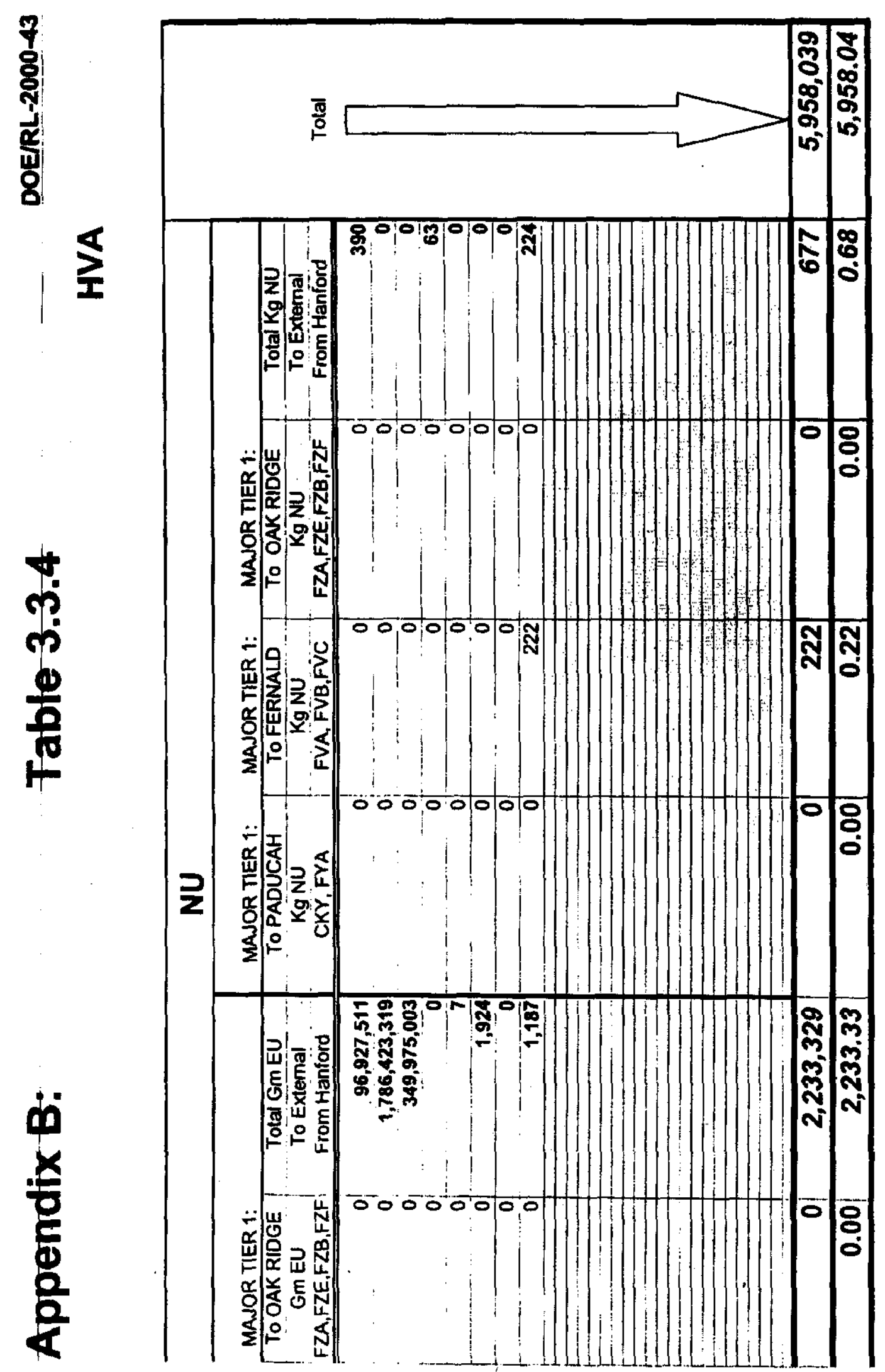




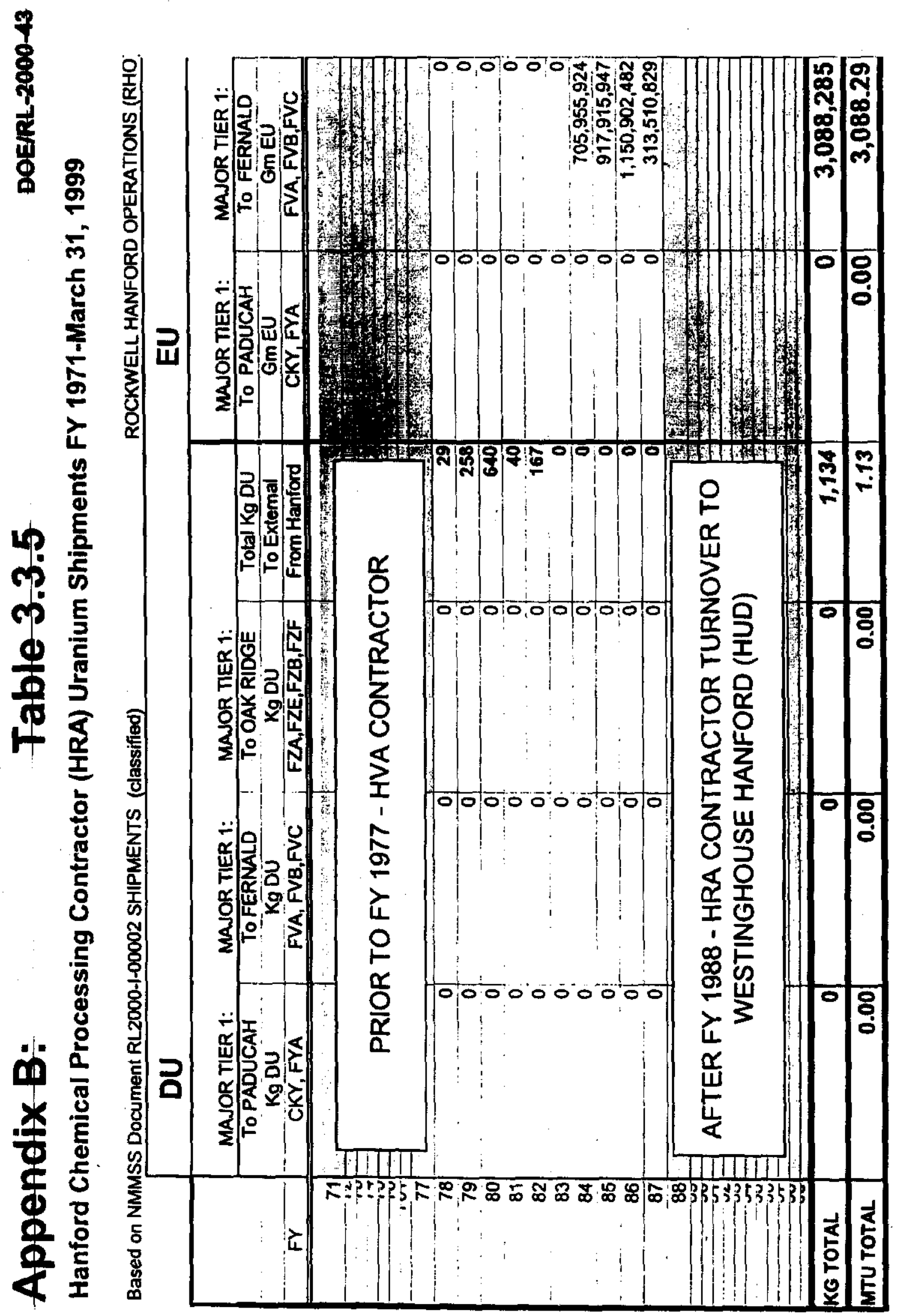

8 


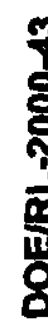
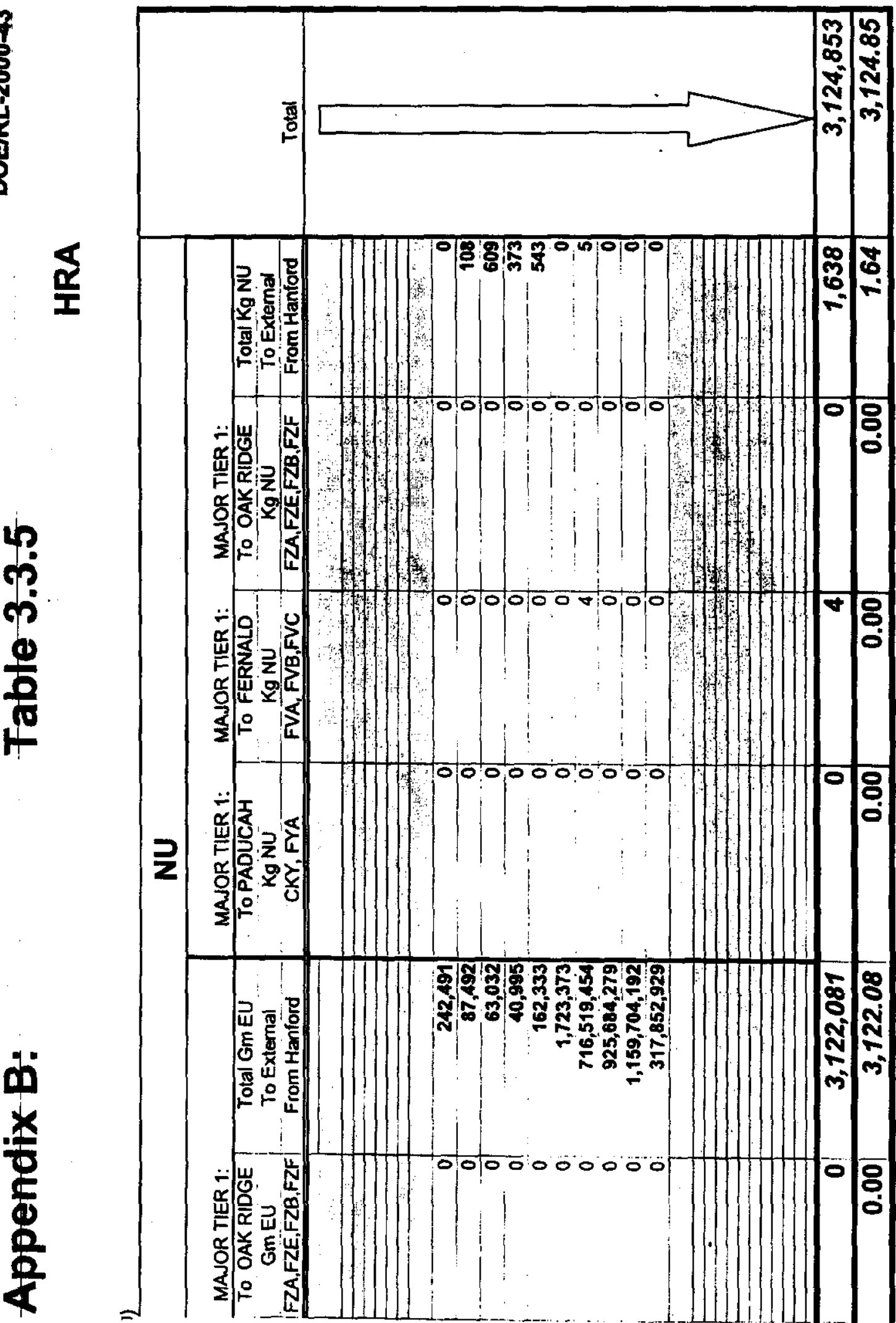

$\hat{\circ}$ 


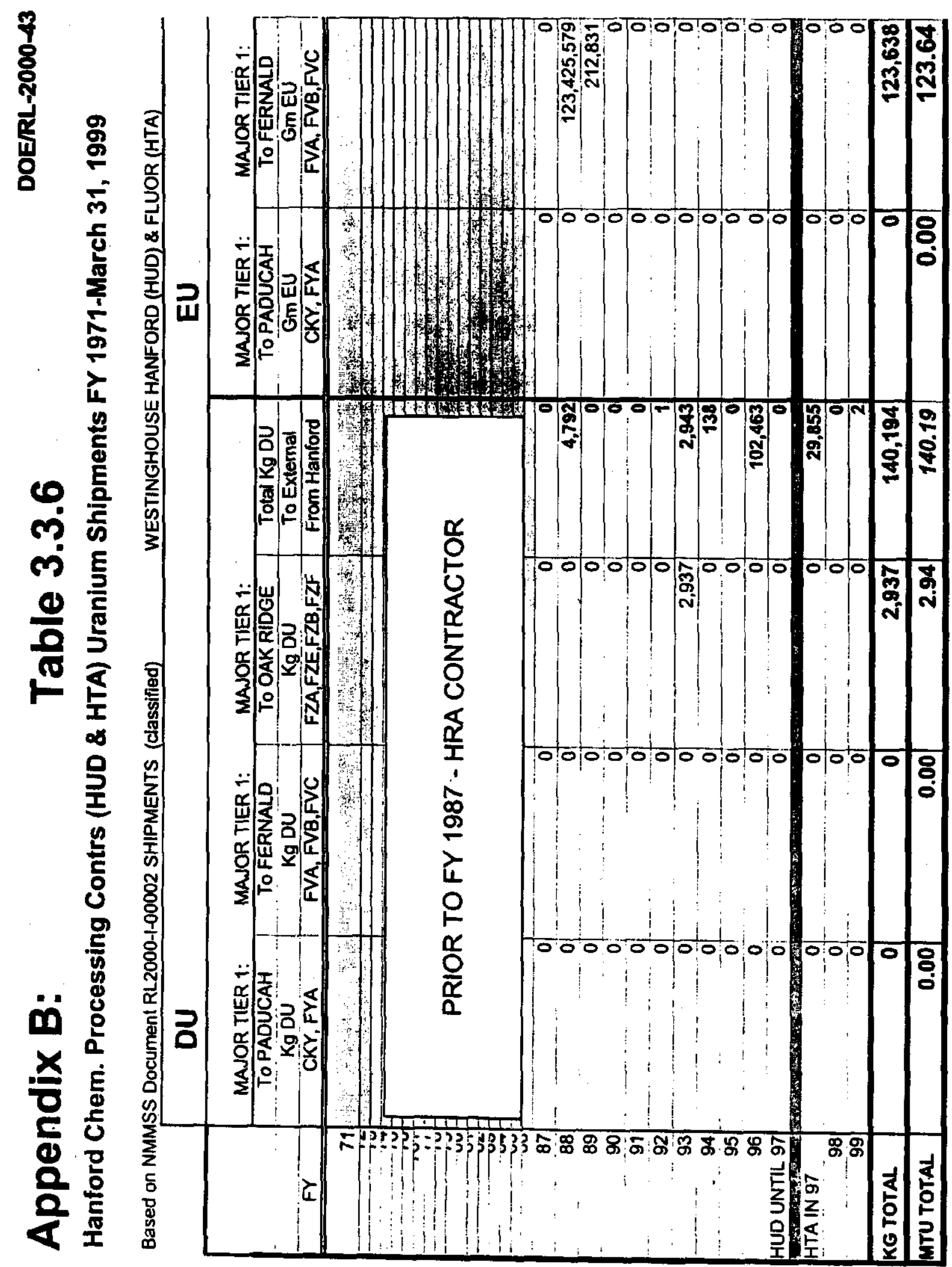




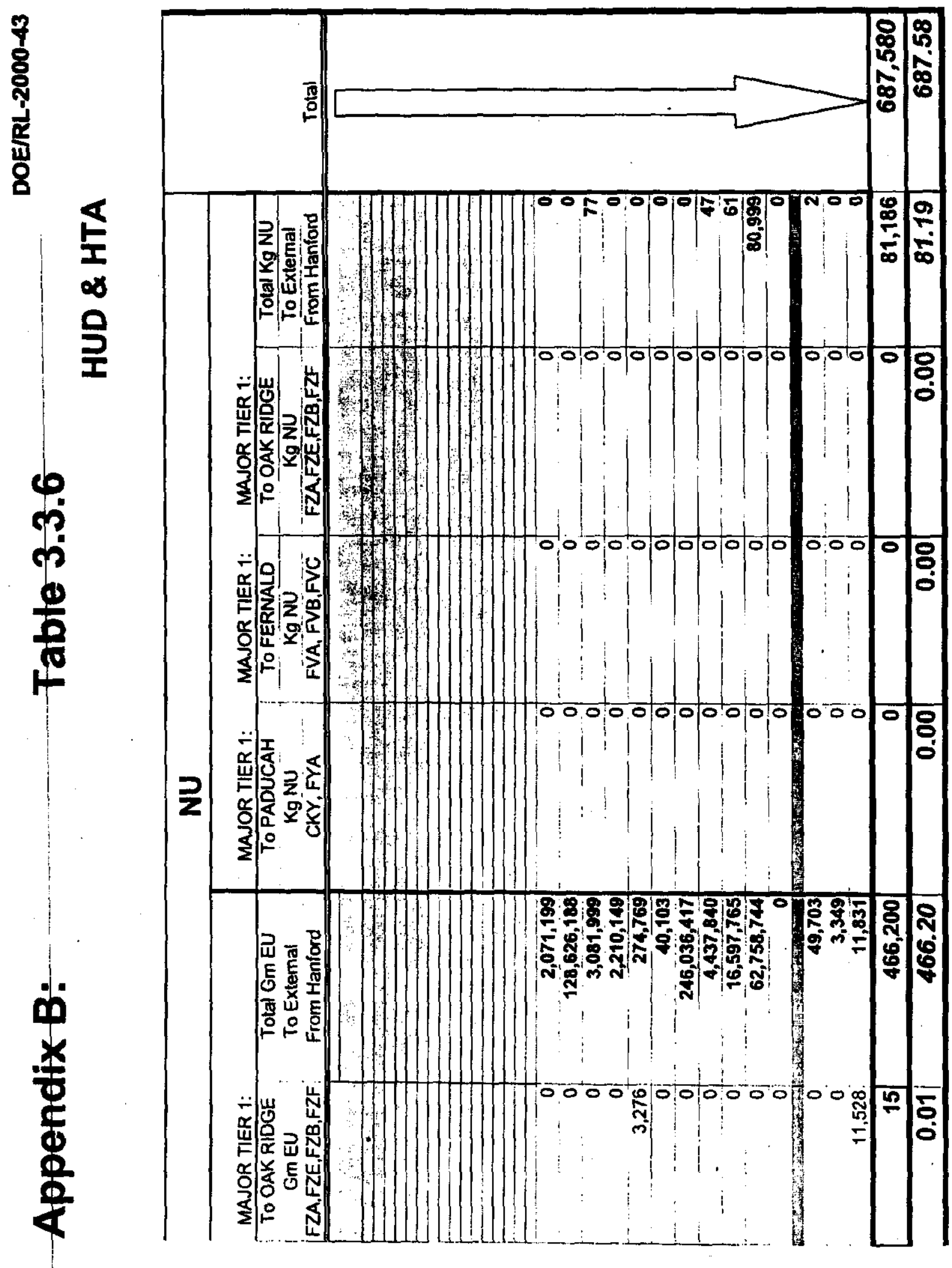




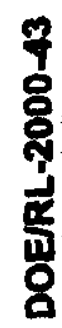

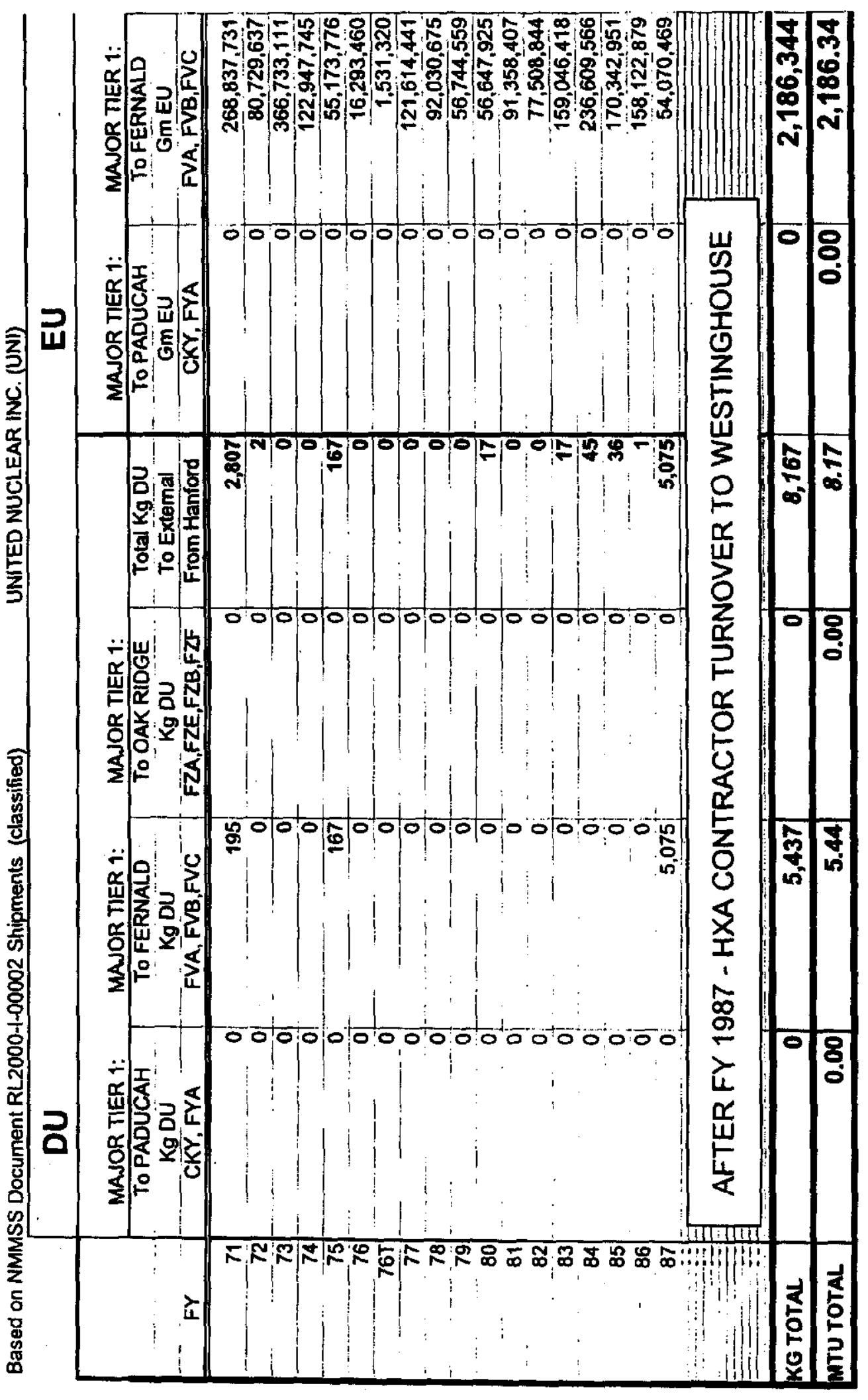




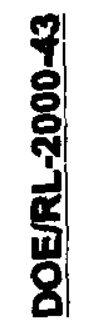

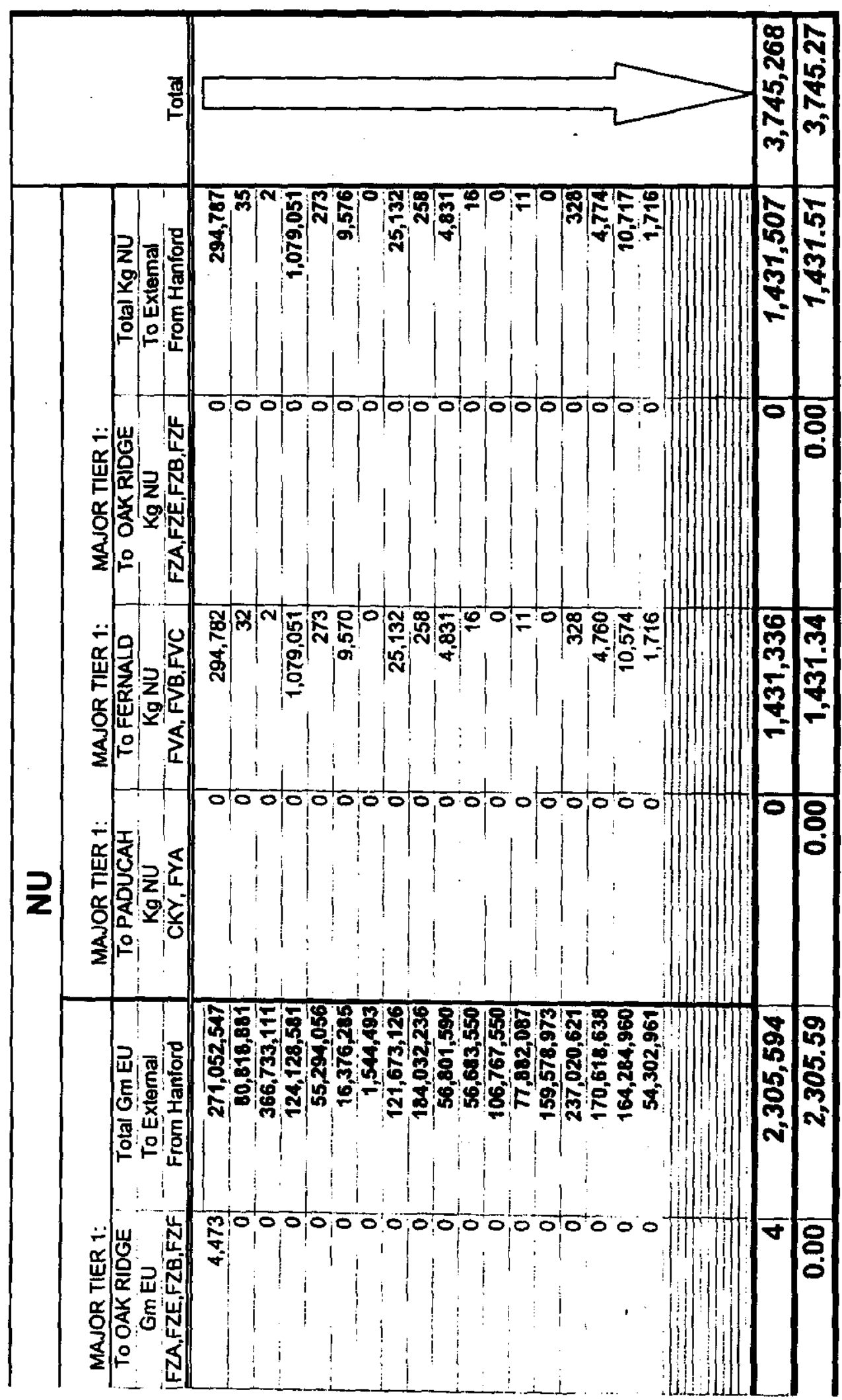


8

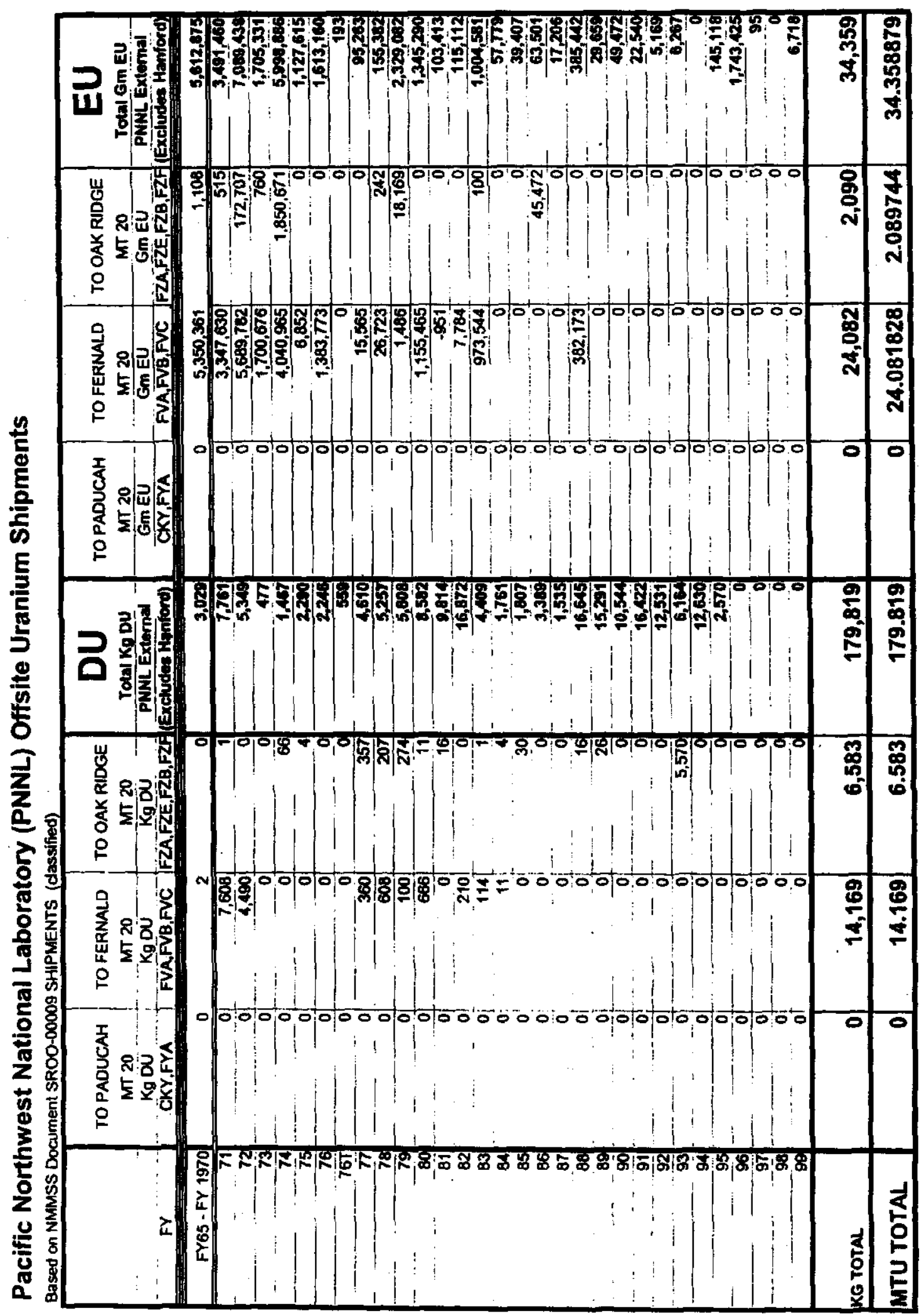


7
8
8
8
8
8

$\frac{1}{9}$

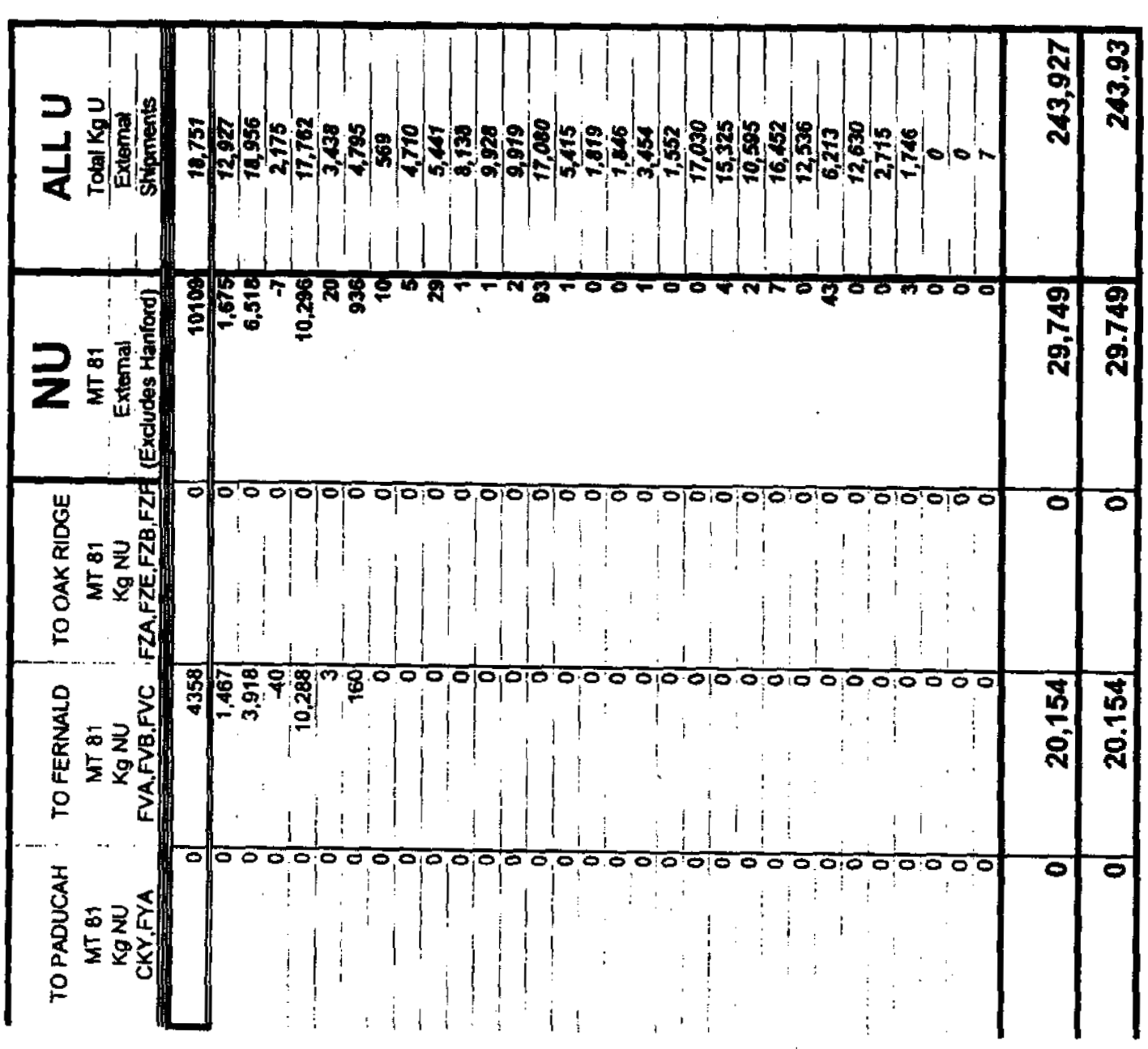




\section{APPENDIX B \\ Section 3 Supplemental Information}

\section{References}

Burge 1965 (classified)

HAN-92119, Burge, GE, to U.S. AEC Richland, Source and Special Nuclear

Materials Balance Reports, July 15, 1965

Byland 1963 (classified)

HAN-85615, J. N. Byland, GE, to U.S. AEC Richland, Source and Special

Nuclear Materials Balance Reports, July 16, 1963

Byland 1964

HAN-88957, J. N. Byland, GE, to U.S. AEC Richland, Source and Special

Nuclear Materials Balance Reports, July 17, 1964

Donihee 1949

HW-15-701, V. D. Donihee, GE, to U.S. AEC Richland, Source and Fissionable

Materials Inventory, January 7, 1949

Donihee 1949a

FTS-668, V. D. Donihee, GE, to U.S. AEC Richland, Source and Fissionable

Materials Inventory, July 8, 1949

Donihee 1951

FTS-670-DEL, V. D. Donihee, GE, to U.S. AEC Richland, Source and

Fissionable Materials Inventory, January 10, 1951

Donihee 1951a

FTS-845-DEL, V. D. Donihee, GE, to U.S. AEC Richland, Source and

Fissionable Materials Inventory, July 11, 1951

Donihee 1952

FTS-953-DEL, V. D. Donihee, GE, to U.S. AEC Richland, Source and

Fissionable Materials Inventory, July 16, 1952

Donihee 1953

FTS-1085-DEL, V. D. Donihee, GE, to U.S. AEC Richland, Source and Fissionable Materials Balance Report, July 15, 1953

Donihee 1954 (classified)

FTS-1311, V. D. Donihee, GE, to U.S. AEC Richland, Source and Fissionable Materials Inventory, July 15, 1954

Donihee 1957

FTS-1980-DEL, V. D. Donihee, GE, to U.S. AEC Richland, Source and

Fissionable Materials Inventory, July 17, 1957 


\section{APPENDIX B \\ Section 3 Supplemental Information}

DOE/RL-2000-43

Donihee 1958

FTS-CLVI-463-DEL, V. D. Donihee, GE, to U.S. AEC Richland, Source and Special Nuclear Materials Balance Reports, July 16, 1958

Donihee 1959

HAN-72720-DEL, V. D. Donihee, GE, to U.S. AEC Richland, Source and Special Nuclear Materials Balance Reports, July 16, 1959

Donihee 1960

HAN-75996-DEL, V. D. Donihee, GE, to U.S. AEC Richland, Source and Special Nuclear Materials Balance Reports, July 18, 1960

Donihee 1961

HAN-79125-DEL, V. D. Donihee, GE, to U.S. AEC Richland, Source and Special Nuclear Materials Balance Reports, July 19, 1961

Donihee 1962

HAN-82406-DEL, V. D. Donihee, GE, to U.S. AEC Richland, Source and Special Nuclear Materials Balance Reports, July 17, 1962

Handshuh 1966

HAN-95170-DEL, J. W. Handshuh, GE, to U.S. AEC Richland, Nuclear Materials Balance Report, June 1966, July 18, 1966

Handshuh 1966a

HAN-96413-DEL, J. W. Handshuh, GE, to U.S. AEC Richland, Nuclear Materials Balance Report, December 31, 1966

Handshuh 1967

HAN-98198, J. W. Handshuh, GE, to U.S. AEC Richland, Nuclear Materials

Balance Report, June 1967, June, 1967

Murphy 1966

HAN-95136-DEL, J.G. Murphy, Isochem, to U.S. AEC Richland, Material Balance Report-June 1966, July 14, 1966

Murphy $1966 a$

HAN-96400-DEL, J.G. Murphy, Isochem, to U.S. AEC Richland, Material Balance Report-December 1966, January 13, 1967

Murphy 1967

HAN-98196, J. G. Murphy, Isochem, to U.S. AEC Richland, Material Balance

Report-June 1967, July 17, 1967 


\section{APPENDIX B \\ Section 3 Supplemental Information}

DOE/RL-2000-43

Murphy 1968

HAN-99439-DEL, J. G. Murphy, Atlantic Richfield Hanford Company, to U.S.

AEC Richland, Material Balance Report-December 1967, January 15, 1968

Murphy 1968a

ARH-699-DEL, J. G. Murphy, Atlantic Richfield Hanford Company, to U.S. AEC

Richland, Material Balance Report-June 1968, July 12, 1968

Murphy 1969

ARH-1036-DEL, J. G. Murphy, Atlantic Richfield Hanford Company, to U.S. AEC Richland, Material Balance Report-December 1968,

January 15, 1969

Murphy 1969a

ARH-1099-6-DEL, J. G. Murphy, Atlantic Richfield Hanford Company, to U.S.

AEC Richland, HVA Material Balance Report-June 1969, July 10, 1969

Murphy 1970

ARH-1099-12-DEL, J. G. Murphy, Atlantic Richfield Hanford Company, to U.S.

AEC Richland, HVA Material Balance Report-December 1969,

January 12,1970

Murphy 1970a

ARH-1540-6-DEL, J. G. Murphy, Atlantic Richfield Hanford Company, to U.S.

AEC Richland, Material Balance Report-June 1970, July 13, 1970

Prudich 1966

HAN-95171-DEL, T. Prudich, Douglas United Nuclear, to U.S. AEC Richland, Material Balance Report-June 1966, July 14, 1966

Prudich 1967

DUN-1916 (HAN-96419), T. Prudich, Douglas United Nuclear, to U.S. AEC

Richland, Material Balance Report-December 1966, January 16, 1967

Prudich 1967a

HAN-98194-DEL, T. Prudich, Douglas United Nuclear, to U.S. AEC Richland, Material Balance Report-June 1967, July 12, 1967

Prudich 1968 (classified)

DUN-3624 (HAN-99434), T. Prudich, Douglas United Nuclear, to U.S. AEC

Richland, Material Balance Report-December 1967, January 11, 1968

Prudich 1968a

DUN-4436, T. Prudich, Douglas United Nuclear, to U.S. AEC Richland, Material Balance Report-June 1968, July 12, 1968 


\section{APPENDIX B \\ Section 3 Supplemental Information \\ DOE/RL-2000-43}

Prudich $1968 \mathrm{~b}$

DUN-5250, T. Prudich, Douglas United Nuclear, to U.S. AEC Richland, Material

Balance Report-December 1968, January 15, 1969

Prudich 1969

DUN-5942-DEL, T. Prudich, Douglas United Nuclear, to U.S. AEC Richland,

Material Balance Report June 1969, June 30, 1969

Prudich 1969 a

DUN-6557, T. Prudich, Douglas United Nuclear, to U.S. AEC Richland, Material

Balance Report-December 1969, December 31, 1969

Prudich 1970

DUN-7049, T. Prudich, Douglas United Nuclear, to U.S. AEC Richland, Material Balance Report-June 1970, June 30, 1970

Shortess 1955

FTS-1481-DEL, C. J. Shortess, GE, to U.S. AEC Richland, Source and Special Nuclear Materials Balance Reports, July 19, 1955

Shortess 1956

FTS-1644-DEL, C. J. Shortess, GE, to U.S. AEC Richland, Source and Special Nuclear Materials Balance Report, July 18, 1956 
DOE/RL-2000-43

\section{Appendix C}

Section 4 - Supplemental Information 


\section{Error}

An error occurred while processing this page. See the system log for more details. 


\section{Error}

An error occurred while processing this page. See the system log for more details. 


\section{Error}

An error occurred while processing this page. See the system log for more details. 


\section{Error}

An error occurred while processing this page. See the system log for more details. 


\section{Error}

An error occurred while processing this page. See the system log for more details. 


\section{Error}

An error occurred while processing this page. See the system log for more details. 


\section{Error}

An error occurred while processing this page. See the system log for more details. 


\section{Error}

An error occurred while processing this page. See the system log for more details. 


\section{Error}

An error occurred while processing this page. See the system log for more details. 


\section{Error}

An error occurred while processing this page. See the system log for more details. 


\section{Appendix D}

\section{Section 5 Supplemental Information}




\section{Error}

An error occurred while processing this page. See the system log for more details. 


\section{Error}

An error occurred while processing this page. See the system log for more details. 


\section{Error}

An error occurred while processing this page. See the system log for more details. 


\section{Error}

An error occurred while processing this page. See the system log for more details. 
DOE/RL-2000-43

\section{Appendix E}

\section{Description of Research Strategies Used in Study}




\section{Error}

An error occurred while processing this page. See the system log for more details. 

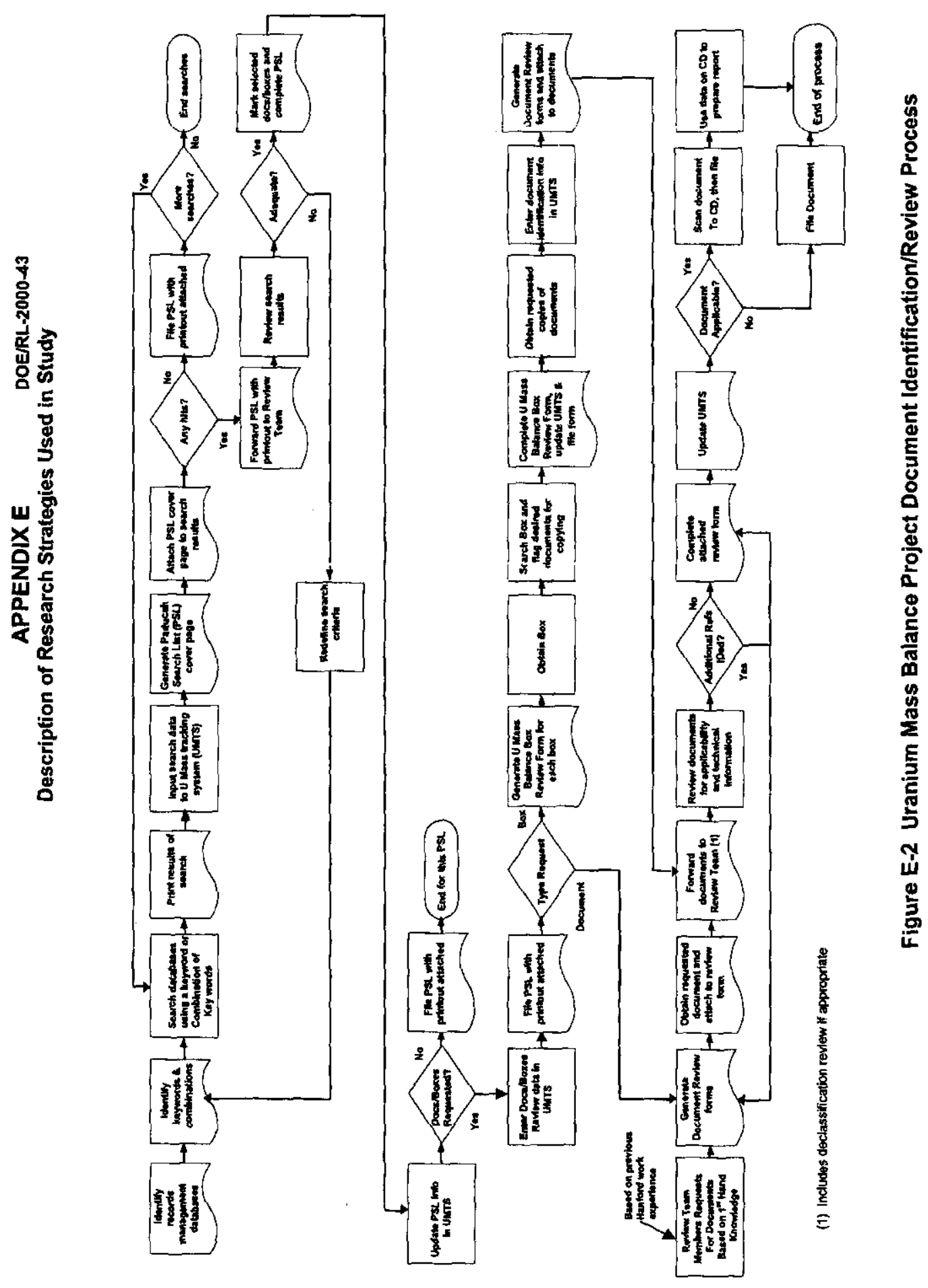


\section{APPENDIX E Description of Research Strategies Used in Study

\section{E.1 Databases Used}

The Technical Review Team members were selected based on their previous experience at Hanford, in most cases including experience directly related to one or more of the facilities involved in the uranium recovery program. Once the team was assembled, the members, based on their past experience, identified the types of records that would be needed to respond to the four specific points in the Deputy Secretary of Energy's letter of direction dated September 15, 1999 [Glauthier, 1999]. Several existing databases were identified that catalogued various types of documentation that might be applicable to this project were searched. These were:

- Human Radiation Experiments Information Management System (HREX) - This publicly accessible database was created in 1994 and contains approximately 392,000 pages of historical documents related to radiation experiments on human subjects performed by or for the Departments of Defense, Energy, Health and Human Services, and Veterans Affairs, as well as the Nuclear Regulatory Commission, the National Aeronautical and Space Administration, the Central Intelligence Agency, and their predecessor organizations.

- OpenNet - This database includes references to Department of Energy (DOE) documents that were declassified and made publicly available after October 1, 1994, in compliance with former Secretary Hazel O'Leary's Openness Initiative. It presently contains approximately 400,000 documents; however, the declassification process is still in progress.

- Records Holding Task Group - This collection of approximately 102,000 classified documents is held in the records holding area of the DOE's Oak Ridge Operations Office. In the summer of 1998, the Hanford "Downwinders" Litigation staff reviewed the entire collection and indexed all Hanford-related documents, which resulted in a listing of approximately 14,000 Hanford related documents. This Hanford-related listing was searched as part of the U-Mass study.

- Hanford Site Historian Database - This database contains documents gathered by the Site Historian in generating several publicly available publications related to various aspects of the Hanford site history.

- Document Declassification Tracking System (DDTS) - This is a site database created in 1995 with approximately 61,000 classified and formerly classified Hanford documents.

- Record Holding Area Management Information System (RHA-MIS) - This database was developed in the mid-1970s as the Hanford Site master database for managing $\mathrm{RL}$ and its contractors' archived boxes of records in storage. The system currently tracks the location and general content of approximately 75,000 boxes of records 


\section{APPENDIX E \\ Description of Research Strategies Used in Study \\ DOE/RL-2000-43}

from the field to various storage locations, including the Federal Records Center in Seattle, WA.

- Document Tracking Application (DTA) - Created in the mid-1970s, this system contains approximately 41,000 classified documents.

- Master - This system was created in the.mid-1970s and contains approximately 750,000 engineering documents related to the Fast Flux Test Facility. Other contractor documents were added to the system between 1982 and 1993, when this system was replaced with the Records Management Information System (RMIS).

- Records Management Information System - This system was created in 1993 and consists of 14 different subsystems with over 1,700,000 documents. The system was not retrofitted to capture documents issued prior to its startup; however, some older documents have been added to the system from time-to-time in special cases. Only the following subsystems were of interest to the Project:

- Records - This subsystem contains over 640,000 documents, including ALARA records, correspondence, declassified documents, engineering drawings, legacy/historical information, media highlights, management system documents, radiological survey records, technical documents, publications, and work packages.

- Tank Farms information Center (TFIC) - This subsystem contains primarily older Westinghouse Hanford Company and Rockwell Hanford Company documents related to the tank farms.

- Solid Waste - This subsystem contains hazardous waste manifests.

- $\mathrm{RL}$ - This subsystem contains RL correspondence.

- Administrative Record (AR) - This subsystem contains documents relied on or considered in order to arrive at a final decision for remedial action for hazardous waste management.

Although, three additional RMIS subsystems were identified and searched, later analyses verified these files could have been eliminated because the information they contained was not germane to the Project.

\section{E.2 Database Keyword Searches}

The Technical Review Team identified keywords or combinations of keywords that related to the facilities, materials, and types of documents that would be used in the database searches in an attempt to identify documents relevant to the Team's 


\section{APPENDIX E \\ DOE/RL-2000-43 \\ Description of Research Strategies Used in Study}

evaluation. Table E-1 shows the primary keywords that were used, normally in combination, in the searches. The team also identified variations in the way in which the keywords might appear in the titles or documents identified in the databases. Combining the keywords into meaningful logical expressions resulted in identifying several hundred queries/combinations of queries to be run on each of the various databases.

Each specific query was assigned a unique identification number (Paducah Search List or PSL number) and was logged into a Project database along with:

- Keywords and logic used in the search

- Name of the database searched

- Date of the search

- Name of the researcher

- Number of documents matching the search criteria (or "hits")

- Date the search results were provided to the Technical Review Team

The above information was reflected on a database generated cover sheet that was then attached to the search results printout. The printout identified the documents or boxes of records that satisfied the search criteria. The cover sheet and printout were then delivered to the Technical Review Team for review.

If the number of hits on a particular query exceeded 200 , only the first two pages of the results were printed and provided for review. The problem of a high number of hits was generally caused by of one of two things:

1) The search criterion was too general.

2) In some databases documents have been scanned and digitized and full text searches using optical character recognition (OCR) software is available; however both the lack of quality of the original documents and the numerous different fonts used in them caused the OCR software to register many false hits.

In those cases, a Technical Review Team member would evaluate the first two pages of hits and determine whether to ask for the rest of the results or to narrow the search criteria and have the search performed again. 


\section{Error}

An error occurred while processing this page. See the system log for more details. 


\section{APPENDIX E Description of Research Strategies Used in Study \\ DOE/RL-2000-43}

titles of the documents listed, determined whether copies of any of the documents should be obtained for Team review. Where appropriate, document titles were flagged to indicate that they were being requested for review. In the case of the RHA-MIS database, the computer printouts provided box numbers, storage locations, and a general description of the types of documents in each box. Again, one or more Review Team members reviewed the list of boxes and flagged those that might contain records related to the Project. The reviewer(s) completed the PSL cover sheet to include the reviewer's name, date of review, whether any documents or boxes were selected and, if so, the number of documents or boxes selected, along with any comments the reviewer wished to make.

\section{E.4 Obtaining Documents and Boxes of Records}

After review by the Technical Review Team the PSL cover sheet and its associated list were used to update the Project database with the information provided from the reviewers. For each document requested by the Technical Review Team, the following information was entered into the Project database:

- A unique document tracking number (for the request)

- The unique PSL number that resulted in the request

- Document identification number (if any)

- Document revision

- Document alias number(s) (if any)

- Document date

- Document Title

- Document source

- Box number

- File folder title (if any)

- Name of requestor

The requested document was then either printed out the document (if it was available online) or a copy was ordered from the appropriate source. When the document became available, the database generated a Document Review/Production Order containing the above information as well as the date the document was delivered to the requestor and the number of pages in the document. In those cases where the requests were for entire boxes of records, arrangements were made to retrieve the boxes from offsite storage if necessary and made available for review in the RL Records Holding Area (RL-RHA). Once the boxes were available in the RL-RHA, the Technical Review Team members who had requested them were notified via Box Review Tracking forms which identified the box number, the box owner, security classification of the box content, and whether the box had been completely scanned. The form also provided the box tracking history. 


\section{APPENDIX E DOE/RL-2000-43 \\ Description of Research Strategies Used in Study}

\section{E.5 Additional Document Searches}

Because of their previous work experience at Hanford, many of the Technical Review Team members were aware of the existence and location of specific documents that would be relevant to the Team's efforts. In such cases the Team member would obtain a copy of a document. A Document Review/Production Order form was initiated for each document obtained in this manner and it was entered into and tracked in the Project database.

\section{E.6 Technical Review of Documents}

One or more members of the Technical Review Team reviewed each document requested to determine whether it contained information relevant to the Team's efforts. If a document contained no relevant information, the reviewer marked the Document Review/Production Order form to indicate that the document was not relevant and then signed and dated the form and returned both to to be used to update the Project database. If a document did contain relevant information, the reviewer also indicated the security classification status, and whether declassification in whole or part was needed. The reviewer also marked the form to identify keywords to be associated with the document in the Project database to assist in future searches by the Project Team or others.

In the case of boxes of records, a Review Team member (normally, the requestor, but not always) examined the contents of a box and flagged any relevant documents for copying. The RL-RHA staff made copies upon request and a Document Review/Production Order was initiated for each document copied. The information was then entered into the previously described Project database.

\section{E.7 Project Records}

The Project records for this project include:

- Documentation (completed Paducah Search List or PSL) for each query run on each database and the marked up computer printouts indicating the documents requested.

- A completed Document Review/Production Order for each of the documents requested showing the results of the Teams review.

- A completed Box Review Tracking form for each box requested showing the results of the box review. 


\section{APPENDIX E \\ DOE/RL-2000-43 \\ Description of Research Strategies Used in Study}

- A computer database that cross-links the queries to the PSLs, the PSLs to the document requests, and the keywords assigned to a document by the Technical Review Team.

In preparing its report, the Technical Review Team cited references to the sources of information used in the report. Copies of the source documents wili be retained by RL until it is determined they are no longer needed. It is the Project's intent to scan these documents onto CD-ROMs and catalog them in a database to minimize future search and duplicating time and expense.

\section{E.8 References}

\section{Glauthier 1999}

Memorandum, T. J. Glauthier, Deputy Secretary of Energy, to All Departmental Elements, Paducah Gaseous Diffusion Plant - Follow-Up Activities, U.S.

Department of Energy, Washington, DC, September 15, 1999 
DOE/RL-2000-43

\section{Appendix F}

\section{Supplemental Information on Hanford Fuel Fabrication}


DOE/RL-2000-43

\section{(This page intentionally left blank)}




\section{APPENDIX F DOE/RL-2000-43 Supplemental Information on Hanford Fuel Fabrication}

\section{F.1 Single Pass Reactor Fuel Fabrication}

\section{F.1.1 Fuel Canning}

The original fuel canning process implemented at Hanford involved the use of an electric heater press, known by workers as the "whiz-bang," to heat and bond the uranium fuel cores to their aluminum jackets. However, the heaters burned out frequently, did not heat the elements and cans to consistent temperatures, and did not produce a uniform bonding. This problem was serious because non-uniform bonding caused thin places in the jacketing which were subject to localized heating during irradiation. These "hot spots" could cause fuel element ruptures in the reactors. By August 1944, the uranium fuel cores were being jacketed in a triple-dip method that consisted of bathing them in molten bronze, tin, and then a molten aluminum-silicon mixture. The bronze used in this process at Hanford was relatively high in tin content (53\% tin and $47 \%$ copper), and the bronze bath itself had a flux cover composed of barium chloride, potassium chloride, and sodium chloride. As fuel cores were dipped into this mixture, they acquired trace coverings of all of these substances.

Initially, the bare uranium cores were cleaned by passing them through a trichloroethylene vapor degreaser. They were then passed through a nitric acid pickling tank, two rinse tanks, and a hot air dryer. Meanwhile, a steel "sleeve" that would surround each can during the dipping process was cleaned in sodium hydroxide; and aluminum end caps and cans were cleaned in a sodium dichromate solution followed by a methanol rinse. The bare uranium cores were dipped in a bronze bath to heat them to a uniform temperature within the uranium beta phase $\left(660^{\circ} \mathrm{C}\right.$ to $\left.770^{\circ} \mathrm{C}\right)$. Then they were placed in a tin bath to: (1) cool them into the uranium alpha phase (less than $660^{\circ} \mathrm{C}$ ) and (2) to remove any excess bronze. Next they were centrifuged to throw off excess tin. Then the cores were immersed quickly in an aluminum-silicon brazing bath while in the uranium alpha phase, and water quenched. The various heating and cooling procedures were done to randomize the uranium grains, thus inhibiting the uranium "growth" (expansion under irradiation) problem. After water quenching, the steel sleeve was pulled away and cleaned with sodium hydroxide and soap to remove any remaining aluminum-silicon. The sleeve then could be reused many times. The thickness of the residual end cap on the element was then measured with a fluoroscope and marked with a punch to indicate the amount that needed to be removed in subsequent end machining. Identification numbers were stamped on the can base end, and the braze line on the end cap was tungsten inert gas welded to seal the porous braze to the end cap and can. A final etching in nitric acid completed the procedures.

Three tests followed the canning process. The first, was the frost test, which consisted of spraying the can with acenaphthene mixed with carbon tetrachloride $\left(\mathrm{CCl}_{4}\right)$. The canned element was then placed into an induction coil to heat its surface. If there was a gas bubble or a non-bonded spot, this spot would become shiny, and the element then would be rejected and sent back through a recycling process. If the bond was good, the acenaphthene was removed with trichloroethylene, and the element was heated in one 


\section{APPENDIX F Supplemental Information on Hanford Fuel Fabrication \\ DOE/RL-2000-43}

of several autoclaves located in the 314 Building. In that step, the canned element was placed into a steam autoclave, which operated at about 100 pounds per square inch gauge (psig) and $175^{\circ} \mathrm{C}$ for more than 20 hours, to reveal any pinholes or incomplete welds. Water from the steam would be conducted through any such openings, and the uranium core would expand rapidly, resulting from the formation of a uranium oxide compound known as $\mathrm{U}_{3} \mathrm{O}_{8}$, and split the aluminum can. If an element passed the autoclave test it then underwent a final radiograph (X-ray) test in the 314 Building, to detect porosity in the end weld bead. Any porosity could have become a pathway for water to contact the uranium fuel and cause the element to rupture during irradiation.

\section{F.1.2 Single Pass Fuel Fabrication Changes}

In 1948, the extrusion press in the 314 Building was excessed, and Hanford began receiving rolled uranium rods from an offsite commercial mill. The rolling process seemed to offer metallurgical advantages, because the uranium could be processed at lower temperatures, which induced less oxidization and produced smaller and more random grains within the metal. From 1950 to 1951, a rolling mill was procured and installed in the 314 Building, to save the costs of shipment to offsite mills. However, this mill was relatively small, and the rolling operation was transferred to a large facility constructed at the Feed Materials Production Center (FMPC), an Atomic Energy Commission (AEC) site in Fernald, Ohio, in 1952. Thereafter, no extruding or rolling operations were conducted at Hanford in connection with the fabrication of fuel elements for single-pass reactors. The 314 Building process continued to operate for the purposes of straightening uranium rods, providing autoclave and radiograph testing of canned elements, and providing uranium scrap processing operations.

In 1954, the 313 Building underwent a major remodeling and expansion, reaching a total size of 182.5 feet by 486 feet, with a total area of 76,633 square feet. At that time, much contaminated equipment and other solid wastes from this building and its immediate surrounding area and from the 303 fresh fuel warehouses were buried. The remodeling occurred at the time that fuel canning technology in the 313 Building switched from the triple-dip process to the new lead-dip process. Lead-dip consisted of immersing the uranium fuel cores in a duplex bath (molten lead covered with molten aluminum-silicon) to preheat the cores in the uranium alpha phase. This step formed an intermetallic compound of uranium and lead $\left(\mathrm{UPb}\right.$ or $\left.\mathrm{UPb}_{3}\right)$ on the core. It was followed by a molten aluminum-silicon bath (also in the uranium alpha phase) to braze and bond the cores to the aluminum cans and caps. This process allowed the first canning bath to occur at a lower temperature (lower than $660^{\circ} \mathrm{C}$ ) because the uranium cores already had been beta heat treated in a molten salt bath at the FMPC. However, the new method introduced a great deal more lead and other heavy metals into 313 Building waste streams. At about the same time that the lead-dip process replaced the triple-dip method, an ultrasonic test replaced the frost test, which eliminated the use of acenaphthene and $\mathrm{CCl}_{4}$. Concurrently, the majority of testing autoclaves were removed from the 314 Building and placed in the north end of the 313 Building. 


\section{APPENDIX F Supplemental Information on Hanford Fuel Fabrlcation \\ DOE/RL-2000-43}

In the early 1960's, just before the eight single-pass reactors at Hanford began to close, experiments were under way in the 304, 3716, and 313 Buildings with a new canning procedure known as the Hot Die Size Process. Also termed the "nickel-plate" procedure, this operation plated uranium fuel cores with nickel, using nickel sulfate, nickel chloride, and boric acid. It included standard fuel fabrication cleaning, degreasing, etching, and testing chemicals and processes. Although the Hot Die Size method was tested successfully, it was not implemented on a large scale because of the impending closures of Hanford's eight original reactors.

\section{F.2 N-Reactor Fuel Fabrication Processing}

Fuel element preparation activities for the single-pass reactors ended in the 313 and 314 Buildings in 1971, when the last of these reactors closed. The 314 Building was modified in the 1970's and was used for a variety of research projects and crafts services. The majority of the fabrication equipment for single-pass reactor fuel elements was removed from the 313 Building between the mid-1970's and the mid-1980's. However, the south end of the 313 Building continued to house major functions in support of N-Reactor fuel production. Among these functions were: (1) the receiving and inspection of uranium billets and other components used to make $\mathrm{N}$ Reactor fuel elements, (2) the chemical passivation of spacers from N-Reactor, (3) the casting and machining of copper-silicon pre-shape components used in N-Reactor fuel elements (beginning in 1973), and, (4) the neutralization and handling of non-uranium-bearing acid wastes from $\mathrm{N}$-Reactor fuel fabrication processes in the 333 Building. Finished N-Reactor fuels and fabrication components, tools, and miscellaneous supplies were stored in the north end of the 313 Building from 1971 to 1987, and an Engineering Development Laboratory, including facilities for working with uranium, was established in this structure in the 1970's.

\section{F.2.1 N-Reactor Fuel Fabrication}

The fuel-making process for the New Production Reactor (N-Reactor) was very different from that used to make fuel for single-pass reactors. Soon after funding was secured for N-Reactor in 1958, a high-pressure heat transfer apparatus was emplaced in the 189/190-D Building, a converted World War II pumphouse in the Site's 100-D Area. Its purpose was to test a new, N-Reactor fuel concept being developed in the 306 Metallurgical Pilot Plant, a 300 Area building dedicated to fuel manufacturing experimentation. The concept first tried for $\mathrm{N}$-Reactor fuel was a wire-wrapped, sevenelement cluster of long, thin fuel rods spaced together in a horizontal flow tube. Each individual element was only 0.625 to 0.704 inches in diameter, and was 35 to 45 inches long. However, attention soon turned to yet another new concept developed in the 306 Building. This idea, of a co-extruded tube-in-tube fuel element design, eventually was adopted for N-Reactor. 


\section{APPENDIX F \\ DOE/RL-2000-43 \\ Supplemental Information on Hanford Fuel Fabrication}

\section{F.2.2 Co-Extrusion Process}

The co-extrusion process began with inspection and cleaning of copper and coppersilicon pre-shapes and backing plates used in the process. The cleansing agents were nitric acid, nitric hydrofluoric, and chromic nitric sulfuric acid. Next, cladding components made from Zircaloy- $2^{T M}$ were degreased, rinsed in nitric and hydrofluoric acid, and dried with forced-air heating. In the meantime, uranium billets were degreased with perchloroethylene, etched with nitric acid, rinsed, dried and inspected. Next, the copper, copper-silicon, Zircaloy- $2^{T M}$, and uranium components were assembled and welded into a billet assembly. This assembly was evacuated of air, leak tested, sealed preheated, and then co-extruded (squeezed together) in the Loewry Press. As the process specifications for this step emphasized: "The quality of the extruded tube is dependent upon many things, not the least of which is skill, care, effort, and precision that are put into the co-extrusion operation."

The process of cleaning, degreasing, etching and drying components, then assembling and pressing them, was repeated for both the outer (larger) and inner (smaller) tubes that made up the tube-in-tube configuration. The extruded tubes then exited the press to a roll-out table where they were rolled continuously for at least six minutes to prevent tube deformation and non-uniform cooling. Next they were sectioned to the specified length, and the ends were machined to create fuel sections or elements. Nitric acid was used to remove copper silicon residues, and nitric sulfuric acid was used to chemically mill (i.e., dissolve away) excess uranium on fuel element ends. Elements then were etched with nitric hydrofluoric and nitric acid, and brazed with an etched braze ring material consisting of Zircaloy- $2^{\mathrm{TM}}$ alloyed with about five percent beryllium. (This braze material previously had been degreased and etched.) The brazed elements were heattreated in a molten salt bath to randomize the uranium grain structure to prevent preferential grain growth that could rupture the elements in the reactor.

The next step in the process was to weld projections or supports onto the fuel elements. Eight lengthwise protrusions were attached to the outer surface of each fuel element, evenly spaced around its diameter. This configuration allowed cooling water to circulate optimally around the elements, without creating hot spots where the sides of elements rested too close to the inner walls of the process tubes. After projections were welded onto the elements, the two tubes (inner and outer) had to be attached together. Support hardware was attached to the outer surface of the inner tube, and locking hardware was affixed to the inner surface of the outer tube. The two tubes were then given a final nitric hydrofluoric acid etch, separately tested in autoclaves, inspected, assembled and interlocked, and stored as finished fuel. The co-extrusion process was carried out continuously in the 333 Building from 1960 until December 1986, reaching a peak volume of approximately 250 finished fuel elements per week in the mid-1980s.

Worker exposure to uranium was controlled. Machining and other fines-producing fabrication activities were conducted within ventilated enclosures. Air exhausted from these enclosures was filtered. Uranium scrap recovery activities such as burning in a controlled atmosphere incinerator, while providing a higher potential for worker uranium 


\section{APPENDIX F Supplemental Information on Hanford Fuel Fabrication \\ DOE/RL-2000-43}

uptake, were limited in scope. Additionally, due to transportation issues with untreated scrap, much of the scrap was processed to a recoverable wet sodium diuranate cake before shipment offsite. Some low concentration liquid wastes were discharged to ponds and cribs for disposal. Dry wastes were packaged and sent to the Hanford waste burial sites for disposal.

\section{F.3 Material Sources}

A number of private contractors were involved with the early fuel fabrication operations. B\&T Metals of Columbus, Ohio, extruded a large quantity of uranium metal rods for Hanford from April through August 1943. Coppenweld Steel Company of Warren, Ohio out-gassed and straightened a large quantity of uranium rods for the reactors between May and August 1943. Revere Copper \& Brass also out-gassed and straightened rods in Detroit. Hanford began out-gassing and straightening its own uranium fuel rods in September, 1944. Baker Brothers of Toledo, Ohio, manufactured unbonded uranium slugs for Hanford from early 1944 through July, 1944. The William E. Pratt Manufacturing Company turned and ground unbonded slugs in the spring of 1944. Between May and August of 1944, McKinney Tool and Manufacturing in Cleveland, Ohio turned and ground unbonded slugs. During the late 1940s and early 1950s, uranium rods were rolled or extruded by Vulcan Crucible Steel Company in Aliquippa, PA, Revere Copper and Brass, and the Brush Beryllium Company in Detroit, Joslyn Manufacturing \& Supply Company in Fort Wayne, Indiana, Allegheny-Ludlum Steel Corporation in Watterville, New York, and Simonds Saw \& Steel Co. of Lockport, NY.

Hanford stopped extruding uranium rods in 1948, switching to rolled rods on site. The AEC shifted the rolling work to the Fernald, Ohio Feed Materials Production Center and it supporting contractors in 1952.

Uranium slug machining was taken over by FMPC at Fernald Ohio, which opened in 1952, and the Weldon Spring plant which opened in 1956. FMPC and Weldon Spring produced ingots of natural, low enriched and depleted uranium to be extruded offsite into tubes and billets for further machining into uranium cores. The cores were then shipped to Hanford for cladding and assembly. The ingots were extruded into tubular billets by Bridgeport Brass Company in Adrian, MI from 1954 to 1961 and later by its corporate successor, Reactive Metals, Inc., in Ashtabula, Ohio. Fernald then shipped the billets to Hanford. 


\section{APPENDIX F DOE/RL-2000-43 Supplemental Information on Hanford Fuel Fabrication}

F.4 References (This entire Appendix is supported by one or more of the following general references.)

DOE/EM-0319 1997

DOE/EM-0319, Linking Legacies, January 1997

Gerber 1992

WHC-MR-0388, M. S. Gerber, Past Practices Technical Characterization Study, 300 Area, December 1992

Gerber 1996

WHC-MR-0521, Rev 0, M. S. Gerber, The Plutonium Production Story at the

Hanford Site, Process and Facilities History, June 1996 
DOEJRL-2000-43

\section{Appendix G}

\section{Supplemental Information on the $\mathrm{UO}_{3}$ Plant}


DOE/RL-2000-43

\section{(This page intentionally left blank)}




\section{APPENDIX G DOE/RL-2000-43 Supplemental Information On The $\mathrm{UO}_{3}$ Plant}

\section{G.1 Operating History Uranium Trioxide $\left(\mathrm{UO}_{3}\right)$ Plant [Gerber 1993]}

The original Uranium Trioxide $\left(\mathrm{UO}_{3}\right)$ Plant was located in a World War II facility known as the 224-U Bulk Reduction Building. This three-story, frame and concrete block structure had just under 12,000 square feet, and had been constructed to house a part of the plutonium separation and concentration process used at Hanford in the 1940s. However, process improvements as early as 1945 demonstrated that the 224-U Building was not needed. Rather than contaminate it with plutonium, Hanford management decided to utilize the building as a training facility until another use was found. The 224-U Building was modified in 1951 to accomplish conversion of Uranyl Nitrate Hexahydrate (UNH) to $\mathrm{UO}_{3}$. This facility subsequently became known as the $\mathrm{UO}_{3}$ Plant.

The facility began test runs in January 1952, and full operations the following month. The first $\mathrm{UO}_{3}$ calciners simply were large pots that heated the UNH in batches. An early difficulty concerned the UNH feed from REDOX, which contained impurities sufficient that much of Hanford's $\mathrm{UO}_{3}$ product "proved to be inadequate for successful processing in the continuous UF $_{6}$ conversion process at Oak Ridge." Process improvements in the REDOX Plant were made during 1952-1953, to correct this situation. The first feed supplies of UNH received from the U-Plant in 1953 also proved to be problematic. Metallic impurities, as well as the nitric acid content and the presence of Tri-butyl Phosphate (TBP) and its decomposition products required that the $\mathrm{UO}_{3}$ produced from initial U-Plant product UNH had to be sent to an intermediate metallurgy facility in Cleveland, Ohio further purification before shipment to Oak Ridge. Additionally, the UPlant UNH foamed, caked and stuck in the pots during the calcining process, so that the $\mathrm{UO}_{3}$ would have to be vacuumed and even chopped out. This condition was undesirable from the standpoints of efficiency, operator safety, and contamination control. However, changes made in the U-Plant rendered the UNH so pure that the $\mathrm{UO}_{3}$ Plant product, by the end of 1953, did not have to be sent offsite for further purification, and was suitable to be shipped and used directly at Oak Ridge. That year, the $\mathrm{UO}_{3}$ Plant processed more than 1.5 times the total fuel inventory of uranium that was received at Hanford.

During 1954, $\mathrm{UO}_{3}$ Plant capacity increased to 18 tons per day with the addition of two gas-fired calciners. The unit cost per ton also dropped to 79 percent that of 1953. Overall production in 1954 was limited, however, by the quantity of feed available from the REDOX and $U$ plants. REDOX experienced many shutdowns caused by equipment failures that year, and the U-Plant was closed for much of the autumn to allow for system modifications that would allow it to process wastes aged only one year (instead of usual three years). Several problems were encountered and overcome during 1954, including high radiation fields around the calciner pots caused by the processing of newer UNH (higher in zirconium, niobium, and ruthenium) from the two Hanford feed plants. This problem was solved by the addition of special shielding to protect operators during pot unloading. Also, sulfamic acid added to the UNH prior to calcination caused some caking in the calciner pots, and renewed foaming occurred due to the presence of organic decomposition products in the UNH. Silicon anti-foaming agents, as well as 


\section{APPENDIX G DOE/RL-2000-43 Supplemental Information On The $\mathrm{UO}_{3}$ Plant}

other sulfur-based additives were used to control these situations. A key improvement that year was the use of vacuum cleaning techniques that enabled the plant to recover 90-95 percent of the oxide powder associated with failed filter bags. A large backlog of such bags that had accumulated since startup, were cleaned and discarded. By year's end, plans were underway to expand the $\mathrm{UO}_{3}$ Plant.

During 1955 , monthly $\mathrm{UO}_{3}$ production averaged 106 percent that of 1954 , while the unit costs per metric ton dropped to 92 percent of that for the previous year. The plant had to shut down for portions of the summer due to contamination problems resulting from high gamma feed from the U-Plant. More persistent problems resulted from the gradual corrosion and mechanical wear of equipment and calciner seals and gaskets to the point where a vacuum could not be maintained in the pots. Airborne contamination around the pots increased until operators had to wear masks for respiratory protection. In 1956, equipment modifications, including new pot agitators, shafts, seals, bearings and supports, as well as new pot cover assemblies, off-gas systems and gasketing. were installed to address these problems.

In the meantime, plans went forward to construct the 224-UA Building, a major addition to the $\mathrm{UO}_{3}$ Plant. The plant was equipped with six large, new, continuous action calciners. These calciners were developed and designed at Hanford, and had large troughs with paddle agitators that essentially turned and mixed the $\mathrm{UNH} / \mathrm{UO}_{3}$ bed throughout the process. The caking and clogging problems that had plagued the pots was obviated by the below-grade valving of the continuous calciners. The new valves used air as an agitant, and maintained a seal between the calciner and the powder pickup bin, while passing a continuous stream of $\mathrm{UO}_{3}$. The new calciners also produced a pebbly product that consisted of spheres with an average diameter of 200 microns (about 1/100th of an inch), as opposed to the granular oxide product of the pot.

The first three of the continuous calciners began operations in the last quarter of 1956, and, despite mechanical difficulties with their powder handling systems during the earliest months, they soon demonstrated their production potential. That December, $\mathrm{UO}_{3}$ Plant throughput exceeded that of any previous month by 27 percent. Overall, the 1956 plant production exceeded that of 1955 by 57 percent.

Another salient improvement made during 1956 was the replacement of the old, 900pound drums used for offsite shipping of the $\mathrm{UO}_{3}$ powder with new T-Hoppers. These containers left the site on specially fitted rail flat cars and served as feed hoppers for the Oak Ridge plant customer.

Installation of the last three of the continuous calciners was completed at the $\mathrm{UO}_{3} \mathrm{Plant}$ in early 1957 . At that time, the 18 pot units were retired from service, and all processing was done through the continuous calciners. Late that year, design scoping was begun for new facilities needed to segregate regular UNH feed from that generated by the processing of E-Metal in the REDOX Plant. The $\mathrm{UO}_{3}$ powder that resulted from processing the two types of UNH streams had significantly different nuclear reactivity levels, and separation was needed by the customer at Oak Ridge. 


\section{APPENDIX G Supplemental Information On The $\mathrm{UO}_{3}$ Plant

During 1958, two new tanks with associated piping and instrumentation were installed and fitted to receive the enriched UNH from the stainless steel, overhead pipeline that brought the UNH from the REDOX Plant. Routine transfers of enriched $\mathrm{UO}_{3}$ from Hanford to Oak Ridge began in early 1959. Meanwhile, in 1958, the $\mathrm{UO}_{3}$ Plant established another high production record that was 5.5 percent higher than that of 1957, and almost double that of 1954. Metallurgical examination of the two-year old continuous calciners showed their condition to be excellent.

In 1958, the U-Plant finished its mission and was shut down. However, PUREX's UNH feed to the $\mathrm{UO}_{3}$ Plant far surpassed that which had been coming from U-Plant. Together, the $\mathrm{UO}_{3}$ and PUREX Plants went on to set and surpass production records almost continually, while the REDOX Plant continued to supply a small stream of enriched UNH until its shutdown in 1967. During 1959, the concentration equipment and the acid recovery system at the $\mathrm{UO}_{3}$ Plant were automated, and in 1960 , for the first time, the calciners were automated so that they could be operated and shut down remotely. Programming of the calciners included preliminary air blowing and steam heating of the feed points, admission and regulation of the feed, and control of the $\mathrm{UO}_{3}$ bed temperature. Steep production climbs at the plant continued through 1961, but dropped off slightly in 1962 due to mechanical and process difficulties at the feed plants (PUREX and REDOX). By 1963, production again was so high that serious consideration was given to constructing a pipeline, or converting an existing one, to carry UNH from PUREX to the $\mathrm{UO}_{3}$ Plant. However, the project did not go forward, and transfers by tanker truck continued. That same year, production of $\mathrm{UO}_{3}$ shipped offsite rose to about 12,000 tons per year, and the capability was added to process UNH derived from "125 Metal." During 1965-1966, an experimental process of conversion of thorium nitrate into thorium oxide powder was carried out in the $\mathrm{UO}_{3}$ Plant, using the old electric pots. The goal of this work was to produce thorium oxide powder suitable for fabrication into reactor target elements for ${ }^{233} U$ production. However, for reasons unrelated to the $\mathrm{UO}_{3}$ Plant, the use of thorium oxide powder was abandoned, in favor of experiments with thorium wafer targets.

Beginning in 1967, $\mathrm{UO}_{3}$ Plant operations were tied exclusively to those of the PUREX Plant. That year, $\mathrm{UNH}$ concentrator modifications in the $\mathrm{UO}_{3}$ Plant improved heat distribution and allowed the calciner feed to maintain a uniformly higher specific gravity, thus producing more powder in the same operating time. Both the $\mathrm{UO}_{3}$ and PUREX plants closed in 1972. However, PUREX resumed operations in late 1983 -- closely followed by $\mathrm{UO}_{3}$ Plant in early 1984 . Since that time, there have been 17 startups at the $\mathrm{UO}_{3}$ Plant, averaging about eight days each, as the plant could calcine UNH at a much faster rate than the PUREX Plant could produce it. Final deactivation orders came for both plants in 1992. In April 1993, the $\cup_{3}$ Plant resumed operations to convert the final 200,000 gallons of remaining $\mathrm{UNH}$ to $\mathrm{UO}_{3}$ powder. That run was the plant's last.

In general, waste management was handled very simply and efficiently at the $\mathrm{UO}_{3}$ Plant. Radiation levels in the UNH were relatively low, as compared with levels in the chemical processing feed plants, as there was no high-level waste generated or processed by the $\mathrm{UO}_{3}$ process. Process condensate was sent to various U-Plant cribs 


\section{APPENDIX G Supplemental Information On The $\mathrm{UO}_{3}$ Plant

over the years, specifically the $216-U-12$ crib in the 1980 s and the $216-U-17$ crib for later operations. Various ditches and swamps received equipment cooling water and the steam condensate, previously the U-Pond and more recently the 214-U Ditch. Airborne $\mathrm{UO}_{3}$ powder was trapped in primary bag filters, with secondary bag filters and then HEPA (High Efficiency Particulate Air) filters added during the 1972 - 1984 shutdown. That period also witnessed the addition of fire protection improvements, a backup power supply for instrumentation, an open faced hood and associated exhaust and filtration equipment for the $\mathrm{UO}_{3}$ loadout, and a nitrous oxide (NOX) monitor for the 296-U-4 stack. Beginning in the late 1950s, the main off-gas from the $\mathrm{UO}_{3}$ process $\left(N O_{X}\right)$, was routed through "wet scrubbers," which sprayed the gas with nitric acid to capture the $\mathrm{NO}_{x}$ vapors and dissolve any entrained solid oxide particulates. The acid mixture was then routed through an acid absorber (bubble-cap tower) and stored in chemical tanks awaiting transfer to PUREX. In the late 1980s, a Fiber Mist Eliminator was added to scrub acid vapors from the UNH concentrator to minimize entrained solution and particulates.

\section{G.2 Process Operations}

The major unit operations performed at the $\mathrm{UO}_{3}$ Plant were concentration of UNH, calcination of $\mathrm{UNH}$ to $\mathrm{UO}_{3}$, packaging of the $\mathrm{UO}_{3}$ product, and nitric acid recovery. Uranium containing wastes were generated during routine operation. The primary waste streams were the liquid effluents discharged to the ground and gaseous effluents released to the atmosphere.

The UNH solution was transferred to the $\mathrm{UO}_{3}$ Plant and stored in Tank C-1 in C-Cell. During operation the UNH solution was accumulated in storage tanks and then transferred to the concentrators in D-Cell. The UNH was concentrated to approximately 100 weight per cent UNH in thermosiphon evaporators. The optimum operating temperature was $125^{\circ} \mathrm{C}$ to $127^{\circ} \mathrm{C}$. The concentrated UNH was stored in a steam heated tank. Off-gas from the concentrator knockout pot was routed through a catch tank to a fiber mist eliminator. The mist eliminator captured UNH droplets entrained from the concentrators and the recycle unit concentrator. The recovered UNH was eventually recycled to PUREX. Part of the condensate, was used as reflux water in the acid absorber tower, and the balance of the condensate was neutralized and pumped to the U-17 crib [Raab 1978; Harmon 1979; Strickland 1993] .

Concentrated UNH was pumped to the 224-U building where the calcination process was conducted and $\mathrm{UNH}$ converted to $\mathrm{UO}_{3}$ powder. Initially calcination was performed using pot calciners. The $\mathrm{UO}_{3}$ product from the pot calciners was unloaded using a pneumatic unloading system, which conveys uranium oxide from the pots and conveys it to bulk storage. The system consisted of an exhauster, a bag filter, a cyclone collector, a rotary valve, a hammer mill, and various pipe and fittings. The pot calciners were replaced by 1956 with continuous calciners. The $\mathrm{UO}_{3}$ particle bed in the calciner was maintained at $270^{\circ} \mathrm{C}$. The shell temperature was maintained at about $500^{\circ} \mathrm{C}$ for optimal efficiency. 


\section{APPENDIX G DOE/RL-2000-43 Supplemental Information On The $\mathrm{UO}_{3}$ Plant}

The $\mathrm{UO}_{3}$ powder was collected from the calciners in ground-level pickup bins and then transferred by the pneumatic transfer system, using air, to the fourth floor of the UA tower to the cyclone separator. From there it flowed by gravity through a hammer mill (not normally used) on the third floor of the tower, then to a storage hopper on the second floor, and was unloaded from the hopper into T-Hopper shipping containers in the powder loadout room. The exhaust air from this operation was routed through primary and secondary bag filters in series, a prefilter, and HEPA filter before discharge to the environment, via a roof exhauster. Powder from the cycione and primary bag filter was collected in the powder hopper. Powder from the secondary bag filter was also collected.

As the UNH was thermally decomposed, oxides, of nitrogen and water were driven off and drawn through the vent piping to the Acid Recovery Tower where they were converted to nitric acid. The system consisted of calciner off-gas scrubbers that remove fine particles of entrained $\mathrm{UO}_{3}$, a vapor cooler, an absorber tower and a system of reflux water addition. The acid was collected and pumped to the 211-U Tank Farm for storage and return to the processing plants. Net acid recovery was about 92 percent of that represented by the incoming UNH solution. The nitric acid had a low residual level (0.043 molar) of UNH.

\section{G.3 Waste Generation [Harmon 1979]}

The processing of $1,000 \mathrm{MTU}$ at the $\mathrm{UO}_{3}$ Plant typically resulted in the generation of $\sim 15$ million gallons of cooling water, plus steam condensate from the acid recovery and uranium nitrate concentration steps, and chemical sewer waste. Total radionuclide content of this water which totaled 120 million gallons in 1972 was less than $2 \mathrm{Ci}$ of combined fission products and alpha-emitting nuclides. This stream was sent to $216-U-$ 10 Pond.

Process condensate, largely from the UNH concentrators in the 224-U Building, averaged about 300,000 gallons annually, containing about $0.01 \mathrm{Ci}$ of total mixed fission products. It was sent to the 216-U-12 Crib.

Approximately $1.2 \times 10^{9} \mathrm{ft}^{3}$ of gases were discharged to the atmosphere from the $\mathrm{UO}_{3}$ Plant annually, containing an average (total) of $6 \times 10^{-3} \mathrm{Ci}$ of fission products and $9 \times$ $10^{-5}$ of alpha emitting radionuclides. The radionuclides were essentially all ${ }^{106} \mathrm{Ru}$ and uranium, respectively.

Solid uranium waste was generated from failed and replaced equipment and normal line-generated process waste. About 120 to $140 \mathrm{ft}^{3}$ (total) was generated during a six week campaign mode of operation. This represented approximately $0.01 \mathrm{Ci}$ of total beta emitters; $0.01 \mathrm{Ci}$ of combined ${ }^{90} \mathrm{Sr},{ }^{137} \mathrm{Cs}$ and ${ }^{106} \mathrm{Ru}$ nuclides; and less than $0.2 \mathrm{~kg}$ of total uranium. The solid wastes were buried in the 200 Area waste burial grounds. 


\section{APPENDIX G Supplemental Information On The $\mathrm{UO}_{3}$ Plant}

\section{G.4 Radiation Exposure}

The early years of $\mathrm{UO}_{3}$ Plant operations were plagued with dusting and radiation problems around the calcination pots and during bag filter changes. Gustavson mentioned [Gustavson 1950] that "the dust problem in the pot room was one of the greatest obstacles in designing the $\mathrm{UO}_{3}$ Building." Gerber cited [Gerber 1993] that Annual Reports reported occasions when "airborne contamination around the pots increased until operators had to wear assault masks." Two separate ventilation systems were installed to address the dust problems [Gustavson 1950]. Manual unloading of the calciner pots and high levels of maintenance were also reported. Radiation fields around the pot calciners resulted in the addition of special shielding in 1954 to protect the operators during pot unloading. The installation of continuous calciners greatly reduced exposure and dusting problems associated with the calcination process. Exposure during bag filter changes was also a concern in the early years of operation due to dusting problems. As a result, protective clothing and respiratory protection were used at these locations.

After many modifications and improvements to process operations, the total complement of workers when the $\mathrm{UO}_{3}$ Plant was in full operation was approximately 30 , including operations, maintenance and supervision during the latter years of $\mathrm{UO}_{3}$ Plant operations. In 1971 to 1972, the average annual whole body occupational radiation dose of the $\mathrm{UO}_{3}$ workers was approximately $1 \mathrm{rem}$; the maximum was $2.3 \mathrm{rem}$ and the minimum was 0.09 rem. However, because this plant operated only part time, the process operations workers were assigned elsewhere for more than half of the operating year [Harmon 1979].

\section{G.5 Contaminate Partitioning}

The major unit operations performed at the $\mathrm{UO}_{3}$ Plant were concentration of UNH, calcination of $\mathrm{UNH}$ to $\mathrm{UO}_{3}$, packaging of the $\mathrm{UO}_{3}$ product, and nitric acid recovery. None of these unit operations would preferentially concentrate or decontaminate the plutonium or neptunium from the uranium. The chemical and physical properties of the actinides are similar under the concentration and calcination operating conditions used at the $\mathrm{UO}_{3}$ Plant such that there was no separation of one transuranic radionuclide from another. The ratio of transuranic constituents to uranium in the $\mathrm{UO}_{3}$ product, residual uranium in waste streams, and uranium in any recovery streams, would have been the same as that in the $\mathrm{UNH}$ feed to the $\mathrm{UO}_{3}$ Plant.

There is some evidence, however, of fission product partitioning during calcination. There is a statement in the $\mathrm{UO}_{3}$ Fission Product Specifications [Knights 1966] that ${ }^{195} \mathrm{ZrNb}$ and ${ }^{99} \mathrm{Tc}$ are carried almost quantitatively through the concentration and denitration processes, whereas ruthenium concentration is reduced by a factor of 2 to 5 . An early report indicated an average decontamination factor (DF) of 6 across the $\mathrm{UO}_{3}$ Plant from U Plant UNH. This was attributed to volatilization of ruthenium during the calcination operation. The acid specific fission product analyses indicated that 95 


\section{APPENDIX G Supplemental Information On The $\mathrm{UO}_{3}$ Plant

percent was ruthenium. [Abrams 1955]. In contrast, the DF from REDOX UNH was less than one, indicating that the ruthenium concentration was significantly lower.

Some technetium heptoxide $\left(\mathrm{TC}_{2} \mathrm{O}_{7}\right.$ - pertechnatate), which has a boiling point of $310^{\circ} \mathrm{C}$, could be expected to be volatilized during the uranium calcination step, which operated at $<300^{\circ} \mathrm{C}$. The off-gas from the calciners was driven off and drawn through vent piping to the Acid Recovery Tower. This system consisted of calciner off-gas scrubbers that remove fine particles of entrained $\mathrm{UO}_{3}$, a vapor cooler, an absorber tower and a system of reflux water addition. Any ${ }^{99} \mathrm{Tc}$ that would have been volatilized would have been recovered along with the $\mathrm{NO}_{2}$, entrained uranium and fission products and been recycled as nitric acid to the reprocessing plants. There is no evidence that any ${ }^{99} \mathrm{TC}$ reached the final exhaust filters. The presence of other beta-gamma fission products would have masked any radiation from the soft beta of the ${ }^{99} \mathrm{Tc}$.

\section{G.6 $\mathrm{UO}_{3}$ Related Incidents}

One incident involving $\mathrm{UO}_{3}$ powder occurred April 12, 1960 when the flexible hose used to load powder into a large shipping container broke and spilled about 1.5 tons of powder in the loadout room, of which 2 to $5 \mathrm{Kg}$ escaped to the loadout pad. This powder spread over the asphalt loading ramp and to the road around the $\mathrm{UO}_{3}$ Plant. Most of the powder was swept up and put in drums for recovery, but the rest of the powder was washed off the asphalt and onto the ground surface. Contaminated soil was removed and buried. The contamination was limited to the immediate areas of the spill. There was no general spread in the 200 West Area, no detectable contamination offsite, and no personnel contamination problems of concern were encountered [HW64898 1960].

There were several incidents involving UNH and liquid effluents. On December 30 , 1954 2,000 gallons of UNH were spilled on the main roadway just east of the 200-East Area hill. No external exposure in excess of permissible limits is known to have resulted from this incident. All individuals involved in this incident were surveyed and found to be free of contamination, and an analysis of the bioassay result indicated no detectable deposition of soluble uranium [HW-34494-DEL 1955].

The most serious radiation event identified during this study involving personnel exposure at the $\mathrm{UO}_{3}$ Plant occurred in December 1960, when the fresh air mask hose being used by an employee was blocked by condensate in the line and the mask was improperly adjusted. The employee inhaled/ingested $7-12 \mathrm{mg}$ of uranium [DOE/AD0015 1991]. Up to that time, this was the highest recorded deposition at the plant. Within 24 hours, $80 \%$ of the uptake had been eliminated, reducing the body burden to $10 \%$ of the permissible level. Subsequent whole body counter examinations a week after exposure showed no detectable uranium. 


\section{APPENDIX G \\ Supplemental Information On The $\mathrm{UO}_{3}$ Plant \\ DOE/RL-2000-43}

\section{G.7 References}

Abrams 1955

$\mathrm{HW}-34808$, R. B. Abrams and L. E. Bruns, Radioactive Decontamination Across the $\mathrm{UO}_{3}$ Plant, January 27, 1955

DOE/AD-0015 1991

DOE/AD-0015, Hanford Process Review, December 1991

Gerber 1993

WHC-MR-0437, M. S. Gerber, A Brief History of the PUREX and $\mathrm{UO}_{3}$ Facilities, November 1993

Gustavson 1950

HW-19400, D. R. Gustavson, An Introduction to the $T B P$ and $\cup_{3}$ Plants, December 20, 1950

Harmon 1979

RHO-CD-768, M. K. Harmon, and R. Shropshire, Environmental Assessment Relating to the Operation of the PUREX and the Uranium Oxide Plants, October 1979

HW-34494-DEL 1955

HW-34494-DEL, Radiological Sciences Department Investigation, Radiation Incident, Class I, No. 406, January 12, 1955

$H W-648981960$

HW-64898, Hanford Laboratories Operation, Monthly Activities Report April 1960, May 15, 1960

Knights 1966

ISO-253, L. M. Knights, $\cup_{3}$ Fission Product Specifications, April 28, 1966

Raab 1978

RHO-CD-519, G.J. Raab and W. C. Schmidt, Flowsheet to Process and Refine Uranium Recovered from Irradiated Fuel Elements: RE 5.11.5.6, Uranium Trioxide $\left(\mathrm{UO}_{3}\right)$ Plant Chemical Flowshoet, November 1978

Strickland 1993

WHC-SD-CP-SAR-002, Rev 6F, G. C. Strickland and R. L. Walser, Uranyl Nitrate Hexahydrate, Uranium Trioxide PUREX, Safety Analysis, January 21, 1993. 
DOE/RL-2000-43

\section{Appendix H}

\section{Timeframe of Events at Hanford}


DOE/RL-2000-43

\section{(This page intentionally left blank)}




\section{Error}

An error occurred while processing this page. See the system log for more details. 


\section{Error}

An error occurred while processing this page. See the system log for more details. 


\section{Error}

An error occurred while processing this page. See the system log for more details. 


\section{Error}

An error occurred while processing this page. See the system log for more details. 


\section{Error}

An error occurred while processing this page. See the system log for more details. 


\section{Error}

An error occurred while processing this page. See the system log for more details. 


\section{Error}

An error occurred while processing this page. See the system log for more details. 


\section{APPENDIX H \\ Timeframe of Events at Hanford}

DOE/RL-2000-43

\section{References}

DOE 1991

DOE/AD-0015, Hanford Process Review, December 1991

DOE 1997

DOE/EM-0319, Linking Legacies, January 1997

Donihee 1950 (classified)

FTS-669, V. D. Donihee to D. F. Shaw, Material Balance Report, July 10, 1950

Gifford 1959

Letter, HAN-71497, A. T. Gifford to V.P. Donihee, Enriched $\mathrm{UO}_{3}$,

March 3, 1959

Gerber 1993

WHC-MR-0440, M. S. Gerber, Multiple Missions: The 300 Area in Hanford Site History, September 1993

Gerber 1993a

WHC-MR-0437, M. S. Gerber, A Brief History of the PUREX and $\mathrm{UO}_{3}$ Facilities, November 1993

Gerber 1995

WHC-MR-0293, Rev 2, M. S. Gerber, Legend and Legacy: Fifty Years of Defense Production at the Hanford Site, June 1995

Gerber 1996

WHC-MR-0521, Rev 0, M. S. Gerber, The Plutonium Production Story at the Hanford Site, Process and Facilities History, June 1996

Gosling 1999

DOE/MA-0001, F. G. Gosling, The Manhattan Project - Making of the Bomb, January 1999

Greenwalt 1947

RHTG-46,879 - Meeting with Dr. CW Greenwalt on Use of K-25 in Connection with Hanford Operations , April 21, 1947

Harvey 1997

DOE/RL-97-INTERNET-1047, D. W. Harvey, Construction History of the Hanford

Site, December 1997 


\section{APPENDIX H \\ Timeframe of Events at Hanford \\ DOE/RL-2000-43}

HW-19140 1951

HW-19140, Uranium Recovery Technical Manual, November 10, 1951

PBS Online 1999

Film, The American Experience, Race for the Superbomb, January 1999

Richards 1952

$\mathrm{HW}-23754$ (HAN-43666), R. B. Richards to F. Hurd, $\mathrm{UO}_{3}$ Trial Production Lots 007, 008, and 009, March 11, 1952

Richards 1952a

HW-23848 (HAN-43786), R. B. Richards to F. Hurd, $\cup_{3}$ Trial Production Lots 010, 011, 012, and 013, March 19, 1952

Smith 1953

HW-27990 by R. E Smith, Summary of Oak Ridge Discussions Relative to Hanford Uranium Trioxide Specifications, May 7, 1953

Sturges 1953

Memo HAN-53121, D. G. Sturges, Shipments of Irradiated Enriched Uranium from Hanford to ARCO, December 21, 1953 
DOE/RL-2000-43

\section{APPENDIX I}

\section{Estimates of Annual Recycled Uranium Constituents Shipped Offsite}


DOE/RL-2000-43

\section{(This Page Intentionally Left Blank)}




\section{APPENDIX I \\ DOE/RL-2000-43 \\ Estimates of Annual Recycled Uranium Constituents Shipped Offsite}

1.1 This appendix contains engineering estimates of annual quantities of constituents ( $\mathrm{Pu}, \mathrm{Np}$, and $\mathrm{Tc}$ ) contained in shipments of recycled uranium shipped to/from the Hanford site. Tables I-1 and I-2 summarize the annual receipts and shipments of recycled uranium to and from the Hanford site during the last fifty years. These tables contain summaries of annual receipt and shipment based upon data presented in Section 3 and Appendix B of this report. Analytical data on the amount of $\mathrm{Pu}, \mathrm{Np}$, and $\mathrm{Tc}$ in recycled uranium received at Hanford is not available since there were no requirements for these measurements. Limited analytical data has been identified which indicates that the recycled uranium shipped offsite from Hanford typically contained $\mathrm{Pu}$ in the range of one to five ppb, Np in the range of 20 to $500 \mathrm{ppb}$, and Tc in the range of 3 to $12 \mathrm{ppb}$. Data supporting these constituent concentration ranges is given in Section 4 and Appendix $\mathrm{C}$ of this report. Data on the concentration of Np and Tc in Hanford recycled uranium is minimal, since there were specification requirements for these elements,

Since it is not possible to provide a complete historical assessment of the constituent levels in all recycled uranium shipped each year, rough estimates of annual quantities of constituents in recycled uranium were made assuming that the constituent levels during the years where analytical data is not available are the same as the constituent levels for years when analytical data is available. These estimates are based upon the constituent levels mentioned above and were done for the bounding minimum and maximum values, and the mean value of the constituent concentration range. Tables $|-3|-$,4 , and $\mid-5$ illustrate the estimated quantities of $\mathrm{Pu}$ contained in the recycled uranium shipped. Tables $\mathrm{I}-$ $6, I-7$, and $\mathrm{I}-8$ illustrate the estimated quantities of neptunium in the recycled uranium shipped. Tables $1-9,1-10$, and $1-11$ illustrate the estimated quantities of technetium contained in the recycled uranium shipped shipped. Tables I-12, I13 , and I-14 present estimates of the Pu, Tc, and $\mathrm{Np}$ constituents in recycled uranium received at Hanford, shipped from Hanford, contained in waste at Hanford, released to the environment at Hanford, or in the current inventory at Hanford. 


\section{Error}

An error occurred while processing this page. See the system log for more details. 


\section{Error}

An error occurred while processing this page. See the system log for more details. 


\section{Error}

An error occurred while processing this page. See the system log for more details. 


\section{Error}

An error occurred while processing this page. See the system log for more details. 


\section{Error}

An error occurred while processing this page. See the system log for more details. 


\section{Error}

An error occurred while processing this page. See the system log for more details. 


\section{Error}

An error occurred while processing this page. See the system log for more details. 


\section{Error}

An error occurred while processing this page. See the system log for more details. 


\section{Error}

An error occurred while processing this page. See the system log for more details. 


\section{Error}

An error occurred while processing this page. See the system log for more details. 


\section{Error}

An error occurred while processing this page. See the system log for more details. 


\section{Error}

An error occurred while processing this page. See the system log for more details. 


\section{Error}

An error occurred while processing this page. See the system log for more details. 


\section{Error}

An error occurred while processing this page. See the system log for more details. 